\title{
Social Network Patterns of Sharing Information on Land Use and Agricultural Innovations in Ethnically Heterogeneous Communities in Ecuador
}

\author{
Dissertation \\ zur Erlangung des Doktorgrades \\ der Fakultät für Agrarwissenschaften \\ der Georg-August-Universität Göttingen \\ vorgelegt von \\ Vladimir Gonzalez Gamboa \\ geboren in San José, Costa Rica
}

Göttingen, Juli, 2013 
D7

\section{Referentin/Referent:}

Prof. Dr. Rainer Marggraf.

2. Koreferentin/Koreferent:

Prof. Dr. Heiko Faust

3. Weiteres Mitglid des Promotionskomitees:

Prof. Dr. Karin Kurz

Tag der mündliche Prüfung: 
I would like to dedicate this thesis to my loving parents, and to those who are not among us, but whose love is still here. 


\section{Acknowledgements}

I would like to acknowledge all the people that had made possible the conclusion of this work. It is with immense gratitude that I acknowledge the support and help of my academic supervisors. I am indebted to many colleagues and friends who supported and motivated me. Special thanks go also to the respondents and the research team of the field research. Thanks go to those who support and believe in me during the field research. To those institutions that supported my work, Deutsche Forschungsgemeinschaft (DFG FOR 813), Friedrich-Ebert Stiftung (FES), and the GeorgAugust-Universität Göttingen, I am indebted to them. This thesis would not have been possible without the love of my family. 


\section{Summary}

A case study in South Ecuador serves as an example to understand the dynamics of adoption of agroforestry species. Agroforestry species become important in land that is totally devoid of forest cover. They can reduce soil degradation, increase local biodiversity and at the same time increase household income. Their use can be seen as a new practice that spreads throughout a region by means of social networks. Sharing information about this potentially sustainable agricultural innovation has become important in a region like southern Ecuador. In this region there are mainly two ethnic groups, namely the Saraguro and the Mestizo-colonos. In the first group are indigenous people and the latter are migrants from other places of the country that went to settle the region during the agrarian reform. The two ethnic groups do have different traditions and land use practices.

Qualitative research shows that there are potential differences in adoption of agroforestry tree species between two ethnic groups. The low adoption rate of Saraguro communal leaders may be an indicator of lower contagion than Mestizo-colonos. Contagion refers to actor $i$ adopting the same innovation as actor $j$ with whom actor $i$ had contacted. It is proposed a heterogeneous diffusion model that addresses network exposure effects and a generalized blockmodel for relational data analysis. It was first hypothesized that the Saraguro indigenous group may have lower access to the information necessary for the adoption of the innovation than MestizoColonos. Nonetheless, the results show that Mestizo-colonos have higher adoption rate than Saraguros.

The network actors' behaviour is shaped by local characteristics, for instance their ethnicity. For the analysis it was taken into account the search 
for advice for the main agricultural activities for the household. On this base, it is proved that indeed there are structural differences on search for advice between ethnic groups. By analyzing ethnic subgroups, the subgroup of Mestizo-colonos has the actors with highest degree of centrality and betweenness. These actors are in the highest cohesive block in cohesive block analysis. Furthermore, a high Burt's constraint shows that low access to structural holes in the network create a differentiation of information sharing between groups. Higher Burt's constraint indicates less access to the information located in other clusters in the network. The periphery of the network plays an important role as a source of advice, as shown by cohesive bloc analysis, which we complement with a k-core analysis. The k-core analysis suggests that different and more diverse information is accessed by Mestizo-colonos as compared to Saraguros. In applied terms this suggests that Saraguros tend to share more similar information within their group than do Mestizo-colonos.

In order to understand patterns of network structure the Exponential Random Graph Models (ERGM) become important. For example, ERGMs help to valuate the importance of reciprocity in the network relations depending on how many reciprocal dyads are found in the observed network. Fitting an exponential random graph model (ERGM) to the network, it is shown that indeed there are differences between two ethnic groups in the way they share information. We explore the network patterns in the sharing on agroforestry species. Sharing information with similar others is limited to the less commercial tree species. The most commercial tree species information is concentrated in one actor, who is Mestizo-colono. Transitive network effects are identified within ethnic groups as long as they share information on different tree species (others than pine). The two ethnic groups share information of different tree species. This shows a different knowledge, where Mestizo-colonos are more related with commercial species. 


\section{Contents}

Contents $v$

$\begin{array}{ll}\text { List of Tables } & \text { ix }\end{array}$

List of Figures $\quad$ x

Nomenclature $\quad$ xii

1 Introduction: Studying social structure in southern Ecuador 1

1.1 A region with diversity of interactions . . . . . . . . . . . 1

1.2 General survey design . . . . . . . . . . . . . . . . . . 4

1.3 Research development . . . . . . . . . . . . . . . 7

1.4 Chapters overview . . . . . . . . . . . . . . . . . 9 9

1.4.1 Chapter 2: Social Network Effects on the Adoption of Agroforestry Species: Preliminary Results . . . . . . . . . 9

1.4.2 Chapter 3: Describing Ethnic Groups in an Advice Network . 10

1.4.3 Chapter 4: Information Network About Agroforestry Tree Species 10

$\begin{array}{ll}\text { References } & 12\end{array}$

2 Social Network Effects on the Adoption of Agroforestry Species:

Preliminary Results of a Study on Differences on Adoption Patterns in $\begin{array}{lr}\text { Southern Ecuador } & 15\end{array}$

2.1 Introduction . . . . . . . . . . . . . . . . . . . 16

2.2 Background: The diffusion of innovations . . . . . . . . . . . 17

2.2.1 Adoption and diffusion of innovation studies: Brief overview . 17 
2.2.2 Network analysis and the diffusion of innovations . . . . . . 18

2.2.3 Network concepts . . . . . . . . . . . . . . . . . . 19

2.3 Semi-structured survey . . . . . . . . . . . . . . . 21

2.3.1 Sample description and hypotheses . . . . . . . . . . 21

2.3.2 Research region conditions . . . . . . . . . . . . 22

2.3.3 Agroforestry options ................. 23

2.3 .4 Overall research design . . . . . . . . . . . . . 26

2.3.5 Empirical methods . . . . . . . . . . . . . 26

2.3.6 Empirical results . . . . . . . . . . . . . . 27

2.3.7 Discussion of empirical results . . . . . . . . . . 30

2.4 Plans for the quantitative research phase . . . . . . . . . . . . . 31

2.4.1 Characterization of the social network . . . . . . . 31

2.4.2 Positional analysis: Block model . . . . . . . . . . . 32

2.4.3 Influence of the social network on the adoption of agroforestry

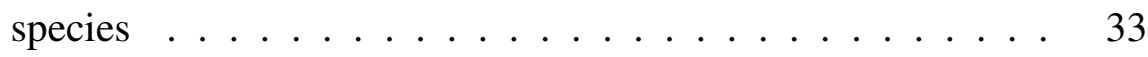

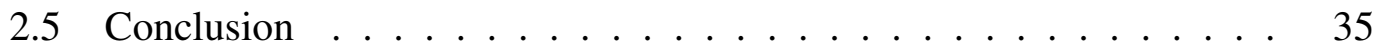

$\begin{array}{ll}\text { References } & \mathbf{3 6}\end{array}$

3 Describing Ethnic Groups in an Advice Network:

A case of ethno-diverse rural communities in southern Ecuador 41

3.1 Introducing the Topic and Social Context . . . . . . . . . . . . 42

3.1 .1 General Introduction . . . . . . . . . . . . . . . 42

3.1.2 Social Context and Motivation . . . . . . . . . . . . 44

3.2 Social Network Theoretical Background . . . . . . . . . . . . . 46

3.2.1 Centrality and Resource Concentration in Social Networks . . 46

3.2.2 Social Network and the Analysis of Groups . . . . . . . . . . 49

3.2.3 The Emergence of Network Structure . . . . . . . . . . 53

3.3 Research Hypotheses . . . . . . . . . . . . . . . . . . 56

3.4 Methodology . . . . . . . . . . . . . . . . . 58

3.4.1 Research Area: Brief Description . . . . . . . . . . . . 58

3.4.1.1 The Region: General Characteristics . . . . . . . 58

3.4.1.2 The Region: Socio-Ethnological Background . . . . 59 
3.4 .2 Survey Design . . . . . . . . . . . . . . 61

3.4.3 Interview Instrument and the Data . . . . . . . . . . . 62

3.4.4 Network Analysis . . . . . . . . . . . . . . . 67

3.4.4.1 Review of Some Previous Work . . . . . . . . . 67

3.4.4.2 Applied Methods . . . . . . . . . . . 70

3.4.4.3 Network Specification . . . . . . . . . . . . 72

3.5 Empirical Results . . . . . . . . . . . . . . . . . 73

3.5.1 Network Descriptive Statistics . . . . . . . . . . . . 73

3.5.2 Cohesive Block Analysis . . . . . . . . . . . . . . 80

3.5.3 Analyzing the Periphery . . . . . . . . . . . . 83

3.5.4 The Tested Research Hypotheses . . . . . . . . . . . . . . . . 86

3.6 Discussion of Results . . . . . . . . . . . . . . . . . . . 87

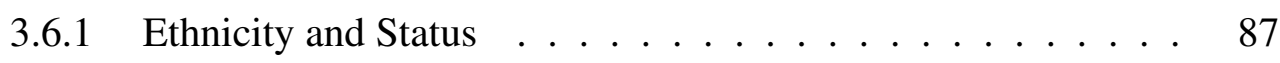

3.6.2 Cohesiveness and Groups . . . . . . . . . . . 93

3.6.3 A Constrained Network _. . . . . . . . . . . . . . . 96

3.7 Conclusions . . . . . . . . . . . . . . . . . . 101

$\begin{array}{ll}\text { References } & 104\end{array}$

4 Social Network Effects on the Search for Information on Agroforestry Tree Species in Rural, Multi-Ethnic Communities in Southern Ecuador 112

4.1 Introduction and General Motivation . . . . . . . . . . . . . . . 113

4.2 Theoretical Background: Modeling Social Networks . . . . . . . . . 115

4.2.1 Social Network Structure: First Insights . . . . . . . . . . . . 115

4.2.2 Social Networks: Dependence in a Relation . . . . . . . . . . 117

4.2.3 Preface for modeling social structure . . . . . . . . . . . . 120

4.2.4 Exponential Random Graph Models (ERGMs) . . . . . . . . 124

4.2.4.1 Network simulation . . . . . . . . . . . . . 126

4.2.4.2 Model estimation . . . . . . . . . . . . 128

4.2.4.3 Some Previous Work . . . . . . . . . . . 128

4.3 Research Area Background . . . . . . . . . . . . . . . . . . . . . . . 129

4.3.1 The Region: General Characteristics . . . . . . . . . . . . . . 129

4.3.2 The Region: Socio-ethnological Background . . . . . . . . . 130 
4.3.3 Adoption of agroforestry species . . . . . . . . . . . . . 133

4.4 Research Hypotheses . . . . . . . . . . . . . . . . . . . . . . 136

4.5 The Structured Survey . . . . . . . . . . . . . . . . . . 138

4.5.1 Survey Design . . . . . . . . . . . . . . . . 138

4.5.2 Interview Instrument and the Data . . . . . . . . . . . . 140

4.6 Empirical Methods: Network Analysis . . . . . . . . . . . . . . . . . 143

4.6.1 Network Specification . . . . . . . . . . . . . . . . . 144

4.6.2 Descriptive Statistics . . . . . . . . . . . . . . . . . . . 145

4.6.3 The Applied Model: The ERGM . . . . . . . . . . . . . . . . 147

4.6.3.1 Model Terms . . . . . . . . . . . . . . . . 147

4.6.3.2 Model Estimation and Goodness of Fit (GOF) . . . 154

4.7 Empirical Results . . . . . . . . . . . . . . . . . . 156

4.7.1 Network Descriptive Statistics . . . . . . . . . . . . . 157

4.7.2 The Exponential Random Graph Model (ERGM) . . . . . . . 158

4.7.2.1 Comparing Models . . . . . . . . . . . . 158

4.7.2.2 Model Parameters . . . . . . . . . . . . . . 160

4.7.2.3 Goodness of Fit (GOF) . . . . . . . . . . . 162

4.7.3 The Tested Research Hypotheses . . . . . . . . . . . . . . . . 164

4.8 Discussion of Results . . . . . . . . . . . . . . . . . . . . 167

4.8.1 Model Advantages . . . . . . . . . . . . . . . . 167

4.8.2 Central Actors and the Diffusion of Information . . . . . . . . 167

4.8.3 Network Structure and Homophilous Actors . . . . . . . . . . 173

4.9 Conclusions . . . . . . . . . . . . . . . . . . . . 178

$\begin{array}{ll}\text { References } & 181\end{array}$ 


\section{List of Tables}

1.1 Researched Communities . . . . . . . . . . . . . . 6

2.1 Tree and fruit tree species adopted by farmers in the research region . 25

2.2 Evolution of research main hypothesis about the diffusion of the adoption 31

3.1 Researched Communities . . . . . . . . . . . . . . . . . 63

3.2 Main Activities in the region related to the search for advice . . . . . 68

3.3 Agricultural Activities Advice Network Statistics . . . . . . . . . . 75

$3.4 g_{a} K$-core: Core/Periphery of Network Actors, where: [ ] n ( ) = [\%row] $\mathrm{n}^{\circ}$-actors $(\%$ colunm $) \ldots \ldots \ldots . \ldots . \ldots 84$

4.1 Main Tree species adopted . . . . . . . . . . . . . . . . 135

4.2 Researched Communities . . . . . . . . . . . . . . . . . . . 140

4.3 Agroforestry sp. Network Statistics _ . . . . . . . . . . . . . . 157

4.4 ERGM Model Results . . . . . . . . . . . . . . . . . . . . . . . . . . 163 


\section{List of Figures}

1.1 Local Interaction of Social Actors . . . . . . . . . . . . . . . 3

1.2 Research Region and Researched Communities . . . . . . . . . . . 8

2.1 Spatial representation of the research area - includes main and secondary roads - thicker lines depict more important roads . . . . . . . 24

2.2 Interactions of key informants; size of the symbols represent betweenness and degree of centrality . . . . . . . . . . . . . 28

2.3 Comparisons within and between adopters and non-adopters $A$ and $B$, and within and between ethnic groups $C$ and $D \ldots \ldots . \ldots 29$

2.4 Sub-groups defined by the Girvan-Newman and Factions methods . 30

3.1 Access across Structural Holes . . . . . . . . . . . . . . . . 55

3.2 Bosque Protector Corazón de Oro . . . . . . . . . . . . . . . . 64

3.3 Advice Searching: Sender-Receiver . . . . . . . . . . . . . . 77

3.4 Centrality of Vertex $i$ in $g_{a} \ldots \ldots \ldots$. . . . . . . . . . 79

3.5 Cohesive blocks hierarchy in $g_{a} \ldots \ldots \ldots$. . . . . . . . 81

3.6 Centrality and Structural Cohesive Blocks of $g_{a} \ldots \ldots . \ldots 82$

$3.7 g_{a}$ vertex size based on income . . . . . . . . . . . . . . 92

3.8 Ego networks for most central actors in $g_{a}$, order $n=1$, i.e. Ego's immediate neighbors . . . . . . . . . . . . . . . . . . 98

3.9 Burt's Constrain and Vertex degree . . . . . . . . . . . . . . 100

4.1 Some basic network configurations . . . . . . . . . . . . . . . 121

4.2 Addition network configurations related to transitivity . . . . . . . 123

4.3 Bosque Protector Corazón de Oro . . . . . . . . . . . . . . . . . 139 
4.4 Topological illustration of model terms . . . . . . . . . . . . . 153

4.5 $g_{T}$ Agroforestry tree species information search network and actors' degree centrality . . . . . . . . . . . . . . . . . . . 159

4.6 Models Goodness of Fit . . . . . . . . . . . . . . . . . . . . 165

$4.7 g_{T}(V=403 E=687)$ edge color based on tree sp. . . . . . . . 170

$4.8 g_{T_{i n c}}(V=199, E=311)$ vertex size based on income $\ldots \ldots$. . . 172 


\section{Nomenclature}

$g \quad$ Representation of any network by a Graph. See Chapter 2, Chapter 3, Chapter 4.

$V \quad$ Number of vertices in a graph. This defines the order of the graph. Equivalent terms for vertex used in this document are: nodes, actors, individuals.

E Number of edges in a graph. This defines the size of the graph. Equivalent terms for edge used in this document are: ties, links, contacts.

$g_{a} \quad$ Graph representation of the network on agricultural activities. See Chapter 3

$g_{a S} \quad$ Subgraph representation of the subnetwork on agricultural activities for the ethnic group Saraguro. See Chapter 3

$g_{a M}$ Subgraph representation of the subnetwork on agricultural activities for the ethnic group Mestizo-colono. See Chapter 3

$g_{T} \quad$ Graph representation: Network on agroforestry tree species. See Chapter 4

$g_{T_{S}} \quad$ Subgraph representation: Subnetwork on agroforestry species for the ethnic group Saraguro. See Chapter 4

$g_{T_{M}} \quad$ Subgraph representation: Subnetwork on agroforestry species for the ethnic group Mestizo-colono. See Chapter 4 


\section{Chapter 1}

\section{Introduction: Studying social structure in southern Ecuador}

\subsection{A region with diversity of interactions}

Southern Ecuador has been a center of attention for research in the last decades. The high biodiversity within this region has led to the combination of many fields of study (Beck et al., 2008)[8]. For many years the German Science Foundation, DFG (for its German name), has financed research on this area. The purpose of research is to understand geographical, geophysical, biological, economical and social phenomena in order to protect local ecosystems and help to achieve sustainable development. One of the biodiversity "hotspots" identified globally resides in southern Ecuador, the Podocarpus National Park (Brehm et al. in chapter 2 in Beck et al., 2008)[8]. For this reason a buffer zone was created in order to avoid the over exploitation of areas surrounding the national park. This buffer zone is called "Bosque Protector Corazon de Oro" (54143 hectares). This zone was created in the year 2000 and is located between the provinces of Loja and Zamora-Chinchipe (Universidad Nacional de Loja, 2006)[64]. The creation of this buffer area has brought many opportunities for research and a big step to protect the local ecosystem. For example, by studying land use in the communities surrounding the national park it can be possible to estimate how is the park affected by human activities and how this effect can be reduced. Moreover, research has also put in evidence the social problems associated with deforestation and 
rural poverty in this area.

The rural communities surrounding Podocarpus National Park are mainly inhabited by two ethnic groups. The first group is the Mestizo-colono whose members arrived to the region mostly at the beginning of the 1960s, motivated by the governmental policies of agrarian reform. These policies gave the newcomers facilities to acquire new land in areas covered by forests (Pohle in chapter 3 in Beck et al., 2008)[8]. As in most Latin American countries, this process took place without any special organization, and reorganized most of the land with low quality for agriculture, for instance, very steep conditions (Abbott, 2005)[1].

The other ethnic group living in the region is the Saraguro. This is an indigenous originally Quechua speaking group, who still preserve many traditions, such as costume, food and crops (Ogburn, 2007; Pohle and Gerique, 2006)[46][49]. The local economy is based on agriculture. Dairy and meat production are the main income sources. Although Saraguros and Mestizo-colonos do show differences in their livelihood systems, they share some economic dependence on cattle ranching (Pohle and Gerique, 2006)[49].

The region has suffered continuing deforestation (Mosandl et al. in chaper 4 in Beck et al., 2008)[8]. The consequences are visible today, for example the endangerment of many species are current problems (Mosandl et al. in chapter 37 in Beck et al., 2008)[8], and degradation of arable land (Pohle and Gerique in chapter 25 in Beck et al., 2008)[8]. Low land yields and low incomes are problems faced by the local settlers of the communities surrounding the National Park (Maza et al., 2010)[43].

For this reason, these communities are the focus of our attention. Improving their living conditions without having a negative long term impact on the local ecosystem is a puzzle of the type that confronts humanity continuously. We want to understand the local patterns of diffusion of information. If we are able to understand how information is spread through interaction networks, we will be able to comprehend the diffusion of sustainable adoptions of farm practices by the local farmers. One adoption that we approach in this work is that of agroforestry tree species. This adoption can help to increase the household income and at the same time increasing the number of trees in the farm (FAO, 2005)[23].

We have identified many adoptions related to agriculture, however, the plantation of tree species is of special interest. For example, in completely deforested areas in- 
troduction of tree species will help to regenerate the soil, reduce erosion, increase biodiversity and protect water sources (Bhagwat et al., 2008; Dawson et al., 2013; Sherr, 1995)[6][19][59]. At the same time farmers may be able to improve their land yields, and to diversify their sources of income (Dawson et al., 2013; FAO, 2005; Sherr, 1995)[19][23][59]. Most (90\%) of the existing tree plantations in Ecuador are based on introduced species such as Pinus spp and Eucalyptus spp (Aguirre, et al., 2006)[2]. These species present some ecological problems that have caused a shift in interest towards use of native species (Mosandl and Günter, 2008)[11].

Considering the cultural differences between Mestizo-colono and Saraguro, and that these two ethnic groups have different knowledge about local flora, we assume that these different cultural patterns also create different patterns in the diffusion of information about these agroforestry tree species. We also expect to find some different relations to the adoption of tree species. This is a part of the analysis that will be developed in the next pages.

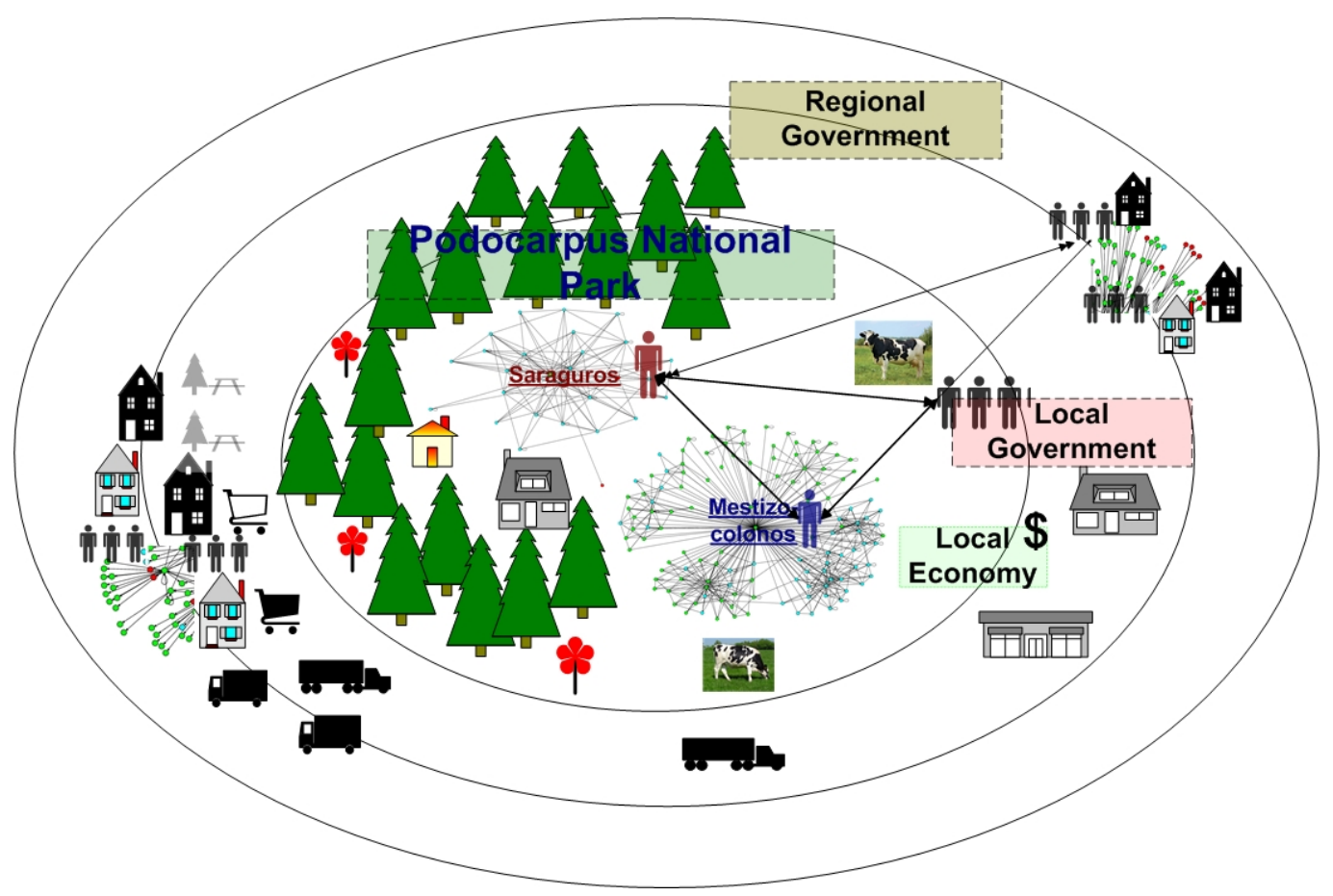

Figure 1.1: Local Interaction of Social Actors

Figure 1.1 presents the interaction between actors in the research region. The concentric spheres represent the different levels (local and regional) at which the actors in- 
teract. For example, Saraguros and Mestizo-colonos interact with the local government (Junta Parroquial) and other organizations such as NGOs (non governmental organizations). The local government also interacts with the regional government (Consejo Provincial) in order to apply local policies, and environmental and agricultural programs, which are of interest to us. Additionally, there are many organizations which gather indigenous people, peasants, religious groups, etc. Inside these organizations either Mestizo-colonos and Saraguros are represented. Nevertheless, Mestizo-colonos are more involved in political participation. This is observed as Mestizo-colonos are majority in the local and regional government, as observed in the field research only one Saraguro was working for the Junta Parroquial de Imbana.

In studying social interactions, we must take into account that individuals tend to group together based on similarities, of which ethnicity is one of the strongest (McPherson et al, 2001)[44]. In the social interaction, individuals' ties influence behavior and the norms at the same time influence the individuals' ties (patterns of create a tie) and behavior (e.g. adoption of an innovation). Social status is one of the main outcomes of social interaction. This results from the social exchange of information, money, agricultural production, etc. If there is an actor or group that has more advantages in the exchange process, this can produce power structures (Molm in Thye and Skovoretz, 2003)[67]. These structures can be analyzed by studying the social interaction through network structures. For example, the access to information through social interaction networks can influence the decision of land use. The land use at the same time may reflect the quality of the information through higher incomes and, therefore, influences economic status.

\subsection{General survey design}

We surveyed communities located at the northern edge of the Podocarpus national Park and within the "Bosque Protector Corazon de Oro", see Figure 1.2a. The communities included in this area are presented in Figure 1.2b. We divided the study into two research phases. The first phase corresponds to an analysis of the adoption of agricultural innovations in the research region. This was done through a series of in-depth semi-qualitative interviews $(n=10)$ with opinion leaders in six communities inside the "Bosque Protector Corazón de Oro". The selected communities are Imbana, Los 
Guabos, San Juan del Oro, El Cristal, El Tibio (El Tibio Bajo and Tibio Alto).

In the first phase a sensitization of the main goals of the study with communal leaders was done. By this means, we aim to inform the communities about the second phase of the research. The results of the first research phase are presented in Chapter 2. Based on the communities (11) surveyed during the second research phase, we conducted a network analysis. All heads of household in these communities were interviewed (a total of $n=208$ households). The network interactions were constructed based on the search for advice on agricultural activities of all households heads (Chapter 3) and the search for information on agroforestry species (Chapter 4).

For the second phase, 11 communities out of 28 located inside the "Bosque Protector Corazon de Oro" were selected (see Figure 1.2a: light gray colored area delimited by a thick line). The selection of the communities was based on an expanded set of communities interviewed during the first research phase. The specific location of the communities in the area can be observed in Figure 1.2b. The red circles with blue fill were included in the first research phase. These communities and six others were included in the second phase (all communities within a red circle in Figure 1.2b).

The criteria for selection of communities for the two research phases were based on two dimensions $(a)$ location of the communities in the region and $(b)$ ethnicity of the members of the communities. Dimension $(a)$ consists in detail on: $(i)$ communities within Corazon de Oro, see Figure 1.2a, (ii) positive collaboration in previous research surveys and (iii) selection should be consistent with the fact that the Mestizo-colono is the group most represented in the region, i.e. a higher number of communities settled by Mestizo-colonos must be selected.

The second dimension, $(b)$, was partly based on the results of a study done in southern Ecuador on socioeconomic factors of agroforestry applied by indigenous and Mestizo-colonos (Byg and Balsey, 2006)[18]. This study suggests that ethnicity and remoteness are key factors to explain adoption of agroforestry on this region (Byg and Balsey, 2006)[18]. Furthermore, we also follow Rogers (2003)[58] who stresses that network communication channels should be addressed to study adoption of innovations. For this reason, is of our interest to select communities for Saraguros and for Mestizo-colonos that have similar characteristics. In this way, we can control over the factors that may improve or limit the diffusion of information as we explain below.

To ensure that communities selected have similar characteristics for Mestizo-colonos 
and Saraguros and to construct the dimensions above explained we were based on: $(i)$ accessibility to roads, (ii) their telecommunications capacity and (iii) their ethnicity. According to accessibility the communities $(i)$ were divided into three groups, those with no access even with a car $4 \times 4^{1}$, those with limited access by car and those with good access by car. The telecommunications criterion (ii) describes whether the local population has no access to telecommunications, access to mobile telephone, or access to a phone at home, or both. This factors may influence the options to access advice. The access to telephone is restricted to some communities with good access. The resulting sample of selected communities based on the two dimensions criteria, $(a)(b)$, is presented in Table 1.1.

Table 1.1: Researched Communities

\begin{tabular}{|c|c|c|c|c|}
\hline Communities & $\mathbf{N}^{\mathrm{a}}$ & Access $^{\mathrm{b}}$ & Ethnic Majority & Telecommunications ${ }^{\mathrm{c}}$ \\
\hline El Cristal & 11 & $\mathrm{Bad}$ & Saraguro & No \\
\hline El Tibio Alto & 24 & Regular & Saraguro & No \\
\hline EI Tbio Bajo & 16 & Regular & Saraguro & No \\
\hline Hierbabuena $^{\mathrm{d}}$ & 20 & Good & Saraguro & Full \\
\hline Imbana & 32 & Regular & Mestizo-colono & Middle \\
\hline San Jual del Oro & 12 & $\mathrm{Bad}$ & Mestizo-colono & Middle \\
\hline Los Guavos & 23 & Regular & Mestizo-colono & No \\
\hline La Libertad & 10 & Regular & Mestizo-colono & No \\
\hline La Union & 19 & Regular & Mestizo-colono & No \\
\hline Sabanilla & 19 & Good & Mestizo-colono & Full \\
\hline Jesus Maria & 22 & Regular & Mestizo-colono & No \\
\hline El Bunque & - & Good & Saraguro & Full \\
\hline
\end{tabular}

a Number of household heads interviewed, contacts of respondents are not included.

${ }^{\mathrm{b}}$ Good if it was possible to access by car on a paved road, Regular if was possible to access by car in an unpaved road, and $\mathrm{Bad}$ if was impossible to access by car through any kind of road.

${ }^{c}$ Full refers to communities with access to mobile telephone signal and optionally a home telephone. Middle indicates access to one communal telephone for all the community. No means no access to mobile telephone or home telephone. In some cases a weak mobile telephone signal was identified but it was unstable and easily disrupted (tested in the field).

d The community Hierbabuena was selected instead of El Bunque.

In order to construct the network relations we have covered at least a third of the

\footnotetext{
${ }^{1}$ A four-wheel automotive vehicle (e.g., a pickup) equipped with four-wheel drive.
} 
communities within "Corazon de Oro". This was a big challenge for the field research. During the field research of the second phase, there was one problem with the $11^{\text {th }}$ community, "El Bunque". After two days in the field we decided to stop and replace ${ }^{1}$ this community. The replacement was done by selecting a community at the boundary of "Bosque Protector Corazon de Oro", near the main road. "El Bunque" was replaced by the community "Hierbabuena", who fulfilled the criteria above explained. The selected community is close to "El Bunque" by following the main road on the direction to "La Merced", as shown on the upper-left side in Figure 1.2b.

\subsection{Research development}

In the first research phase we analyzed possible differences of adoption of agroforestry tree species between Saraguro and Mestizo-colono ethnic groups (Chapter 2). Generally, we were partially motivated by the little information about indigenous peoples access to information and adoption of innovations, and by low knowledge of diffusion of information between and within indigenous and non-indigenous. By using social network analysis we found that there are potentially different patterns on how information, necessary for the adoption, is shared between and within the ethnic groups. These possible differences may drive into more advantages for one ethnic group at the moment to access information necessary to take decisions on land use. This information may also influence the likelihood of the household to access a higher income and use more sustainable land use practices.

For example, poor households' adaptation to climate change may be improved if access to information through the social network is so that the local farmers can reduce their vulnerability to climatic change by having information on price changes, rain patterns and offer and demand. This is important because indigenous groups such as Saraguros are often economically marginalized.

For this reason, we conducted a second research phase where we analyzed the search for advice through the social network on all agricultural activities. This way, we could find different patterns on how the two ethnic groups search the advice necessary for the land use decisions and for the possible adoption of innovations (Chapter 3). The

\footnotetext{
${ }^{1}$ When the research team was there, there was a problem with a local epidemic that made it impossible to conduct the research. The health of the team members would have been endangered.
} 


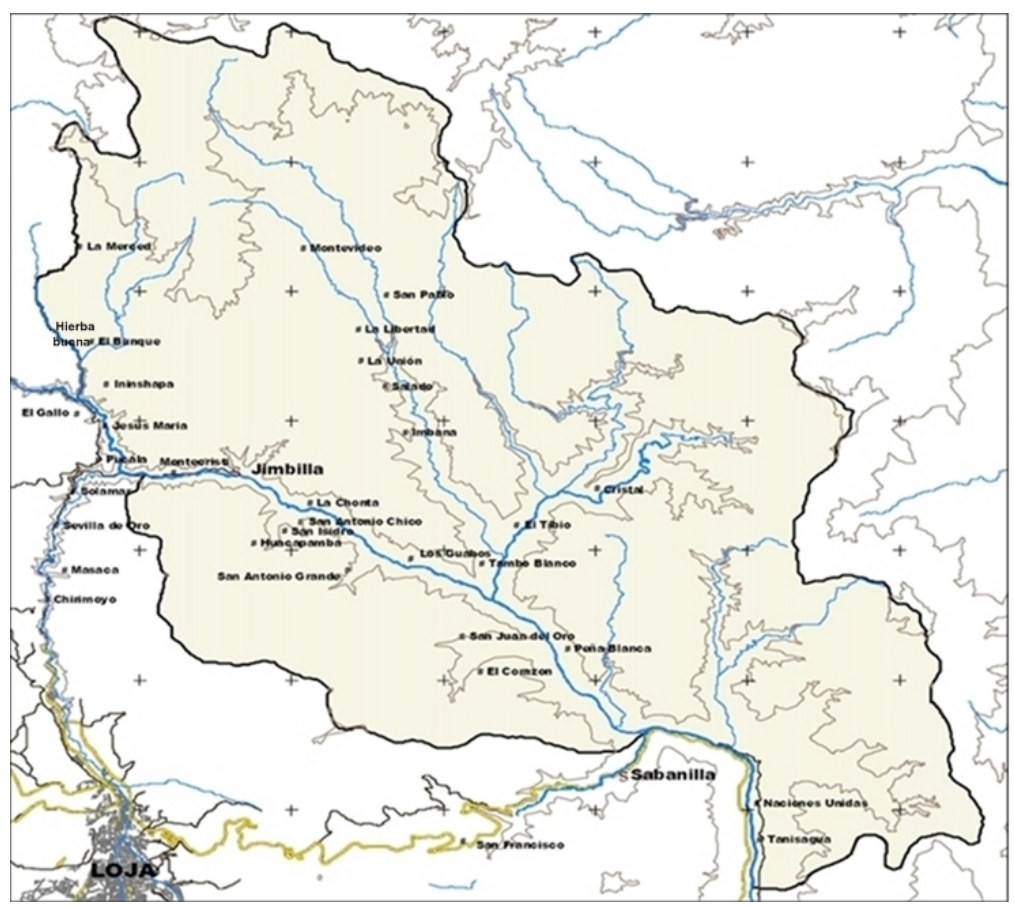

(a) Bosque Protector Corazón de Oro. Source: Universidad Nacional de Loja, 2006[64].

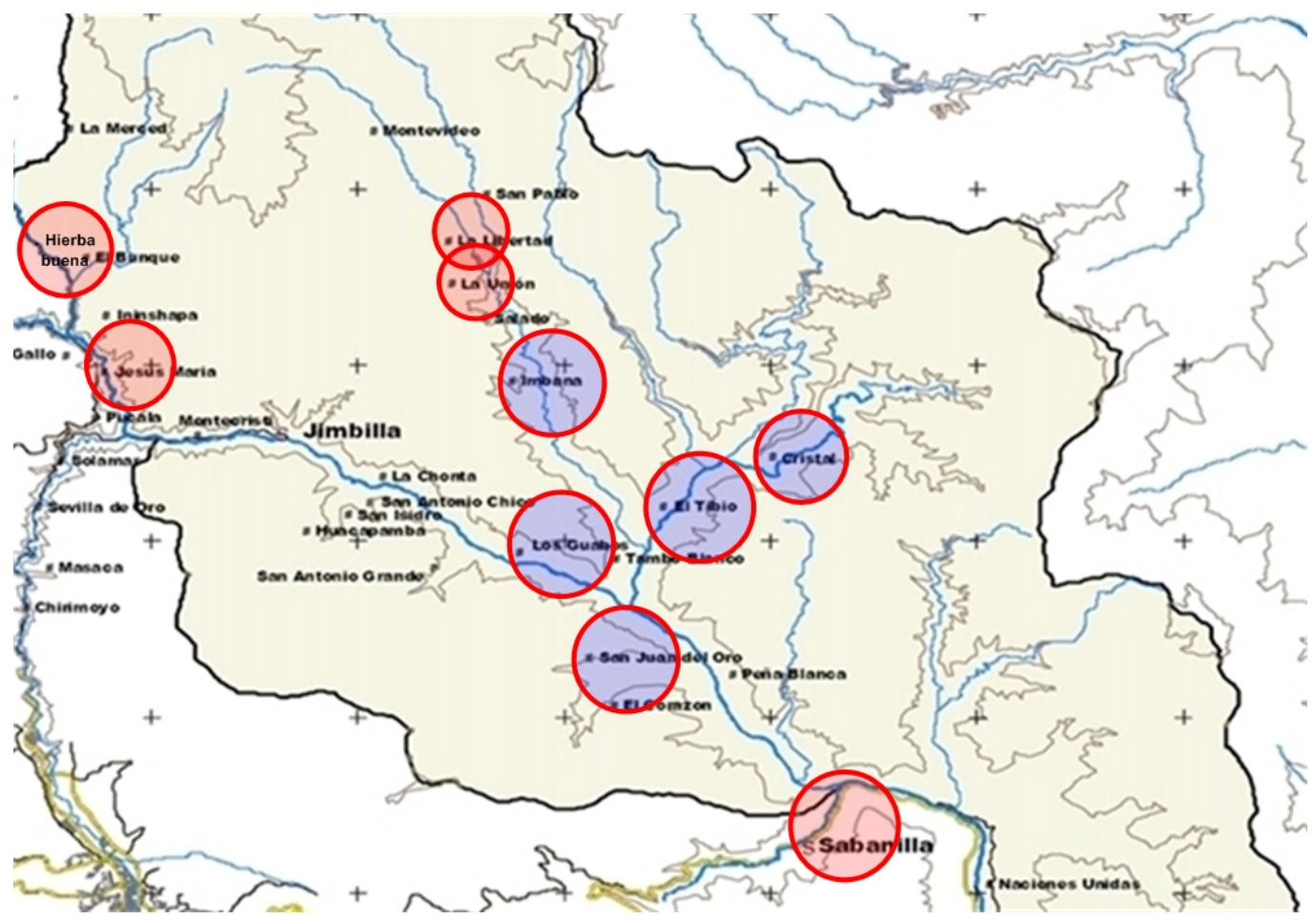

(b) Location of Selected Communities: Red circles: communities included in the two research phases, Red circles-blue fill: communities included in first research phase.

Figure 1.2: Research Region and Researched Communities 
second analysis on the social network patterns was done to the search for information on agroforestry tree species. This analysis was of special interest to us because the potential environmental and socio-economical benefits of planting trees inside the farm (Chapter 4). The results show that the non-indigenous ethnic group Mestizo-colono is better positioned in the network in order to access more information related to higher income sources and more diverse sources of information. Furthermore, the access to this kind of information may result in a more sustainable farm system. In the next subsection, we present a summary of each chapter in order to give the reader a better overview of the document.

\subsection{Chapters overview}

Here we present the main content of each of the chapters developed on this work. The first to be explained is Chapter 2, this chapter presents the main insights of the first research phase. After that, Chapter 3 and Chapter 4 are described. These two last chapters present the main results, theoretical and methodological explanations of the second research phase.

\subsubsection{Chapter 2: Social Network Effects on the Adoption of Agro- forestry Species: Preliminary Results}

A case study in South Ecuador serves as an example to understand the dynamics of adoption of agroforestry species. Qualitative research shows that there are potential differences in adoption between two ethnic groups. The two ethnic groups related to changes in land use are the Saraguro and the Mestizo-colonos. The two differ markedly in terms of cultural patterns and some land use practices. The adoption rate of Saraguro communal leaders of agroforestry tree species may be an indicator of lower contagion than Mestizo-colonos. Thus, we propose a heterogeneous diffusion model that addresses network exposure effects and a generalized blockmodel for relational data analysis. We hypothesize that Mestizo-colonos have higher adoption rate than Saraguros. The Saraguro indigenous group may have lower access to the information necessary for the adoption of the innovation than Mestizo-Colonos. 


\subsubsection{Chapter 3: Describing Ethnic Groups in an Advice Network}

Studying the advice on agricultural activities helps us to disentangle how information is shared throughout social networks in rural communities in southern Ecuador. Based on an independent sample of respondents of 208 households, we generated an advice network of 561 nodes and 1410 network ties. This network addresses the search for advice on local agricultural activities. The data suggest that there are, in fact, structural differences in search for advice between ethnic groups.

The subgroup of Mestizo-colonos has the actors with highest degree of centrality and betweenness. These actors are in the highest cohesive block in cohesive block analysis. Furthermore, a high Burt's constraint shows that structural holes in the network create a differentiation of information sharing between groups. Higher Burt's constraint indicates less access to the information located in other clusters in the network. The periphery of the network plays an important role as a source of advice, as shown by the cohesive block analysis, which we complement with a k-core analysis. The results suggest that different and more diverse information is accessed by Mestizo-colonos as compared to Saraguros. This suggests that Saraguros tend to share more similar information within their group than do Mestizo-colonos.

\subsubsection{Chapter 4: Information Network About Agroforestry Tree Species}

Tree species suitable for agroforestry ("agroforestry species") can be important constituents of sustainable land use options in pasture-dominated landscapes of southern Ecuador.

Using an exponential random graph model (ERGM) and a comprehensive sample, it conclusively shown that, indeed, information searching differences exist between two ethnic groups. It is also described the differences between the ethnic groups' tree adoption and the relation to the importance for sustainable landscape development. Searching information with similar others is limited to the less commercial tree species. The most commercial tree species information is concentrated in one actor, who is Mestizo-colono. Transitive network effects are identified within ethnic groups as long as they search information on different tree species (others than pine). The two ethnic 
groups search information of different agroforestry tree species. This shows a different knowledge on tree species, where Mestizo-colonos are more related to commercial species. 


\section{References}

[1] Abbott A. (2005). Counting Beans: Agrobiodiversity, indigeneity and agrarian reform. The Professional Geographer 57(2): pp:98-212. 2, 44, 45, 58, 59, 60, $129,130,131$

[2] Aguirre N., Günter S., Weber M., and Stimm B. (2006). Enrichment of Pinus patula plantations with native species in Southern Ecuador. lyonia 10(1): pp:33-45. 3,171

[3] Bhagwat S., Willis K.J., Birks J.B. and Whittaker R.J. (2008). Agroforestry: a refuge for tropical biodiversity?. Trends in Ecology and Evolution 23(5): pp:261267. $3,134,136$

[4] Byg A. and Balsev H. (2006). Palms in indigenous and settler communities in southeastern Ecuador: farmers' perception and cultivation practices. Agroforestry Systems 67: pp: 147-158. 5, 174

[5] Beck E., Kottke I, Bendix F. Makeschin F. and Mosandl R. (2008). Gradients in a Tropical Mountain Ecosystem of Ecuador: Vol. 198. Ecological studies. Berlin Heidelberg. Germany: Springer-Verlag. 1, 2, 17, 22, 23, 58, 60, 61, 114, 129, 130, $131,132,133,134,136,174$

[6] Dawson I., Guariguata M., Loo J., Weber J, Lengkeek A., bush D., cornelius J., Guarino L., Kindt R., Orwa C., Russell J. and Jamnadass R. (2013). What is the relevance of smallholders' agroforestry systems for conserving tropical tree species and genetic diversity in circa situm, in situ and ex situ settings? A review. Biodiversity Conservation 22: pp:301-324. 3, 113, 133, 134, 136, 174 
[7] FAO (2005). Realizing the economic benefits of agroforestry: experiences, lessons and challenges. In State of the World's Forests. FAO 2005. pp:88-97. 2, 3, 113, $114,133,134$

[8] Günter S., Stimm B. and Weber M. (2004). Silvicultural contributions towards sustainable management and conservation of forest genetic resources in Southern Ecuador. Lyonia 6(1): pp:75-91. 25

[9] Maza, B., Barkmann, J., von Walter, F., and Marggraf, R. (2010). Modelling smallholders production and agricultural income in the area of the Biosphere reserve "Podocarpus-El Condor", Ecuador. Georg-August-Universität Göttingen: Department of Agricultural Economics and Rural Development, Working Paper, 1004. 2, $21,22,23,43,45,58,59,60,89,114,129,130,131,134,168$

[10] McPherson M., Smith-Lovin L. and Cook J. (2001). Birds of a Feather: Homophily in Social Networks. Annual Review of Sociology 27: pp: 415-444. 4, 45, $57,71,87,115$

[11] Mosandl R. and Günter S. (2008). Sustainable management of tropical mountain forests in Ecuador. In: S.R., Gradstein, J. Homeier, and D. Gansert (Eds.), Biodiversity and Ecology Series (2): The tropical mountain forest (97-107). Göttingen: Universitätsverlag Göttingen. 3

[12] Ogburn D.E. (2007). Incas Past and Present. Stanford Journal of Archaeology 5: pp: 134-163. 2, 44, 61, 87, 89, 93, 132, 175

[13] Pohle, P. and Gerique, A. (2006). Traditional ecological knowledge and biodiversity management in the Andes of southern Ecuador. Geographica Helvetica, 61(4): 275-285. 2, 16, 22, 43, 45, 58, 60, 89, 93, 113, 129, 131, 132, 174

[14] Rogers E. (2003). Diffusion of innovations. Free Press (5th ed.). New York. USA. $5,42,49,69,88,90,96,115,116,133,169,171,174,176$

[15] Sherr S. (1995). Economic factors in farmer adoption of agroforestry: Patterns observed in Western Kenya. World Development 23(5): pp:787-804. 3, 133, 134

[16] Thye S. and Skvoretz J. (2003). Power and Status. Advances in Group Processes Vol. 20. Series Ed. Lawler and Thye S. Elsevier Ltd. Oxford. UK. 4, 47, 48, 88 
[17] Universidad Nacional de Loja (2006). Estado de Conservacion del area de Bosque y Vegetacion Protectora "Corazon de Oro". In Informe Tecnico: Estado de Conservacion de areas Protegidas y Bosques Protectores de Loja y Zamora Chinchipe y Perspectivas de Intervencion. Centro Integrado de Geometría Ambiental (CINFA), Herbario Reinaldo Espinosa Loja and Carrera de Ingenieria Forestal. Loja. Ecuador. 1, 8, 58, 62, 114, 129, 138 


\title{
Chapter 2
}

\section{Social Network Effects on the}

\section{Adoption of Agroforestry Species:}

\section{Preliminary Results of a Study on}

\section{Differences on Adoption Patterns in Southern Ecuador}

This chapter is a slightly modified version of the publication: Gonzalez V., Barkmann J. and Marggraf R. (2010). Social network effects on the adoption of agroforestry species: Preliminary results of a study on differences on adoption patterns in Southern Ecuador. Procedia-Social and Behavioral Sciences 4: pp: 71-82.

\begin{abstract}
A case study in South Ecuador serves as an example to understand the dynamics of adoption of agroforestry species. Qualitative research shows that there are potential differences in adoption between two ethnic groups. The adoption rate of Saraguro communal leaders may be an indicator of lower contagion than Mestizo-colonos. Thus, we propose a heterogeneous diffusion model that addresses network exposure effects and a generalized blockmodel for relational data analysis. We hypothesize that Mestizocolonos have higher adoption rate than Saraguros. The Saraguro indigenous group
\end{abstract}


may have lower access to the information necessary for the adoption of the innovation than Mestizo-Colonos.

Keywords: network analysis, adoption of sustainable innovations, Southern Ecuador ethnic-groups

\subsection{Introduction}

Southern Ecuador has witnessed rapid socio-economic development in recent years. Mining, tourism, and agriculture have expanded and lead to large-scale ecological changes in this global 'hotspot' of biological diversity (Levin and Reenberg, 2002; Myers et al., 2000)[46][25]. Illegal timber extraction and the conversion of partly protected forests to pastures pose ongoing challenges to the regional human-environment relationship (Gerique and Pohle, 2006)[49]. To reduce biodiversity loss and other unwarranted consequences of deforestation, the Podocarpus National Park and the surrounding Podocarpus-El Condor UNESCO Biosphere Reserve were established at the border of the Loja and Zamora-Chinchipe provinces. The region is not only biologically, but also ethnically diverse with at least three ethnic groups living in the area. Two are indigenous. Since several years, ecological as well as socio-economic conditions for the conservation of biodiversity and for sustainable land use options in the area are investigated by an interdisciplinary research group funded by the German Science Foundation (research groups 413 and 816; www.tropicalmountainforest.org). One of the options to reduce the stress on biological diversity and natural resources is the adoption of agroforestry practices. Basically, this means little more than that trees are incorporated in agriculturally productive landscape (see Section 2.3.3). Several agroforestry systems have been shown to harbour a substantial part of the biological diversity of the original ecosystems while providing improved sustenance for the local population (Price, 1995; Steffan-Dewenter et al., 2007)[50][34].

From the perspective of a local farmer practicing an exclusively pasture-based form of diary and cattle production, the inclusion of trees represents an innovation. Innovation is defined as "Ideas or practices that are perceived as new, applied in the productive system and spread" (cf. Rogers et al., 2005)[29]. Innovation theory suggests that the diffusion of an innovation is strongly associated with social network effects 
(Rogers, 1995; Valente, 1999)[28][38]. The adoption of agroforestry tree species in our southern Ecuador research area offers an opportunity to study ethnicity and sociocultural effects on agricultural adoption patterns. This topic is pressing because the indigenous populations in many regions worldwide are particularly susceptible to environmental or social changes, e.g., because they command less financial capital or have more narrowly defined natural resource-dependent livelihood options (Schneider et al., 2007)[33].

In this paper we analyse the results of a preliminary qualitative study on ethnic, socio-cultural and socio-structural factors that potentially influence the adoption of smallholder agroforestry options in the Podocarpus-El Condor region. In the project region two ethnic groups can be found that practice pasture-based agriculture, the indigenous Saraguros - a Quechua-speaking group of highland dwellers -, and Spanishspeaking Mestizo-colonos representing the non-indigenous majority population in Ecuador. From previous research it is known that Saraguros and Mestizo-Colonos differ in their agricultural resource use. Specifically, it was claimed that the Saraguros tend to have more trees on their farms (Pohle and Gerique in Beck et al., 2008)[8]. But does the adoption of agroforestry tree species in fact differ between Saraguros and Mestizo-colonos? If so, can these differences be traced back to differences in the social structure of the communities with respect to communication patterns about agricultural innovations? We propose to use social network analysis tools to answer these questions.

The paper is structured as follows. First it has a section that describes the theoretical and conceptual background of the diffusion of innovations. The a section that describes the sample and research area, and presents our empirical results follows. The last section is dedicated to the proposed models for a further quantitative phase.

\subsection{Background: The diffusion of innovations}

\subsubsection{Adoption and diffusion of innovation studies: Brief overview}

In 1943 a pioneering study of Ryan and Gross demonstrated that not only economic factors but also social factors influence technology adoption (Ryan and Gross 1943; Valente and Rogers, 1995)[32][40]. One form of incorporating such social factors is 
based on the analysis of learning from others (Acemoglu et al., 2008; Besley and Case, 1993; Conley and Udry, 2001, 2005; Jackson, 2008;

Stoneman, 1981)[2][9][16][7][43][62]. This is taken one step further in explicit network perspectives on innovation. Within such networks social processes occur that influence "how individuals form opinions and eventually adopt or not adopt an innovation", a concept called contagion (Valente, 1999)[38].

There are different models that address the diffusion of innovations, such as threshold models of collective behaviour (Delre et al., 2007; Granovetter, 1986; Valente, 1996)[8][15][37], which are important since the adoption rate and the adoption threshold depend on the network structure (Jackson and Yariv, 2005)[21]. Other models, like deterministic diffusion models, perform a cumulative analysis of adopters over time (Rogers, 1995; Valente and Rogers, 1995)[28][40]. Due to some disadvantages diffusion models have been translated into event history. Conceptually, some variables such as individuals' intrinsic characteristics, spatial position, and time decay influence are incorporated (Greve et al., 1995; Myers, 2000; Strang and Tuma, 1993)[16][24][36]. For this reason the latter models are of interest to us to explain the adoption of an innovation in different periods of time.

There are also some theories that are important to explain the diffusion process. One important approach within social network theory that tries to explain why some individuals are capable to innovate and change more quickly than others is Strength of Weak Ties (SWT) theory (Granovetter, 1973, 1983)[31][39]. Granovetter's important contribution is a classification of connections in a social network based on the degree to which they convey information. Another remarkable approach, known as Innovation Theory, was developed by Everett Rogers (1995)[28]. Developed in the early 60's, it explores how new ideas are incorporated into a culture. More recently, Rogers et al. (2005)[29] argued that in heterogeneous groups connected by common aims an innovator may guide, to a certain extent, the emergence of innovation adoption.

\subsubsection{Network analysis and the diffusion of innovations}

How can network analysis help us understand the spread of the adoption of agroforestry species in southern Ecuador? Traditionally, in the region cattle ranging and timber extraction have been non-integrated activities. Nonetheless, in this context agroforestry 
integrates the concept of planting tree species within the farms exclusively used for cattle ranching. Thus, for the local farmers this represents an innovation as it is perceived as a new practice in the productive system. Importantly, the diffusion process of the adoption of these species flows through social networks. Farmers interact with other farmers and disseminate their ideas about whether to plant these trees species or not. Thus, we can determine who influences whom. Theoretically, the people with whom we interact may influence our own ideas and decisions since the spread of ideas flows through social interaction networks.

Interestingly, in different populations the social network can have different characteristics that make the individual have more access to information or even become totally excluded (Valente and Davis, 1999)[65]. Here the authors want to underscore the advantage of network analysis in determining whether one ethnic group is more related to and receives more benefits from the adoption of agroforestry species than the other ethnic group. Thus, a better understanding of a diffusion process is possible by understanding the spread of ideas and opinions through social networks. Individuals are exposed to the innovation through their contact with others in the social network.

\subsubsection{Network concepts}

In this section we provide the necessary conceptual background for the empirical analyses. Formally, a network consists of a set of nodes (also points or vertices) with connections between them called edges (or links). In social networks, the nodes represent social actors, often individuals. Thus, the social network is represented by the graph $G$, with $N$ nodes and $E$ edges, $G=N, E$. Formally speaking, network structure is the pattern of edges between such nodes. The edges can either be undirected or directed. In directed networks each link has an origin (tail) and a destination (head) (Brandes and Elebach, 2005)[11]. The most fundamental network configurations in directed networks between two (dyad) or three nodes (triad). An undirected dyad $i, j$ is usually symbolized by $i, j$, and by $(i, j)$ for a directed dyad. The case of dyad mutuality may represent a restricted exchange of resources or information (Koehly and Pattison in Carrington et al., 2000)[15]. The three-cycle may represent a more generalized exchange in substructures larger than a dyad, where no prompt reciprocity is necessarily required. 
Centrality of a node is a very important concept of network analysis (cf. Freeman, 1977)[25]. Degree is the simplest centrality measure of a node $i$ that is specified as $d(i)$ of $i$ if the relation in the graph is undirected (Kosschützki et al., in Brandes and Elebach, 2005)[11]. Out-degree centrality $d(i)=d^{+}(i)$ is the number of edges that have $i$ as origin. In-degree centrality $d(i)=d^{-}(i)$ is the number of edges that have $i$ as destination. A second, more complex measure of centrality is betweenness of a node (Freeman, 1977)[25]. If we look at two nodes that need not be directly linked, there may be one or more paths between them. The shortest path is called geodesics. Thus, one node is considered to be central at the degree in which the node is found between other nodes on their shortest paths. A node has a high betweenness if a high fraction of all geodesics of the network pass through it. Thus, $b(i)$ is defined as the fraction of the shortest paths between all pairs of nodes that pass through node $i$ (Rozenfeld et al., 2008)[31]. With $\delta_{j u}(i)$ the number of shortest paths passing through $i$, we obtain formally,

$$
b(i)=\sum_{j \neq u \neq i} \delta_{j u}(i) / \delta_{j u} .
$$

It has been observed that network actors with high centrality measurements also tend to be connected with other highly connected actors. This characteristic is known as assortativity (Rozenfeld et al., 2008)[31]. A third centrality measure is max-flowbetweenness vitality $C F(i)$ (Koschützki et al., in Brandes and Erlebach, 2005)[11], which determines the maximum flow between $u$ and $j$ through $i$. Flow is the amount of information that is conveyed. In our case the flow will depend on the frequency of the contact between actors. The objective of max-flow-betweenness vitality is to measure to what extent the maximum flow between two actors depends on a third actor $i$. This measure is highly useful since it takes into account all independent paths along which information can flow, and not just the shortest paths (Freeman et al., 1991)[10]. If $u, j \in N$ and $i \neq j, i \neq u$; thus:

$$
C F(i)=\sum_{u, j \in N, f j u>0} f_{j u}(i) / f_{j u}
$$

and $f_{j u}(i)=f_{j u}-f^{\prime}{ }_{j u} \cdot f^{\prime}{ }_{j u}(i)$ is the maximal $j-u$ flow in $G \backslash i$ (without $i$ ), $f_{j u}(i)$ is the amount of flow which must pass through actor $i$ (Koschützki et al. in Brandes and Erlebach, 2005)[11]. In other words, if the flow going through $i$ is divided between all 
pairs of actors where $i$ is neither a source nor a receiver, we can estimate the proportion of the flow that depends on $i$. This produces a measurement between 0 and 1 (Freeman et al., 1991)[10]. In our case, if Mestizo-colonos concentrate a significant part of the information flow that may lead to an unbalanced share of the information between ethnic groups.

Structural Equivalence is a network measure that refers to nodes with a structurally similar position in the network which do not necessarily have a direct link between them (Valente, 1999)[38]. Two nodes are said to be structurally equivalent if they have the same relation to all other nodes. Therefore, two structurally equivalent nodes are exactly interchangeable (Hanneman and Riddle, 2005)[18]. Regular Equivalence also refers to two nodes which have an identical relative position with respect other nodes. In this case, however, the other nodes need not be identical (Hanneman and Riddle, 2005)[18].

\subsection{Semi-structured survey}

\subsubsection{Sample description and hypotheses}

As mentioned in Section 2.2.2 the adoption of agroforestry species is perceived as a new practice for the households in the region. The transition to an integrated system like agroforestry implies a change in the local productive structure. The adoption process that stays behind is complex and dynamic. Thus, as was explained in the last sections, social network analysis is an important methodological tool to understand the diffusion of innovation process. In the following we explain why we selected this research region and what the importance of planting agroforestry species in this context.

A survey of 135 local farming households in the region shows that $35 \%$ of the households get a survival subsidy (=30 USD/month; Bono De Desarollo Humano), and that $17 \%$ work as farm hands. The main products are meat, curd, and a traditional maize-bean-mix. Pastures are manually weeded and not fertilized. Their main interest in extension services is in cattle reproduction, pasture/resource conservation management and new crops (Maza et al., 2010)[43]. Southern Ecuador is highly heterogeneous in terms of culture and traditions. Thus, the local farming households do not form a 
uniform group (Pohle and Reinhardt, 2004)[26]. While the indigenous Saraguros are a Quechua-speaking group of Inca-descendants, the Mestizo-colonos represent the nonindigenous rural population of Ecuador. In spite of several differences, the members of both groups are predominantly smallholder farmers with a livelihood based on dairy and meat production.

Mestizo-colono communities are more numerous in the project region than Saraguro communities. Most Mestizo settlers came to the region as result of the agrarian reform during the 1960s. Their main income-generating activity is cattle ranching. Pohle and Gerique in Beck et al. (2008)[8] report that, in the areas where the Saraguros settle, the landscape displays more trees, while the areas settled by Mestizo-colonos are at times completely devoid of trees. In comparison to Saraguros, Mestizo-colonos have a reduced knowledge of local flora, but have a more comprehensive knowledge of crop plants and pasture varieties (Pohle and Gerique in Beck et al., 2008; Gerique and Pohle, 2006)[8][49]. Production function analysis suggests that, on average, Mestizo households generate higher per hectare income from their farms than Saraguro household (Maza et al., 2010)[43].

The Saraguros have been practicing cattle ranching since the early nineteenth century (Pohle and Reinhardt, 2004)[26]. Their traditional system of arable agriculture includes maize, beans, potatoes, other tubers and fruit. Their home gardens can include trees in a multi-strata arrangement, and have been hypothesized to be a sustainable, near optimal form of rural land use (Pohle and Reinhardt, 2004)[26]. Nonetheless, cattle ranching has become the most important income-generating activity for the Saraguros of the project area. Gerique and Pohle (2006)[49] suggest that the higher prevalence of trees in the case of the Saraguros may be an expression of a more sustainable form of agriculture based on traditional knowledge. Thus we hypothesize that:

- $H$ : the adoption of tree planting is higher in Saragoro households

\subsubsection{Research region conditions}

The biological diversity of Southern Ecuador is extremely high even by global standards, probably because of the extreme topographic heterogeneity of the region (Homeier, 2008)[34]. The topography is generally very steep and rugged, and also the soils 
are very heterogeneous. More than 280 tree species have been identified at the northern tip of the Podocarpus National Park alone (Homeier, 2008)[34]. Tropical rain forest is widespread at up to $1800 \mathrm{~m}$ a.s.l. Tropical evergreen cloud forests are found at higher elevations (Rollenbeck, 2006)[30]. Eight out of 15 main vegetation types identified in Ecuador are present (Beck et al. chapter 36 in Beck et al., 2008)[8].

Some of the principal problems in the region have been deforestation and illegal timber extraction. In the survey by Maza et al. (2010)[43], 10 of 135 respondents admitted openly to have cut forest for pastures, partly inside the local forest reserve. Deforestation affects the ecological integrity of the adjacent Podocarpus National Park (146,280 hectares), southern Ecuador's first conservation area (Pohle and Reinhardt, 2004)[26]. The communities of the region are interconnected by a road and path system of differing quality. The bigger communities are connected by principal roads suitable for motor traffic. Smaller communities are connected often only by secondary roads accessible at maximum by four-wheel drive cars, or even by small paths (see Figure 2.1). The road from Loja to Zamora is mostly inhabited by Mestizo-colonos. The Saraguros settle north of the road between Loja and Zamora in communities such as El Tibio and El Cristal (Figure 2.1). Communities as Imbana and El Tibio have been recently well connected by secondary roads.

\subsubsection{Agroforestry options}

Of 135 farmers interviewed in the research region, $42 \%$ have planted trees (Maza et al., 2010)[43]. The tree species planted by more than $5 \%$ of the sample are shown in Table 2.1. The fact that almost half of the farmers have planted at least one tree species shows that tree planting is widespread among local farmers. Pinus patula is a fast growing exotic pine used for timber. Alnus acuminata is a fast growing native tree used for timer and fuel wood that has the additional potential to improve soil conditions, since Alnus is a nitrogen-fixing species. Of all trees, farmers rate this species best on average (Maza et al., 2010)[43]. Eucapyptus globulus is a fast-growing exotic specie used for timber and fuel wood. Cupressus macrocarpa is a rather slow-growing native tree with high timber value. Moreover, several fruit tree species are grown in larger quantities, totalling more than $5 \%$. In addition to timber production, the nonfruit trees are often used as live fences. From a conservation point of view, it is hoped 


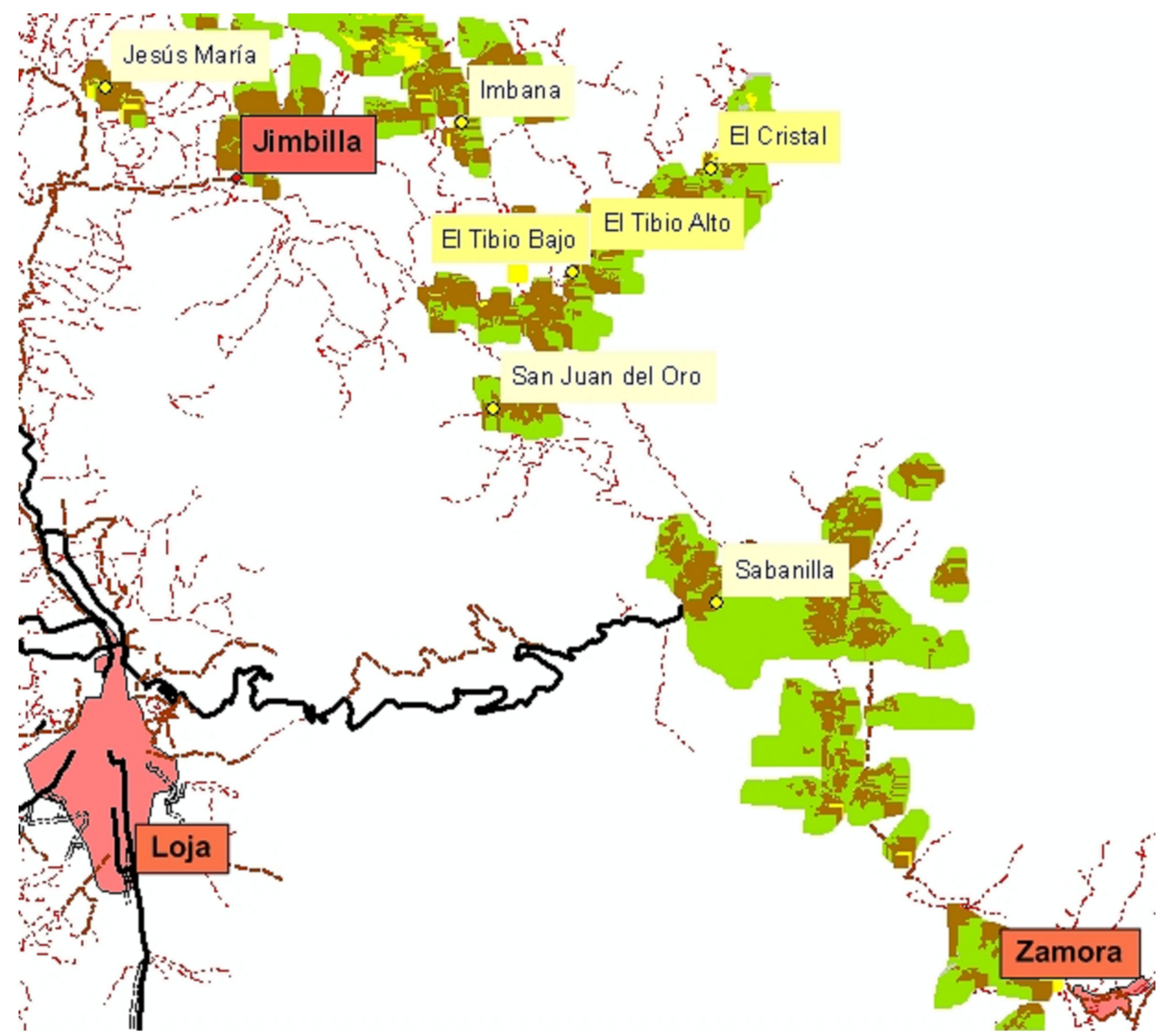

Figure 2.1: Spatial representation of the research area - includes main and secondary roads - thicker lines depict more important roads 
that local farmers reduce illegal timber extraction and at the same time increase household income by planting trees on their farms. In the ideal case, the landscape recovers some of its original biological diversity, farming household incomes are increased, soil-erosion is avoided, and the need for further deforestation is alleviated. Furthermore, if local tree species are planted, agroforestry can be a complementary means to protect forest genetic resources (Günter et al., 2004)[17].

Table 2.1: Tree and fruit tree species adopted by farmers in the research region

\begin{tabular}{|c|c|c|c|}
\hline Scientific Name & Common Name & Main Use & Origin \\
\hline Pinus patula & Pino & Timber-Life fence & Exotic \\
\hline Alnus acuminata & Aliso Rojo & Timber & Native \\
\hline Eucalyptus globulus & Eucalipto & Timber-Life fence & Exotic \\
\hline Cupressus macrocarpa & Cipré & Timber-Life fence & Exotic \\
\hline Juglans neotropica & Nogal & Timber & Native \\
\hline Tabebuia chrysantha & Guayacán & Timber-Life fence & Native \\
\hline Prunus persica & Durazno & Fruit tree & Exotic \\
\hline Erythrina edulis & Guato & Fruit tree-Life fence & Native \\
\hline Nectandra laurel & Laurel & Timber-Life fence & Native \\
\hline Inga spp. & Guaba machetona & Fruit tree & Native \\
\hline Ficus sp. & Higuerón & Timber-Life fence & Native \\
\hline Brugmansia candida & Guando & Medicinal plant & Exotic \\
\hline Malus domestica & Manzana & Fruit tree & Exotic \\
\hline Persea americana & Aguacate & Fruit tree & Native \\
\hline Prunus serotina & Capulí & Fruit tree (Home Garden) & Exotic \\
\hline Citrus sinensis & Naranjo & Fruit tree & Exotic \\
\hline Cedrela montana & Cedro rojo & Timber-Life fence & Native \\
\hline Grias peruviana & Inaco & Fruit tree & Native \\
\hline Syzygium jambos & Poma Rosa & Fruit tree & Exotic \\
\hline
\end{tabular}




\subsubsection{Overall research design}

The results presented below were obtained during the first phase of a two-phase research project on social network effects on the adoption of agroforestry tree species in south Ecuador. The core of the first phase consists of a small number of in-depth semi-qualitative interviews with opinion leaders in several local communities. Rogers (1995)[28] points out that opinion leaders have extensive interpersonal links with their followers. Importantly, they adopt innovations before their followers. If they do not adopt an innovation, they can have a negative effect on diffusion (Valente and Davis, 1999)[65]. Thus, we hoped that the interviews will improve our understanding of the local adoption processes enough to qualitatively test our initial hypotheses. By including leaders from different communities and differing ethnicities, it should be possible to disentangle pure location from ethnic effects. Ideally, we hoped to derive some first analytical models of network structure. Finally, the results will be used to construct a questionnaire for the second, quantitative phase of the research that will include all household heads of eight communities (Figure 2.1).

\subsubsection{Empirical methods}

During the first field visit, we interviewed ten community leaders from five communities (El Tibio, El Cristal, Los Guavos, Imbana and San Juan de Oro). The selection of the leaders was done with help of other researchers who had been working in the research area. Leaders were selected who appeared to $(i)$ be actively involved in community life, (ii) act as opinion leaders, (iii) be able to be trusted and relied upon, and finally $(i v)$ have a positive attitude towards collaboration. The interview guide included questions about the history of innovations in the region, whether the respondents adopted them or not, characteristics of the innovations, and when and how the innovation was introduced to the community, and by whom. Additionally, we asked whether our key informants knew the other community leaders on our list of informants, and how frequent the contact was. Of several addressed innovations, the adoption of agroforestry species turned out to be most suitable for further study as a major local agricultural innovation. Thus, the innovation in our context is the adoption of at least one of the tree species listed in Table 2.1.

The main results of this phase of the study are presented as a series of network 
graphs (see Section 2.3.6). These graphs depict the network structure based on contacts between informants that occurred at least once in the last three months. This information was obtaíned by a interview were a specific question was done to recall the contacts during this period. By calculating the adjacency matrix $N \times N$ of 10 key informants to analyze the interaction patterns based on the information of agroforestry species, we display results of the centrality measures betweenness and degree. In the graphs, the nodes (informants) are spatially arranged by community. The size of the node symbols represents their centrality. The colour of the nodes depicts the ethnic group. The shape of the symbol shows if the actor has adopted agroforestry species or not. The graphical representations and centrality calculations were estimated with NET DRAW, package for social network analysis (http://www.analytictech.com).

While we present all connections between the actors in Figure 2.2, only selected connections are shown in Figure 2.3 to highlight the role of ethnic groups in adoption. We form a group of adopters $N_{A}$ (circles) and of non-adopters $N_{N A}$ (triangles). Furthermore, we subdivide the set of edges $E: E_{W}$ is the set of edges within each of the subsets, and $E_{B}$ are the edges between sets. To test empirically for the existence of subgroups, the Girvan-Newman algorithm was used along with the Factions method (Figure 2.4). The Girvan-Newman algorithm is based on measure of edge betweenness that change as edges are successively removed (Girvan and Newman, 2002)[12]. The Factions method organizes actors into mutually exclusive groups that maximize the connectivity of each partition (Hanneman and Riddle, 2005)[18].

\subsubsection{Empirical results}

The betweenness graph (Figure 2.2) does not show any notable difference between adopters and non-adopters, and between ethnic groups. Of the four Saraguro opinion leaders, three have not adopted. They did not adopt although they did interact with adopters. Apparently, there is a low "infectiousness" or contagion between ethnic groups. The graphs also show assortativity, for instance, Lucio and Rodrigo are two highly connected nodes, and they are directly connected.

In Figure 2.3, we isolated the possible influence of adopters on non-adopters. Graph $3 A$ reveals that adopters form two distinct groups. In comparison to $3 B$, we find that there are the same number of links between adopters and non-adopters (8) 


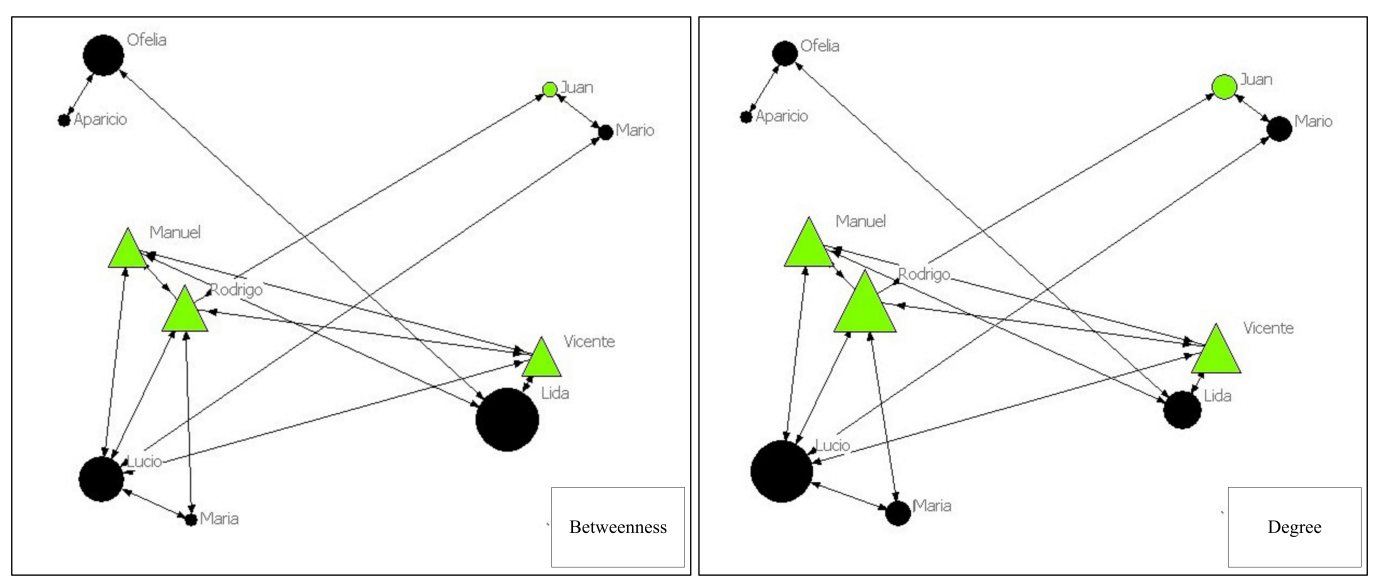

Figure 2.2: Interactions of key informants; size of the symbols represent betweenness and degree of centrality

[Saraguros green; Mestizo - colonos black; circles: adopters, triangles: non-adopters] [A tie shows at least one contact during the last three months before the interview took place].

and between groups (7). This difference is the same if community leaders are grouped according to ethnicity $(8: 7)$. Accordingly, Saraguros' (green colour) interaction is basically the same in Graph $A$ and $C$; and also if we compare Graphs $B$ and $D$ (Figure 2.3). It is important to mention that within non-adopters $100 \%$ of the possible links are present. However, just $27 \%$ of the possible links within adopters are fulfilled. Furthermore, within Saraguros $87 \%$ of all possible intra-links are present, but within Mestizo-colonos just 27\%. It seems that group cohesion within Saraguros is stronger than within Mestizo-colonos. It is difficult to obtain much deeper information from the analysis of graphs with such a small number of nodes. However, some additional results can be extracted. Interactions of a higher order are observed within adopters, e.g. 3-stars and more than one cycle. We also observe dyad restricted exchange.

Interestingly, the actors with higher degree centrality are from the communities Imbana and El Tibio (Lucio and Maria; Manuel and Rodrigo). Figure 2.1 shows that these two villages are connected by a secondary road facilitating contact between communities. Therefore, it seems that there is a subdivision which may reflect geographical and local limitations on infrastructure. Clearly, the subgroup represented by black nodes is the most highly connected sub-group including the most central actors (Figure 2.4). Those actors are also geographically close. The results from both methods are very similar in this respect. 


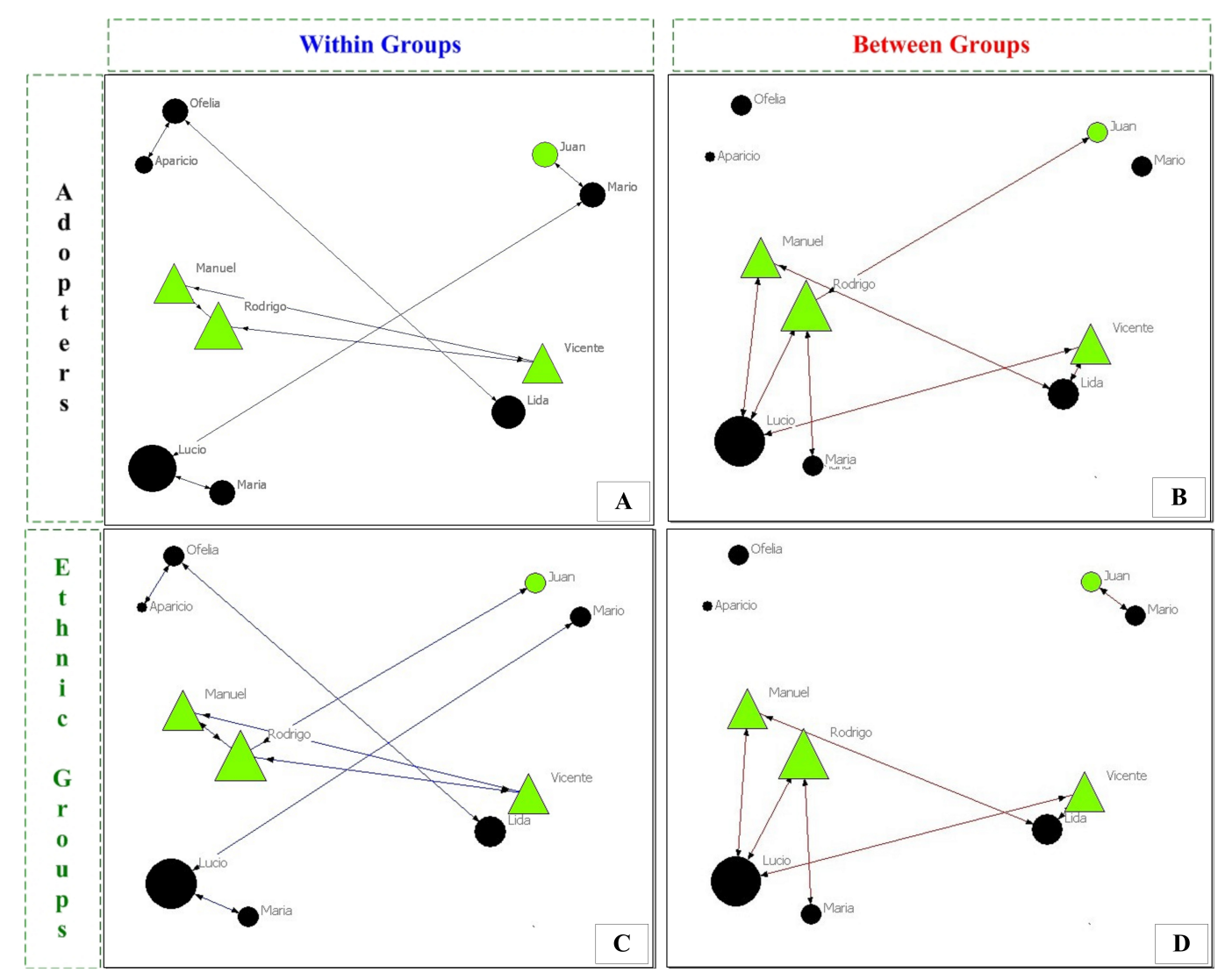

Figure 2.3: Comparisons within and between adopters and non-adopters $A$ and $B$, and within and between ethnic groups $C$ and $D$

[Saraguros green; Mestizo - colonos black; circles: adopters, triangles: non-adopters] [A tie shows at least one contact during the last three months before the interview took place]. 

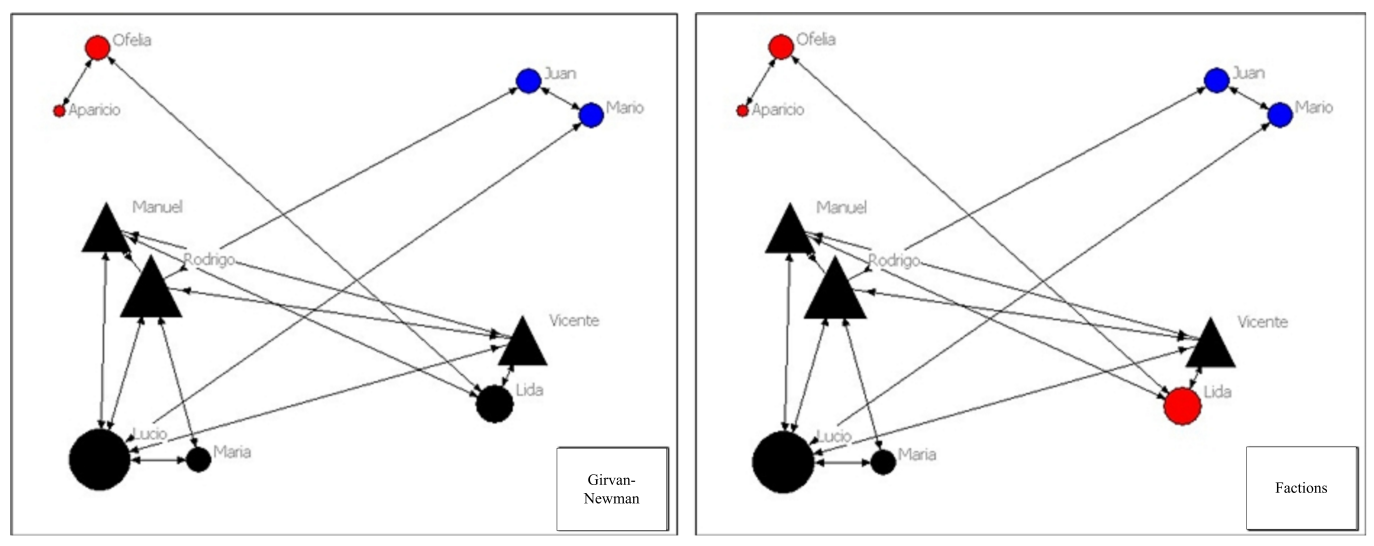

Figure 2.4: Sub-groups defined by the Girvan-Newman and Factions methods

[subgroups indicated by colour-coding] [A tie shows at least one contact during the last three months before the interview took place].

\subsubsection{Discussion of empirical results}

Contrary to the expectations based on previous literature on the project area, we did not find that the interviewed Saraguro households plant more often trees on their farms than the Mestizo-colonos. Although the small sample of our mainly qualitatively-oriented study does not allow for statistical tests of the respective hypothesis (Section 2.3.1), the results are suitable to call into question our initial hypothesis however: Adherence to traditional more poly-cultural forms of agriculture (including home gardens) does result in a higher adoption of tree planting in Saraguro households (Table 2.2). This is clearly not the pattern that we have in our small sample. Furthermore, the network analyses carried out are consistent with the lower adoption rates of the interviewed Saraguro community leaders. In particular, there are two, internally well-linked groups. One consists exclusively of Mestizo-Colonos, and the group of the three nonadopters. Quantitative methods to identify subdivisions detect that one of the adopter groups, the second adopter group and the non-adopter group are found in the "central" subgroup (black in Figure 2.4). Some of these results may be best explained by local geographical factors that have the potential to shape communicative networks, i.e., via the road network. This indicates that spatial proximity in terms of access may override ethnic influences in social network terms. Consequently, we adjust our hypotheses for the next step of quantitative research as follows (see Table 2.2): 
1. Mestizo-Colonos are more likely to adopt tree planting on their farms.

2. Saraguros may have less access to information on (often introduced) tree species useful for agroforestry.

Table 2.2: Evolution of research main hypothesis about the diffusion of the adoption

\begin{tabular}{lll}
\hline Items & Before field research & After field research \\
\hline Comparative Hypotheses & $\begin{array}{l}\text { Saraguros' probability to adopt } \\
\text { is higher than for Mestizo- } \\
\text { colonos }\end{array}$ & $\begin{array}{l}\text { Mestizo-colonos probability } \\
\text { to adopt is higher than for } \\
\text { Saraguros }\end{array}$ \\
Justification & $\begin{array}{l}\text { Saraguros have more experience } \\
\text { with multi-crop and home gar- } \\
\text { den production }\end{array}$ & $\begin{array}{l}\text { Saraguros may have less ac- } \\
\text { cess to the information about } \\
\text { adoption }\end{array}$ \\
\end{tabular}

\subsection{Plans for the quantitative research phase}

\subsubsection{Characterization of the social network}

The quantitative study to be carried out in summer 2010 is planned to go far beyond the initial empirical analyses presented in Section 2.3. The social network samples will be composed of around $i=240$ nodes with $i \in N, N=\left\{n_{1}, \ldots, n_{240}\right\}$ and edges $e \in E, E=$ $\left\{e_{1}, \ldots, e_{r}\right\}$. The nodes are distributed in a set of $M$ villages, $m \in M, M=\left\{m_{1}, \ldots, m_{8}\right\}$. One actor is assigned only one village. Furthermore, it is pertinent to make a distinction between the two ethnic groups: Let L be actor's attribute Ethnic-group, where $L=$ $\{1,0\}$. Thus, a node $i \in m$ can belong to one of two possible ethnicities Mestizocolonos or Saraguros:

$$
L= \begin{cases}1 & \text { if } i \text { Mestizo } \\ 0 & \text { otherwise }\end{cases}
$$

By asking the respondents "Who do you seek out for advice regarding agroforestry? And who are your friends?", directional information on network interactions can be collected. Let $W$ be the set of the type $W=\left\{w_{1}, w_{z}\right\}$ with $z$ representing the local universe of types of social relations. The type of the relationship $w$ codes for the 
directionality information. Directionality allows us to set up a "block model" with $W=\left\{w_{1}, w_{2}\right\}$, for $W=\{$ Advise,Friendship $\}$ (cf. Koehly and Pattison in Carrington et al., 2005)[15]. If there is a relationship between two individuals $i$ and $j$, for $i, j \in N$; $i \neq j$; then the interaction of the network individuals will be represented in a $N x N$ adjacency matrix denoted as $X$. Accordingly, in the set of ordered pairs we record the presence or absence of an edge as follows. $X_{i j}$ can be:

$$
X_{i j}= \begin{cases}1 & \text { if }(i j) \in E \\ 0 & \text { otherwise }\end{cases}
$$

\subsubsection{Positional analysis: Block model}

The purpose of the block model is to test the following hypotheses:

- $H_{1}$ : The individuals that are higher in the rank are Mestizo-colonos.

- $\mathrm{H}_{2}$ : The role conveying information of agroforestry species of the most connected actors in the Saraguro community is not as important as in the Mestizocolono community.

Based on Doreian et al. (in Carringtonet al., 2005)[15], a generalized rankedcluster block model is constructed. Let $P$ be a set of positions or images of clusters of nodes. In addition, $\mu: N \rightarrow P$ is the mapping that assigns each individuals to its position based on the network links. Therefore, a cluster of units $C(t)$ with some position $t \in P$ is: $C(t)=\mu^{-1}(t)=\{x \in N: \mu(x)=t\}$. Thus, $C(\mu)=\{C(t): t \in P\}$, that is, the partition or clustering of the individuals in $N$. The type of link is recalled here, once we know the kind of link between the positions $u$ and $v$. The respective clusters $C_{u}$ and $C_{v}$ are mapped into the image. So $E\left(C_{u}, C_{v}\right)$ reflects the structure of the block. For the partitions of the set $N$ into clusters, we assume an equivalence relation. Recalling our network $G=\{N, E\}$, let $\Phi$ be the set of equivalence relations of the regular equivalence in $G$. Therefore, each equivalence relation $\sim$ on $N$ estimates the partition $C$ of $N$. If $\Psi$ is the set of all partitions into $h$ clusters from the relationships from $\Phi$, than the next step is to construct an $F(C)$ criterion function which has the following properties: (i) $F(C) \geq 0$, and (ii) $F(C)=0 \Longleftrightarrow \sim \in \Phi$. To estimate $F(C)$, 
we have to measure the fit of a clustering by comparing it to an ideal cluster. The ideal cluster has relations within each partition and between them. Thus,

$$
F(C)=\sum_{C_{u}, C_{v} \in C} \min _{B \in B\left(C_{u}, C_{v}\right)} \delta\left(E\left(C_{u}, C_{v}\right), B\right)
$$

where $\delta$ determines the inconsistency between the block $E\left(C_{u}, C_{v}\right)$, and $B$ is the ideal block. The sum of local inconsistencies $\delta\left(E\left(C_{u}, C_{v}\right), B\right)$ is the global inconsistency. The local inconsistency is also the sum of the differences between the observed link and the value of the ideal block (Doreian et al. in Carringtonet al., 2005)[15]. After construction the appropriate criterion function that reflects the selected equivalence, a local optimization clustering process must be carried out. It should be repeated for different initial partitions to find the highest number of possible clusters.

\subsubsection{Influence of the social network on the adoption of agroforestry species}

To test for social network influences in detail, we need a model that accounts for adoption and for ethnic differences. Moreover, the role of the more central actors should be analysed to understand the spread of the adoption. With such a model, we should be able to test the following hypotheses:

- $H_{1}$ : Actor centrality may directly affect the individual propensity to adopt.

- $H_{2}$ : Actors with high centrality measurements are more influential within their communities.

- $H_{3}$ : Mestizo-colono leaders may be more infectious in their respective communities than Saraguro leaders.

- $H_{4}$ : Mestizo-colonos are more susceptible to adopt than Saraguros.

- $H_{5}$ : Actors with a max-flow betweenness vitality closer to one are mainly Mestizocolonos.

- $H_{6}$ : Adoption is positively correlated with the similarities of actors' characteristics related to their ethnic group. 
The model assumes time-constant links. In other words, whoever was a friend at the moment of the survey was also a friend at the moment of adopting agroforestry species. The only time variant variable will be the moment at which each farmer adopted. Our model follows the explanations of Valente in Carrington et al., (2005)[15] and the models developed by Strang and Tuma (1993)[36] and Greve et al. (1995)[16]. We start with: $\log \operatorname{Pr}\left(y_{i, t}=1\right)=$

$\beta_{0}+\sum \beta_{D} D+\sum \beta_{O} O+\sum \beta_{T} T_{t}+\sum \beta_{A} A+\sum \beta_{X} X+\beta_{I} I_{t} C_{(x)}(y)+\beta_{U} U_{t} C_{(x)}(y)+\beta_{F} C_{F}(i)$

where: $y_{i}(t)$ is the binary indicator of behaviour (adoption), following Strang and Tuma (1993)[36], $Y_{i}(t)=\{1,0\}$ is a binary variable:

$$
Y_{i}(t)= \begin{cases}1 & \text { if } i \text { adopted by time } t \\ 0 & \text { otherwise }\end{cases}
$$

$\beta_{0}$ is the intercept. $\beta_{D}$ is the parameter that estimates vectors of $D$ socio-demographic characteristics constant in time. $\beta_{O}$ is the parameter that estimates the geographical characteristics $O$ of the communities constant in time. $\beta_{T}$ is the parameter of $T_{t}$ time variant terms, for details about time transformations, see Strang and Tuma (1993)[36]. $\beta_{A}$ is the parameter that estimates vectors of $A$ intrinsic characteristics of individual $i$, namely the ethnic group. $\beta_{X}$ is the parameter of $X$ social network matrices, constant on time.

$\beta_{I}$ is the parameter that estimates vector of $I$ that describes the infectiousness of actor $\mathrm{j}$ as it influences all other actors by his behaviour. More specifically, it explains the influence of each individual (who has adopted) over all others in the social network $G$. If there are more adopters in the network in each period, there is a higher probability of influence on future adopters. Thus, infectiousness at time $t$ is the sum of in-degree centrality multiplied by the time-varying proportion of adopters in the social network (Valente in Carrington et al., 2005)[15]. We have that $i, j \in N$. The population $N$ is divided into sets, $N^{\prime}(t)$ of adopters in a period $t$, and a set of $N^{\prime \prime}(t)$ of non-adopters in a period $t$. e.g., $i \in N^{\prime}(t)$ and $j \in N^{\prime \prime}(t)$ (Greve et al., 1995)[16].

$\beta_{U}$ is the parameter that estimates vector $U$ or the susceptibility of actor i (who has not adopted) to be influenced by the group of prior adopters. An important interaction is to determine susceptibility as a function of the size of the ethnic group. 
In this case, one can multiply the measure of centrality (out-degree) by the rate of time varying adoption of Mestizo-colonos (cf. Myers, 2000)[24]. This variable describes susceptibility to intra-population linkages (Strang and Tuma, 1993)[36]. $\beta_{F}$ is the parameter that estimates vectors of $C F(i)$ max-flow-betweenness vitality (see Section 2.2.3). Here we want to measure the maximum flow of information related with agroforestry species that flows through each single node in the social network, and the frequency of the contacts.

Extensions of the proposed model can be done by including structural equivalence (see Section 2.2.3). The model parameters can be estimated by maximum likelihood estimation. If one of the parameters is significant, it indicates that change in behaviour (adoption) is associated with network exposure.

\subsection{Conclusion}

The type of results we hoped to generate are likely to find an interested audience not only in the scientific community but also in policy makers. The successful application of the UNESCO Biosphere Reserve needs to be complemented in a long-term management plan that takes into account the ecological as well as the cultural diversity of the area. The expected results may be highly useful not only for promoting tree planting on farms but also for the design of more general communication strategies with the rural population. This will be particularly true if we do in fact find that there are different patterns for sharing information among and between the ethnic groups.

\section{Acknowledgments}

The authors want to thank Frank von Walter for his help on the spatial data, Byron Maza for sharing his survey results. Thanks go also to the respondents and the research team. Special thanks go to Alejandro Gallardo for his comments on this paper. The field research was financially supported by the Deutsche Forschungsgemeinschaft (DFG FOR 813), Friedrich-Ebert Foundation, and the Georg-August-Universität Göttingen. 


\section{References}

[1] Acemoglu D., Dahleh M., Lobel I. and Ozdaglar A. (2008). Bayesian learning in social networks. National Bureau of Economic Research, Working Paper 14040. Cambridge. 18, 90

[2] Besley T. and Case A. (1993). Modeling technology adoption in developing countries. The American Economic Review 83 (2): pp:396-402. 18, 90, 151

[3] Beck E., Kottke I, Bendix F. Makeschin F. and Mosandl R. (2008). Gradients in a Tropical Mountain Ecosystem of Ecuador: Vol. 198. Ecological studies. Berlin Heidelberg. Germany: Springer-Verlag. 1, 2, 17, 22, 23, 58, 60, 61, 114, 129, 130, $131,132,133,134,136,174$

[4] Brandes U. and Erlebach T. (2005). Network Analysis: Fundamental Foundations. Springer-Verlag Berlin Heidelberg. Germany. 19, 20, 47, 49, 50, 145, 146, 147, 151

[5] Carrington P., Scott J. and Wasserman S. (2005). Models and Methods in Social Network Analysis. Cambridge University Press. New York. USA. 19, 32, 33, 34, $52,53,62,120,141$

[6] Conley T. and Udry C. (2001). Social learning through networks: The adoption of new agricultural technologies in Ghana. American Journal of Agricultural Economics 83(3): pp:668-673. 18, 90, 151, 171

[7] Conley T. and Udry C. (2005). Learning About a New Technology: Pineapple in Ghana. Yale University: Economic Growth Center, Working Paper, 817. 18 
[8] Delre S., Jager W. and Janssen M. (2007). Diffusion dynamics in small-world networks with heterogeneous consumers. Comput Math Organiz Theor 13: pp:185202. 18

[9] Freeman L. (1977). A set of measures of centrality based on betweenness. Sociometry $40(1)$ : pp. $35-41.20,47,146$

[10] Freeman L., Borgatti S. and White D. (1991). Centrality in valued graphs: A measure of betweenness based on network flow. Sociometry 40(1): pp. 35-41. 20, 21

[11] Gerique, A., and Pohle, P. (2006). Traditional ecological knowledge and biodiversity management in the Andes of southern Ecuador. Geographica Helvetica, 61(4), 275-285. 2, 16, 22, 43, 45, 58, 60, 89, 93, 113, 129, 131, 132, 174

[12] Girvan M. and Newman M. (2002). Community structure in social and biological networks. PNAS 99(12): pp:7821-7826. 27

[13] Granovetter M. (1973). The Strength of Weak Ties. The American Journal of Sociology 78(6): pp: 1360-1380. 18, 49, 53, 88, 116

[14] Granovetter M. (1983). The Strength of Weak Ties: A Network Theory Revisited. Sociological Theory 1: pp: 201-233. 18, 53, 88

[15] Granovetter M. and Soong R. (1986). Threshold models of interpersonal effects in consumer demand. Journal of Economic Behavior and Organization 7: pp:8399. 18

[16] Greve H., Strang D. and Tuma N. (1995). Specification and estimation of heterogeneous diffusion models. Sociological Methodology 25: pp:377-420. 18, 34

[17] Günter S., Stimm B. and Weber M. (2004). Silvicultural contributions towards sustainable management and conservation of forest genetic resources in Southern Ecuador. Lyonia 6(1): pp:75-91. 25

[18] Hanneman R. and Riddle M. (2005). Introduction to social network methods. University of California, Riverside, CA, USA. [Text file] http://faculty.ucr.edu/ hanneman/21, 27 
[19] Homeier, J. (2008). The influence of topography on forest structure and regeneration dynamics in an Ecuadorian montane forest. In: S.R., Gradstein, J. Homeier, and D. Gansert (Eds.), Biodiversity and Ecology Series (2): The tropical mountain forest (97-107). Göttingen: Universitätsverlag Göttingen. 22, 23, 129

[20] Jackson M. (2008). Social and Economic Networks. First Edition. Princeton University Press. New Jersey. 18, 90, 95

[21] Jackson M. and Yariv L. (2005). Diffusion on social networks. économie publique 16(1): pp:3-16. 18

[22] Levin G. and Reenberg A. (2002). Land use driven conditions for habitat structure: A case study from the Ecuadorian Andes. Geografisk Tidsskrift, Danish Journal of Geography 102: pp:79-92. 16

[23] Maza, B., Barkmann, J., von Walter, F., and Marggraf, R. (2010). Modelling smallholders production and agricultural income in the area of the Biosphere reserve "Podocarpus-El Condor", Ecuador. Georg-August-Universität Göttingen: Department of Agricultural Economics and Rural Development, Working Paper, 1004. 2, 21, 22, 23, 43, 45, 58, 59, 60, 89, 114, 129, 130, 131, 134, 168

[24] Myers D. (2000). The diffusion of collective violence: Infectiousness, susceptibility, and mass media networks. American Journal of Sociology 106 (1): pp:173208. 18,35

[25] Myers N., Mittermeier G., Mittermeier R., Da Fonseca G. and Kent J. (2000). Biodiversity hotspots for conservation priorities. Nature 403: pp:853-858. 16

[26] Pohle P., and Reinhardt S. (2004). Indigenous knowledge of plants and their utilization among the Shuar of the lower tropical mountain forest in southern Ecuador. Lyonia, 7(2),133-149. 22, 23

[27] Price C. (1995). Economic evaluation of financial and non-financial costs and benefits in agroforestry development and the value of sustainability. Agroforestry Systems 30: pp:75-86. 16, 133

[28] Rogers E. (1995). Diffusion of innovations. Free Press (4th ed.). New York. USA. $17,18,26$ 
[29] Rogers E., Medina U., Rivera M. and Wiley C. (2005). Complex adaptive systems and the diffusion of innovations. The Innovation Journal: The Public Sector Innovation Journal 10(3): article 29. 16, 18

[30] Rollenbeck R. (2006). Variability of precipitation in the Reserva Biólogica San Francisco / Southern Ecuador. Lyonia 9(1): pp:43-51. 23

[31] Rozenfeld A., Arnaud-Haond S., Hernandez-Garcia E., Eguiluz V., Serrao E. and Duarte C. (2008). Network analysis identifies weak and strong links in a metapopulation system. PNAS 105(48): pp:18824-18829. 20

[32] Ryan R. and Gross N. (1943). The diffusion of hybrid seed corn in two Iowa communities. Rural Sociology 8: pp:15 - 24. 17

[33] Schneider S.H., Semenov S., Patwardhan A., Burton I., Magadza C.H.D., Oppenheimer M.,..., Yamin F. (2007). Assessing key vulnerabilities and the risk from climate change. In: M.L. Parry, O.F. Canziani, J.P. Palutikof, P.J van der Linden and C.E. Hanson (Eds.), Climate Change 2007: Impacts, Adaptation and Vulnerability. Contribution of Working Group II to the Fourth Assessment Report of the Intergovernmental Panel on Climate Change (779-810). Cambridge: Cambridge University Press. 17

[34] Steffan-Dewenter I., Kessler M., Barkmann J.,Bos M., Buchori D., Erasmi M.,..,, Tscharntke T. (2007) Tradeoffs between income, biodiversity, and ecosystem functioning during tropical rainforest conversion and agroforestry intensification. PNAS 104: pp:4973-4978. 16

[35] Stoneman P. (1981). Intra-firm diffusion, Bayesian learning and profitability. The Economic Journal 91(362): pp:375-388. 18, 90, 151, 171

[36] Strang D. and Tuma N. (1993). Spatial and temporal heterogeneity in diffusion. The American Journal of Sociology 99(3): pp:614-639. 18, 34, 35

[37] Valente T. (1996). Social network thresholds in the diffusion of innovations. Social Networks 18: pp:69-89. 18

[38] Valente T. (1999). Network Models of the diffusion of Innovations. Hampton Press, INC. (2th ed.). New Jersey. USA. 17, 18, 21 
[39] Valente T. and Davis R. (1999). Accelerating the diffusion of innovations using opinion leaders. ANNALS, AAPSS, 56: pp: 55-67. 19, 26, 69, 176

[40] Valente T. and Rogers E. (1995). The origins and development of the diffusion of innovations paradigm as an example of scientific growth. Science Communication 16(3): pp:238-269. 17, 18 


\title{
Chapter 3
}

\section{Describing Ethnic Groups in an Advice Network:}

\section{A case of ethno-diverse rural communities in southern Ecuador}

\author{
Vladimir Gonzalez Gamboa, Jan Barkmann and Rainer Marggraf
}

\begin{abstract}
Studying the advice network of agricultural activities helps us to disentangle how information is shared in rural communities in southern Ecuador. In this region there are mainly two ethnic groups related to changes in land use, namely the Saraguro and the Mestizo-colono. The first group are indigenous people and the latter are immigrants from other places with in the country who settled in the region during the agrarian reform in the 1960s. The two differ markedly in terms of cultural patterns and some land use practices. A previous analysis suggested that there may also be differences in how information related to adoption of agricultural practices is shared between and within these ethnic groups. Based on an independent sample of respondents from 208 households, we generated an advice network of 561 nodes and 1410 network ties. This network addresses the search for advice on local agricultural activities. The data suggest that there are, in fact, structural differences in the search for advice between
\end{abstract}


ethnic groups.

When analyzing ethnic subgroups, one find that Mestizo-colono subgroup has the actors with highest degree of centrality and betweenness. These actors are in the highest cohesive block in the cohesive block analysis. Furthermore, a high Burt's constraint shows that structural holes in the network create a differentiation of information sharing between groups. A higher Burt's constraint indicates less access to the information located in other clusters in the network. The periphery of the network plays an important role as a source of advice, as shown by the cohesive block analysis, which we complement with a k-core analysis. The results suggest that different and more diverse information is accessed by Mestizo-colonos as compared to Saraguros. In applied terms this suggests that Saraguros tend to share more similar information within their group than do Mestizo-colonos.

Keywords: Advice Network, Ethnic Groups, Social Network Analysis, Cohesive Blocks, Network Periphery

\subsection{Introducing the Topic and Social Context}

\subsubsection{General Introduction}

In such rural areas of which there are many in southern Ecuador, the study of advice networks may help to understand the diffusion of agricultural information. For instance, analyzing the advice network of agricultural information in this region is of great importance in order to understand the adoption of new agricultural technologies. This is important because the local economy is based on agricultural production. Most of the farms are small and vulnerable to poverty, as is highlighted by the Latin American Commission for the Economy (in Spanish CEPAL "Comisión Económica para America Latina"1). Importantly, farmers that are able to access new information may be more likely to innovate (Rogers, 2003)[58], and to overcome poverty this way. Another factor related to the importance of studying advice search in rural communities is the fact that environmentally degraded areas make the local populations more vulnerable, not only to poverty, but also to climate threats. This is the case of many indigenous

\footnotetext{
${ }^{1}$ http://www.eclac.org/
} 
peoples in Latin America (Byg and Salick, 2007)[14]. Furthermore, southern Ecuador is more environmentally vulnerable to farmers' land use, because Podocarpus National Park is located in this region.

Agriculture is the most important income source in this culturally diverse region. In terms of smallholder agriculture, two ethnic groups shape much of the agricultural landscapes of southern Ecuador, and they influence land use change along the forest/agriculture frontier (Pohle and Gerique, 2006)[49]. These groups are the indigenous Saraguro and the Mestizo-colonos. Pasture-based cattle and diary production dominate agriculture in both groups (Pohle and Gerique, 2006; Maza et al., 2010)[49][43]. Previous work by Gonzalez et al. (2010)[27] suggests that there may be differences in how information on agroforestry species is shared between and within the two ethnic groups. The present paper explores network effects on the search for advice for agricultural activities in depth. Gonzalez et al. (2010)[27], underline an important hypothesis to be tested, namely, that: Mestizo-colonos are the most sought for information on agricultural activities.

To explain the search for advice on agricultural activities in rural communities, we use social network analysis. Social network analysis gives us tools to see how structural patterns emerge from the search for advice. Once these patterns are identified, we then identify factors that cause one individual or group of individuals to have less or more access to information on these activities.

As suggested above, analyzing the search for advice is key to understanding how information is accessed and whether there are uniform structural patters to access it. We focus on the search for advice on the most important agricultural activities within regard to income generation. Within these activities, many are new and perceived as innovative, e.g., the husbandry of new cattle species, black-berry cultivation or the use of organic fertilizers (see Table 3.2). More specifically, if we know how individuals in the network can access agricultural information, we will have more realistic information on the way the adoption of sustainable rural agricultural systems might take place. For example, the inclusion of trees in agricultural management ("agroforestry") can contribute to a diversification of income, the conservation of natural resources, and to the local adaptation to climate change. 


\subsubsection{Social Context and Motivation}

"The commonality provides a basis for unifying the members, to be sure; but it does not specifically direct these particular persons to one another. A similarity so widely shared could just as easily unite each person with each possible other. This too, is evidently a way in which a relationship includes both nearness and remoteness simultaneously. To the extent to which the similarities assume a universal nature, the warmth of the connection based on them will acquire an element of coolness, a sense of the contingent nature of precisely this relation the connecting forces have lost their specific, centripetal character." George Simmel, 1908.

As Georg Simmel (1908)[61] points out, being part of a group of any kind has several implications. Some of these, such as sharing the same ethnicity, gives a special character to members' identification with the group. We have included the analysis of groups' memberships in networks when testing whether the subgroup membership created upon searching for advice in our network is based on ethnicity. In the research region there are two ethnic groups, the Mestizo-colonos and the Saraguros. The members of these ethnic groups are immersed in a social context that we briefly describe here. Between the 1980s and 1990s there was a reduction of rural state programs that affected indigenous groups in Ecuador. The land reform in the 1960s weakened ethnic identities, since it supported the migration of peasants to other areas, and created conflict with indigenous communities for land. In organizing these reforms, the state was the main actor, as a centralized power entity (Abbott, 2005)[1].

More recently, indigenous peoples' rights have been recognized (Yashar, 1998)[74]. For example, indigenous people have achieved the use of their lands with some autonomy from the central government (Van Cott, 2007)[66]. The CONAIE ${ }^{1}$ is a symbol of the national movement (Yashar, 1998)[74]. Saraguros native from southern Ecuador have had within representation in this organization (Ogburn, 2007)[46]. Since 1990 the indigenous political party, Pachakutik, has had an important role in representing indigenous peoples in Ecuador (Van Cott, 2007)[66]. This social context shows that there are differences in the social relations between ethnic groups. Indigenous peoples still preserve some of their ancestral agricultural practices, while Mestizo-colonos usually make use of agricultural practices introduced by the Europeans during colo-

\footnotetext{
${ }^{1}$ Confederation of Indigenous Nationalities of Ecuador, in Spanish "La Confederación de Nacionalidades Indígenas del Ecuador".
} 
nial rule (Abbott, 2005)[1]. For example, Mestizo-colonos introduced the plantation of new "races" of beans with rapid growth. Native bean "races" have higher protein but a less developed market (Abbott, 2005)[1]. In part, this has inspired us to analyze ethnic subgroups and to search for different patterns in the ways they seek advice.

Within the 11 communities (sampled) in our research area there is always an ethnic group that is in the majority, and in the sample as a whole, Mestizo-colonos are a majority (see Section 4.5.1). Importantly, homogeneity within communities may be explained in part by considering homophily. According to McPherson et al. (2001)[44], Homophily is defined as the principle whereby relations between similar individuals take place at higher rate than between dissimilar individuals. For instance, similarities due to ethnicity/race creates the strongest division in the social environment (McPherson et al., 2001)[44]. For this reason, we address the divisive effects that individuals of the same ethnicity may have on the search for advice. Knowing that ethnicity is one of the major and "natural" attributes that divide groups into subgroups motivates us to disentangle the network patterns of the search for advice on agricultural activities.

We wanted to test whether there are indeed differences between ethnic groups in the way they search for advice, as is suggested by Gonzalez et al. (2010)[27]. For this reason we planned to compare network statistics of ethnic subgroups of the advice network. The goal is to understand the information search patterns and to create a basis that may help policy makers to propose concrete recommendations to improve the access to information. Essentially, this paper looks for differences in the ways of searching for advice on agricultural activities throughout the network. Given that there are differences in knowledge between indigenous Saraguros and Mestizo-colonos in southern Ecuador (Gerique and Pohle, 2006)[49], that Mestizo-colonos have higher incomes (Maza et al. 2010)[43] and that communal leaders of Mestizo-colonos are more involved in the adoption of agricultural innovations (Gonzalez et al. 2010)[27], we want to determine whether indigenous Saraguros are less sought for advice than are mestizo-colonos?

This paper's aim is to supply the information needed to set up strategies to better understand the patterns in the search for advice. This necessity was recently underscored by Skouflas et al. (2009)[64] for the case of indigenous people in Latin America. More specifically, Skoufias et al. (2009)[64] conclude that social network effects are strong among indigenous peoples in Mexico. They also point out the urgent need 
for this kind of analysis to be incorporated into local evaluation projects to improve policies. Most of the network research on ethnic groups has been conducted in urban areas or rural areas in industrial countries, less work has been done on developing countries and networks (Bodin and Prell, 2011; Marney et al., 2007)[10][48]. There still is a need to understand structural patterns in the diffusion of information and in the search for advice in rural areas in Latin America. This paper contributes to the knowledge of social network analysis in these areas.

In the following pages we first present the general background of the most important theoretical network concepts to be used in the paper. This is followed by a description of the social actors and of the characteristics of the region researched. Then, the data collecting process and methods are explained. Next, the empirical results section, the discussion and conclusions of the study are presented.

\subsection{Social Network Theoretical Background}

The aim of this section is to familiarize the reader with the social network concepts used and developed in the rest of the paper.

Social Network Analysis (SNA) studies the relations and type of interactions between vertices, $V$, in a network, $g$. The number of nodes (individuals, actors), $n$, defines the order of a graph, $g$. In a specific social context, social actors (vertices in the network) influence, and are influenced by, other actors. As based on Graph Theory, the edge set, $E$, contains the relations between vertices in the network, $g$. The number of edges defines the size of the graph $g$ (Chartrand, 1985)[21]. The edges are called ties, or links, within the social network analysis context.

\subsubsection{Centrality and Resource Concentration in Social Networks}

One of the main concepts developed in network theory is the concept of centrality. Centrality accounts for the fact that, there are some individuals who are more central than others. Their position in the network influences that they have a major number of edges or are located between other individuals. Two centrality statistics are addressed in this paper, namely, degree and betweenness centrality. The first one, the degree centrality of individual $i, C_{D}=d(i)$ is defined as the number of $i$ (vertex) neighbors 
(adjacent vertices) (Koschützki et al. in Brandes and Erlebach, 2005)[11]. For directed graphs there is indegree centrality when $i$ is nominated (mentioned) by other individuals and outdegree centrality when $i$ nominates (mentions) other individuals in $g, C_{i_{D}}$ in $=d^{-}(i)$ and $C_{i_{D} \text { out }}=d^{+}(i)$, respectively. The correlation between indegree and outdegree centrality can be estimated. This correlation shows the correlation between the indegree and the outdegree of an actor $i$ (Agneessens and Wittek, 2012)[4]. Positive and high in-outdegree correlation means that the individuals that seek $i$ for advice are many and are the same whom $i$ also seeks for advice.

The second centrality measure is betweenness centrality $C_{b}$. Applying the formal concept described by Freeman (1977)[25], the $C_{b}$ of individual $i$ is: $C_{b i}=\sum_{i \neq s, i \neq j, j \neq s} \frac{b_{i s j}}{b_{i j}}$. Where $b_{i s j}$ are all the possible shortest paths between two vertices $i$ and $j$ passing through vertex $s$, and $b_{i j}$ are all the possible shortest paths between $i$ and $j$; for $i, j, s \in$ $V(g)$. Shortest paths are possible shortcuts that connect two individuals in the network.

In a social relation in the network there is always some kind of exchange (Emerson, 1976)[25]. Therefore, to understand the role of central actors in the network it is necessary to understand the concept of exchange in a social relation. The centrality of individuals in the network implies that actor $i$ has a more advantageous position in comparison to other actors in the network when exchanging resources, e.g. accessing advice and information (Marsden, 1983)[49]. In this context, accessing advice is considered as a kind of exchange. In a directed network the exchange can be reciprocated, where both actors receive and give information, or negotiated, where the information and advice can be given without asking for information back. In addition, in the negotiated exchange other types of exchange may take place, for example, the information giver may receive recognition for his knowledge, or future reciprocity may be expected (Molm in Thye and Skvoretz, 2003)[67].

Network Exchange Theory (NET) explains the dynamics of networks and the exchange of resources (of any kind) between individuals and groups. As Yamagishi and Cook (1990)[75] point out, in exchange networks it is possible to assess the probability to access information. Conceptually, the access to the paths (links or edges) of exchange can result in power concentration within the network. Where the exchange takes place there are mutual dependence structures in which individuals control, for 
example, information that other network members value (Molm in Thye and Skvoretz, 2003)[67]. For a description of NET applications and development see Walker et al. (2000)[72].

If there is any kind of inequality in the amount or quality of the exchanged resource, in a dependent relation in the network, the exchange may lead to an imbalance in the dependency in the network. This creates structural power. Structural power can be defined as the inequality of benefits obtained by more powerful actors. These actors tend to be less excluded from profitable exchange (Molm in Thye and Skvoretz, 2003)[67]. For example, following the NET, strong power concentration in exchange networks occurs when an actor in the network exclusively has a specific kind of information, to the extent that people in other positions in the network have given public recognition to this actor or invest resources to access the information. The strong power actor gets most of the available information and can exclude another actor from a profitable exchange. Conversely, a weak power position in a network occurs when actors are more likely to be excluded from the exchange (Lovaglia et al., in Thye and Skvoretz, 2003)[67]. If these actors are excluded, inequality is produced within reciprocal exchange. In this situation the benefits flow with one direction, to one actor (Molm in Thye and Skvoretz, 2003)[67].

Theoretically, the exchange is reciprocal as long as there is no negotiation between the actors involved in the exchange (Molm in Thye and Skvoretz, 2003)[67]. The advice relation in networks is characterized by low reciprocity and exclusion (Agneessens and Wittek, 2012; Molm in Thye and Skvoretz, 2003)[4][67]. The actor who asks for advice is not sought back (asymmetric relation), and the actor could be excluded from a profitable exchange situation. The strong power actor may have higher status, therefore, by requesting information from actors with lower status, he would reduce status recognition. For example, if the strong power actor is a specialist, he would lose credibility if he resorts to someone who is not an expert (Agneessens and Wittek, 2012; Lazega et al., 2012)[4][41]. The status can emerge from the (i) economic position of the actor, (ii) from the political position and contacts of the actor, (iii) from skills and knowledge (Agneessens and Wittek, 2012)[4].

It is important to address status in networks, as above, because actors in an advice relation may select advisors based their status (Blau, 1964; Emerson, 1976; Lazega et al., 2012)[8][25][41]. A high status actor may try to exchange status recognition for 
advice. For this reason an advice network tends to be centralized around a few actors that accumulate many contacts (high degree centrality) (Lazega et al., 2012)[41].

Generally, in highly centralized advice networks, disadvantaged members try to mitigate their position by searching information from actors that share some similarities, i.e., homophilous actors. Searching information from homophilous actors has the advantage that the information exchange with similar others is likely to be more effective (Rogers, 2003) [58] and to involve the presence of solidarity (Agneessens and Skvoretz, 2012; Lazega et al., 2012)[3][41]. Advice networks have two characteristics which are particulary important for this analysis: First, they are hierarchical, i.e., there are few actors with high degree centrality and many actors with low degree centrality, and second, they are cohesive, because the actors ask counterparts with similar traits for information, forming in, this way strongly connected, clustered structures. These clustered structures tend to be strongly connected through many ties. For this reason, if one actor within the cluster disappears the cluster will not all apart, that is to say, the cluster is a cohesive structure. These structures are explained in the subsection below.

\subsubsection{Social Network and the Analysis of Groups}

In network analysis, the fact that individuals are embedded in a specific social structure is fundamental explaining social interaction. Individuals can gather in groups according to a common interest (Granovetter, 1973)[31]. They can also be naturally grouped because they share a specific characteristic, such as ethnicity (Borhek, 1970; SmithLovin, 2003)[12][65]. The social actor can be embedded in a group where he or she interacts with other group members. This is the origin the cohesiveness of groups. A group is cohesive if its connectivity does not depend on one or on a reduced number of members, instead, many or all members have ties with many members. For instance, groups are cohesive when the group reproduces positive member attitudes and behaviors. In these conditions, cohesive groups are self-maintaining and tie reciprocity can indicate group cohesion (Friedkin, 2004)[33].

Cohesion of groups is a fundamental area of network analysis, where network density is one of the central concepts (Kosub in Brandes and Erlebach, 2005)[11]). The density of a network can be formally defined as the ratio of $u$ edges of a graph $g$ of order $n$, as follows (White and Harary, 2001)[73]: $\delta(g)=\frac{2 u}{n(n-1)}$. Generally, high 
density is present when the individuals of a group have a large neighborhood.

There are many ways to identify cohesive subsets (cohesive groups) in a graph. Generally, a cohesive subset is a subset of network members that are somehow more densely connected within the group than they are with members outside (Pattison, 1993)[54]. We describe some of the methodologies developed identify cohesive groups below. An important graph theoretic concept related to group cohesiveness in networks is the clique. Formally, a clique is a maximal complete subgraph of $g$ of the order of at least 3 ( $n \geq 3)$, in this context, "maximal complete" means that all group members have ties with all other group members. Thus, cliques are perfectly dense groups, where each individual has edges with each other member (all members). As we observe in the upper right part of Figure 3.1, all four member of this subgroup are all connected with everyone. Cliques can also be seen as perfectly dense cohesive structures that are compact and connected (Kosub in Brandes and Erlebach, 2005)[11]. Cliques can be methodologically useful estimating structural groups (Burt1978)[14], and as a general indicator of what is happening in the network. Nonetheless, their calculation has some disadvantages when cliques overlap, i.e., when individuals in one clique are included in other cliques. This situation can create confusion in the interpretation of results (Everett and Borgatti, 1998; Prell, 2012).[26][57]

To approach groups in networks it is essential to describe structural cohesion. This concept formally includes group characteristics (attributes) of a set of individuals, the positional dimension of groups (in the network) and individual membership (within groups). Furthermore, the number of independent paths (number of links between any two actors in the network) and cohesiveness related connectivity (described below) are important concepts fo the analysis of groups in social netwoks and for the study of structural cohesiveness (White and Harary, 2001)[73]. For instance, as higher the density within a group is, the higher too is the cohesiveness that holds together the individuals in the group. Cohesiveness increases if there are many independent paths connecting them.

The connectivity $(\kappa)$ of $g$ is the smallest number of vertices removed from $g$ that creates a disconnected subgraph ${ }^{1}$. The cutvertex in a connected graph, $g$, is the ver-

\footnotetext{
${ }^{1} \mathrm{~A}$ graph can be divided into components or subgraphs (subset of vertices and edges in $g$ ) by disconnecting one or more of its vertices. Formally, $h$ can be a subgraph of $g$ if the vertices of $h$, $V(h) \subseteq V(g)$, and if the edges of $h$ also do, $E(h) \subseteq E(g)$ (Chartrand, 1985).[21]
} 
tex the removal of which separates $g$ (Chartrand, 1985)[21]. Thus, a vertex cut - set is a set of vertices whose removal dissects the connected graph $g$ into two components (subgraphs). In this context, a block is a maximally connected subgraph with no cutvertices (White and Harary, 2001)[73]. Formally, a cohesive block of a graph $g$ is defined as a $k$-component ${ }^{1}$ that, if related to connectivity, estimates the cohesion of the block. Based on this, White and Harary (2001)[73] propose a method for the study of the structure of social cohesion and for the identification of cohesive subsets. As a result, their method has a series of hierarchically nested $k$-components ordered in higher levels of cohesion.

The concept of nestedness, as used by Moody and White (2003)[52], refers us to structural cohesion and to the concept of embeddedness developed by Granovetter (1992)[40]. Embeddedness can have local and globalproperties. The first refers to the outcomes of an action, such as exchange in a dyadic relation, i.e., an economic outcome. The latter refers to the degree to which actors become involved in cohesive groups. For instance, within these cohesive groups, the exchange of information should be more efficient (Granovetter, 1992; Moody and White, 2003)[40][52]. Embeddedness indicates that, in being a member of a cohesive group in a network, the individual faces a set of resource constraints different from those faced by actors who are not embedded in this group. For example, the group may have less knowledge of a specific sustainable agricultural activity that may improve the income of the group and the sustainability of the resources. From this perspective, the group influences the adaptation of the members to external situations, such as climate change. The network patterns inside a group may mean that inside a high cohesive group there is a good capacity to spread norms and information. For example, if a group member of a highly cohesive group brings a new activity into a region, the information about this activity may be rapidly diffused among the group members. In this context, nestedness captures structural cohesion and embeddedness (Moody and White, 2003)[52].

Based on the theoretical approach of White and Harary (2001)[73], Moody and White (2003)[52] provide an algorithm for empirical research on cohesive blocking. This algorithm identifies cohesive groups, and, at the same time, the position of the group in the network structure. They estimate connectivity (by cutvertex) to measure the effects of structural cohesion. Generally, the less connected vertices (minimal size

\footnotetext{
${ }^{1} k$ here is referred as the size of the $c u t-$ set.
} 
separating vertex set) are separated until a minimum degree cut is reached. Essentially, the method groups the vertices into a similar cohesive group (based on density). This is repeated until groups (subgraphs) with maximal connectivity are obtained, i.e., until the next cut generates only isolated vertices (minimum degree cut). Accordingly, highly cohesive groups are nested inside less cohesive groups (Moody and White, 2003)[52]. For example, suppose that we have a network of farmers and that we want to identify cohesive groups of farmers based on group connectivity and density. Then, the first step is to eliminate the minimum number of farmers (cutvertex) required to disconnect the farmers with least ties (minimum degree cut). These, now disconnected, farmers form the first cohesive group, the least cohesive. This procedure is repeated until we obtain a group of farmers where a new minimum elimination of farmers (cut) required will create only isolated farmers.

One of the structures often identified by the method described above is the core/periphery. To identify a core/periphery structure one must use a method of identification of vertices interaction. For this task the $k$-core is widely used [62]. The $k$-core concept of network cohesion, as defined by Seidman (1983)[62], is based on the minimum degree of a vertex. It creates a sequence of subgraphs in which cohesion gradually increases. Essentially, the $k$-core identifies subgraphs that have a minimum degree greater than or equal to $k$, where individuals outside the cohesive regions are linked by single paths, and can be interpreted as being the periphery of the network. To study core/periphery structures an approach was developed to separate a single core from the periphery (Everett and Borgatti, 1999; Borgatti and Everett, 1999)[22][10].

To illustrate the explaination above we can use an example. We assume that we have a group of farmers in a region, and that we want to know who are in the most connected and cohesive subgroup of farmers. First, we eliminate the farmers with the least ties. The resulting network of farmers will be more tightly connected and dense than before this first elimination. We can repeat this procedure until we have just a small group of farmer, each connected with all others. There will be $k$ number of subgroups.

A widely used method to identify and understand positions and roles in the network is known as blockmodelling. Formally, this method compiles different methods for partitioning networks given a specific criterion (Batagelj, 1997; Dorein et al. in Carrington et al, 2005; Ferligoj et al., 2011)[5][15][30]. These methods analyze the 
role and positions of social relations based on structural or regular equivalence. These concepts are explained below.

Two individuals are structurally equivalent if they are interconnected in exactly the same way to others in the network. In other words, if they have exactly the same relations with exactly the same actors (Lorrain and White, 1971; Ferligoj et al., 2011)[47][30]. In turn, regular equivalence is a generalization of structural equivalence, where two equivalent (regular) actors are connected to actors with the same role, but these are not exactly the same actors (Dorein et al. in Carrington et al, 2005)[15].

For example, in a country $A$, there are farmers consulting a national institution about pastures. All the farmers that consult the same institution about the same topic are structurally equivalent. Now we assume that in a second country B, the local farmers also consult a national institution about pastures. These farmers in country $B$ are regular equivalent to the farmers in country $A$.

\subsubsection{The Emergence of Network Structure}

After exploring groups in networks, we can interlock these concepts into wider structural network definitions. Conceptually, individuals embedded in local groups also interact with other groups, creating larger network interactions. This creates a major extension of a network, with global effects. More specifically, individuals embedded in more dense groups are at the same time clustered and interlocked, forming bridges with other dense groups and creating a higher structure. Granovetter (1973, 1983)[31][39] attributes this bridging to weak ties of individuals that are strongly connected within their own groups. The weak ties serve as source of information from outside the group to the highly dense substructure.

Burt (2005)[12] also attributes this possibility of exchanging information in the network to structural holes. Individuals are concentrated on activities of their own group, creating in this way holes in the flow of information between other groups (Burt, 2004; 2005)[16][12]. At a wider structural level, dense subgroups with homogeneous information create structural holes of information flow between groups. There are individuals that bridge these holes between groups. Therefore, these individuals increase the probability of accessing new and diverse information as they help to diffuse information between groups. Burt (2004, 2005)[16][12] calls this mechanism 
"brokerage of social capital".

To assess the role of the structural holes, Burt (2004)[16] proposes a network constraint to measure the brokerage. The constraint index proposed by Burt is a composition of density, hierarchy and network size, as follows:

$C_{i j}=\left(p_{i j}+\sum_{s} p_{i s} p_{s j}\right)^{2}$, for $i \neq j \neq s$. Within the parenthesis we have the proportion of ties of $i$ that are directly or indirectly related to contact $j$. Here, $p_{i j}$ in essence captures the proportion of $i$ 's resources invested in contact $j$. This is because actor $i$ would have to contact other actors that are between $i$ and $j$. This is measured by the density of $i$ 's ties (adjacent ties). If $i$ has many ties between different dense clusters, $i$ would have more access to information via a shorter distance (path length = number of edges). For instance, if $j$ and $s$ were in different clusters, the constraint of $i$ would be lower than that of $j$ if $j$ only had ties in the same cluster, as it is illustrated in Figure 3.1. For details in the calculations see Gabor (2012)[26].

If, $p_{i j}=\frac{z_{i j}}{\sum_{s} z_{i s}}$, and $z_{i j}$ is a measure from zero to one between actors $i$ and $j . z_{i j}$ is measured using the frequency with which actor $i$ was cited (nominated) as a contact or source of advice (Burt, 2004)[16]. Then, we have that $\sum_{i} c_{i j}$ is the network constraint index $C$. This way, it is possible to determine how constrained an individual, a group or a network is. The brokerage capacity of their members is based on the structural holes created by the individuals between clusters. 


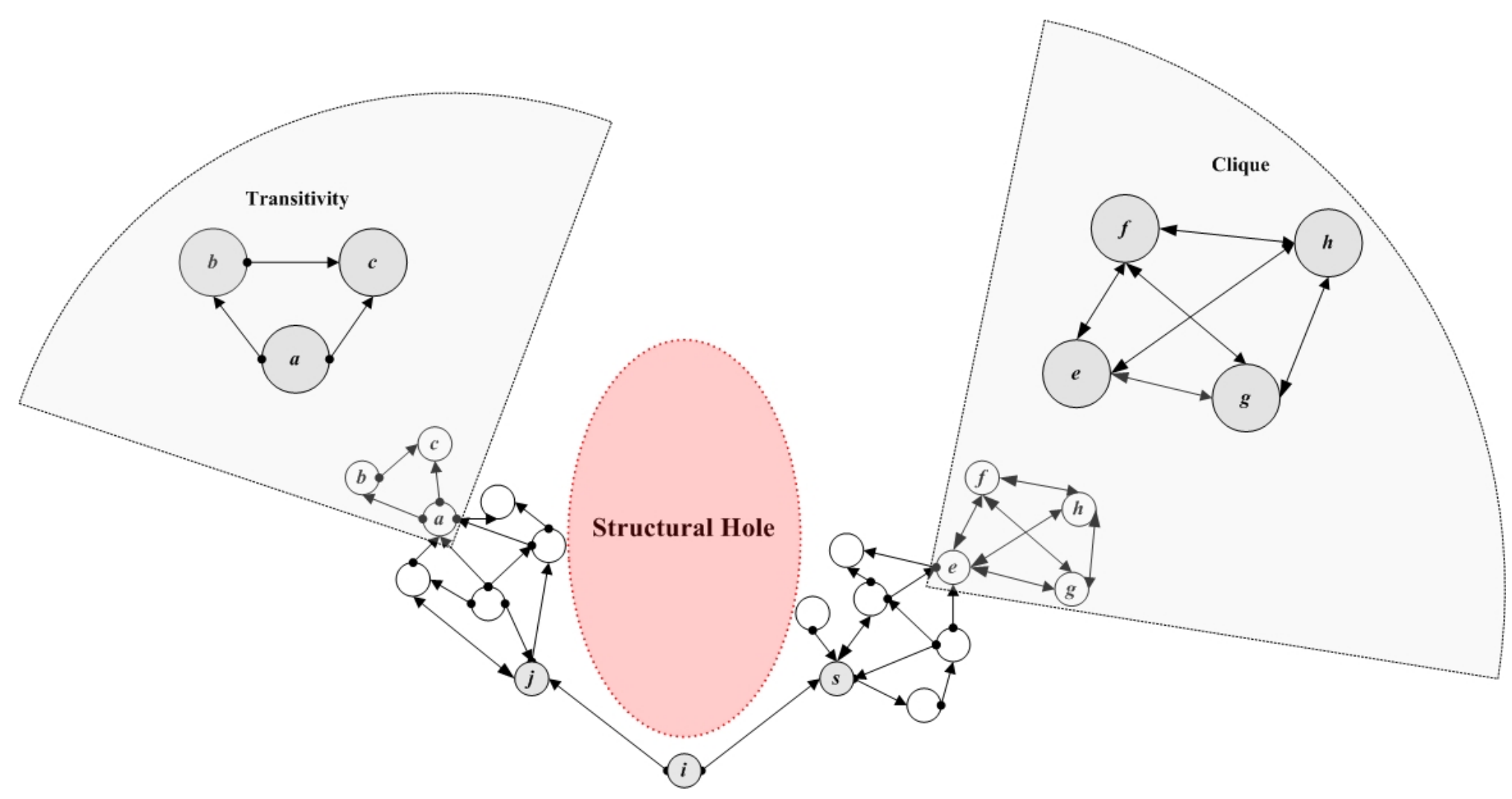

Figure 3.1: Access across Structural Holes 
One indicator that there are dense connected subgroups is transitivity. In densely regions of the network, where there are many actors connected, one basic indicator that there is a tendency towards a hierarchical structure is the presence of transitive triads (triads: three actors connected). As shown in the left upper part of Figure 3.1, transitivity represents a situation in which two actors $a, b$ are linked to a third actor, $c$, while a directed link also exists between $a$ and $b$. The transitive triads show a tendency towards a more hierarchical network structure because there is an actor $c$ receiving two nominations (receiver of two directed ties), and actors $a$ and $b$ (senders) are sending a directed tie to actor $c$.

\subsection{Research Hypotheses}

After have reviewed the theoretical background, we set up the research hypotheses that will be empirically tested. The network data on the search for advice for agricultural activities was used to test the hypotheses in light of the literature. The hypotheses were tested with social network analysis techniques. Each hypothesis is briefly explained below. Moreover, we describe how each hypothesis will be tested. For a description of the models used see Section 3.2 for a theoretical approach and Section 3.4.4.2 for an applied description.

- $H_{1}$ : Mestizo-colonos are the actors with the highest degree centrality in the network.

Based on previous results by Gonzalez et al. (2010)[27], we expect Mestizocolonos to have higher degree centrality, since they are more involved with the adoption of innovations. Therefore, we expect that, through advice, they can access more information from different sources about new profitable activities than Saraguros can. The highest degree centrality in advice networks is usually related to power structures (Lazega et al., 2012)[41]. For this reason $H_{1}$ is of interest to us.

We test this hypothesis with the descriptive statistics degree and betweenness centrality.

- $\mathrm{H}_{2}$ : Mestizo-colonos who are more central in the network are in the highest 
cohesive group.

We test this hypothesis, to know if there is a group of Mestizo-colonos that may control information in the advice network. The hypothesis is tested by applying a cohesive block analysis and the centrality statistics explained in Section 3.2.1 and presented in the results section, Section 3.5.1.

- $\mathrm{H}_{3}$ : Saraguros are within the highest cohesive block.

This hypothesis is inspired in the fact that, in a hierarchical and highly centralized network, some groups search for mitigation strategies to overcome hierarchical power and status. This is true if the strong power actors concentrate information valuable for Saraguro members (Lazega et al, 2012)[41]. This hypothesis tests whether indigenous Saraguros have many members in highly cohesive groups. This is important, since ethnicity produces the strongest division in social relations (McPherson et al., 2001)[44]

This hypothesis will be tested by applying cohesive block analysis.

- $\mathrm{H}_{4}$ : Saraguros tend to search more information in the periphery-outside the sample research region.

This hypothesis is based on the theoretical approach described by Lazega et al. (2012)[41]. Given the hierarchy of the advice network, Saraguros may tend to search for advice in the periphery (maybe outside the research area). This may function as mitigation of the effects of the centralized network.

To test this hypothesis we use $k$-core analysis.

- $H_{5}$ : Mestizo-colonos access more information from different clusters in the network.

We want to test whether Mestizo-colonos have more access to advice across structural holes than Saraguros. According to Burt (2004)[16], access to information in different clusters (clique like structures) across structural holes gives a more advantageous position in the network to actors. Access to more information in different clusters reduces the network constraint of the actors.

We test $\mathrm{H}_{5}$ with the Burt's Constraint statistic, described in Section 3.2. 


\subsection{Methodology}

In this section we first give a general description of the research area and of the ethnicity of the actors living in this area. After that we explain the survey design that we used to collect the empirical data. The survey instrument and the data are described below.

\subsubsection{Research Area: Brief Description}

\subsubsection{The Region: General Characteristics}

In southern Ecuador, we can find one of the most diverse ecosystems. This may be related to the topographic heterogeneity of coast, Amazonian rainforest and highlands. For example, more than 280 tree species have been identified in the northern portion of the Podocarpus National Park (Homeier, 2008). This National Park is noteworthy for this biodiversity and it represents a so-called 'hotspot' of biodiversity worldwide (Brehm et al. in chapter 2 in Beck et al., 2008)[8].

The region has witnessed an accelerated social and economic development in the last two decades. This has been based on the exploitation of the abundant natural resources. For instance, activities such as mining, tourism, agricultural land use expansion (Universidad Nacional de Loja, 2006)[64] have increased rapidly. Problems such as illegal timber extraction, the lack of land titles (Mosandl et al. in chaper 4 in Beck et al., 2008; Gerique and Pohle, 2006)[8][49] and the introduction of new nonsustainable agricultural technologies (Abbott, 2005)[1] have caused many side-effects in southern Ecuador. One of the most important side effects is deforestation. In a survey by Maza et al. (2010)[43], 10 of 135 respondents openly admitted having cut forest for pastures, partly inside the local forest reserve. Deforestation affects the ecological integrity of the adjacent Podocarpus National Park (Mosandl et al. in chaper 4 in Beck et al., 2008)[8].

Southern Ecuador comprises two provinces, Loja and Zamora-Chinchipe province. These two provinces have a high share of the economically active population involved in agriculture: $44 \%$ in the Loja province and $57.9 \%$ in Zamora-Chinchipe (Pohle, chapter 3, in Beck et al., 2008)[8]. However, agricultural production is not sufficient to satisfy the basic needs of many households. A survey of 135 local farming house- 
holds in the region shows that $35 \%$ of the households receive a survival subsidy $(=30$ USD/month; Bono De Desarollo Humano), and that $17 \%$ work as farm-hands. The main agricultural products are meat, curd, and a traditional maize-bean-mix. Pastures are manually weeded and not fertilized. Farmers' main interest in extension services is in cattle reproduction, pasture/resource conservation management and new crops (Maza et al., 2010)[43].

In the researched communities face-to-face contact is still one of the most important communication channels, see Section 3.4.2 for an explanation. Communities without adequate access to the main road do not receive a mobile telephone signal. In some cases it is only possible to access a community-administered telephone used mostly for emergencies, as in the case of the community San Juan del Oro in the province of Zamora-Chinchipe. This was confirmed during the field research.

The communities located inside the research area, depicted in Figure 3.2, are interconnected by a road and small paths of varying levels of quality, some of which may collapse during the rainy season. The more central communities are connected by main roads suitable for motor traffic. Other smaller communities are connected often by roads accessible only by four-wheel drive vehicles. The area along the principal road from Loja to Zamora is settled mainly by Mestizo-colonos. The Saraguros are located north of the road between Loja and Zamora e.g., in communities such as El Tibio and El Cristal. Communities such as Imbana and El Tibio have been adequately connected by gravel roads recently. The communities included in this field research are depicted in Figure 3.2 by a red circle.

\subsubsection{The Region: Socio-Ethnological Background}

In southern Ecuador there are mainly two ethnic groups related to land use. The first one are the Mestizo-colonos, who represent the non-indigenous rural population of Ecuador. The proportion of Mestizo-colonos living in souther Ecuador in percentages are: $92.8 \%$ of the total population of the Loja province and $83.2 \%$ of the total population of the Zamora-Chinchipe province (Pohle in Beck et al., 2008)[1]. Mestizo-colono communities are more numerous in the project region than Saraguro communities, and so is the total number of inhabitants. Most Mestizo settlers came to the region as a result of the agrarian reform during the 1960s. With the agrarian reform new agricultural 
technologies were introduced to the region that had a direct impact on the traditional ways of agriculture and farm activities (Abbott, 2005; Pohle in Beck et al., 2008)[1][8]. For example, cattle ranching became an important source of income (Pohle in Beck et al., 2008)[1], and in agriculture the introduction of new crop races, with high yields, caused agrobiodiversity loss (of native species) (Abbott, 2005)[1].

Mestizo-colonos main income source is the cattle ranching. In areas where the Saraguros settle, the landscape has more trees, while the areas settled by Mestizocolonos are at times completely devoid of trees (Pohle and Gerique, in Beck et al., 2008)[8]. In comparison to Saraguros, Mestizo-colonos have reduced knowledge of local flora, but have a more comprehensive knowledge of crop plants and pasture varieties (Pohle and Gerique in Beck et al., 2008; Gerique and Pohle, 2006)[8][49]. Production function analysis suggests that, on average, Mestizo-colono households generate higher per hectare income from their farms than Saraguro households (Maza et al., 2010)[43]. Pohle (in Beck et al., 2008)[8] confirmed that Mestizo-colonos are more related to cash-oriented activities than are the indigenous Saraguros.

The second ethnic group are the Saraguros who are indigenous peoples and is one of twelve Quechua speaking groups in Ecuador. Their relation to the local ecosystems is well recognized (De la Torre et al., 2006; Gerique and Pohle in Beck et al., 2008)[20][8]. Saraguros have adopted cattle ranching since the early nineteenth century. In the beginning it was a complement of their traditional system of mixed cultivation (Pohle in Beck et al., 2008)[8]. Their traditional system of arable agriculture includes maize, beans, potatoes, other tubers and fruit. Their home gardens can include trees in a multi-strata arrangement, and have been hypothesized to be a sustainable, near optimal form of rural land use (Pohle and Gerique in Beck et al., 2008)[8]. Nonetheless, cattle ranching has become the most important income-generating activity for the Saraguros of the project area. Interestingly, Pohle and Gerique (2006)[49] suggest that the higher prevalence of trees in the case of the Saraguros may be an expression of a more sustainable form of agriculture based on traditional knowledge. A study by Gonzalez et al. (2010)[27] shows that the adoption of agroforestry tree species by Saraguros and Mestizo-colonos have different patterns. Saraguros, despite their knowledge of local tree species, are less related to the adoption of tree species. Their access to information about adoption options may be lower than that of the Mestizocolonos. 
As mentioned above, Saraguros are indigenous, an important fact, as being indigenous is closely related to self-cultura identity, to self-governance (Dove, 2006)[21], to marginalization and to recognition within many social spheres (Van Cott, 2007)[66]. A study about the ethnic Saraguro in southern Ecuador explores their process of identity construction, which for Saraguros is close related to their connection with the Inca past (pre-European civilization) (Ogburn, 2007)[46]. Saraguros are one of the most prosperous indigenous groups in Ecuador, e.g., many Saraguros have completed studies in education and medicine. Moreover, one of the Saraguros' main activists is part of the Confederation of the Indigenous Peoples of Ecuador. Saraguros are proud of their identity, this gives a strong cohesiveness to their ethnic group, as is shown by the use of their distinctive hairstyle and traditional clothing (Ogburn, 2007)[46]. This sense of identity differentiates the Saraguro ethnic group from the Mestizo-colono. Generally, indigenous cultures tend to give priority to collective identities over those of the individual community members (Van Cott, 2007)[66].

Importantly, in spite of several differences, the members of both ethnic groups are predominantly smallholder farmers with a livelihood based on dairy and meat production (Pohle and Gerique, 2008)[8]. Mestizo-colonos have been traditionally more related to the political institutions. However, the indigenous groups have had a more active presence in the Ecuadorian political sphere begining in the 1970s, which has been especially strong since the 1990s. Proof of that is the Ecuadorian indigenous party Pachakutik (Van Cott, 2007)[66]. This Party has many followers among the indigenous Saraguros in southern Ecuador.

\subsubsection{Survey Design}

The present survey is part of the second phase research on social network effects on the adoption of agricultural innovations in southern Ecuador. For details on the first phase see Gonzalez et al. (2010)[27]. Given the results obtained in the first phase, it was decided to conduce a broader survey to analyze if there are differences in how the members of the two ethnic groups, Saraguro and Mestizo-colono, access advice on agricultural activities in the network. For a detailed explanation of the whole research see Chapter 1.

In the following paragraphs, we explain how the data was collected in the field. 
Figure 3.2 presents the communities where the questionnaire was applied. For the survey, $\mathbf{N}=208$ household heads in 11 communities were interviewed. These are also presented in Table 3.1. The survey took place in communities settled in the proximities of the Podocarpus National Park and within the Bosque Protector Corazón de Oro. These communities are of interest because their agricultural activities may have a direct impact on the Podocarpus National Park (Universidad de Loja)[64]. For details see explanation in Section 3.4.1.1.

In general, the selection of the communities was based on an expanded set of communities interviewed in the first research phase. The criteria for selection of communities for the two research phases were based on two dimensions: $(a)$ the location of the communities in the region and $(b)$ the ethnicity of the members of the communities. For a detailed explanation of this point see Chapter 1.

In Table 3.1 the communities are classified according to accessibility. They were divided in to three groups, those no accessible, even with a $4 \times 4^{1}$ car, those with limited accessibility by car and those witheasiyly accessible by car (good). See also note $b$ in Table 3.1. The telecommunications criterion describes whether the local population has $(i)$ no access to telecommunications, $(i i)$ access to mobile telephones, or (iii) access to a phone at home, or both a mobile phone and a phone at home. These factors may influence the possibility of accessing information on agricultural activities, as face-to-face communication becomes more important. As observed in Table 3.1, access to a telephone is restricted to some communities with good accessibility. The dimention ethnicity is explained in Section 3.4.1.2. Table 3.1 presents the interviewed communities.

\subsubsection{Interview Instrument and the Data}

We interviewed all (census) household heads in all the communities included. We did not sample the network (Frank in Carrington et al. 2005)[15]. It is important to clarify that we only interviewed the household heads. Therefore, the network was based only on their answers, and it was assumed that they were the persons who made decisions regarding land use. To generate the names (nomination) of the individuals in the advice network we asked each interviewee openly to name those individuals he turned to for

\footnotetext{
${ }^{1}$ A four-wheel automotive vehicle (e.g., a pickup truck) equipped with four-wheel drive.
} 
Table 3.1: Researched Communities

\begin{tabular}{lllll}
\hline Communities & $\mathbf{N}^{\mathrm{a}}$ & Access $^{\mathrm{b}}$ & Ethnic Majority & Telecommunications $^{\mathrm{c}}$ \\
\hline El Cristal & 11 & Bad & Saraguro & No \\
El Tibio Alto & 24 & Regular & Saraguro & No \\
El Tbio Bajo & 16 & Regular & Saraguro & No \\
Hierbabuena & 20 & Good & Saraguro & Full \\
Imbana & 32 & Regular & Mestizo-colono & Middle \\
San Jual del Oro & 12 & Bad & Mestizo-colono & Middle \\
Los Guavos & 23 & Regular & Mestizo-colono & No \\
La Libertad & 10 & Regular & Mestizo-colono & No \\
La Union & 19 & Regular & Mestizo-colono & No \\
Sabanilla & 19 & Good & Mestizo-colono & Full \\
Jesus Maria & 22 & Regular & Mestizo-colono & No \\
\hline
\end{tabular}

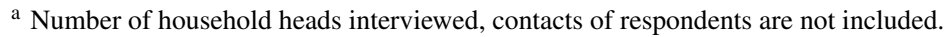

${ }^{\mathrm{b}}$ Good if it was possible to access by car on a paved road. Regular if was possible to access by car in an unpaved road, and Bad if was impossible to access by car through any kind of road.

${ }^{\mathrm{c}}$ Full refers to communities with access to a mobile telephone signal and optionally a home telephone. Middle indicates access to one communal telephone for all the community. No means no access to mobile telephone or home telephone. In some cases a weak mobile telephone signal was identified but it was unstable and easily disrupted (tested in the field). 


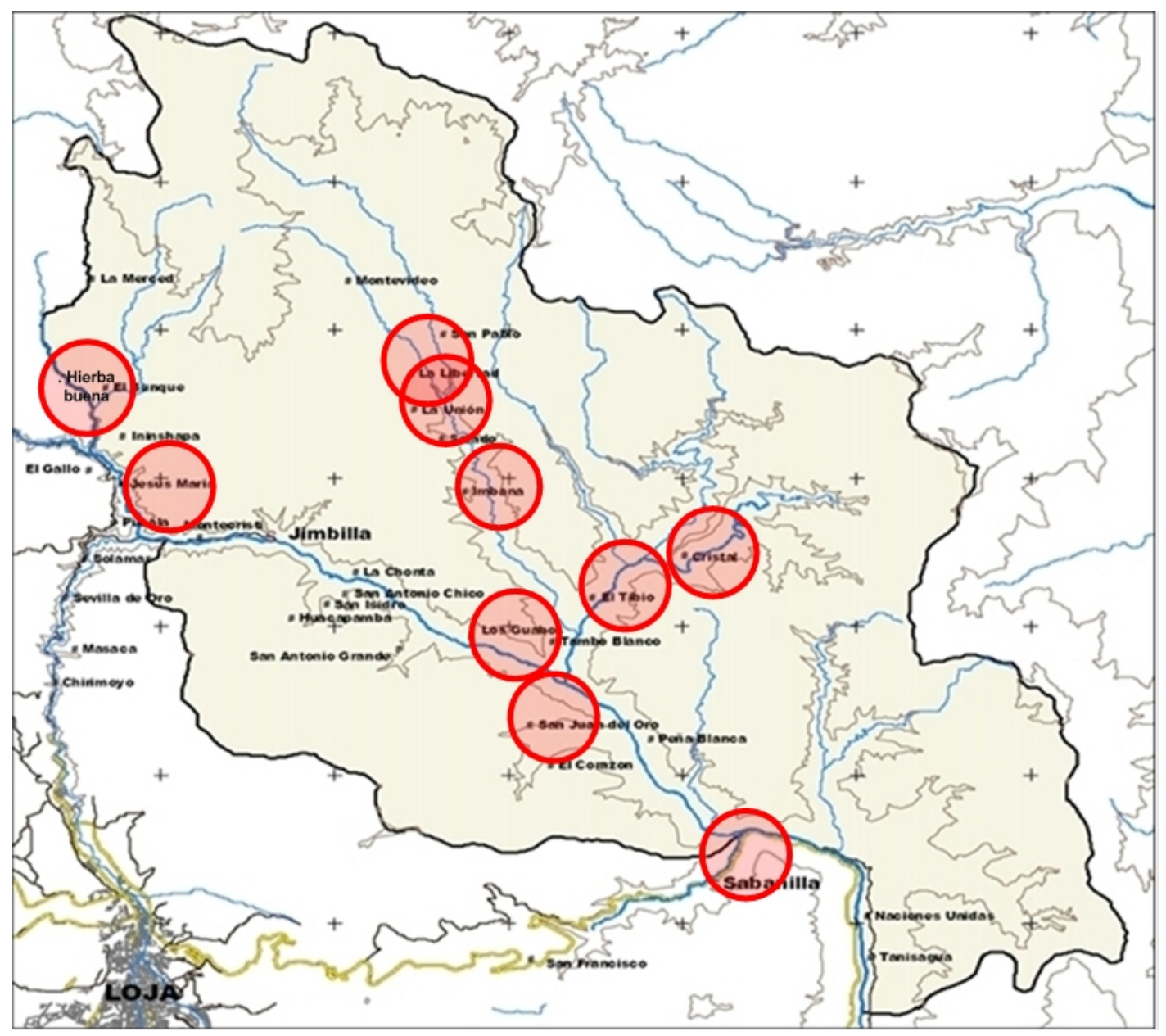

Figure 3.2: Bosque Protector Corazón de Oro

[Red circle: communities included in the second research phase]. 
advice. We did not ask for a fixed number of nominations. Setting a fixed number of possible nominations in a directed network can carry some problems. For instance, the interpretation of mutualized (reciprocated ties) data can be complicated (Goodreau, 2007)[28]. Another method used to generate names (nominations) is the use of a list of actors, but this may be problematic if there is a large population or a big community.

We tried the last method, mentioned above, in the pretest of the survey questionnaire. The list was quite big and could have caused problems in the collection of the data, consuming more time (around an hour). After that, we left the nominations open. Another factor that was observed in the pretest was that there were some nominated ties from outside the sample research area. We thought that it would be suitable to capture these individuals as well, since they were also a source of advice for our respondents. However, our target population was still the respondents of the communities in Table 3.1.

The respondents' nominations included individuals who were not household heads but whom we identified within a household, given that we had a detailed list of all household members. ${ }^{1}$ Some contacts or ties lived outside the 11 communities (sample research area), and were therefore counted as a contact from outside. This way we set our network boundaries. However, their role in the network could be important as external sources of information. Therefore, while the places of residence of the contact nominations are from 11 communities inside the research region, ties in 44 communities outside the research region were counted.

The advice network, $g_{a}$, was constructed by asking each respondent whom the respondent searched for advice on the activities shown in Table 3.2. The advice network $\left(g_{a}\right)$ is comprised of 561 individuals, these are interconnected by 1410 ties. The questionnaire listed the main agricultural activities of each household. We stress that the questions apply only to the search for advice. More specifically, the following was asked:

- $(i)$ who recommended the activity to the respondent,

- (ii) where the respondent learned the activity,

\footnotetext{
${ }^{1}$ That could be the case of the son of a household who was too young to be interviewed but was mentioned as a contact. These were some exceptions and very few cases. This person is counted as contact (tie) in the network, however, their ties were not interviewed, see limitations.
} 
- (iii) who was sought if there was a problem related to the activity,

- (iv) who was sought if there was any question about the cultivation, etc.,

- (v) who had recommended any course or workshop,

- (vi) who had recommended changes or improvement in the activity,

- (vii) whether the person had searched relatives, neighbors etc. for any general advice about their agricultural activities.

This way, a detailed map of the search for information and of the advice network for each activity was obtained. This paper focuses on the agricultural activities' advice network (individuals searched and being sought for advice). The main agricultural activities that are related to the search for advice are listed in Table 3.2.

- Clarification: Actors living outside the sampled communities: Before the field research, it was expected that most of the contacts (ties) of the advice searching network would be from inside the communities interviewed. Even after the pretest of the questionnaire, it was not expected that a big share of the advice network would be outside. It is easier, in terms of time and resources, to access information available first hand, inside the communities. Therefore, some contacts from outside the sampled communities were expected, if a periphery existed, but not many (40\% out of 561 actors). The questions asked were not meant to elicit names outside the communities set. Specific information about the nominations was requested once the nomination was made, e.g. place of residence.

These actors (living outside the sample communities) represent a source of advice that must be included, even though these actors are out of the physical limit of our sample research communities. We had to include them (the outside actors) because we are interested in the advice network directly generated by the sampled communities. The sample of communities is the base upon which to construct the advice network that depicts the search for information. Actors living outside the interviewed communities are a part of the advice network that is 
formed by analyzing the relational patterns, even if they do not live in the communities. There is no doubt that including these actors enriches the analysis of network patterns in an advice network.

In the application of the questionnaire, leaving the nominations open caused us to have many ties outside the sampled communities. The information that we have from these ties may be limited, but may reflect a specific situation of the advice network in the study area (Frank, 1980)[29]. The advice is searched outside the communities for reasons described in the following pages.

- Data limitations: Given that we include the outside advice sources, we expect a higher number of assymetric (no reciprocated ties) ties than would be the case without these actors. Nevertheless, it could be that this does not affect inferences made about the network. On the contrary, this could improve inferences about the patterns of advice-seeking.

Only ten respondents refused to be interviewed, and some of them were mentioned as contacts. In spite of this, the network data were quite complete. We only interviewed the household heads and those who take the decision of adoption. There were some actors nominated that were not respondents and that lived in a household in the communities of the sample research area. These cases were few. One possibility to deal with these actors in the analysis would be to set each household as the actors of the network; and not each respondent and person nominated. Nonetheless, this would create difficulties in testing the hypotheses that refer to differences between Saraguro and Mestizo-colono ethnic groups. For example, there are households where the head of the house is Saraguro and his wife is Mestizo-colono. These cases would have created some difficulties in reaching conclusions about the ethnic differences.

\subsubsection{Network Analysis}

\subsubsection{Review of Some Previous Work}

Some previous work on cohesive group stresses that the use of cohesive groups analysis can be useful to localize central actors in the network (Frank, 1996)[28]. Furthermore, centrality is closely related to cohesive subgroups (Borgatti and Everett, 
Table 3.2: Main Activities in the region related to the search for advice

\begin{tabular}{|c|c|c|}
\hline Activity & $\%$ of $\mathrm{N}$ & $\%$ of individuals in $g_{a}{ }^{a}$ \\
\hline Pastures $^{\mathrm{b}}$ & 76 & 24.1 \\
\hline Cattle & 70.7 & 50.4 \\
\hline Poultry and Eggs & 67 & 13 \\
\hline Corn & 62 & 10 \\
\hline Guinea Pig ${ }^{c}$ & 55 & 12.3 \\
\hline Plantain $^{\mathrm{d}}$ & 48.6 & 4.1 \\
\hline Tree Tomato & 47 & 6 \\
\hline Vegetables & 43.3 & 11.2 \\
\hline Horse & 38.5 & 5.9 \\
\hline Pig & 34.1 & 8 \\
\hline Lemongrass $^{\mathrm{e}}$ & 29.8 & 1.2 \\
\hline Sugar Cane & 22 & 2.1 \\
\hline Organic Agriculture $^{\mathrm{f}}$ & 19.7 & 12 \\
\hline Coffee $^{\mathrm{g}}$ & 16.3 & 3.4 \\
\hline Blackberry & 9.1 & 0.7 \\
\hline
\end{tabular}

${ }^{\mathrm{a}}$ The contacts that were sought for advice for each activity, detailed source of information analysis in the section on empirical results.

${ }^{b}$ Pastures are not necessarily related to cattle in the search for advice, although they are closely linked.

${ }^{c}$ Cavia porcellus, local name cui domesticated and originary from the Andes.

${ }^{\mathrm{d}}$ Includes plantain, banana and other musa species.

${ }^{\mathrm{e}}$ Known in Ecuador as hierba luisa, Cymbopogon sp. is used as medicinal plant and for tea infusions.

${ }^{\mathrm{f}}$ Here as the more recently incorporated concept in the region to use organic fertilizer and organic pesticides.

${ }^{\mathrm{g}}$ For the year 2011 was a relatively new activity introduced by local organizations in the region. 
2006)[11]. Importantly, if a central actor has access to new and specialized information on agriculture, he may have a more advantageous position to innovate and to access new resources (Valente and Davis, 1999; Rogers, 2003).[65][58]

There are divided opinions on the use of blockmodelling and cliques to study subgroups. Some results have shown difficulties into analyzing groups by using structural equivalence. For instance, one can compare within and between cohesive subgroup structures by mapping interactions in order to characterize the process of the influence of one group of actors on another. More specifically, one can also make a comparison between a cohesive groups model and a map based on blocks. Nonetheless, the block model has been shown not to support a better characterization of the social actors (Frank, 1996)[28].

Burt (1978)[14] carried out important work related to group cohesion and social homogeneity. In this case, subgroup analysis based on structural equivalence are more desirable to those that approach cohesion with clique structures (Burt, 1978)[14]. Nonetheless, other studies also approach social homogeneity by testing comparable structural cohesion and structural equivalence models. The higher the homogeneity (based on teachers' expertise) is within groups, the better the prediction made by structural cohesion models will be. There is little support to know whether structural equivalence explains social homogeneity (Friedkin, 1984)[32].

Important work has been done in relation to ethnicity in the study of groups. All agree that ethnicity has a strong influence on social division. For instance, a study about ethnic-groups and cohesion indicates that being in a specific ethnic group is a "natural" attribute of the social actor. The problem stressed refers to those groups studied where the individuals can not choose whether or not to be a member of the group. There may also be some restrictions of the social relations within and outside the group, i.e., racial prejudices (Borhek, 1970)[12]. A study related to ethnicity has been done on community cohesion. This studied the case of a British prison, where ethnicity was related to the prisoner's identity. In this study, self-identification with an ethnic group had the greatest significance for the prisoner, i.e., in this group he could find solidarity (Phillips, 2007)[55].

By studying interpersonal networks and social support in an urban, ethnicallymixed community, it is established that kinship ties are more important for Hispanics than for Anglos. In this case, given the strong ties of social support (within and between 
Anglos and Hispanics), the community is ethnically segregated. For instance, Hispanics invest more effort to built kin-based communities (Schweizer et al., 1998)[60]. Ethnicity has also been studied in Latin America for the case of indigenous people. Some studies have shown that in Latin America strong ties, solidarity, social exchange based on kinship, cooperation and division of time shared in labor are characteristics of indigenous social networks (Collins, 1983; Skoufias, 2009)[22][64].

\subsubsection{Applied Methods}

Following we describe the models that we use to empirically test the research hypotheses explained in Section 3.3. Recalling the research hypotheses we want to explain in detail the methods used.

- $H_{1}$ : Mestizo-colonos are the actors with the highest degree centrality in the network.

- $\mathrm{H}_{2}$ : Mestizo-colonos who are more central in the network are in the highest cohesive group.

- $H_{3}$ : Saraguros are within the highest cohesive block.

- $H_{4}$ : Saraguros tend to search more information in the periphery-outside the sample research region.

- $H_{5}$ : Mestizo-colonos access more information from different clusters in the network.

To test $H_{1}, H_{5}$ we have explained in detail the methods in Section 3.2. To test $\mathrm{H}_{2}, \mathrm{H}_{3}$ and $\mathrm{H}_{4}$ we explain here the methods more in detail. These methods are also addressed in Section 3.2.

To test the hypotheses $\mathrm{H}_{2}$ and $\mathrm{H}_{3}$, we have fit the data to the cohesive block model. This model fit the data well. We have chosen it to determine the structurally cohesive groups in the network. The cohesive block model shows, in a stratified manner, how the interaction is between individuals when they search for advice and then they form cohesive blocks. Generally, cohesive blocking identifies all cohesive subgroups in the 
network $g_{a}$ and relates them to each other by nesting the subsets (Moody and White, 2003)[52], for more detail see Section 3.2.2.

If we test $\mathrm{H}_{2}$ and $\mathrm{H}_{3}$, we will be able to know if there is a group of Mestizo-colonos in the network that may control information contained in advice giving. Cohesive block analysis can also show the interaction of the different cohesive groups with each other. For instance, it can show how the search for advice forms cohesiveness for each ethnic group. Moreover, cohesive block analysis can help us explain where central actors are embedded. To make the position of central actors in a cohesive group easier to comprehend, we have visualized $g_{a}$ 's cohesive blocks combined with the centrality measures (degree and betweenness), see Figure 3.6. The cohesive block model shows, in a hierarchical fashion, where the individuals are embedded in cohesive groups. The vertex color represents the hierarchy of the cohesive blocks in the advice network. For an illustration of the hierarchy of the cohesive groups see Figure 3.5, and for an explanation of the method see Section 3.2.2.

The hypothesis $\mathrm{H}_{4}$ is based on the analysis of the periphery of the network. The theory says that in a hierarchical and highly central network some groups search for mitigation strategies to overcome hierarchical power and status (Lazega et al, 2012)[41]. Furthermore, this hypothesis tests whether indigenous Saraguros search for advice by referring to other Saraguros in the periphery of the network, living out side the research sample area (explained below). Saraguros are a minority in the ethnicity - based network of the case study area. As we review in Section 3.4.4.1, ethnicity produces the strongest division in social relations (McPherson et al., 2001)[44]. For this reason, Saraguros that need to solve farm problems and to access information may access advice from other Saraguros, who are outside the search sample.

Given that the results of the cohesive block analysis show a core/periphery pattern, we have decided to use a $k$-core analysis to see more specificities and attributes of the members of the periphery. The periphery represents an important fraction of the advice network, $g_{a} . k$-core analysis was chosen because its result is equivalent with the periphery of the cohesive block analysis, i.e., indegree $=1$ and outdegree $=$ 0 . The $k$-core is identified based on the vertex degree centrality, see Section 3.2.2 (Seidman, 1983)[62]. This means that the higher the $k$-core is, the higher the number of actors contacted will be. The higher $k$-core has some correspondence with the high-degree members in the cohesive block analysis. This may help the interpretation 
of the analysis of the network relations. We have also applied this analysis because, once the cohesive block analysis was applied, it lost some flexibility for additional analysis, e.g., the analysis of membership of cohesive blocks and $g_{a}$ attributes. Thus, the $k$-core, in this case (not always), is complementary to our analysis. This way, the $k$-core analysis help us to test $H_{4}$.

Peripheral actors are linked to the network and do have structural importance (Everett and Borgatti, 1999; Borgatti and Everett, 1999).[22][10]. The periphery is composed of individuals linked by a single edge to the rest of the network. Following Everett and Borgatti (1999)[22], we specify that our network has only two subgroups: one connected core and a periphery of individuals loosely connected to the core. By doing a $k$-core analysis, we fit each vertex in a $k$-core $\left(k-\right.$ core $\left._{g}\right)$ of $g_{a}$. Thus, a vertex $i \in V\left(g_{a}\right)$ can be in the core $C_{g}$ or in the periphery $P_{g}$, but not in the core and the periphery at the same time (no overlapping is allowed). If $i \in P_{g}$, then $i \notin C_{g}$. Therefore, the vertex can be only in the periphery of $g_{a}$. In Table 3.4 we define the periphery as $i \in P_{g}$ if and only if $k-$ core $_{g}=1$.

The models have been applied using the $R[51]$ environment for statistical analysis. More specifically, we used igraph version 0.5x (Gabor, 2012)[26] to estimate the cohesive block model, the $k$-core model and to estimate some statistics. In addition, sna (Butts, 2012)[13] version 2.2-0 of STATNET (Handcock et al., 2003)[32], including in $R$ environment, was used to estimate statistics, such as connectivity $(\kappa)$.

\subsubsection{Network Specification}

Formally, our network $g_{a}$ has an order $n=561, V=\left\{v_{1} \ldots v_{n}\right\}$, if $V\left(g_{a}\right)$ is the number of vertices in $g_{a} . g_{a}$ has size $u=1410$, and $E=\left\{e_{1} \ldots e_{u}\right\}, E\left(g_{a}\right)$ is the number of edges in $\left(g_{a}\right)$. The vertex $i$ can belong to two ethnic groups Saraguro or Mestizo-colonos. Thus, an individual $i$ can have an attribute $L$, where:

$$
L= \begin{cases}1 & \text { if } i \text { Mestizo-colono } \\ 0 & \text { otherwise }\end{cases}
$$

The individual $i$ belongs to any of $c$ communities, $c=55$, if $c \in M$, where $M$ is the set of all possible communities, $M=\left\{\begin{array}{lll}c_{1} & \ldots & c_{n}\end{array}\right\} . c$ is the set of communities having at least one individual $1 \leq c \leq n$. The set $M$ also has two attributes, for communities 
inside or outside the sample research region. Thus, $i$ can be in $c, c=\{$ in,out $\}$. If $i \in c_{\text {in }}$, always $i \notin c_{\text {out }}$. In $g_{a}$ an edge between $i$ and $j$ can exist so that $\{i j\}, i \neq j$ and $i \in c_{\text {in }}$ and $j \in c_{\text {out }}$. Moreover, there are 11 communities inside the sample research area, $c_{i n}=\left\{c_{i n_{1}} \ldots c_{i n_{11}}\right\}$, and there are 44 communities outside the sample research area, $c_{\text {out }}=\left\{c_{\text {out }_{1}} \ldots c_{\text {out }_{44}}\right\}$.

In the directed network $\left(g_{a}\right) Z$ is the set of types of social relations based on the search for advice, $Z=\left\{z_{A}\right\}$; for $Z=\{$ Advice $\}$. The network of the searching for advice on agricultural activities, $g_{a}{ }^{1}$, can be decomposed into two subgraphs, the $g_{a S}$ for the Saraguro, the network of which only includes intra-ethnic-group linkages. The second subgraph is $g_{a M}$ for intra-ethnic-group linkages of Mestizo-colonos.

\subsection{Empirical Results}

The analysis is based on the advice searched on agricultural activities in rural communities in southern Ecuador. From Section 3.5.1 to Section 3.5.3 we present the main results of the applied methods explained before. The empirical results are presented in such a fashion so as to clarify the importance of these results for testing the research hypotheses.

\subsubsection{Network Descriptive Statistics}

The results of this section will help us to empirically test the hypotheses $H_{0_{1}}$ and $H_{0_{5}}$ :

- $H_{1}$ : Mestizo-colonos are the actors with highest degree centrality in the network.

- $H_{5}$ : Mestizo-colonos access more information from different clusters in the network.

We asked respondents whom they sought or asked for information concerning agriculture. Based on this, we constructed a directed graph, $g_{a}$. The reciprocity $y^{2}$, of $g_{a}$, confirms the literature that indicates that this statistic tends to be low for advice networks. Following Table 3.3, the probability that a tie is reciprocated is higher in $g_{a S}$

\footnotetext{
${ }^{1} g_{a}$ also includes interaction with institutions working with agriculture.

${ }^{2}$ The search for information does not necessarily imply the necessity to reciprocate. Reciprocity is the returned tie of one individual to another individual.
} 
(0.111) than in $g_{a M}(0.088)$. The diameter and the average path length in $g_{a s}(10$; $3.99)$ is lower than in $g_{a M}(11 ; 4.15)$. This information means that, in the search for advice, the distance between individuals of the same ethnic group is greater on average for Mestizo-colonos.

We observe in $g_{a S}(0.012 ; 0.286)$ a higher density and transitivity than in $g_{a M}$ $(0.0052 ; 0.138)$. The transitivity at the network level is almost double between subgraphs. This suggests that the Saraguro as an ethnic group tends more towards sharing the same information internally than do Mestizo-colonos, e.g., in the first group an individual is more likely to contact someone in their ethnic group who also contacts someone that the individual contacts. This triangulation may help us to understand the formation of local clusters and structural holes in the search for advice (see Section 3.6.3 for discussion). This can also be seen in the number of cliques: $g_{a S}$ (6) has more cliques than $g_{a M}(5)$.

If we observe the mean indegree, outdegree and mean degree (see Table 3.3) we may think that there are similar patterns in the search for advice. In addition, the correlation between indegree and outdegree centrality shows us the extent to which individuals send and receive ties. This correlation ${ }^{1}$ is higher for $g_{a S}(0.45)$ than for $g_{a M}(0.35)$. The higher the correlation is, the less centralized is the subgroup. In $g_{a}$ this correlation is quite low (0.16), which can also be observed in Figure 3.3. Few individuals receive many nominations (outdegree).

Structurally, the Saraguro subgraph $\left(g_{a S}\right)(55.88)$ has a lower mean betweenness than the Mestizo-colono subgraph $\left(g_{a M}\right)$ (80.55). This position of being between two other actors, in $g_{a}$, is shown mostly by Mestizo-colonos. In $g_{a S}$ (63.6) Burt's constraint is lower than in $g_{a M}$ (68.7). In general, Burt's constraint is high, considering the maximum of 100 (Burt, 2004)[16]. Nonetheless, the network structure of $g_{a M}$ has the highest constraint.

To depict advice search in $g_{a}$ and for each subgraph $g_{a S}$ and $g_{a M}$, we plot the senders and receivers ${ }^{2}$ in the search for advice (see Figure 3.3). Interestingly, in $g_{a}$ there are six individuals nominated more than 120 times as source of information.

\footnotetext{
${ }^{1}$ The in-outdegree correlation shows the correlation between the indegree and the outdegree of an actor $i$ (Agneessens and Wittek, 2012)[4]. Positive and high means that the individuals that seek $i$ for advice are many and the same whom $i$ also seeks for advice.

${ }^{2}$ The person seeking information is a sender and the person nominated as an information source is a receiver.
} 
Table 3.3: Agricultural Activities Advice Network Statistics

\begin{tabular}{|c|c|c|c|}
\hline Network Statistics & $\begin{array}{l}\text { Whole Network }{ }^{\mathbf{a}} \\
\left(g_{a}\right)\end{array}$ & $\begin{array}{l}\text { subgraph-Sarag. } \\
\left(g_{a S}\right)\end{array}$ & $\begin{array}{l}\text { subgraph-Mestizo-c. } \\
\left(g_{a M}\right)\end{array}$ \\
\hline Vertices $^{\mathrm{b}}$ & 561 & 166 & 332 \\
\hline Edges & 1410 & 330 & 574 \\
\hline Mean-indegree & 2.51 & 2.04 & 1.73 \\
\hline Mean-outdegree & 2.51 & 1.99 & 1.73 \\
\hline in-outdegree correlation ${ }^{\mathrm{c}}$ & $0.16[t=3.92]$ & $0.45[t=6.41]$ & $0.35[t=6.91]$ \\
\hline Mean-degree & 5 & 4.07 & 3.46 \\
\hline Mean-betweenness & 312.29 & 55.88 & 80.55 \\
\hline Transitivity - global $^{\mathrm{d}}$ & 0.127 & 0.286 & 0.138 \\
\hline Reciprocity & 0.076 & 0.111 & 0.088 \\
\hline Diameter & 12 & 10 & 11 \\
\hline Average - path-length & 4.95 & 3.99 & 4.15 \\
\hline Density & 0.0045 & 0.012 & 0.0052 \\
\hline Cliques & 7 & 6 & 5 \\
\hline Mean-Burt's-const. ${ }^{\mathrm{e}}$ & 66.9 & 63.6 & 68.7 \\
\hline
\end{tabular}

${ }^{\mathrm{a}}$ Includes interaction and linkages with institutions.

${ }^{\mathrm{b}}$ Includes individuals mentioned as a source of advice and who lives outside the research area.

${ }^{\mathrm{c}}$ For all the $t$ statistics the $p-$ value $=0.000$ with a $95 \%$ confidence interval.

${ }^{\mathrm{d}}$ Ratio of transitive triads and connected triple (three actors) of the graph. We refer here to global transitivity to distinguish it from local transitivity, not addressed here.

e Burt's constraint can assume a value $0 \leq c \leq 1$, here it is multiplied by 100 (Burt, 2004)[16]. 
These six actors nominate less than 40 individuals as references of information. If we observe $g_{a M}$, there are four Mestizo-colonos who receive about 80 nominations each. These patterns are very similar to the interactions (intra-inter groups) in $g_{a}$. In the case of $g_{a S}$ the behavior is very different, and considerably more homogeneous. There are very few individuals with many more nominations (receivers) than others. The intragroup structure to search for advice related to agricultural activities is indeed different in $g_{a S}$ than in the other ethnic group, $g_{a M}$. It is also different when the Saraguros interact with the rest of the local actors in $g_{a}$. 


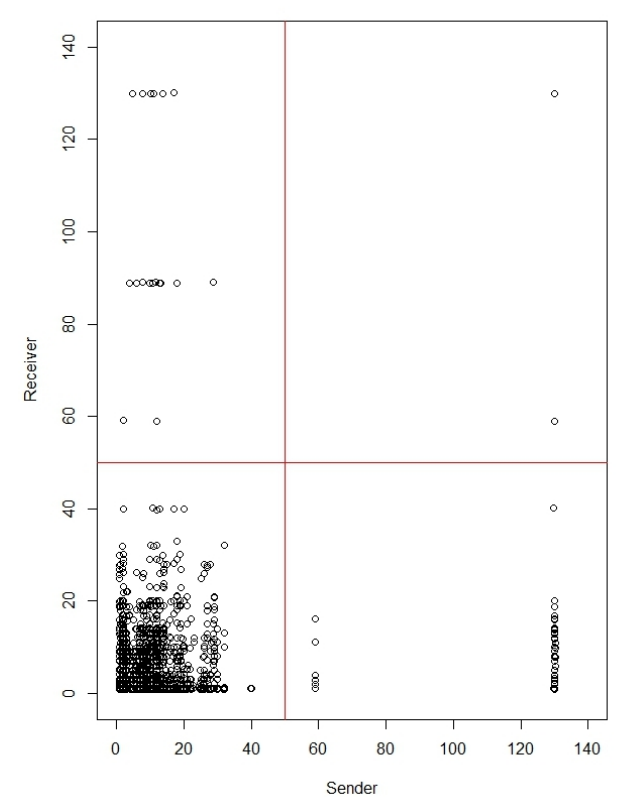

(a) Advice Network: $g_{a}$

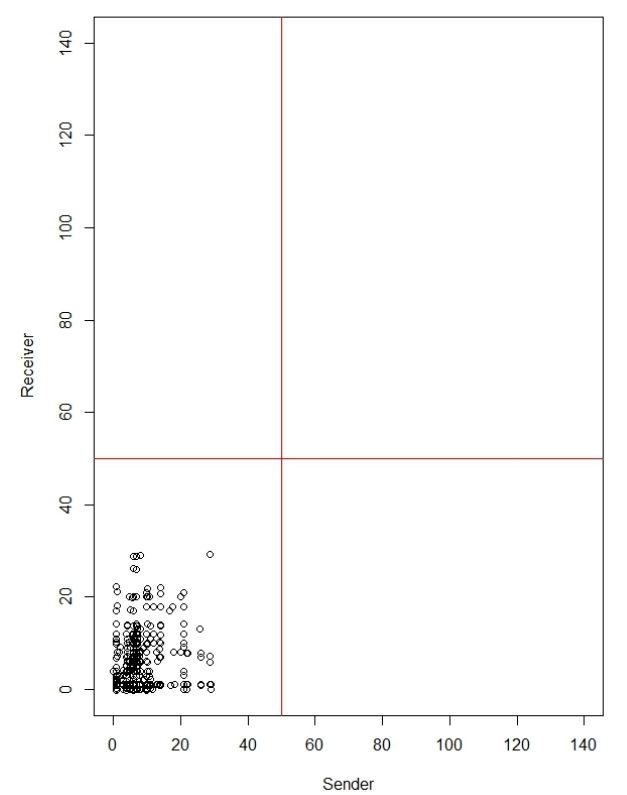

(b) Subgraph for Saraguro ethnic group: $g_{a}$

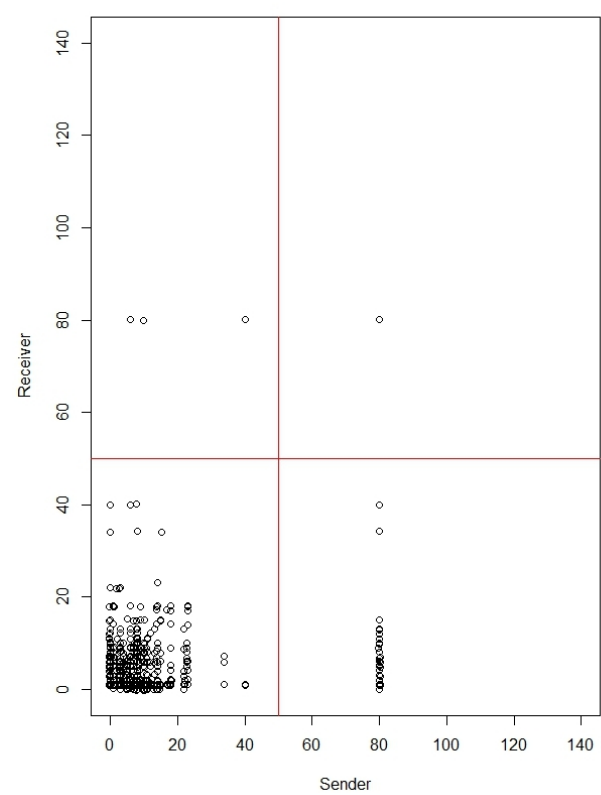

(c) Subgraph for Mestizo-colono ethnic group: $g_{a M}$

Figure 3.3: Advice Searching: Sender-Receiver

[Each point represents an actor $i: x$ axis for the number of actors searched by actor $i$ for advice, $y$ axis for number of actors who searched actor $i$ for advice]. 
This raises the question of who in the network is most sought for advice. By introducing the network centrality statistics of degree and betweenness, we can observe who is most sought for advice in $g_{a}$, illustrated in Figure 3.4. The individuals with the highest degree and betweenness centrality are from the Mestizo-colono ethnic group. Saraguros have a different and less centralized way of searching for advice than Mestizo-colonos do. Observing $g_{a}$, it is clear the most sought actor for advice. It seems that some institutions also have an important role in giving advice. The most central institution is the Junta Parroquial de Imbana. If we estimate the betweenness centrality, the role some individuals play of being between the two shortest paths connecting two other individuals, this is performed mostly by Mestizo-colonos. 


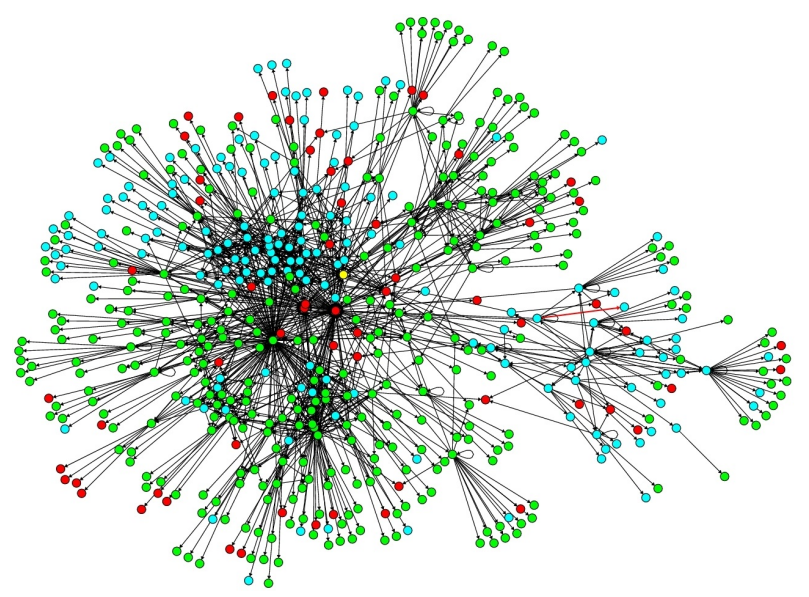

(a) $g_{a}$

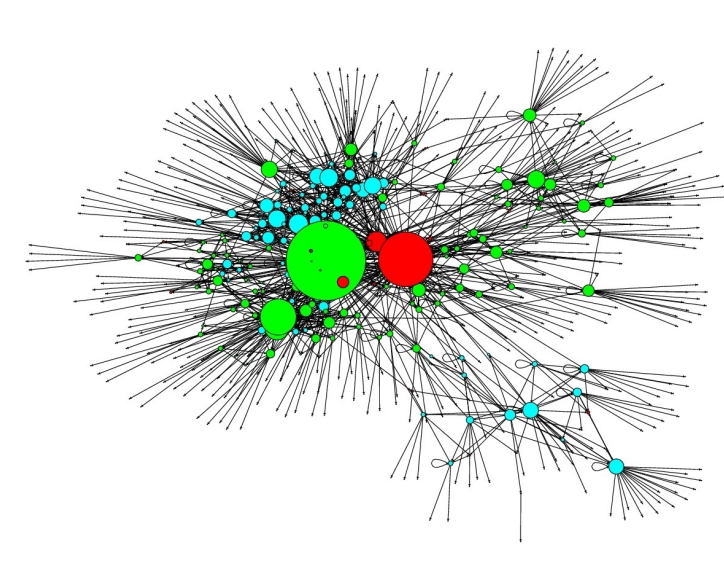

(b) $g_{a}$ vertex size based on degree centrality

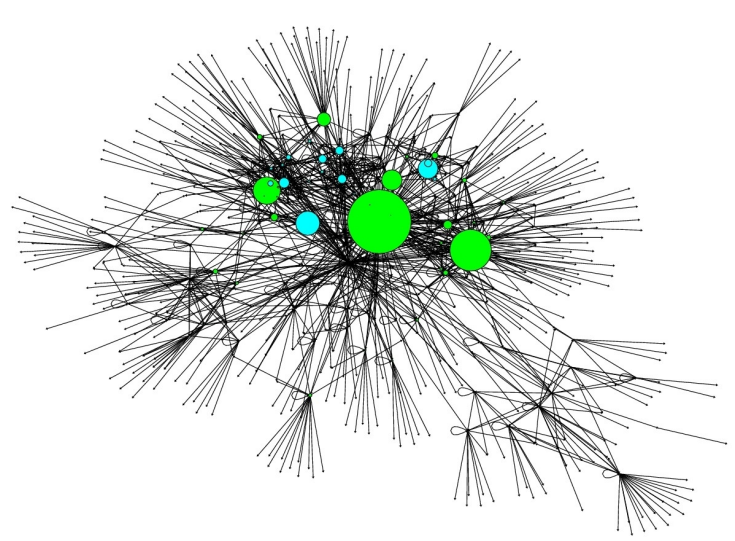

(c) $g_{a}$ vertex size betweenness centrality

Figure 3.4: Centrality of Vertex $i$ in $g_{a}$ 


\subsubsection{Cohesive Block Analysis}

The results of this section empirically test the hypotheses $H_{2}$ and $H_{3}$ :

- $\mathrm{H}_{2}$ : Mestizo-colonos who are more central in the network are in the highest cohesive group.

- $\mathrm{H}_{3}$ : Saraguros are within the highest cohesive block.

In $g_{a}$, very few actors are the most central and they do receive many nominations. Likewise, the network is not strongly connected, i.e., few actors keep the network tied together. The degree of connectedness is $\kappa\left(g_{a}\right)=0.994^{1}$, and the closer $\kappa$ to 1 , the more weakly the network is connected ${ }^{2}$, i.e., it is disconnected by removing few actors. As we see, these central actors are in the highest cohesive group in $g_{a}{ }^{3}$, see Figure $3.4 \mathrm{~b}$ and Figure 3.6b. Thus, by disconnecting this group a big part of the search for advice on agricultural activities will fall apart.

Figure 3.5 depicts the cohesive block model results. The vertex color shows, in a hierarchical fashion the highest cohesive groups in $g_{a}$, from top to bottom. Based on the cohesive block hierarchy presented in Figure 3.5, the cohesive blocks from less cohesive ( 1 dark-blue colored) to most cohesive ( 7 red colored) are shown. There are 7 cohesive blocks, and in this context we also refer to these blocks as subgroups. As observed in Figure 3.6, the most highly central Mestizo-colonos are all in cohesive group 7 (red color) and the highest degree Saraguros are found mainly in the cohesive group 4 (dark-green color) and 7, with a few in cohesive block 5 (light-green color), see Figure 3.6b and Figure 3.6c. At this level in the cohesive block we can observe many groups in the same block. We observe many Saraguros subgroups and fewer Mestizocolonos, if we compare degree centrality, in Figure 3.6b. This can be observed by comparing degree centrality graphs of $g_{a}$, Figure $3.6 \mathrm{~b}$ and Figure $3.4 \mathrm{~b}$. Being in the same cohesive block does not mean that Saraguros and Mestizo-colonos must be tied

\footnotetext{
${ }^{1}$ Calculated in sna package (Butts, 2012).[13]

${ }^{2} \mathrm{~A}$ graph is connected if each vertex can reach every other vertex in the network. The degree of connectedness is defined as: $\kappa=1-\left[\frac{P}{N(N-1) / 2}\right]$, where $P$ is the number of vertices that are mutually reachable, and $N$ the total number of vertices. The denominator is the total number of pairs (Krackhardt, 1994)[40].

${ }^{3}$ The degree of connectedness is presented only for $g_{a}$ and not for the ethnic subgraphs. To build the intra-link subgraphs the edges with the other ethnic group were eliminated. Thus, some individuals were isolated. This by definition, is already a disconnected graph.
} 


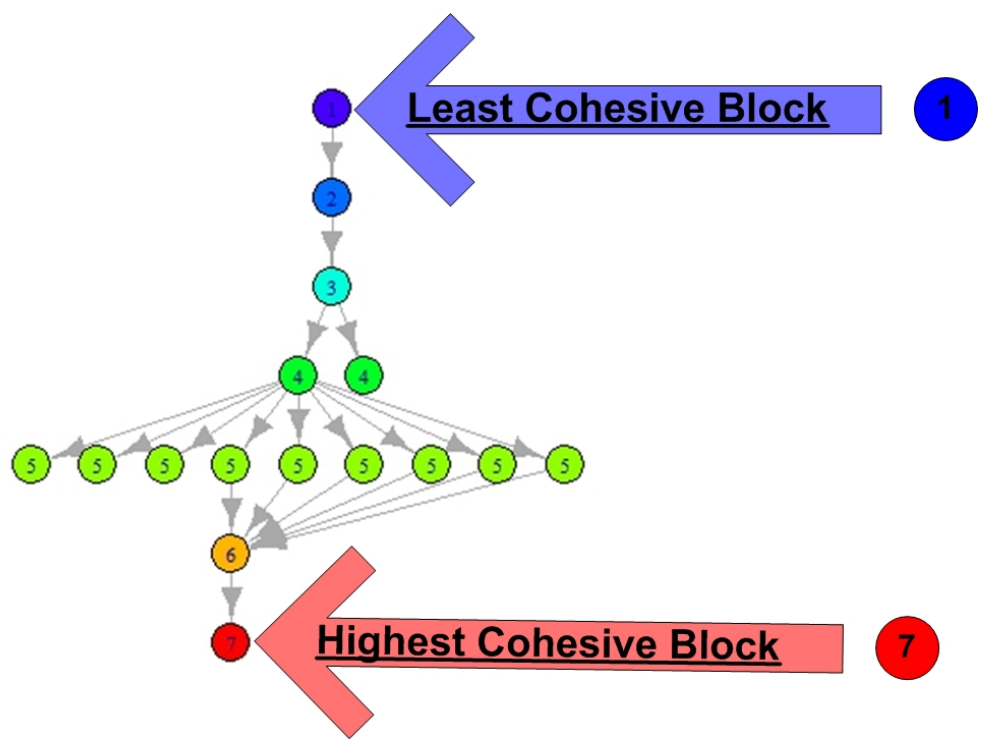

Figure 3.5: Cohesive blocks hierarchy in $g_{a}$

[Right side legend: Arrow $\downarrow$ shows direction to a higher rank, from vertex color $=$ dark - blue, the least cohesive group (1) to vertex color $=$ red, the highest cohesive group (7)]

together, but rather, that they are similarly tied within their groups. Summarizing, Saraguros are more cohesive because they have many actors in cohesive blocks 5,6,7, and the central actors are members of the cohesive blocks 4, 5,7. Conversely, Mestizocolonos have many actors in cohesive blocks 1,2,3 and the central actors are mostly in cohesive block 7.

As Moody and White (2003) explain, cohesive block analysis usually has two possible options. In our case, the advice network on agricultural activities, $g_{a}$, forms a core/periphery structure, where there is a periphery of individuals loosely connected to a cohesive core, as we explain in the next subsection. 


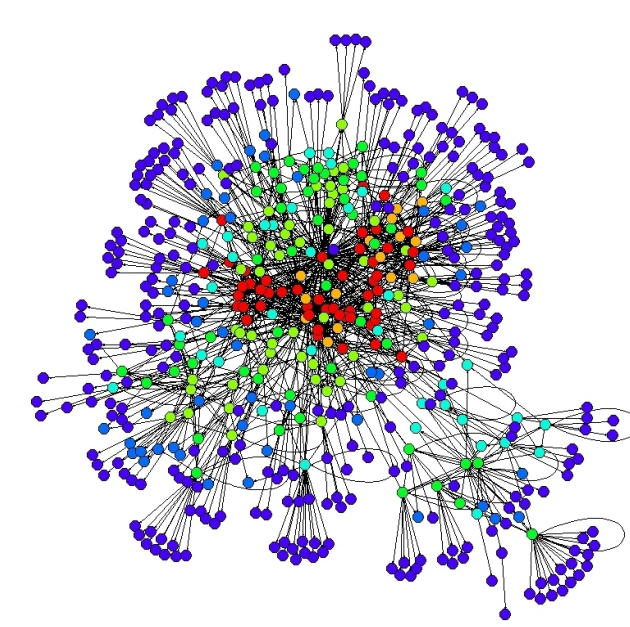

(a) $g_{a}$ Structural cohesive blocks

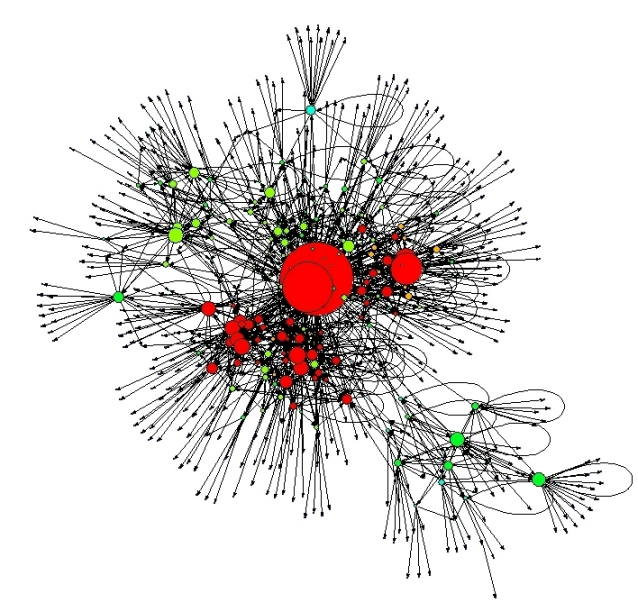

(b) Cohesive blocks vertex size based on

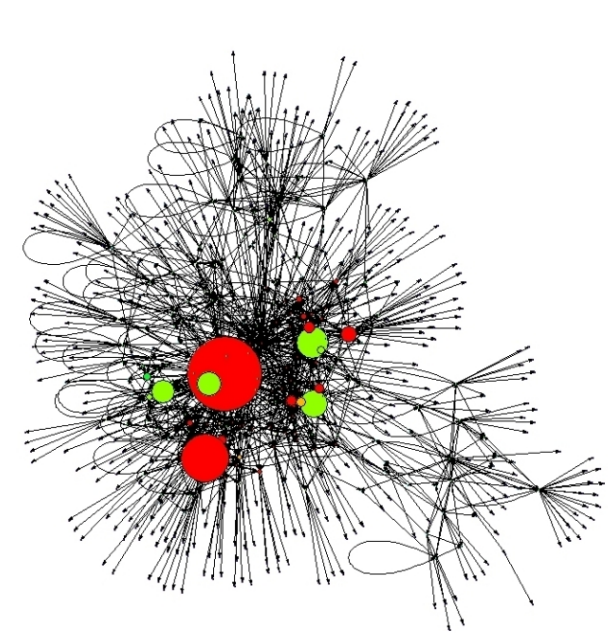

(c) Cohesive blocks vertex size based on betweenness centrality in $g_{a}$

Figure 3.6: Centrality and Structural Cohesive Blocks of $g_{a}$

[vertex: color $=$ dark - blue, the least cohesive group (1), color $=$ light - blue $:(2)$, color $=$ cyan $:(3)$, color $=$ dark green : (4), color $=$ light - green $:(5)$, color $=$ orange $:(6)$ and color $=$ red, the highest cohesive group (7)] 


\subsubsection{Analyzing the Periphery}

The results of this section will help us to test the hypothesis empirically:

- $\mathrm{H}_{4}$ : Saraguros tend to search more information in the periphery-outside the sample research region.

In order to understand the role of the periphery we have performed a $k$-core analysis to disentangle the core/periphery. The periphery results are congruent with the cohesive block analysis, since the $k$-core $=1$ shows the maximal subgraph that has at least degree $k \geq 1$ (see Figure 3.6a). In this case, both cohesive block analysis and $k$-core analysis coincide in that the location of the periphery is when $k=1$ and cohesive - block $=1$ (blue color $=$ least cohesive block). Details of the membership in the core/periphery are shown in Table 3.4.

As presented in the subsection before, some institutions working in the region are also in cohesive group 7. It is important to mention that the first level (the periphery $=$ cohesive group 1 ) in the rank includes mostly ties of the respondents who also live outside of the research area and institutions that work at the regional level, see Figure 3.4a. This first level of the cohesive blocks represents $55 \%$ of all the actors in $g_{a}$. They are an important source of information. Some information comes from outside $\Rightarrow$ inside (the researched communities) and also diffuses, via advice giving, locally in highly hierarchically structured cohesive groups. 
Table 3.4: $g_{a} K$-core: Core/Periphery of Network Actors, where: [ ] n ( ) $=[\%$ row $] \mathrm{n}^{\circ}$-actors $(\% \text { colunm })^{\mathrm{c}}$

\begin{tabular}{|c|c|c|c|c|c|c|c|}
\hline \multirow{2}{*}{$K$-core } & \multicolumn{2}{|c|}{ Institution $^{\mathrm{a}}$} & \multicolumn{2}{|c|}{ Mestizo-colono } & \multicolumn{2}{|c|}{ Saraguro } & \multirow{2}{*}{$\sum$} \\
\hline & inside $^{b}$ & outside & inside & outside & inside & outside & \\
\hline 1 & [2] $8(73)$ & [10] $31(60)$ & [20] 63 (34) & [40] 124 (86) & [17] 53 (39) & [10] $30(100)$ & {$[100] 309(55)$} \\
\hline 2 & [4] 2 (18) & [6] $3(6)$ & [40] $19(10)$ & [32] $15(10)$ & [17] 8 (6) & [0] $0(0)$ & {$[100] \mathbf{4 7}(8)$} \\
\hline 3 & [0] $0(0)$ & [21] 5 (10) & [38] $9(5)$ & [13] $3(2)$ & [29] 7 (5) & [0] $0(0)$ & [100] 24 (4) \\
\hline 4 & [0] $0(0)$ & [14] 4 (8) & [59] 17 (9) & [3] 1 (1) & [24] 7 (5) & [0] $0(0)$ & {$[100] 29(5)$} \\
\hline 5 & [0] $0(0)$ & [10] 5 (10) & [55] 27 (14) & [0] $0(0)$ & [35] 17 (13) & [0] $0(0)$ & [100] 49 (9) \\
\hline 6 & [0] $0(0)$ & [2] $1(2)$ & [83] 35 (19) & [2] $1(1)$ & [12] 5 (4) & [0] $0(0)$ & [100] $42(7)$ \\
\hline 7 & [0] $0(0)$ & [0] $0(0)$ & [40] $6(3)$ & [0] $0(0)$ & [60] $9(7)$ & [0] $0(0)$ & [100] 16 (3) \\
\hline 8 & [2] 1 (9) & [7] $3(6)$ & [26] $12(6)$ & {$[0] 0(0)$} & [65] $30(22)$ & [0] $0(0)$ & {$[100] 46(8)$} \\
\hline \multirow[t]{2}{*}{$\sum$} & [2] 11 (18) & [9] $52(82)$ & [34] $188(57)$ & [26] 144 (43) & [24] $136(82)$ & [5] 30 (18) & \multirow[t]{2}{*}{ [100] $561(100)$} \\
\hline & \multicolumn{2}{|c|}{ [11] $\mathbf{6 3}(100)$} & \multicolumn{2}{|c|}{ [59] $\mathbf{3 3 2}(100)$} & \multicolumn{2}{|c|}{ [30] $\mathbf{1 6 6}(100)$} & \\
\hline
\end{tabular}

a The institutions are governmental and non-governmental. Some of the local institutions are farmers and indigenous organizations. Others have a regional character, such as the Consejo Parroquial, that has a local presence.

${ }^{\mathrm{b}}$ Inside and outside refers to whether the actors are living inside or outside of the communities interviewed (sample research area). For instance, if the institution did not have local and physical representation it was counted as being located outside the research area.

${ }^{\mathrm{c}}$ The quantity in ( ) corresponds to the percentages \% of the columns $\downarrow$, the quantity in [ ] corresponds to percentage \% of the rows $\rightarrow$. In the middle is the number of actors for each category. 
The first implication of these results is that there is information coming from outside the research area. The second pertain to the role of the periphery in the advice network. The third concerns the level of importance of inside and outside advice for each ethnic group. A very important result is that most of the periphery actors live outside the interviewed communities. As explained in Section 4.5.2, the majority of the individuals interviewed were Mestizo-colonos. In $g_{a}$, about $59 \%$ of the individuals in the network are Mestizo-colonos.

As presented in Table 3.4, 55\% of the actors in the advice network are in the periphery. It is very important to remark that $60 \%$ of the periphery lives outside the researched communities. Furthermore, most of the institutions are in the periphery, these are different kind of organizations, both governmental and non-governmental. Of all the actors, $11 \%$ are institutions. About $62 \%$ of the institutions are in the periphery, $82 \%$ are outside the sample research area and $49 \%$ are outside of the area and at the same time in the periphery.

Additionally, $61 \%$ of the periphery are Mestizo-colonos, $12 \%$ are institutions and $27 \%$ are Saraguros. This is not surprising, since Mestizo-colonos are a majority in this advice network. Nonetheless, what does draw one's attention is that $56 \%$ of the Mestizo-colonos are in the periphery. Of all the Mestizo-colonos in the periphery, $86 \%$ are living outside. Mestizo-colonos also search for an important share of their advice in neighboring communities that also included in the project area ("in" communities). We observe in Table 3.4 that $40 \%$ of the 561 actors are from outside of the sample research region. Of these, 64\% are Mestizo-colonos, 23\% are Saraguros and 13\% are institutions. Thus, proportionately, for Mestizo-colonos these contacts (ties) are a more important source of advice than for Saraguros.

Generally, there is a tendency for Mestizo-colonos to seek more advice in the periphery-outside than Saraguros. For instance, if we expand our definition of periphery to $k$-core $\leq 2,67 \%$ of the Mestizo-colonos are in the periphery, in contrast to $55 \%$ of the Saraguros. For Saraguros, the main sources of advice are inside the sample research area. Although 50\% of the Saraguros are in the periphery, only $18 \%$ of their advice network is outside the area and all of these individuals are in the periphery. Just $32 \%$ of the advice network of Saraguros is inside the area and in the periphery. ${ }^{1}$

\footnotetext{
${ }^{1}$ Most of these people did not mention many contacts, or mentioned them only once. They have few or no agricultural actvities.
} 
Situated in $k-$ core $=8$ is the highest central institution, namely the Consejo Parroquial de Imbana. This is the local institution in charge of some agricultural projects in the region (local government). The most central actors among Mestizo-colonos who also live in Imbana are in the same $k$-core. In the case of Saraguros, individuals from different communities, such as Tibio Bajo, Tibio Alto Cristal and Hierbabuena, are in the $k$-core $=8$, i.e., the high degree members are less concentrated.

\subsubsection{The Tested Research Hypotheses}

Here we explain briefly whether the research hypotheses were accepted or not. A detailed explanation is left for the discussion of results.

- $H_{1}$ : Mestizo-colonos are the actors with the highest degree centrality in the network.

This hypothesis was accepted. The Mestizo-colono ethnic group has the actors with the highest degree centrality.

- $\mathrm{H}_{2}$ : Mestizo-colonos who are more central in the network are in the highest cohesive group.

We accept this hypothesis. By comparing the degree centrality representations and the cohesive block analysis we show that central Mestizo-colonos are among the highest cohesive groups in the network.

- $\mathrm{H}_{3}$ : Saraguros are within the highest cohesive block.

We accept this hypothesis. There is a group of Saraguros that are among the highest cohesive blocks in the network.

- $\mathrm{H}_{4}$ : Saraguros tend to seek more information in the periphery-outside the sample research region.

We reject hypothesis $H_{4}$. It was demostrated that Saraguros seek fewer actors for advice in the periphery - outside the sample research region than Mestizocolonos do.

- $H_{5}$ : Mestizo-colonos access more information from different clusters in the network. 
We partially reject this hypothesis. The $g_{a m}$ subgraph shows that Saraguros' intra - group interactions span more structural holes by having less constrained actors. However, the Mestizo-colono ethnic group has the more central actors. The theory suggests that these actors may access more advice across structural holes (Burt, 2005)[12]. This is widely discussed in Section 3.6.3.

\subsection{Discussion of Results}

\subsubsection{Ethnicity and Status}

In order to understand hypothesis $H_{1}$ and its test better we discuss the relation between centrality, status and ethnicity. By analyzing ethnic subgroups in $g_{a}$, we recall Borhek (1970)[12], who remarks that there may be two kinds of group boundaries for ethnic groups, namely, one cultural and one structural. Indigenous identity is defined mostly by the interaction with homophilous actors within the group. In the past years, with the presence of CONAIE, this inter-community network has been strengthened; this may be the case for Saraguros. For instance, in the region there are some indigenous organizations, e.g., the Federation of Indigenous Saraguros, in Spanish: Federación Indigena de Saraguros (FISS). The identity as an indigenous people is very important and strong for the Saraguros (Ogburn, 2007)[46].

The Saraguro ethnic group presents what McPherson et al. (2001)[44] called inbreeding homophily. They are internally more strongly connected than Mestizocolonos, and tend to search for advice inside their own ethnic group. Ethnicity is a "natural" attribute and it has been identified as creating the strongest division in social environment (Borhek, 1970; McPherson, 2001)[12][44]. Importantly, Smith-Lovin (2003)[65] points out that, for indigenous groups, self-identity is salient until the member is embedded in a network with another group as a contrast. Therefore, indigenous Saraguros' sense of identity, cultural patterns and the fact that they are a minority (in the region) may cause them to have structural patterns in the search for advice on agriculture matters that are internally different from those of Mestizo-colonos. Thus, the advice network's division is ethnically oriented.

Different cultural patterns and opinions may make it more difficult to move ideas and information between groups (Burt, 2005)[12]. $g_{a}$ is a network that Burt (2005) 
would call a closed network, where the individuals are strongly connected directly or indirectly and where they are also connected through a central actor, i.e., a very hierarchical network. As Granovetter (1973, 1983)[31][39] and Burt (2005)[12] suggest, the scarcity of ties between groups that function as paths of advice giving in $g_{a}$ can lead to a dysfunctional sharing of information through the bridging of paths. Mestizo-colonos who have the actors with highest betweenness centrality at the same have the highest degree centrality.

The high degree centrality may show the concentration of information in few individuals. The high centrality in an advice network may be an indicator of the concentration of information. The concentration of information may be related to the access to power and to status in the region (Walker et al., 2000)[72]. Rogers (2003)[58] remarks that high status actors that are opinion leaders tend to share information with other high status actors. This kind of homophily hinders the diffusion of the information required for innovation adoption. If information circulates mainly among few individuals and institutions, there may be a request of information not only from individuals that need this information, but also from others that want to be connected to more powerful and influential actors. For Saraguros, information on agricultural activities as a means to access power and status is less important because the information flow is more homogeneously distributed (less concentrated in few actors). This is supported by the higher reciprocity in $g_{a S}$ than in $g_{a M}$ (see Section 3.5.1). Importantly, Molm, in Thye and Skvoretz (2003)[67] concludes that reciprocal exchanges generate weaker power structures in networks.

As remarked by Agneessens and Skvoretz (2012)[3], in the case of reciprocity in a group with a common identity, a favor does not necessarily have to be returned to the same individuals, but can instead be returned to another member of the same group. In the absence of this group identification, members may have to wait for repayment for favors done. Importantly, in cohesive groups the tendency towards reciprocal ties is higher (Friedkin, 2004)[33]. Therefore, Saraguros show a high tendency to be more cohesive and to reciprocate more as an ethnic group in searching for information on agricultural activities. This was supported by the number of central actors among Saraguros in the high cohesive blocks. This is widely discussed in the next subsection.

Lazega et al. (2012)[41] and Agneessens and Wittek (2012)[4] point out that the selection of an advisor can be used to exchange status and recognition. In our case 
the paucity of paths that potentially convey information in the region may reduce the options of advisor selection to very few. In this context, homophily effects on the selection of the advisor are seen as mitigation of such a power - status trade off in the network. As we mention, higher similarity based on ethnicity can lead to higher solidarity and less centralized power - status network exchange mechanisms through advice giving (Lazega et al., 2012)[41]. This is the case of the Saraguro subgroup, which tends to have a stronger group identity than Mestizo-colonos (Ogburn, 2007)[46]. This can be observed because Saraguros, indigenous people, show some traditions and agricultural practices that are different from those of the Mestizo-colonos (Phole and Gerique, 2006)[49].

Our results agree with Lazega et al (2012)[41], who state that advice networks tend to be hierarchical and cohesive. Search for similarities on information search partners create cohesive groups in the network as a mitigation strategy. What we found is that the hierarchical feature of the network is stronger in this case than in the cohesive one. We observe that Saraguros are in a disadvantage position in $g_{a}$. This may have negative effects on the search for advice, as central actors with power-status concentration may not want to share their expertise via advice on different agricultural activities with everyone. In this respect, much will depend on the highly central Mestizo-colono actors related to the Consejo Parroquial de Imbana.

We may expect the influence of central actors on agricultural activities to be balanced by the role of the periphery. As we mentioned, central actors have a more privileged position. This is because they can access new information about local activities via ties with other central actors in the same cohesive group, e.g., new species of cattle, cures for illnesses, new pastures, and changes in local prices of milk and cheese. This information is important, and influences decisions related to agricultural activities. This may cause some change in status, because individuals increase their income and become more influential in the network. As we have confirmed, Maza et al. (2010)[43] found that Mestizo-colonos have a higher income per capita than Saraguros. Thus, of the four forms of status mentioned by Agnessens and Wittek (2012)[4] $g_{a}$ mirrors economic and political status relations.

Regarding economic status, the most central Mestizo-colono had one of the highest incomes in the year $2010^{1}$. However, for the whole sample the correlation between

\footnotetext{
${ }^{1}$ Income for the year before the survey.
} 
income and degree centrality was $0.36^{1}$. The most central actors' incomes are among the highest in $g_{a}$. Mestizo-colono mean income was 3292 USD and Saraguros mean income was 2180 USD. This agrees with information provided by the United Nations $(\mathrm{UN})^{2}$, which shows the Gross National Income (GNI) per capita for the year 2009 to be 4082.8 USD. In rural areas like the "Sierra" (Andes) more than half of the households are poor, and average income falls, according to CEPAL. ${ }^{3}$ Importantly, the income of the most central Mestizo-colono for the year 2010 was 11080 USD and the income for the most central Saraguro for the same year was 1850 USD. The actor with the highest income is a Mestizo-colono, 12750 USD, observed on the right side in Figure 3.7.

Based on previous research on "learning from others" in networks (Acemoglu et.al., 2008; Goyal, 2007; Jackson, 2008)[2][37][43], and considering proposals by such authors as Stoneman (1981)[62], Besley and Case (1993)[9], Conley and Udry (2001)[16] and Udry and Conley (2004)[63], we assume the decision perspective of a farmer (household), who makes a decision choosing to maximize the profit. A farmer gains experience based on the profit information that other farmers in the network (advice network) share with each other. In the end, the individual tends to seek information not only from those whom he sees as having expertise, but also from those he thinks have had the experience of success. In this context success is the increase of farm profit. This is recognized by Rogers (2003)[58] to be highly important for the case of the diffusion of information.

As we show above, the most central Mestizo-colono had an income above the mean income for Mestizo-colonos and even further above the mean income for Saraguros. In this perspective, those to be consulted are not necessarily those who supposedly know more, but rather those whose income reflects their economic success within an agricultural activity. The income is illustrated in Figure 3.7; the size of the nodes are based on the income of the individuals and the color associated with the ethnic groups. We can confirm that the larger nodes correspond to Mestizo-colonos (green color) ${ }^{4}$.

\footnotetext{
${ }^{1} t=4.7, p-$ value $<0.001$.

${ }^{2}$ Ecuador economic statistics: http://data.un.org/CountryProfile.aspx?crName=ECUADOR

${ }^{3}$ Comision Economica para America Latina. Economic Comission for Latin America from the UN: http://www.eclac.org/.

${ }^{4}$ If we want to represent the size of network $g_{a}$ based on the income of its members, $g_{a}$ is reduced in some members, if $g_{a_{i n c}}$ is equivalent to $g_{a}$ if the size of nodes is based on their income. In this case $V\left(g_{a_{\text {inc }}}\right)=259, E\left(g_{a_{\text {inc }}}\right)=627$, this graph did not include 224 actors living out side the sample research
} 
To interpret better the status effect in $g_{a}$, we follow concepts by Agneessens and Wittek (2012)[4], and assume that actors with higher status tend not to seek advice from actors of lower status. This is confirmed by the correlation between indegree and outdegree presented in Table 3.3. Here, Saraguros who request information tend to be sought for information the same individuals, as is confirmed by the in-outdegree correlation in $g_{a S}\left(0.45\right.$ correlation), as compared with Mestizo-colonos, $g_{a M}(0.35)$. We have to clarify that given the share of advice sources of Mestizo-colonos outside the research area, where we have not requested information, there is a bias towards asymmetric ties. Nonetheless, the correlation in $g_{a}$ is quite low (0.16), showing that high central Mestizo-colonos with high income seek less advice from fewer sources, but are sought as advice source by many whose income is lower, as is depicted in Figure 3.7. For example, the ties of central actors are indegree $=124$ and outdegree $=$ 6.

As for political status, the Mestizo-colonos are more active in the region. The most central actors are Mestizo-colonos, who are related directly or indirectly to other Mestizo-colonos working with local institutions, the most important of which is the Consejo Parroquial in Imbana. This institution fulfills tasks and in some aspects it is responsible for whole communities. In recent years, some Saraguros became active in this institution, as we can observe in Figure 3.8 (red colored node for institutions) of the Ego network for the most central Saraguro. Nonetheless, Mestizo-colonos are a majority in the politically influenced institutions. At the moment that the field research was carried out, there was only one Saraguro actor who was working for the Consejo Parroquial.

The concentration of advice in few actors that group together in a highly cohesive group may create dysfunctional diffusion patterns. The results are the mitigation strategies that actors that see difficulties in accessing the information develop. In the first case, Saraguros form a more homogeneous diffusion group that at the same time is more cohesive as an ethnic group. In the case of the Mestizo-colonos that cannot access the central actors in the highest cohesive group, they search for information in the periphery-outside of the sample research area.

area, 62 institutions, 11 actors that refused to give information about their income and 5 actors who were mentioned as a source of information refused to be interviewed. Therefore, the graph representation differs from the other $g_{a}$ visualizations. The, $g_{a}$ is disconnected because the aforementioned actors are not included. 


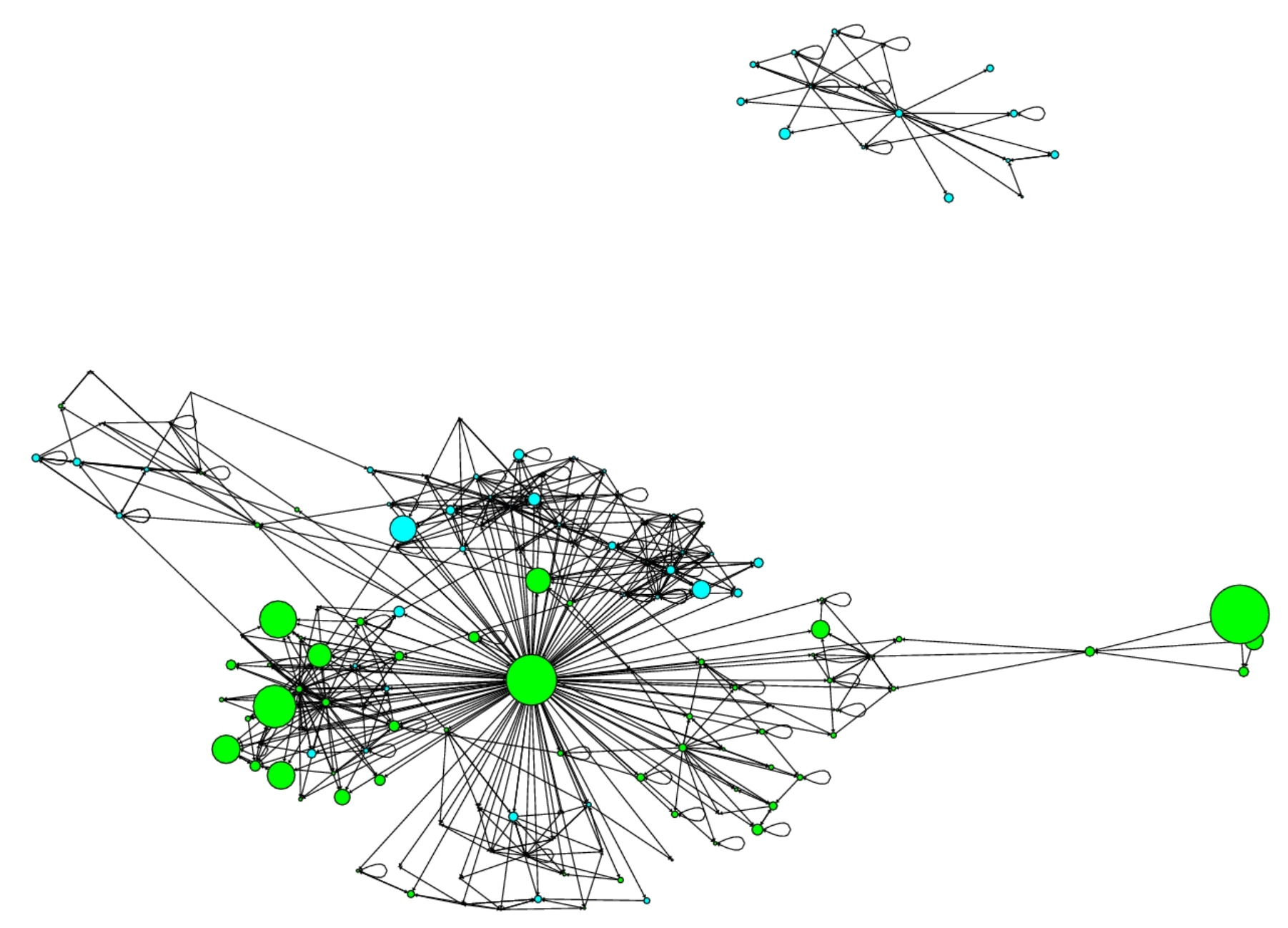

Figure 3.7: $g_{a}$ vertex size based on income

[Vertex color: Green=Mestizo - colono, Cyan=Saraguro $]$ 


\subsubsection{Cohesiveness and Groups}

We have found that the indigenous ethnic group, the Saraguro, is less centralized in sharing information on agricultural activities and at the same time, is more densely connected internally than the Mestizo-colono ethnic group. In $g_{a}, 506$ out of 1410 edges are links between ethnic groups, and 36\% of the advice searched is through links outside the searcher's own ethnic group. This means that many network relations in $g_{a}$ are based on intra-ethnic group relations.

The network statistics show a general picture of what is happening (see Section 3.5.1). There is a tendency for Saraguros to search for advice inside their own ethnic group, more so than Mestizo-colonos do. That is shown by the in-out-degree correlation and reciprocity, which are higher for the Saraguro than for Mestizo-colono if we analyze only intra-ethnic group links. Reciprocity shows that the probability of a Saraguro reciprocating a Saraguro tie is greater than that a Mestizo-colono reciprocating a Mestizo-colono tie. This is also suggested by the $k-$ core analysis.

The Saraguro intra-ethnic group subgraph, $g_{a S}$, has a higher intra-ethnic group density, higher transitivity and more cliques than the Mestizo-colonos' $g_{a M}$. Saraguros also have a lower network diameter and a smaller average path length on their intraethnic group advice network than the Mestizo-colono ethnic group (see Table 3.3). This shows that Saraguros, when searching for advice, have a less centralized structure than Mestizo-colonos do. Saraguros have cultural factors that differ from the intergroup interactions of Mestizo-colonos (Ogburn, 2007; Pohle and Gerique, 2006)[46][49]. The Saraguros' more homogeneous patterns of sender-receiver may corroborate that. For instance, the network density tells us that Saraguros request more information from members of their own ethnic group than Mestizo-colonos do. Like Burt (2004)[16], we have also found that the density is higher within than between groups. The results agree with Agnesseens and Skvoretz (2012)[3].

As suggested by Moody and White (2003)[52], the structure of $g_{a}$ is very vulnerable and structurally cohesive weak. The advice network depends on very few actors, as we observe in Figure 3.4 and Figure 3.6. A disconnection of the cohesive group that contains the highly central Mestizo-colonos would cause the whole network to fall apart. The information flow on agricultural activities is likely to be disrupted by the 
absence of these actors. Nonetheless, intra-ethnic groups' subgraphs reflect a strong cohesiveness. Comparing ethnic-groups, $g_{a s}$ has a lower Burt's constraint, is more densely intra-related and there are fewer high degree actors sought as a source of information than is the case in $g_{a M}$. Compare Figure 3.3b and Figure 3.3c.

By disentangling the structure of a network, the $k$-core analysis has helped us to see detailed information about the periphery. The $k-$ core $=8$ gathers individuals with high degree centrality. This is also congruent with the cohesive block analysis, where the high degree centrality actors are in the cohesive - block $=7$ for the case of Mestizocolonos. Many subgroups of Saraguros in cohesive - block $=7$ confirm that Saraguros are more homogeneously and cohesively connected than Mestizo-colonos. At the same time, Saraguros are also homogeneously distributed in the $k$-cores that are based on nodes' degrees (Seidman, 1983)[62]. The high degree centrality actors are the same with high in-degree centrality and betweenness centrality for Mestizo-colono. This is not the case for Saraguros, for whom different individuals assume these central roles. For instance, the Saraguros with high betweenness are in the cohesive - block $=5$ and those with high degree centrality are in cohesive - blocks $=4,5,7$ (see Figure 3.4).

The Mestizo-colono ethnic group displays more centralized advice seeking behavior since it has more actors with the highest degree of centrality than the Saraguro group. Nevertheless, both ethnic groups are constrained to a point, since the information is either concentrated in $g_{a}$ central actors or in an important amount of advice coming from the periphery of the network, based on one-path links. In both cases, Mestizocolonos' intra-ethnic group have a tendency to be more constrained than Saraguros. Clearly, Mestizo-colonos receive more information from the periphery and from out side the research area than Saraguros do. Having access to the periphery may be a way to mitigate the hierarchical advice network (Lazega et al. 2012)[41]. From this perspective, the Mestizo-colonos are more favorably situated in the advice network, since they capture more and diverse information from members of the periphery (Marsden, 1983)[49], especially from outside the sample research area, as is shown in Section 3.5.3.

More specifically, the individuals in the periphery (based on one-path linkages) in $g_{a}$ are sought for information. Most of these are outside of the communities (e.g., Loja) and include some institutions or organizations that work in agriculture. Given that the advice required is not found within their communities or in other adjacent actors, the 
individuals do have to invest time and resources to search for information, especially considering that communication facilities such as telephones are no accessible to the majority. Importantly, Loja, the capital of the province of Loja, by itself, concentrates $23 \%$ of the periphery. In the city of Loja live $38 \%$ of the actors living outside the sample research area.

Conceptually, the fact that it is mostly the Mestizo-colonos who search for advice outside the sample research area has an implicit cost. For instance, to access information available in Loja, time and money must be spent traveling to the city, even though this may be combined with other purposes. The advantages and benefits should reflect that this effort is required (Burt, 2005; Goyal, 2007; Jackson, 1996; 2008)[12][37][42][43]. For example, improving knowledge about an activity can increase farm income by increasing productivity. In the city of Loja there it is mostly Mestizo-colonos (indegree $=59$ ) who are sought for advice, in comparison to Saraguros (indegree $=9$ ) and Institutions (indegree $=18$ ).

Sometimes, the individuals are forced to ask for information where they think they can have access to it, e.g., in the city or with professionals in agriculture. As Mood and White (2003)[52] describe, one of the possible results of a cohesive blocking model is to obtain a periphery and a strongly cohesive group in the center of the graph. Therefore, the actors in the periphery of the network have an important role giving advice, specially to Mestizo-colonos. Another factor to be mentioned regarding the role of the periphery, is the kind of information that the periphery offers to individuals. As we can see, the periphery counts for $55 \%$ of the network actors. Moreover, $60 \%$ of the periphery is made up of sources from outside the research area, as we observe in Table 3.4. This proportion is really high, considering that the $k$-core $=1$ consists of directed one-length paths. A lower quota is desired for a more connected and cohesive network (White and Harary, 2001; Friedkin, 1984)[73][32]

Our empirical results show that central actors, mostly Mestizo-colonos, are in the same cohesive group as the most central institution working in agricultural development in the region. Friedkin (2004)[33] also suggests that our results indicate that a most highly cohesive group dictates the $g_{a}$ local access to information, as long as the group members are able to decide who receives information. We may assume that the most highly cohesive block, with the most central actors, controls the advice on agricultural activities within the sample research area, since they have the highest degree 
centrality. This may influence who receives advice, in $g_{a}$.

Friedkin (2004)[33] remarks that cohesive groups are, to a point, self-maintaining, as they reproduce strong group identification. Highly central actors are tied together in a cohesive block in $g_{a}$, thus, they may share the same information, which at the same time is sought by a large number of network members (degree centrality). But those network members who are nearest to this cohesive block may profit more from this information exchange than those whose social distance is greater. White and Harary (2001)[73] point out that individuals more cohesively connected to 'leaders' (may be high central) are likely to remain in the same block. In the case of Saraguros, being part of the ethnic group has a stronger influence on group cohesiveness it does for Mestizo-colono.

The role of the central actors is expected to be as opinion leaders who through advice, help to diffuse information required for the adoption of innovations in agricultural practices (Rogers, 2003)[58]. Nevertheless, the concentration of advice in only few actors may cause dysfunctional diffusion patterns.

\subsubsection{A Constrained Network}

Given the empirical evidence we have accepted the hypothesis $H_{5}$. The results must be discussed in order to understand the local access to advice on agricultural activities. Moody and White (2003)[52] include nestedness on their analysis, a concept that implies that individuals within dense clusters have access to different resources and are constrained to these. Thus, individuals embedded in cohesive groups are constrained to accessing advice on agricultural activities. Burt's constraint confirms these results for a highly constrained information-advice network. In $g_{a}$ the advice search is hierarchical and very dependent on the periphery. If we desegregate $g_{a}$ and extract the ego network of the individuals with the highest degree centrality, in each ethnic group we observe how the actors from different ethnicities "gathered" around the source of advice. We consider what Burt (2004)[16] pointed out, i.e., that the access to information depends on how the structural holes between groups are spanned. In $g_{a}$, differences in information search within ethnic groups cause fewer structural holes (higher network constraint), which is reflected by long average path lengths, especially for Mestizocolonos. 
Following Figure $3.8 \mathrm{~b}$, for the Mestizo-colono ego-network ${ }^{1}$ there are some strict single-ethnicity-based clusters and other mixed-ethnicity clusters. Where there are mixed interactions of ethnicities, there are visible formations of structural holes. For the case of the Saraguro with the highest degree centrality, the search for information is considerably less concentrated. The Mestizo-colono central actor and his neighborhood $(n=1)$ follow a structure with the central individual in the middle. In Figure 3.8a, in the Saraguro's neighborhood such a centralized structure is difficult to find. As Burt's constraint shows, the capacity to access advice across structural holes (many ties in different clusters) in the network of the central actors is different for each ethnic group. Clearly, the Mestizo-colonos' most central actor has more access to advice across these holes and may have advantages arising from that (status or political power). For example, in an advice network this would mean more access to information from other local clusters, and more diverse information. On this basis, the actor may be better prepared to make decisions on land use than an actor without access to this information.

The central Mestizo-colono is able to capture information from different groups. The Saraguro ego network is made up mostly of other Saraguros. Saraguros tend to create more transitive triads internally. Therefore, they tend to be more clustered towards the inside. For instance, as we observe in Figure 3.8, the high central Saraguro has less access to other clusters outside his own ethnic group than the central actor of the Mestizo-colonos. Thus, the Mestizo-colono has more access to advice across structural holes (also see the higher mean betweenness centrality of Mestizo-colonos in Table 3.3 and in Figure 3.4).

Burt (2004)[16] found that actors that are more central in a organization have more opportunities for brokerage. Therefore, there is a close correlation between centrality and network constraint. Our results show the same. It seems that there is no linear correlation between degree centrality ${ }^{2}$ and network constraint. Thus, by taking the logarithm of the constraint it was easier to see the correlation. As we have found, the constraint of the network $g_{a}$ with few actors with high degree centrality is highly constrained. At the same time these central actors have individually low constraints.

\footnotetext{
${ }^{1}$ The ego-networks are based on the ties of the actors with higher indegree centrality and the ties of their contacts, $n=1$, in $g_{a}$. Therefore, these representations are also based on advice searching.

${ }^{2}$ Betweenness centrality does not show a strong correlation between having high betweenness centrality and having low constraint in the network.
} 


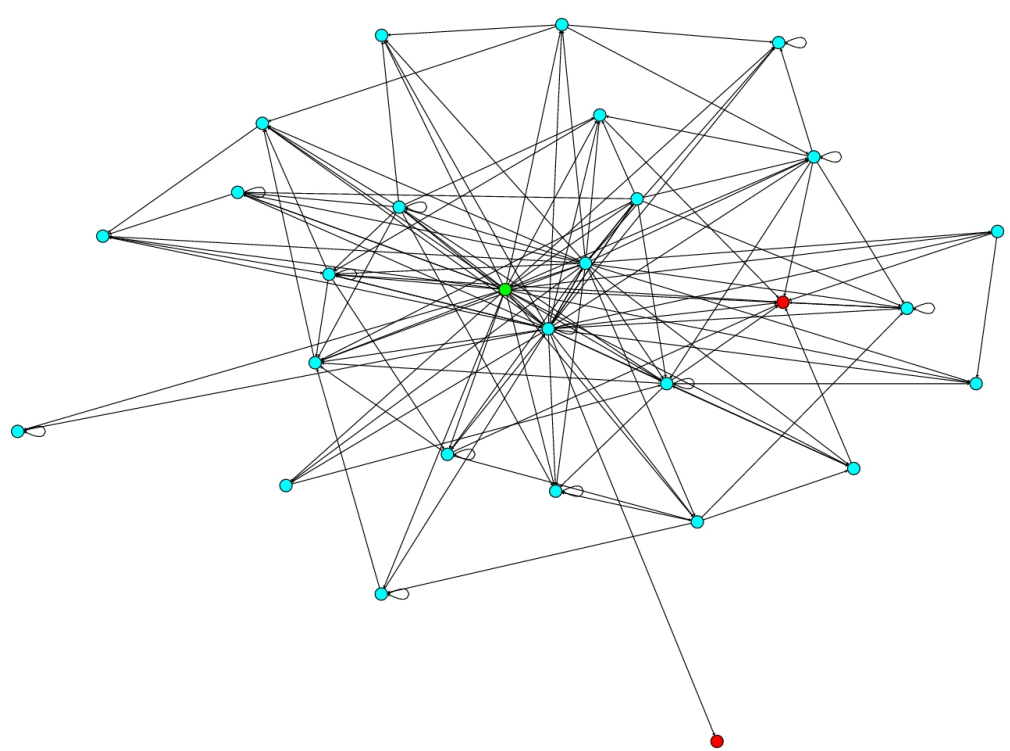

(a) Saraguro with the highest indegree centrality ego network in $g_{a}$ : Burt's - Constraint $=10.3$, cohesive - group $=7, k-$ core $=8$

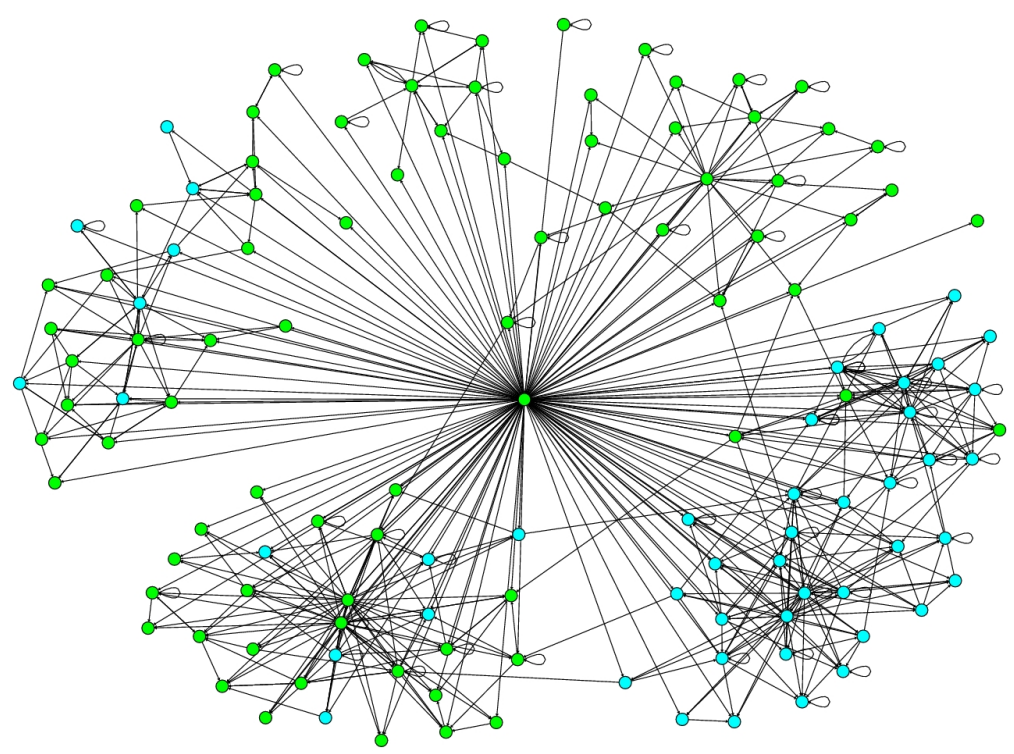

(b) Mestizo-colono with the highest indegree centrality egonetwork in $g_{a}:$ Burt's - Constraint $=2.2$, cohesive - group $=7, k-$ core $=8$

Figure 3.8: Ego networks for most central actors in $g_{a}$, order $n=1$, i.e. Ego's immediate neighbors

[Vertex color: Red=Institution, Green=Mestizo - colono, Cyan=Saraguro $]$ 
However, they constrain and make the whole network vulnerable (see Figure 3.9). Most actors depend on them to access information on agricultural activities. 


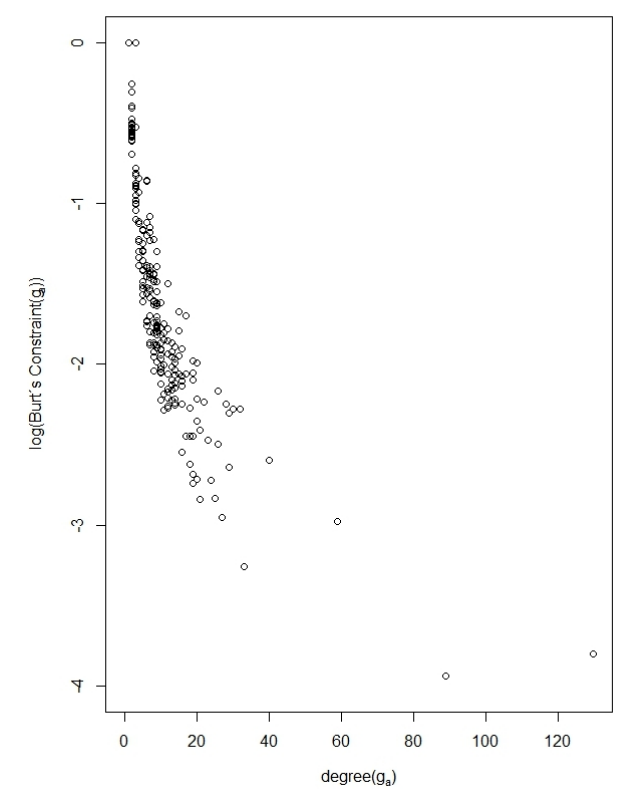

(a) Burt's Constraint (mean $=66.9)$ vs. degree in $g_{a}$

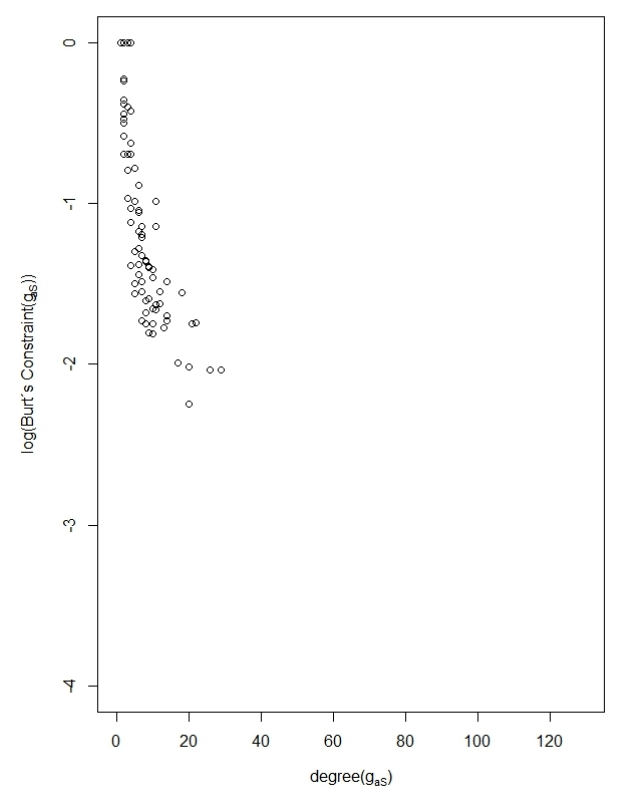

(b) Burt's Constraint (mean $=63.6$ ) vs. degree in $g_{a S}$

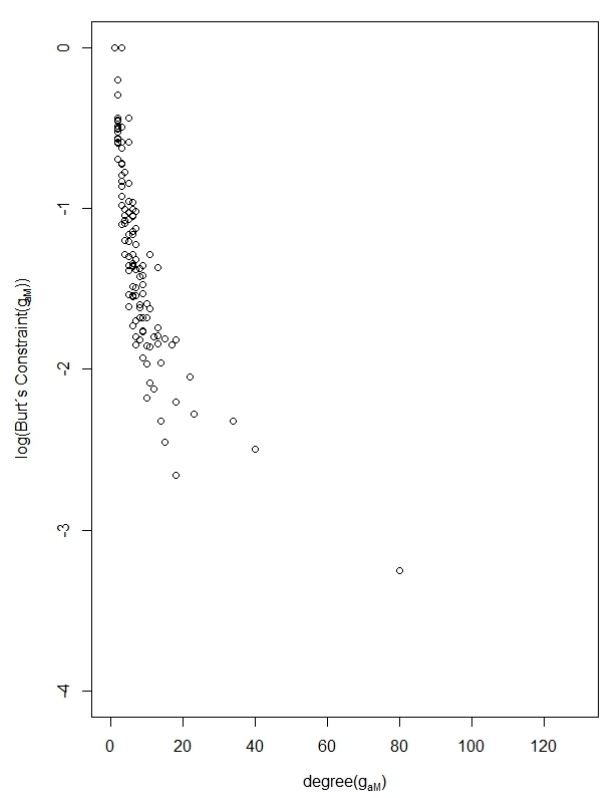

(c) Burt's Constraint $($ mean $=68.7)$ vs. degree in $g_{a M}$

Figure 3.9: Burt's Constrain and Vertex degree

[Axis $x$ depicts the degree of an actor $i$, axis $y$ shows the logarithmic transformation of the Burt's constraint for actor $i$ ]. 
In this work some aspects were not explored, however, we have opened the door for subsequent analyses. For instance, multiplexity was not explored by analyzing the overlapping of ties in the friendship network $g_{f}$ and in the advice $g_{a}$ network (friendship data was also gathered in the field research). Multiplexity can indicate that individuals seek advice from those who also are their friends. Kinship analysis also deserves special attention in future analyzes of groups in rural areas and of indigenous people. This is important since family ties are especially important for indigenous people. Another special analysis that can be made based on our results is one on power structures and the exchange network of $g_{a}$. For further analysis, geographical location may help to underscore important roles of the periphery in the advice network. This may be important since in the periphery there are many communities. Thus, including the geographical distance may help to comprehend network patterns of advice searching between ethnic groups.

\subsection{Conclusions}

We observe different groups in $g_{a}$ with different ethnic backgrounds that have different patterns for searching for advice. The global arrangement of the network patterns to access advice shows that the Saraguro ethnic group searches more homogeneously. Advice search within the Saraguro group tends to be more homogeneous, since this ethnic group is more cohesive and is less hierarchical internally than Mestizo-colonos. We observe more Mestizo-colonos with higher degree centrality; we accept $H_{1}$.

Who you ask for advice does matter. In the case of Mestizo-colonos who have a broader contact with actors outside the research area, access to advice is higher and is expected to be more diverse than for Saraguros, for this reason we reject $H_{4}$. Saraguros, whose patterns in searching for advice are less centralized in few individuals tend to have less contacts outside the research area. Thus, the probability of their sharing the same kind of information is higher than for Mestizo-colonos. This was explained by the in-outdegree correlation. Saraguros are more homophilous, as they search for more advice within they own ethnic group. Their sources of advice are more limited. This results in less diverse sources of advice for the improvement of their agricultural practices and for innovation in their livelihoods. This may be reflected in their low income. The advice search structure is more homogeneous for Saraguros and more 
hierarchical for Mestizo-colonos.

There is a great effort by the individual who invests in searching for information outside the community and outside the ethnic group. Face-to-face contact in this rural area is still an important factor in the search for advice in the network. However, we did not include the physical distance in the analysis, Only the inside-outside differentiation between actors in the sample settlements and outside of these settlements mirrors physical distance to some degree.

There are cultural differences in the patterns used in the search for advice. Structurally, cohesiveness reduces power concentration, and it facilitates access to advice across structural holes, as long as it is not concentrated in a group or few actors. Saraguros as a group tend to be more cohesive, since they have many actors within many cohesive blocks with high ranks. Moreover, the position of the actors' group in the network and the actors' own position do affect his access to agricultural information. In $g_{a}$ the hierarchy is stronger than the mitigation effect of cohesive groups. The search for advice on agricultural activities takes place vertically.

The advice network, $g_{a}$, spanned fewer structural holes where the information can be conveyed than if the advice network were not so centralized in few actors. The connectivity of $g_{a}$ is very low and vulnerable to rupture by the removal of few individuals that are tied to the highest cohesive group. Conclusively, few Mestizo-colono actors may take special advantage by accessing information across structural holes, as we demonstrated. Conversely, Saraguros have less access to advice across these structural holes, and for this reason we reject $H_{5}$.

Saraguros may mitigate the status of power structures with more cohesive structures than Mestizo-colonos', as we accept $\mathrm{H}_{3}$. Less central Mestizo-colonos mitigate the hierarchical structure of access advice by accessing the periphery-outside for advice, therefore we reject $H_{4}$. Mestizo-colonos are better positioned in political and economical status than Saraguros. Thus, high degree actors and higher income may be related to more access to agricultural information. This is represented by accessing more advice across structural holes.

The information necessary to encourage local farmers to adopt agricultural innovations and to improve their household income seems not to be easily accessed through searches for advice in the network studied. Central actors are at most sought for advice, especially with Mestizo-colonos. A less centralized network and more homogeneous 
access to advice may give more advantages to local communities. Communities and actors that have more access to information may be in a better position to adapt and recover from fluctuations in local prices and to adopt more sustainable agricultural practices. In the end, this means an improvement in household conditions and in the farmers' adaptive capacity to external changes. 


\section{References}

[1] Abbott A. (2005). Counting Beans: Agrobiodiversity, indigeneity and agrarian reform. The Professional Geographer 57(2): pp:98-212. 2, 44, 45, 58, 59, 60, $129,130,131$

[2] Acemoglu D., Dahleh M., Lobel I. and Ozdaglar A. (2008). Bayesian learning in social networks. National Bureau of Economic Research, Working Paper 14040. Cambridge. 18, 90

[3] Agneessens F. and Skvoretz J. (2012). Group differences in reciprocity, multiplexity and exchange: Measures and application. Quality and Quantity 46: pp: 1523-1545. 49, 88, 93, 146

[4] Agneessens F. and Wittek R. (2012). Where do intra-organizational advice relations come from? The role of the informal status and social capital in social exchange. Social Networks 34: pp: 333-345. 47, 48, 74, 88, 89, 91, 128, 137, 145, 151,171

[5] Batagelj V. (1997). Notes on blockmodeling. Social Networks 19: pp. 143-155. 52

[6] Beck E., Kottke I, Bendix F. Makeschin F. and Mosandl R. (2008). Gradients in a Tropical Mountain Ecosystem of Ecuador: Vol. 198. Ecological studies. Berlin Heidelberg. Germany: Springer-Verlag. 1, 2, 17, 22, 23, 58, 60, 61, 114, 129, 130, $131,132,133,134,136,174$

[7] Besley T. and Case A. (1993). Modeling technology adoption in developing countries. The American Economic Review 83 (2): pp:396-402. 18, 90, 151

[8] Blau P.M. (1964). Exchange and Power in Social Life. John Wiley, New York. 48 
[9] Bodin Ö. and Prell C. (2011). Social Networks and natural resource management. Cambridge University Press. Cambridge. UK. 46, 114

[10] Borgatti S. and Everett M. (1999). Models of core/periphery structure. Social Networks 21: pp. 375-395. 52, 72

[11] Borgatti S. and Everett M. (2006). A graph-theoretic perspective on centrality. Social Networks 28: pp. 466-484. 69

[12] Borhek J.T. (1970). Ethnic-group cohesion. American Journal of Sociology 76(1): pp. 33-46. 49, 69, 87

[13] Brandes U. and Erlebach T. (2005). Network Analysis: Fundamental Foundations. Springer-Verlag Berlin Heidelberg. Germany. 19, 20, 47, 49, 50, 145, 146, 147,151

[14] Burt R. (1978). Cohesion versus structural equivalence as a basis for network subgroups. Sociological Methods and Research 7(2): pp: 189-212. 50, 69

[15] Burt R. (2002). Bridge Decay. Social Networks 24: pp: 333-363.

[16] Burt R. (2004). Structural Holes and Good ideas. American Journal of Sociology 110(2): pp: 349-399. 53, 54, 57, 74, 75, 93, 96, 97, 116

[17] Burt R. (2005). Brockerage and Closure: An introduction to social capital. Oxford University Press. Oxford. UK. 53, 87, 88, 95

[18] Butts C. (2012). Package 'sna'. www.statnet.org. 72, 80, 155

[19] Byg A. and Salick J. (2007). Indigenous Peoples and Climate Change. Centre Publication Tyndall Centre for Climate Change Research, Oxford, United Kingdom. 43, 113

[20] Carrington P., Scott J. and Wasserman S. (2005). Models and Methods in Social Network Analysis. Cambridge University Press. New York. USA. 19, 32, 33, 34, $52,53,62,120,141$

[21] Chartrand G. (1985). Introductory graph theory. Dover Publications Inc. New York. USA. 46, 50, 51 
[22] Collins J. (1983). Fertility determinants in a High Andes community. Population and Development Review 9(1): pp: 61-75. 70

[23] Conley T. and Udry C. (2001). Social learning through networks: The adoption of new agricultural technologies in Ghana. American Journal of Agricultural Economics 83(3): pp:668-673. 18, 90, 151, 171

[24] De la Torre L. Muriel P. and Balslev H. (2006). Etnobotánica en los Andes del Ecuador. In Edit. Moraes M, Øllgaard B, Kvist L, Borchsenius F and Balslev H. Universidad Mayor de San Andrés, Botánica Económica de los Andes Centrales: pp:246-267. La Paz, Bolivia. 60, 131

[25] Emerson R. (1976). Social Exchange Theory. Annual review of Sociology 2: pp. 335-362. 47,48

[26] Everett M. and Borgatti S. (1998). Analyzing clique overlap. Connections 21(1): pp. 49-61. 50

[27] Everett M. and Borgatti S. (1999). Peripheries of cohesive subsets. Social Networks 21: pp. 397-407. 52, 72, 176

[28] Frank K. (1996). Mapping interactions within and between cohesive subgroups. Social Networks 18: pp. 93-119. 67, 69

[29] Frank O. (1980). Samplin and Inference in a Population Graph. International Statistical Review: 48(1): pp:33-41. 67

[30] Ferligoj A., Doreian P. and Batagelj V. (2011). Positions and Roles. Pp: 425446 in The SAGE Handbook of Social Network Analysis. edt. J. Scott and P.J. Carrington. SAGE publications Ltd. London. UK. 52, 53

[31] Freeman L. (1977). A set of measures of centrality based on betweenness. Sociometry 40(1): pp. 35-41. 20, 47, 146

[32] Friedkin N. (1984). Structural Cohesion and equivalence explanations of social homogeneity. Sociological Methods and Research 12(3): pp: 235-261. 69, 95 
[33] Friedkin N. (2004). Social Cohesion. Annual Review of Sociology 30: pp: 409425. $49,88,95,96$

[34] Csardi G. (2012). Package 'igraph'. http://igraph.sourceforge.net/. 54, 72, 155

[35] Goodreau S. (2007). Advances in exponential random graph $\left(p^{*}\right)$ models applied to a large social network. Social Networks 29: pp: 231-248. 65, 125, 128, 142, $148,150,151,155,156,162$

[36] Gonzalez V., Barkmann J. and Marggraf R. (2010). Social network effects on the adoption of agroforestry species: Preliminary results of a study on differences on adoption patterns in Southern Ecuador. Procedia-Social and Behavioral Sciences 4: pp: 71-82. 43, 45, 56, 60, 61, 113, 132, 134, 136, 138, 141, 176

[37] Goyal S. (2007). Connections: An introduction to the economics of networks. First Edition. Princeton University Press. New Jersey. 90, 95

[38] Granovetter M. (1973). The Strength of Weak Ties. The American Journal of Sociology 78(6): pp: 1360-1380. 18, 49, 53, 88, 116

[39] Granovetter M. (1983). The Strength of Weak Ties: A Network Theory Revisited. Sociological Theory 1: pp: 201-233. 18, 53, 88

[40] Granovetter M. (1992). Problems of explanation in economic sociology. Pp: $25-$ 56 in Networks and organizations: Structure, form, and action. Edt. N. Nohria and R.G. Eccles. Boston, MA: Harvard Business School Press. USA. 51

[41] Handcock M., Hunter D., Butts C., Goodreau S. and Morris M. (2003). statnet: Software tools for the Statistical Modeling of Network Data. www.statnet.org. 72, $149,153,155$

[42] Jackson M. and Wolinsky A. (1996). A strategic model of social and economic networks. Journal of economic theory 71: pp:44-74. 95

[43] Jackson M. (2008). Social and Economic Networks. First Edition. Princeton University Press. New Jersey. 18, 90, 95 
[44] Krackhardt D. (1994). Graph Theoretical Dimensions of Informal Organizations. In Carley K. and Prietula M. Eds. Computational Organization Theory: pp: 89111. Lawrence Erlbaum and Associates. Hillsdale, N.J. 80, 177

[45] Lazega E., Mounier L., Snijders T. and Tubado P. (2012). Norms, status and the dynamics of advice networks: A case study. Social Networks 34: pp: 323-332. 48, $49,56,57,71,88,89,94,121,129$

[46] Levin G. and Reenberg A. (2002). Land use driven conditions for habitat structure: A case study from the Ecuadorian Andes. Geografisk Tidsskrift, Danish Journal of Geography 102: pp:79-92. 16

[47] Lorrain F. and White H. (1971). Structural equivalence of individuals in social networks. Journal of Mathematical Sociology 1: pp:49-80. 53

[48] Marney I., Erickson B., Quashie-Sam J. and Timmer V. (2007). Transfer of knowledge on Agroforestry management practices: the structure of farmer advice networks. Ecology and Society 12(2): pp. 32.46

[49] Marsden P. (1983) Restricted access in networks and models of power. American Journal of Sociology 88(4): pp:686-717. 47, 94

[50] Maza, B., Barkmann, J., von Walter, F., and Marggraf, R. (2010). Modelling smallholders production and agricultural income in the area of the Biosphere reserve "Podocarpus-El Condor", Ecuador. Georg-August-Universität Göttingen: Department of Agricultural Economics and Rural Development, Working Paper, 1004. $2,21,22,23,43,45,58,59,60,89,114,129,130,131,134,168$

[51] McPherson M., Smith-Lovin L. and Cook J. (2001). Birds of a Feather: Homophily in Social Networks. Annual Review of Sociology 27: pp: 415-444. 4, 45, $57,71,87,115$

[52] Moody J. and White D. (2003). Structural cohesion and embeddedness: A hierarchical concept of social groups. American Sociological Review 68: pp. 103-127. $51,52,71,93,95,96$

[53] Ogburn D.E. (2007). Incas Past and Present. Stanford Journal of Archaeology 5: pp: 134-163. 2, 44, 61, 87, 89, 93, 132, 175 
[54] Pattison P. (1993). Algebraic Models for Social Networks. In series: Structural analysis in the social sciences. Edt. Granovetter M. Cambridge University Press. New York. USA. 50

[55] Phillips C. (2007). Ethnicity, identity and community cohesion in prison. Pp: 75-86. In Identity, Ethnic Diversity and Community Cohesion. Edt. Wetherell M., Lafleche M. and Berkeley R. SAGE Publications Ltd. London. UK. 69

[56] Pohle, P. and Gerique, A. (2006). Traditional ecological knowledge and biodiversity management in the Andes of southern Ecuador. Geographica Helvetica, 61(4), 275-285. 2, 16, 22, 43, 45, 58, 60, 89, 93, 113, 129, 131, 132, 174

[57] Prell C. (2012). Social Network Analysis: History, theory and methodology. SAGE Publications Ltd. London. UK. 50

[58] R Development Core Team (2008). R: A language and environment for statistical computing. R Foundation for Statistical Computing, Vienna, Austria. ISBN 3-900051-07-0, URL http://www.R-project.org. 72, 149, 155

[59] Rogers E. (2003). Diffusion of innovations. Free Press (5th ed.). New York. USA. $5,42,49,69,88,90,96,115,116,133,169,171,174,176$

[60] Schweizer T., Schnegg M. and Berzborn S. (1998). Personal networks and social support in a multiethnic community of southern California. Social Networks 20: pp. $1-21.70$

[61] Simmel G. (1908). The Stranger. In On Individuality and social Forms. Edt. Levine D. 1971. In Series The Heritage of Sociology. Edt. Janowitz M. The University of Chicago Press. Chicago. USA. 44

[62] Seidman S. (1983). Network Structure and Minimum Degree. Social Networks 5: pp. 269-287. $52,71,94$

[63] Skvoretz J. and Agneessens F. (2007). Reciprocity, Multiplexity, and Exchange: Measures. Quality and Quantity 41: pp. 341-357. 
[64] Skoufias E., Lunde T. and Patrinos H.A. (2009). Social Networks among indigenous peoples in Mexico. Policy Research Working Paper: 4949. The World Bank. 45,70

[65] Smith-Lovin L. (2003). Self, Identity and Interaction in an Ecology of Identities. Advances in Identity Theory and Research: 167-178. 49, 87

[66] Stoneman P. (1981). Intra-firm diffusion, Bayesian learning and profitability. The Economic Journal 91(362): pp:375-388. 18, 90, 151, 171

[67] Thye S. and Skvoretz J. (2003). Power and Status. Advances in Group Processes Vol. 20. Series Ed. Lawler and Thye S. Elsevier Ltd. Oxford. UK. 4, 47, 48, 88

[68] Udry C and Conley T. (2004). Learning About a New Technology: Pineapple in Ghana. Economic Growth Center. Yale University. Working Paper 888. 90, 151, 171

[69] Universidad Nacional de Loja (2006). Estado de Conservacion del area de Bosque y Vegetacion Protectora "Corazon de Oro". In Informe Tecnico: Estado de Conservacion de areas Protegidas y Bosques Protectores de Loja y Zamora Chinchipe y Perspectivas de Intervencion. Centro Integrado de Geometría Ambiental (CINFA), Herbario Reinaldo Espinosa Loja and Carrera de Ingenieria Forestal. Loja. Ecuador. 1, 8, 58, 62, 114, 129, 138

[70] Valente T. and Davis R. (1999). Accelerating the diffusion of innovations using opinion leaders. ANNALS, AAPSS, 56: pp: 55-67. 19, 26, 69, 176

[71] Van Cott D.L. (2007). Latin America's Indigenous Peoples. Journal of Democracy 18(4): pp:128-141. 44, 61, 131, 132, 133

[72] Walker H., Thye S., Simpsom B., Lovaglia M., Willer D. and Markovsky B. (2000). Network Exchange Therory: Recent developments and new directions. Social Psychology Quarterly 63(4): pp. 324-337 48, 88

[73] White D. and Harary F. (2001). The cohesiveness of blocks in social networks: Node connectivity and conditional density. Sociological Review 31(1): pp. 305359. $49,50,51,95,96$ 
[74] Yashar D. (1998). Contesting Citizenship: Indigenous movements and Democracy in Latin America. Comparative Politics 31(1): pp. 23-42. 44

[75] Yamaguishi T. and Cook K. (1990). Power relations in exchange networks: A comment on "Network exchange Theory". American Sociological Review 55(2): pp. 297-300. 47 


\title{
Chapter 4
}

\section{Social Network Effects on the Search for Information on Agroforestry Tree Species in Rural, Multi-Ethnic Communities in Southern Ecuador}

\author{
Vladimir Gonzalez Gamboa, Jan Barkmann and Rainer Marggraf
}

\begin{abstract}
Agroforestry can reduce soil degradation, increase local biodiversity and at the same time increase household income. The use of agroforestry tree species can be seen as a new practice that spreads throughout a region by means of social networks. Sharing information about this potentially more sustainable agricultural innovation has become increasingly important in a region like southern Ecuador. In this region there are mainly two ethnic groups the Saraguro and the Mestizo-colonos. Previous research by Gonzalez et al. (2010) showed that there may be differences in how the information related to agroforestry species is shared between and within the two ethnic groups. After applying an exponential random graph model (ERGM), we show that indeed there are differences between two ethnic groups in the way they search for information. We explore the network patterns in the search for information on agroforestry species. Searching for information with similar others is limited to the less commercial tree
\end{abstract}


species. The most commercial tree species' information concentrates around one actor, who is Mestizo-colono. Transitive network effects are identified within ethnic groups as long as actors search for information on different tree species. The two ethnic groups search for information on different tree species. This indicate that the two groups have a different type of knowledge, where Mestizo-colonos' knowledge is more related to commercial species.

Keywords: South Ecuador Ethnic Groups, Social Network Analysis, Exponential Random Graph Models, Network-Information

\subsection{Introduction and General Motivation}

The cultural diversity of southern Ecuador represents a challenge when trying to evaluate and determine the social structural patterns of the search for information. Little is known about the differences between ethnic groups and about possible similarities in the ways in which they seek information about agricultural innovation. In terms of smallholder agriculture, two ethnic groups shape much of the agricultural landscapes of southern Ecuador, and influence land use change at the forest-agriculture frontier. These groups are the indigenous Saraguro and the Mestizo-colonos. Pasture-based cattle and diary production dominate agriculture in both groups. The inclusion of trees in agricultural management ("agroforestry") may contribute to a diversification of income, to the conservation of natural resources, and to the local adaptation to climate change (Byg and Salik, 2007; Dawson et al., 2013; FAO, 2005)[14][19][23]. An indigenous group, the Saraguro, use more diverse cropping systems than do the local Mestizo-colonos (Gerique and Pohle, 2006)[49]. However, it has been shown, that indigenous groups may have less access to the information necessary for the adoption of agricultural innovation (Gonzalez et al., 2010)[27].

In an article about adoption patterns of agroforestry species in southern Ecuador, Gonzalez et al. (2010)[27] found preliminary evidence suggesting that the diffusion of information also differs between Saraguro and Mestizo-colonos. The first study relies on the small sample size of a quantitative pilot study, however. Using a much more comprehensive sample and more advanced social network modeling techniques, we want to test conclusively whether these differences in the search for information exist, 
and, if so, to characterize the search for information in and between both ethnic groups.

The adoption of potentially useful tree species in pasture-dominated landscapes of the region can be seen as an agricultural innovation, enriching the set of sustainable land use options. Through a better understanding of how information in agricultural innovations is shared within and spreads through multi-ethnic social networks, we hope to facilitate future agricultural diffusion processes. Ultimately, regional and local extension practitioners and policy makers could incorporate ours results into their activities in order to facilitate diffusion of information about agriculture, or about health related and socio-economic topics.

The project area is located in the proximity of Podocarpus National Park, and within the buffer zone of the recently established "Podocarpus-El Condor" UNESCO Biosphere Reserve (Universidad Nacional de Loja, 2006)[64]. The alleviation of wide - spread poverty (Maza, 2010)[43], a reduction of continuing forest loss (Mosandl et. al., chapter 4 in Beck et al., 2008)[8], and the rehabilitation of degraded pasture landscapes (Knoke et al., 2009)[39] are highly important aims to ensure the long-term protection of the regions exceptional biological diversity and its associated ecological benefits. The introduction of agroforestry trees onto pastures can combine several of these aims, as it has the potential to increases biodiversity and farming household income.

There are few social network studies related to multi-ethnic social netwoks conducted in rural areas in developing countries. Some studies can be found in Bodin and Prell (2011)[10]. Therefore, we want to fill this gap by explaining how social structure can influence the access to and the diffusion of information in small communities that surround a national park. This paper wants to underscore the differences in the search for information based on ethnic differences. We also estimate whether social structural patterns may limit or facilitate the search for information and the diffusion of information on agroforestry tree species. We also want to contribute to reduce the gap in information on how to improve the farmer to farmer diffusion of agroforestry species as described by FAO (2005)[23]. 


\subsection{Theoretical Background: Modeling Social Networks}

In order to understand how social structure can affect the search for information on agroforestry tree species and to determine whether individuals from one ethnic group are in a more advantageous position (in the network) to search for information we explain some theoretical concepts for modeling social relations by applying the social network analysis. To refer to actors we use also us the term vertices, which is the formal name used in graph theory for a node. Node is a term used more often for actors or individuals in social network theory. We also use these two concepts interchangeable with actors (individuals). Within the formal description of a graph we use vertices. If we are describing the network we use node, and for general context and analysis we use the term actor (individual). The same applies to the term edges used within graph theory, and the term ties used within social network theory. For general explanations we may also use links or contacts.

\subsubsection{Social Network Structure: First Insights}

A social tie (dyadic relation) between two individuals can be formed when two individuals meet within a specific social context. The social context determines the reason they form a tie, e.g., to ask for information about an observable innovation, a job, etc. The probability that these individuals form a tie is higher if they belong to the same ethnic group, live in the same region, belong to the same family, etc. The fact that a relation between similar individuals takes place at a higher rate than between dissimilar individuals is known as homophily (McPherson et al., 2001)[44]. According to McPherson et al. (2001)[44] ethnicity/race creates the strongest division in the social environment. This means that the probability that ethnically dissimilar individuals form a tie will be lower than if they share an ethnicity. Rogers(2003)[58], underscores the advantages of social relations between similar individuals in the diffusion of innovations. The diffusion of information is key in explaining diffusion of innovations. Thus, if two individuals share ethnicity, common ideas and beliefs, communication between them is more likely to be effective (Rogers, 2003)[58]. For example, this could mean that people may follow someone who is similar to them in adopting an innovation like planting a particular agroforestry tree species. 
Homophily may accelerate the diffusion of information between those individuals connected within a close-knit structure (Rogers, 2003)[58]. Individuals with similar characteristics or who share some beliefs tend to form close strongly connected cliqueknit structures where most or all members know each other. Inside these structures there is a high probability that members share the same kind of information (Granovetter, 1973)[31]. There are some individuals that tend to have many ties in many clique structures, and therefore may have access to different information shared within each structure. Burt(2004)[16] calls this process network brokerage. These individuals have an important role in the whole network in that they connect close-knit structures and therefore ensure the diffusion of information throughout the network. Some of these bridging individuals tend to be opinion leaders who are sought for advice because they are seen as technically competent, have higher status, are economically successful, etc. Because of this, heterophilous contacts (those with a tendency to form ties with dissimilar individuals) may improve the diffusion of innovations (Rogers, 2003) [58].

These opinion leaders usually tend to receive many nominations (they are receivers), that is, are sought by many individuals (who are senders) in the network during the search for information. These relations usually are asymmetric. An asymmetric relation is created if one individual searches for a person, forming a tie, but this tie is not reciprocated (not returned). In network terms, individual $i$ searches for individual $j$, but individual $j$ did not search for individual $i$. The most sought individuals connect many clique structures, and become central in the network. This degree centrality is measured by the sum of the ties of each individual within a network. Networks with highly central individuals tend to have a skewed degree distribution, i.e., a few individuals have many ties and most of individuals have few. Therefore, being between many clique structures may give many advantages to the highly central individuals, since they can access heterogeneous information sources.

Being central in a network brings with it the concept of dependence in a social relation. For instance, let us assume that there are three individuals $i, j, s$, and that there are two cliques (groups) formed $A, B$. If individual $i$ is in group $A$ and individual $s$ is in $B$ and $j$ knows both $i$ and $s$, but $i$ and $s$ do not know each other, than $i$ may depend on $j$ to access the information in $B$ that is shared by $s$. There is a probability that $i$ and $s$ may form a tie. It could be more probable that they form a tie given that both know individual $j$ than just by chance (randomly). If we assume that $j$ is an opinion 
leader, the diffusion of the information may depend on individual $j$ to some degree. The concept of dependence in social networks is explained in more detail below.

\subsubsection{Social Networks: Dependence in a Relation}

As mentioned above, the network is created by many structures that are linked (tied) together by bridging ties. These structures show how actors form a bigger structure. The network patterns organize and give a specific structure to the network. These patterns are known as network configurations. A network configuration can also be defined as a small subgraph that may represent a local regularity (see next paragraph) in the social network structure, e.g., a dyad relation, reciprocity (reciprocated ties or mutual ties), or a triangle (three connected nodes). The network process of creating network patterns should not be understood only as a dynamic process restricted to longitudinal analysis. The structural processes of tie formation produce network patterns that come into evidence in cross-sectional data (Lusher and Robins, chapter 3 in Lusher et al, 2013)[42]. If we analyze cross sectional data we can interpret social mechanisms that have as result a specific network structure, e.g., by modeling the network structure.

To understand the concept of network dependence we should start clarifying that social relations are local. The network configurations are seen as local because their origin is a dyadic relation, a pair of individuals that form a tie (but are not seen separately) (Lusher and Robins, in chapter 3 in Lusher et al, 2013)[42]. The tie is formed within a specific social environment or context, and the dyadic relation is the starting point to relate this tie to other relations with other individuals in the network. The presence of other ties in the network may influence the presence of a new tie. Therefore, by studying the dependence among ties we can analyze possible patterns/tendencies of tie formation. For example, we can study local tie formation if we know that there are two ethnic groups. Thus, we may suppose that given that individuals $i, j$ belong to ethnic group $\hat{A}$, they may have a higher probability of searching for information from each other about their agroforestry tree species, than from a third individual $s$ that is dissimilar because belongs to the ethnic group $\hat{B}$. These kind of theoretical assumptions help us to infer from the data that there can be tendencies to form ties. These network patterns (explained more in detail in Section 4.2.3) may results in a higher probability to the formation of a new tie than a random network, where every tie with 
any individual (node) has the same probability of being formed.

Another important concept to understand network relations is the fact that ties can organize themselves into patterns. These give some order to tie formation; the presence of some ties influences the formation of other ties. This is known as network self-organization property. Exogenous network effects, such as homophily effects, can influence tie formation. These are closely related to the intrinsic attributes of the individuals, e.g., being part of an ethnic group. Therefore, the attributes of individuals may affect their interaction in the network. Endogeneous effects are those in which the network patterns arise as a result of the internal process of the arrangement of network ties (Lusher and Robins, in chapter 3 in Lusher et al, 2013)[42]. For instance, if one tie is formed, a kind of network relation could be created in which two actors, $i, j$, search for advice from actor $s$. This tells us that one actor $(s)$ is searched more than the other two actors, if we only consider the network relations of these three actors. These networks relations can be also called network patterns.

The formation of a tie also depends on the existence of other ties. This happens even if we are not aware of those other ties in the network. For instance, if there is an individual $i$ that is popular (high degree centrality), the probability of this person going on to meet more people in the future than those who are not popular is higher. This person therefore becomes even more popular, in other words, the network becomes more centralized, where one actor has many ties and most others have few. The process of becoming more popular is known as preferential attachment (Barabási and Albert, 1999)[7].

The tie is the basis of the study of social relations and the main variable used in the statistical modeling of social networks. The dependence between actors deviates from the standard statistical approaches that call for independence of units of observation (Lusher and Robins, in chapter 3 in Lusher et al., 2013)[42]. An independent dyadic relation is one where the probability of tie formation does not depend on the value or existence of another tie (Goodreau et al., 2009)[30]. For example, the notion of independence tells us that if we just recently met a person $i$ and the next day we met person $s$, these tie formation (realization of tie variables ${ }^{1}$ ) are considered to be independent. The realization of one tie does not help to predict the realization of the other

\footnotetext{
${ }^{1}$ A tie variable refers to the fact that two individuals, let say $i$ and $j$, have formed a tie. This is represented as $y_{i j}$.
} 
tie. However, for social relations this is not always the case, i.e., it may not always be consistent with reality. It is not the same as flipping coins, where the realizations are seen as independent from each other (Koskinen and Galina, in chapter 6 in Lusher et al., 2013)[42]. For example, let us consider a case where individual $i$ already knew individuals $s$ and $j$, and, we assume that the formation of any tie is independent of the existence of other existing ties. The probability of $y_{j s}$ is independent of the ties $y_{i j}$ and $y_{i s}$. But if we assume dependence between actors, the probability will be based on the existing condition that $s$ and $j$ already share a tie with actor $i$. Following Koskinen and Galina (in chapter 6 in Lusher et al, 2013)[42] there are four forms of dependence among tie variables:

1. Bernoulli assumption: Similar to the coinflip, the tie variables (tie realizations) are independent and identically distributed (i.i.d.) Bernoulli variables (presence or existence of a tie). The probability of a graph is proportional to the weighted sum of number of edges (ties).

2. Dyad-independent assumption: This includes a form of dyad dependence. If there is a directed network, the probability that individual $j$ would searche individual $i$ for information depends on $i$ searching $j$. This is limited only to a dyad relation.

3. Markov dependence assumption: This dependence assumption refers to the endogenous process of tie formation taking into account the presence of other ties between the actors. For instance, if there is a tie from $i \rightarrow j$ and a tie from $j \rightarrow s$, then the probability that $i$ will form a tie with $s$ depends on the existence of a tie $\{j s\}$. This was vastly explored in the Markov models of Frank and Strauss (1986)[24]. Under the Markov dependence assumption two ties in the network are regarded as independent unless they share a node (Koskinen and Daragonova in Lusher et al., 2013)[42]. In this case the (log-) probability of obtaining a graph, in which actors' ties have a specific number and arrangement is proportional to the weighted sum of the counts of different structural configurations, e.g., edges (dyad relation) or triangles (edges between a triad or involving three actors). This assumption is limited to three actors' configurations. This could be seen as limited, because it does not capture the influence of network ties outside the triad. 
4. Realization-dependent models: Suggested by Pattison and Robins (2002)[48], these models assume that two tie variables, $y_{i j}$ (tie between persons $i, j$ ) and $y_{s k}$ (tie between persons $s, k$ ) may be conditionally dependent given the presence of other tie variables in the network. This dependence would exist even thought the actors forming the tie variables do not share a node (known other person in the other tie variable). This assumption is known as partial conditional independence assumption. This assumption includes the Markov dependence assumption but expands to additional network configurations (explained in Section 4.2.3).

Social network models that include Markov configurations are difficult to test statistically (as explained in next subsection). Recently, there has been a development in statistical inference techniques applied to network analysis that are more capable of dealing with dependent network structures (Hunter and Handcock, 2006; Snijders et al., 2010)[35][61]. These are explored in the next subsection.

\subsubsection{Preface for modeling social structure}

The dyadic relation between two network actors (individuals, persons, nodes, nominations) is the basis for understanding how people group together to form dense structures, like clusters and cliques. A way to identify network patterns is by counting the number of different configurations in a network. This can be statistically estimated, as we will explain in Section 4.2.4. Some fundamental network configurations in directed networks between two (dyad) or three nodes (triad) are displayed in Figure 4.1. In network configurations for a directed network, arcs represent the ties, and arrows show their directionality. The actor sending a tie is a sender and the one receiving a tie is a receiver. In all depicted cases, the network consists of the actors $i, j, s$. The case of dyad mutuality may represent a restricted exchange of information between actors $i$ and $j$. The exchange of information is restricted, as there are only two actors involved (Koehly and Pattison in Carrington et al., 2005)[15].

Three actors connected by three edges can form a three - cycle or a transitive triad (equivalent to transitivity). The three-cycle represents a generalized exchange in substructures larger than a dyad (Koehly and Pattison in Carrington et al., 2005)[15]. This exchange may result in more inclusive information sharing compared to the restricted 
exchange, since the information may flow in a cyclical manner. The configuration transitivity represents a situation in which two actors $i$ and $s$ are linked to a third actor, $j$, while a directed link also exists between $i$ and $s$. The transitive triads show a tendency toward a more hierarchical network structure, because there is a tie $s$ receiving two nominations (arcs or directed ties). As Lazega et al. (2012)[41] stress, in advice networks transitive triads have an important role and, together with a lower presence of three-cycles, could be regarded a local advice hierarchy (few actors are the most searched as source of advice). The last configuration in Figure 4.1 is a out -star. Sending ties in a directed network is known as outdegree centrality. In the out - star the actor $s$ is sending two ties, for this reason this is also called a $2 o u t-s t a r$. If there were three ties it would be a $3 o u t-s t a r$, and so on. For example, in this configuration actor $s$ seeks information by asking actors $i$ and $j$ where to obtain seeds of a tree species.
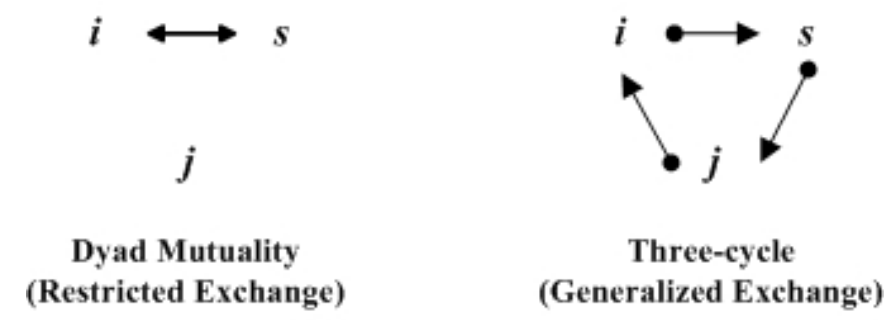

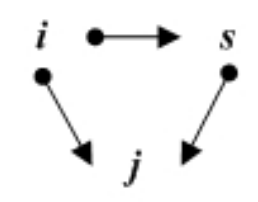

Transitivity

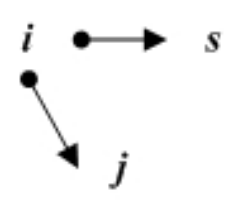

Out-star

Figure 4.1: Some basic network configurations

The transitivity concept has a key role in the comprehension of the dynamics of network patterns. Transitivity is usually found in highly dense regions of the network, i.e., in regions where there are many ties between many actors. Thus, the presence of transitivity may show that within these areas some individuals receive more nominations (incoming ties) and are part of many transitive ties. As we explained before, an actor in a transitive triad can count two incoming ties. These incoming ties are known 
as indegree centrality in directed networks. For example, an actor who is a part of two transitive triads can be sought by four other actors. Suppose that in Figure 4.1 actor $j$ is also part of another transitive triad. This actor would then have four nominations. In light of the data and social theory, one may want to discover the reason why actor $j$ is being sought and at the same time actor $i$ seeks $j$ and $s$. For instance, actor $i$ asks for information on agroforestry tree species from actors $s, j$ and actor $j$ is asked by actors $i, s$. This may (depending on the context and on the attributes of actor $j$ ) be a result of a situation in which actor $j$ has more specialized knowledge on tree species. Meanwhile, actor $i$ wants to start planting new tree species on his farm.

In a transitive triad we can find other nested configurations. For example, in the transitive triad we find a $2 i n-s t a r$ or, equivalently, a two indegree, the actor $j$. There is also the 2out-star in actor $i$. Another configuration found in a transitive triad is shown in Figure 4.2. This is called a twopath, $j \rightarrow i \rightarrow s$. This configuration is important to determine whether there is a correlation between the indegree and outdegree of an actor (Robins et al., 2009)[57]. For instance, if we also find that $j \leftarrow i \leftarrow s$, then the actors whom I ask for information ask me for information back. There is a likelihood that the kind of information among these three actors tends to be the same. This configuration is also important because if there are many twopaths (Figure 4.2) seen in the network the probability that a new tie will form a transitive triad is higher than if there are few twopaths in the network. If there are nested configurations one should take special care in modeling the network. Some or most of the configurations nested should be included in the model. This will ease the interpretation of the results by separating the effects of the nested configurations (Koskinen and Daragova en chapter 7 in Lusher et al, 2013)[42].

Higher order configurations take place between more than three actors. For instance, Snijders et al. (2006)[60] propose new statistics that account for triad closure (transitive triads for more than three nodes), which was re-parameterized by Hunter and Handcock (2006)[35]. The new parameter is known as geometrically weighted edgewise shared partner distribution (GWESP). As shown in Figure 4.2, the probability that $j_{2}$ will form a tie with $j_{1}$ will be conditional on the shared partners they have, in this case actors $i$ and $s$. This number of shared partners is estimated by the configuration GWESP.

This way, GWESP is a parametric form of the distribution of shared edge (tie) 
counts. It counts the number of shared partners in transitive triads. The difference between this and a normal transitive triad is that the partners (ties) counted can be more than three actors, until the number reaches $k$ shared partners, as shown in Figure 4.2. Essentially, each additional shared partner contributes to the decline of a positive influence on the likelihood that two individuals form a tie (Goodreau et al., 2009; Hunter, 2007)[30][36]. Intuitively, this measure of transitivity shows that, as the number of ties that actor $i$ increases, the likelihood that actor $j_{1}$ will form a tie with all of them decreases, given that there is a tie $y_{i, j_{1}}$. This captures, in essence, the notion that the more neighbors one's partner has, the lesser is the likelihood that one will form a tie with all of them.

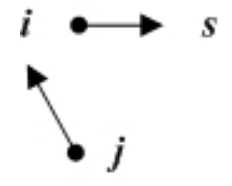

Twopath

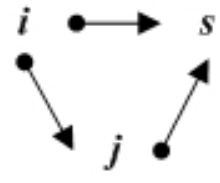

Transitivity

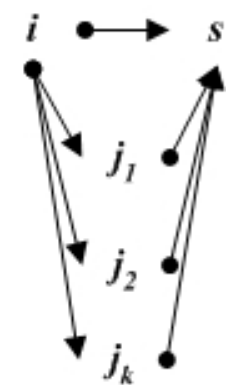

GWESP

Figure 4.2: Addition network configurations related to transitivity

We have explained above some important network configurations, that are also essential in order to detect patterns of tie formation. These patterns result in a specific network structure that, studied in a cross-sectional data set, serves to create a model that will simulate the observed network. The simulation of the observed network is the basis for examining the network configurations that make up the network. For example, if we find that there are many twopaths in the observed network, we may include the twopath in the model that we construct to simulate the observed network. This point is explained in the next subsection. The most used network models in simulating and modeling network structures are the Exponential Random Graph Models, or ERGMs. These models are useful to determine how social structure may constrain or facilitate the formation of ties, as explained in the next subsection. 


\subsubsection{Exponential Random Graph Models (ERGMs)}

To understand the network structural patterns in the network of agroforestry tree species $\left(g_{T}\right)$ to be explained and empirically modeled, we propose the use of Exponential Random Graph Models (ERGMs). A ERGM is also known in the literature as a $p^{*}$ class of models (Wasserman and Pattison, 1996; Pattison and Wasserman, 1999; Robins et al, 1999)[68][47][54]. Conceptually, ERGMs model the likelihood of ties among vertices in a network. Lusher et al. (2013)[42] clarify that this class of models offers a model option for network structure because it accounts for the presence of ties in the network, as we explain below.

As we explained in the subsection above, the network configurations account for local patterns: see Section 4.2.2. These network configurations, once included in the model, are used to estimate parameters that show the importance (magnitude) of the configurations in the network. This is based on counting the number of the network configurations in the network. The essence of using these configurations is to see how, from a dyad (local configuration), other configurations arise (Lusher et al., 2013)[42].

The network ties in an ERGM are estimated as random variables. As Robins et al. (2007a)[55] points out, with stochastic models the researcher is able to capture regularities in the process of tie formation. The main idea is to infer whether the network configurations are more likely to be observed in the studied network than would be expected by chance. This means that, if the tie variable were formed in a random network, each tie would have the same probability of being formed. The model variables are the network configurations. The configurations included in a specific model will have a particular likelihood of generating a specific network structure. Thus, the probability of observing a specific network structure depends on how many configurations (also known as subgraphs, see Section 4.2.2) are present. For example, there are actors that search for information about agroforestry species, these actors belong to two different ethnic groups. We may expect that some homophily effects will be found. For example, actor $i$ questions actor $j$ preferably because they share some similarity, e.g., they belong to the same ethnic group, and, actor $i$ identifies himself with actor $j$. Therefore, there would be a tendency to form a tie based on them having the same ethnicity. If the process of forming a tie is random, it does not matter if actor $i$ shares ethnicity with actor $j$, all the ties would have the same chance of being formed. In 
contrast, on the other extreme, if no randomness were be accepted, all actors in ethnic group $\hat{A}$ would question only actors of the same ethnicity as themselves, something that usually is not close to reality. For this reason, we expect some tendencies. How strong is the homophily effect in our example? This will be shown by the parameter of homophilous dyads configuration.

The aim of the model is to interpret social structure and so as to analyze which configurations, e.g. homophily dyads, reciprocity, twopaths or transitive triads, are relevant to understand the tie formation and the structure of the network. The general form of the exponential random graph model is (Lusher et al. 2013; Robins et al., 2007a Robins et al., 2007b)[42][55][56]:

$$
\operatorname{Pr}(Y=y)=\left(\frac{1}{\lambda}\right) \exp \left\{\sum_{A} \eta_{A} g_{A}(y)\right\}
$$

Where: $Y$ is the $n \times n$ adjacency matrix for the network that includes all variables, $Y_{i j}=1$ if there is an edge from vertex $i$ to $j$ and 0 otherwise. $y_{i j}$ is the observed value of the network variable $Y_{i j}$ and $y$ denotes the matrix of observed edges, the observed network. A represents the network configurations, i.e., a set of nodes and a subset of ties connecting all or part of the nodes in a specific configuration ${ }^{1} . \eta_{A}$ is the parameter or coefficient of $A$ that defines the magnitude of $g_{A}(y)$. In other words, $\eta_{A}$ weighs the relative importance of the predictors $g_{A}(y)$ for the probability of a tie. $g_{A}(y)$ reflects the change in the conditional log-odds of a tie for each unit increase in $g_{A}$ that the tie would create (Goodreau, 2007)[28]. $g_{A}(y)=\prod_{y_{i j} \in A} y_{i j}$ is the network statistic of the configuration $A ; g_{A}(y)=1$ if the configuration is observed in the network $y$ and 0 otherwise. In other words, $g_{A}(y)$ represents the model covariates and we expect these configurations (statistics) to affect the probability of the network structure forming. If the parameter $\eta_{A}$ is positive this means that the effects of the configuration increase the probability of a tie, this is explained in more detail below in model estimation.

$\lambda$ is a normalizing constant that ensures the probability distribution of the above equation, since $\lambda$ is equivalent to $\sum_{A} \exp \left\{\eta_{A} g_{A}(y)\right\}$ (Goodreau, 2007)[28]. Thus, this constraints the probabilities add up to 1 , since $\lambda$ is the numerator that adds all possible

\footnotetext{
${ }^{1}$ For instance: indegree, triangle, two-path, GWESP, etc.
} 
networks with $n$ individuals. The model may also include node attributes (e.g., ethnicity, gender, etc.) contained in $X$ (Hunter, 2007)[36]:

$\operatorname{Pr}(Y=y)=\left(\frac{1}{\lambda}\right) \exp \left\{\sum_{A} \eta_{A} g_{A}(y, X)\right\}$. Thus, $g_{A}(y, X)$ includes the statistics or network - configurations defined by the researcher, where the probability of occurrence of $y$ is conditional on $X$.

The model in Equation (4.1) can be equivalent to saying that the log-odds for an edge formation taking place given the state of the rest of the network is (Goodreau et al., 2008)[29]:

$$
\operatorname{logit}\left(Y_{i j}=1\right)=\eta_{A} \delta\left[g_{A}(y, X)\right]_{i j},
$$

In Equation (4.2), $Y_{i j}$ is an actor pair in $Y$ and $\delta\left[g_{A}(y, X)\right]_{i j}$ is the change (amount of change) in $g_{A}(y, X)$ if the value $y_{i j}$ (realization) has a value of 0 or 1 . More specifically, $g_{A}(y, X)$ changes by the realization of a tie, since there is a mutual dependency of the ties. $\eta_{A}$ shows that forming a tie will increase $g_{A}$ by 1 ; the log-odds of the new tie increase by $\eta_{A}$. The probability of formation of this new tie will affect other network statistics $g_{A}$. The $X$ for attributes is fixed.

\subsubsection{Network simulation}

We have seen that the units of study in social network analysis are the ties in social relations, these ties would be the variables of a model. If we model and test directly the observed network we will have $n(n-1)$ possible ties (edges) ${ }^{1}$, therefore, this will be the number of parameter estimators in the case of a directed network, where $n$ is the number of nodes (vertices, actors or individuals). For example, if we model, $g_{T}$, the network of agroforestry tree species, we have: $n=403$, which corresponds to 162006 parameter estimators. This quantity of parameter estimators would be impossible to calculate empirically. It would require too long a computing time. For this reason, the network is simulated. The observed network is the only network within a distribution of networks that has a unique label of nodes and ties in an exact combination. This distribution of possible networks is uniform because each graph with $n$ nodes has the same probability being formed (Robins and Lusher in chapter 4 in Lusher et al., 2013)[42]. In other words, structurally identical networks (graphs) are equally probable. They

\footnotetext{
${ }^{1}$ This is for all possible ties, not only the realizations, or the already existing ties.
} 
have the same structure, that is, the same combination and number of network configurations. This is known as the homogeneity assumption (Koskinen and Daraganova in chapter 7 in Lusher et al., 2013)[42]. In this way, the parameter estimators will be calculated for the parameter configurations that together yield a probability for a network structure. Thus, by understanding which network effects are present in the observed network we include different configurations to estimate them in the model. At the end we want to construct a model that has the same likelihood as the observed network in the distribution of networks, that also has the same configurations, therefore, the same network structure.

As explained above, $g_{A}(y)$ is the count of configurations in the graph. $g_{A}(y)$ also shows the process needed in order to get closer to a network with the same likelihood of the observed network. The main idea is that in the process of simulation we select two nodes randomly. If there is no tie between these nodes we create it. If the likelihood of the resulting network increases (likelihood of being closer to the observed network and higher than the older graph) we accept the change. For this reason $g_{A}(y)$ is also called the change statistics (Koskinen and Daraganova in chapter 6 in Lusher et al., 2013)[42]. Every time that we create a tie all the configurations in the network change, since one tie may influence others (dependence assumption). The counts of these configurations also changes and this results in another network with a higher probability (closer to the observed network). The next step is the same, but now one starts with the resulting distribution of the networks with the new likelihood, if it was higher than the old graph's likelihood (if not, one stays in the old graph and repeats the procedure). This sequence of updating graphs is repeated until the likelihood no longer improves. When this happens it has converged and become stable. This process using the updating rule described is the core of the Metropolis-Hastings algorithm, used to produce the network sample. Once the procedure has converged one is in the target distribution. The target distribution is based on the last graph in the sequence, which will be the basis for the sample point. Based on this, the maximum likelihood estimation will be calculated. To create the sample one should decide how many iterations should be required (this is set by the researcher, and is usually high: 10000). This number of iterations is known as burn-in (Koskinen and Snijders in chapter 12 in Lusher et al., 2013)[42]. In this case, the last chain of networks burn-in is used to generate several graphs with the same distribution. 


\subsubsection{Model estimation}

Following the process described in the last paragraph, we now want to fit the network configurations so as to have them be equal to the observed network. We want to fit a model that, as far as possible, best represents the data, the Maximum Likelihood Estimation. Analytically, it follows that the expected value statistics are equal to the observed statistics (applied to all statistics-configurations), $E_{\eta}\left(g_{A}(Y)\right)=\left(g_{A}\left(y_{o b s}\right)\right)$, $E_{\eta}\left(g_{A}(Y)\right)-\left(g_{A}\left(y_{o b s}\right)\right)=0$, where $g_{A}(Y)$ is a value of the statistics from the distribution, and $y_{o b s}$ is the observed network. This is known as the moment equation. By using the moment equation, one intends to find the value of the parameter $\eta$ that gives maximal support to the data. A value for $\eta$ is chosen and if $E_{\eta}\left(g_{A}(Y)\right)-\left(g_{A}\left(y_{\text {obs }}\right)\right) \neq 0$ the process is repeated until $E_{\eta}\left(g_{A}(Y)\right)-\left(g_{A}\left(y_{o b s}\right)\right)=0$.

\subsubsection{Some Previous Work}

Lusher and Robins (2013)[42] investigated social selection in secondary school students by asking them who the the influential actors in their school were. They found that there was a homophily effect for the ethnocultural background of the boys when they nominated influential actors. Another study approached the influence of actors perceived as having negative attitudes in an organization. In this case the homophily effect tended to be negative, since fewer people tend to approach these actors (Robins et al., 2009)[57].

Another study documents that among teenagers, network exogenous variables such as race and gender are important understanding friendship selection. These variables, together with endogenous network variables, such as common friends (shared partners) explain tie formation (Goodreau, 2007)[28]. Another study on adolescent friendship networks concludes that sociodemographic attributes of the actors, such as ethnicity, are important explaining friendship formation. For example, the more homogeneous the non-Hispanic population in the school is, the more cohesive the Hispanic friendships tend to be (Goodreau et al., 2009)[28].

Agneessens and Wittek (2012)[4], investigating advice within organizations, conclude that the tendency to ask for advice increases within the department where an employee works. Additionally, homophily and hierarchy are factors that influence the search for advice in organizations (Agneessens and Wittek, 2012)[4]. A study on ad- 
vice seeking among court judges found that the most central advisor in the network tended to rise in status. (Lazega et al., 2012)[41]. The lesser status actors tended to build more homophilous ties as a mitigation strategy in status game of gaining approval for specific decisions. The hierarchy is based on actors being sought for their knowledge and experience (Lazega et al., 2012)[41].

In general, most of the studies have confirmed that homophily effects are important to explain tie formation, e.g., friendships or advice seeking. However, network structural variables in all studies have significant effects and were determinant factors explaining social structure and social relations in the network.

\subsection{Research Area Background}

\subsubsection{The Region: General Characteristics}

Southern Ecuador has one of the most diverse ecosystems in the world (Brehm et al. in chapter 2 in Beck et al., 2008)[8]. This may be related to the topographic heterogeneity of the coastal, Amazonian rainforest and highlands ecosystems (Homeier, 2008)[34]. For example, more than 280 tree species have been identified in the northern side of the Podocarpus National Park (146,280 hectares). This National Park is noteworthy for this biodiversity and it represents a so-called 'hotspot' of biodiversity worldwide (Brehm et al. in chapter 2 in Beck et al., 2008)[8].

Given the richness in natural resources, the region has witnessed rapid socio - economic development in the last two decades. Activities such as mining, tourism, agricultural land use expansion (Universidad Nacional de Loja, 2006)[64] have increased rapidly. Other problems such as illegal timber extraction, and the lack of land titles (Mosandl et al. in chaper 4 in Beck et al., 2008; Gerique and Pohle, 2006)[8][49] as well as the introduction of new non-sustainable agricultural technologies (Abbott, 2005)[1] have caused many side-effects in southern Ecuador. One of the most important side effects is deforestation. In a survey by Maza et al. (2010)[43], 10 of 135 respondents admitted openly having cut forest for pastures, partly inside the local forest reserve. Deforestation affects the ecological integrity of the adjacent Podocarpus National Park (Mosandl et al. in chaper 4 in Beck et al., 2008)[8].

Importantly, southern Ecuador's economy is based mainly on agriculture. Loja and 
Zamora-Chinchipe ate two provinces in southern Ecuador with a high share of their economically active population involved in agriculture: $44 \%$ in the province of Loja and $57.9 \%$ in the province of Zamora-Chinchipe (Pohle in chapter 3 in Beck et al., 2008)[8]. However, agricultural production is not sufficient to satisfy the basic needs of many households. A survey of 135 local farming households in the region shows that $35 \%$ of the households receive a survival subsidy (=30 USD/month; Bono De Desarollo Humano), and that $17 \%$ work as farm-hands. The main agricultural products are meat, curd, and a traditional maize-bean-mix. Pastures are manually weeded and not fertilized. Farmers' main interest in extension services is in cattle reproduction, pasture/resource conservation management and new crops (Maza et al., 2010)[43].

As explained in Section 4.5.1, we found that face-to-face contact is still one of the most important communication channels. Communities without adequate access to the main road do not receive a mobile telephone signal. In some cases it is only possible to access a community-administered telephone used mostly for emergencies, as in the case of the community San Juan del Oro in the province of Zamora-Chinchipe.

The communities in the research area depicted in Figure 4.3 are interconnected by a road and small paths of different quality that may collapse during the rainy season. The more central communities are connected by main roads suitable for motor traffic. Other smaller communities are connected often by roads accessible only using fourwheel drive vehicles. The area along the principal road from Loja to Zamora is settled mainly by Mestizo-colonos. The Saraguros are located north of the road between Loja and Zamora, e.g., in communities such as El Tibio and El Cristal. Communities such as Imbana and El Tibio have been adequately connected by gravel roads recently.

\subsubsection{The Region: Socio-ethnological Background}

Southern Ecuador is a culturally diverse region, therefore, one critical point to consider are the ethnic differences. The ethnic groups living in the research region, namely, Mestizo-colono and the indigenous Saraguro, must be described for our purposes. On one side, the Mestizo-colonos represent the non-indigenous rural population of Ecuador. The percentage of Mestizo-colonos living in souther Ecuador is: $92.8 \%$ of the total population of Loja and $83.2 \%$ of the total population of Zamora-Chinchipe (Pohle in Beck et al., 2008)[1]. Mestizo-colono communities are more numerous in 
the project region than Saraguro communities, and so are the number of their inhabitants. Most Mestizo settlers came to the region as a result of the agrarian reform during the 1960s. With the agrarian reform new agricultural technologies were introduced to the region that had a direct impact on the traditional ways of agriculture and farm activities (Abbott, 2005; Pohle in Beck et al., 2008)[1][8]. For example, cattle ranching became an important source of income (Pohle in Beck et al., 2008)[1], and in agriculture the introduction of new crop races, with high yields, caused agrobiodiversity loss (of native species) (Abbott, 2005)[1].

Mestizo-colonos' main income-generating activity is cattle ranching. Pohle and Gerique, in Beck et al. (2008)[8], report that, in the areas where the Saraguros settle, the landscape has more trees, while the areas settled by Mestizo-colonos are at times completely devoid of trees. In comparison to Saraguros, Mestizo-colonos have reduced knowledge of local flora, but have a more comprehensive knowledge of crop plants and pasture varieties (Pohle and Gerique in Beck et al., 2008; Gerique and Pohle, 2006)[8][49]. Production function analysis suggests that, on average, Mestizocolono households generate higher per hectare income from their farms than Saraguro households (Maza et al., 2010)[43]. Pohle (in Beck et al., 2008)[8] confirmed that Mestizo-colonos are more related to cash-oriented activities than are the indigenous Saraguros. See also discussion in Chapter 3.

In contrast, southern Ecuador's indigenous people represent $3 \%$ of the population of Loja and $12.2 \%$ of that of Zamora-Chinchipe, and $6.8 \%$ of the country as a whole (Pohle in chapter 3 in Beck et al., 2008)[8]. These percentages are based on selfidentification, and could be understimated numbers. The Interamerican Development Bank reports that in Ecuador $43 \%$ of the total population are indigenous people (Van Cott, 2007)[66]. The indigenous Saraguro is one of twelve Quechua speaking groups in Ecuador, and their relation to the local ecosystems is well recognized (De la Torre et al., 2006; Gerique and Pohle in Beck et al., 2008)[20][8]. However, with the continuous ecosystem degradation, Saraguros' and other indigenous peoples' knowledge of native species is confronting a more accelerated loss than the knowledge of the non-indigenous population (De la Torre et al., 2006)[20].

Saraguros have adopted cattle ranching since the early nineteenth century. In the beginning it was a complement of their traditional system of mixed cultivation (Pohle in Beck et al., 2008)[8]. Their traditional system of arable agriculture includes maize, 
beans, potatoes, other tubers and fruit. Their home gardens can include trees in a multistrata arrangement, and have been hypothesized to be a sustainable, near optimal form of rural land use (Pohle and Gerique in Beck et al., 2008)[8]. Nonetheless, cattle ranching has become the most important income-generating activity for the Saraguros of the project area. Interestingly, Pohle and Gerique (2006)[49] suggest that the higher prevalence of trees in the case of the Saraguros may be an expression of a more sustainable form of agriculture based on traditional knowledge. This suggests that, despite some loss of traditional knowledge, ecosystem degradation and changing household economies the indigenous Saraguros still preserve some of their traditional land systems. Importantly, a study by Gonzalez et al. (2010)[27] shows that the adoption of agroforestry tree species by Saraguros and Mestizo-colonos shows different patterns for each. Saraguros despite their knowledge of local tree species, are less involved with the adoption of tree species. Their access to information about adoption options may be lower than for Mestizo-colonos.

The process through which the Saraguros adopt new agricultural technologies and, at the same time, preserve many of their traditional productive systems, comprises a complex system where many variables interact. One main factor that differentiates Saraguros from Mestizo-colonos is that Saraguros are indigenous peoples. Being indigenous is closely related to self-cultural-identity and to self-governance (Dove, 2006)[21], to marginalization and to recognition in many social spheres (Van Cott, 2007)[66]. A study about the ethnic Saraguro in southern Ecuador explores their process of identity construction, this, in the case of the Saraguros, is closely related to their connection with the Inca past (pre-European civilization) (Ogburn, 2007)[46]. Saraguros are one of the most prosperous indigenous groups in Ecuador, e.g., many Saraguros have coursed studies in education and medicine. And one of the main Saraguros who is an social activist is part of the Confederation of the Indigenous Peoples of Ecuador. Saraguros are proud of their identity, and this gives a strong cohesiveness to their ethnic group. This, is shown by using their distinctive hairstyle and traditional clothing (Ogburn, 2007)[46]. This sense of identity differentiates the Saraguro ethnic group from Mestizo-colono. Generally, indigenous cultures tend to assign priority to collective identities over those of the individual community members (Van Cott, 2007)[66].

In spite of several differences, the members of both ethnic groups are predom- 
inantly smallholder farmers with a livelihood based on dairy and meat production (Pohle and Gerique, 2008)[8]. Mestizo-colonos have been traditionally more related to the political institutions. However, the indigenous groups have had a more active presence in the Ecuadorian political sphere since the 1970s, and their presence has been stronger since the 1990s. Proof of this is the Ecuadorian indigenous party Pachakutik (Van Cott, 2007)[66]. This Party has many followers among the indigenous Saraguros in southern Ecuador.

\subsubsection{Adoption of agroforestry species}

Agroforestry systems are those that integrate trees with annual crop cultivation, livestock production and other farm activities (Dawson et al., 2013; FAO, 2005)[19][23]. Basically, the use of tree species and fruit tree species among pastures and agricultural land gives many benefits to the farm system. The tree species used this way are called agroforestry tree species here. In the present study, the adoption of agroforestry tree species is seen as an agricultural innovation. According to Rogers' (2003)[58] definition, innovations are: "Ideas or practices that are perceived as new, applied in the productive system and spread". There are several potential benefits in adoption of agroforestry tree species since it can support livelihoods and ecosystem functions (Dawson et al., 2013)[19].

More specifically, the adoption of agroforestry tree species may be important in the economic short-term, because their use may improve the ability to survive fluctuations in production conditions and sales (Price, 1995)[50]. In this respect, the introduction of fruit trees, together with timber species, holds particular promise because a tree system alone will seldom be interesting to farmers unless it can produce tangible short-term economic benefits (Arnold, 1983)[5]. Growing trees on farms may increase per hectare farming income (Dawson et al., 2013; FAO, 2005; Sherr, 1995)[19][23][59]. Some agroforestry systems are only slightly labor intensive, and often their labor requirements are less tied to seasonal patterns when compared to arable crops (Arnold, 1983)[5]. By providing additional production options agroforestry can diversify livelihood strategies and improve farming household risk management (Knoke et al., 2009)[39]. However, information on the benefits, on species selection and management, as well as on access to inputs and to commercialization 
options must be available. Otherwise, farmers are not likely to adopt agroforestry tree species successfully (FAO, 2005)[23].

There are many environmental benefits of planting agroforestry tree species. They provide habitats outside protected areas and can serve as natural corridors for many species. Therefore, agroforestry trees improve the connectivity of landscape components, making conservation more effective (Bhagwat et al., 2008, Dawson et al., 2013)[6][19]. In addition, trees maintain productivity of the soil by protecting it from erosion and wind. The trees also provide shade for cattle (Sherr, 1995)[59]. Other environmental benefits derived from agroforestry species are insitu (place of origin) conservation of tree species (Stimm et al., in chapter 33 in Beck et al., 2008)[8], water catchment protection, fixation of carbon and improvement of agrobiodiversity (Dawson et al., 2013)[19]. Agroforestry tree species reduce the pressure on protected areas by providing timber and non-timber forest products to the household and at the same time the higher tree cover more species in the landscape (Bhagwat et al., 2008)[6].

In the project area, the use of agroforestry tree species has already been present, according to a working paper based on information of the DFG (German Science Foundation) 816 Research Unit Ecuador C3.2 (Maza et al., 2010)[43]. Based on a random sample of 135 households, out of a total population of 500, up to $43 \%$ of farmers have adopted agroforestry species. Of these, some $85 \%$ have adopted timber and 15\% fruit tree species. These results coincide with ours, as described below (see Table 4.1). The information on agroforestry tree species found in the present study was collected by asking respondents: which tree species they have planted? The starting point was a list based on a first pilot study (Gonzalez et al., 2010)[27]. The tree species obtained are listed in Table 4.1

There are mainly fruit trees in the region (see Table 4.1). The species Persea americana and Prunus persica are two widely used species. The first one is native from America and grows from Chile to Mexico. The fruits are commercially important (Ospina in Vozzo, 2010)[67]. The second one is an exotic species from the Andes. The genus Prunus grows throughout North, Central and South America (Arnáez and Moreira in Vozzo, 2010)[67]. The third most adopted tree species is the Erytrina edulis, known in southern Ecuador as Guato or Porotón. This tree is native to the Andean region. This species is considered a multipurpose tree and ideal for agrolimentary programs, for soil and watersheds management, and for agroforestry programs (Barrera 
Table 4.1: Main Tree species adopted

\begin{tabular}{|c|c|c|c|}
\hline Scientific Name & Common Name ${ }^{a}$ & $\% \mathbf{N}^{\mathrm{b}}$ & Main Use ${ }^{c}$ \\
\hline Persea americana & Esp: Aguacate, Eng: Avocado & 55.3 & Fruit tree \\
\hline Prunus persica & Esp: Durazno, Eng: Peach & 48.5 & Fruit tree \\
\hline Pinus patula & Esp: Pino, Eng: Pine & 48.5 & Timber, Live fence \\
\hline Erythrina edulis & Guato & 41.8 & Fruit tree, Live fence \\
\hline Eucalyptus globulus & $\begin{array}{l}\text { Esp: Eucalipto, Eng: Eucalyp- } \\
\text { tus }\end{array}$ & 38.5 & Timber, Live fence \\
\hline Juglans neotropica & Nogal & 33.2 & Timber \\
\hline Cupressus macrocarpa & Esp: Cipré, Eng: Cypress & 28 & Timber, Live fence \\
\hline Alnus acuminata & Aliso Rojo & 26 & Timber \\
\hline Malus domestica & Esp: Manzana, Eng: Apple & 23.1 & Fruit tree \\
\hline Tabebuia chrysantha & Guayacán & 22.6 & Timber, Live fence \\
\hline Citrus sinensis & Esp: Naranjo, Eng: Orage & 20.2 & Fruit tree \\
\hline Psidium guajava & Esp: Guayaba, Eng: Guava & 19.2 & Fruit tree, Live fence \\
\hline Brugmansia candida & Guando & 18.3 & Medicinal plant \\
\hline Nectandra laurel & Laurel & 16.3 & Timber, Live fence \\
\hline Ficus sp. & Higuerón & 15.4 & Timber, Live fence \\
\hline
\end{tabular}

${ }^{a}$ Common name in Esp : for Spanish and Eng : for English language. If there is only one name, that means that it is only known with that common name in Spanish.

${ }^{\mathrm{b}} \mathbf{N}=208$ household heads interviewed. We present the percentage (\%) of farmers that reported having planted the agroforestry tree species.

${ }^{\mathrm{c}}$ Live fence refers to species that are used as a fence in the home gardens or on the farm. 
et al. in Vozzo, 2010)[67]. The seeds of Erytrina edulis have a high protein content, and, sub-products such as flour can be commercialized. These trees fertilize pastures since their leaves decompose easily and serve as fertilizer (Barrera et al. in Vozzo, 2010)[67].

Following Table 4.1, the main agroforestry tree species used as timber is Pinus patulata. According to Stimm et al. (in chapter 33 in Beck et al., 2008)[8], most reforestation projects in Ecuador use exotic tree species. The main species are those of the genera Eucalyptus, Pinus and Cupressus. The exotic tree species can generate negative environmental side effects. For example, Pinus sp. can invade natural reserves and reduce biodiversity (Richardson, 1998; Dawson, 2013)[52][19]. Conversely, planting native tree species can conserve local biodiversity and trees' genetic resources (Bhagwat et al., 2008; Dawson, 2013; Stimm et al. in chapter 33 in Beck et al., 2008)[6][19][8]. Some native tree species such as Juglans neotropica, Alnus acuminata, Tabebuia chrysantha and Ficus sp. have been studied by Stimm et al (in chapter 33 in Beck et al., 2008)[8] in a study of seed ecology of native species in southern Ecuador. The main limitation that these native species have in order to be introduced in reforestation programs is the lack of tree seed sources and appropriate propagation techniques. Another problem that native species confront in order to be incorporated in formal agroforestry tree species programs is that usually there are no markets for their products (Dawson, 2013)[19].

\subsection{Research Hypotheses}

In Chapter 3 we analyzed the general advice network around agricultural activities, $g_{a}$. The previous analysis included advice on agroforestry tree species. Given the importance of agroforestry, we now focus exclusively on this aspect of the advice network. We apply sophisticated network analysis tools and statistical models. We will test the following hypotheses:

- $H_{1}$ : The Mestizo-colono ethnic group has the individuals with highest degree centrality in the network.

This hypothesis is suggested by the fact that Mestizo-colonos may have more access to the information necessary to adopt (Gonzalez et al., 2010)[27]. There- 
fore, some central members may have more contacts and may be questioned at most when other individuals search for information on agroforestry tree species.

- $\mathrm{H}_{2}$ : Actors with higher income tend to be searched preferentially for advice and for information.

This hypothesis tests whether individuals search for information on agroforestry tree species because of the economic benefits that the species may give (see Section 4.3.3). We expect individuals to follow those who have economic success and economic status (Agneesseens et al., 2012)[4].

- $\mathrm{H}_{3}$ : There is a high tendency to form transitive triads within members of the same ethnic group.

Based on the theoretical assumptions in Section 4.2 we expect actors to form transitive triads. These triads may be based on ethnicity, given that Saraguros and Mestizo-colonos show differences in their knowledge of plants and their cultural patterns (see Section 4.3.2). We expect there to be a high tendency in the network toward the formation of transitive triads based on ethnicity.

- $\mathrm{H}_{4}$ : The model with network endogenous variables, Model A, can better estimate the probability of tie formation than the model with only homophilous variables, Model B

In Section 4.6 we test two models. Model B contains variables (network statistics) based on homophily, and Model A contains also statistics that capture the network configurations explained in Section 4.6.3.1 (for theoretical background see Section 4.2). We want to test whether the model that addresses network endogenous variables, Model A, can explain the observed network better, by fitting the data, than Model B. Model B basically includes homophilous variables, which counts for the probability to form a tie based on similarities between actors. Thus, we expect that by including network configuration in Model A we can capture network effects that clarify how the search for information on agroforestry tree species takes place.

- $H_{5}$ : Saraguros have a higher probability of forming homophilous ties than Mestizocolonos do.

This hypothesis is based on the information on Section 4.3.2, where it was 
stressed that Saraguro ethnic group members relate more to a strong group identity. Therefore, Saraguros' propensity to form homophilous ties is expected to be higher than for Mestizo-colonos.

\subsection{The Structured Survey}

This section describes how the data was collected, the kind of data obtained and how this data was used to test the hypotheses listed in Section 4.4. Then we describe the results of the empirical analysis. After this, and based on the theoretical background described in Section 4.2 and on the main features of the research area addressed in Section 4.3.2 we proceed to discuss the empirical results and draw conclusions regarding the hypotheses.

\subsubsection{Survey Design}

The present survey is part of the second phase research on social network effects on the adoption of agricultural innovations in southern Ecuador. For details on the first phase see Gonzalez et al. (2010)[27]. Generally, given the results obtained in the first phase, it was decided to conduce a broader survey to test the network effects on adoption patterns and social structure. For a detailed explanation of the entire research scheme see Chapter 1.

We now explain how the data was collected in the field. Figure 4.3 presents the communities where the questionnaire was applied. For the survey, $\mathbf{N}=208$ household heads of 11 communities were interviewed. These are also presented in Table 4.2. The survey took place in communities settled in the proximities of the Podocarpus National Park and within the Bosque Protector Corazón de Oro. These communities are of interest because their agricultural activities may have a direct impact on the Podocarpus National Park (Universidad de Loja)[64]. For details see explanation in Section 4.3.1.

In general, the selection of the communities was based on an expanded set of communities interviewed in the first research phase. The criteria for selection of communities for the two research phases were based on two dimensions $(a)$ based on the location of the communities in the region and $(b)$ based on the ethnicity of the members 
of the communities and the remoteness of the communities. For a detailed explanation see Chapter 1.

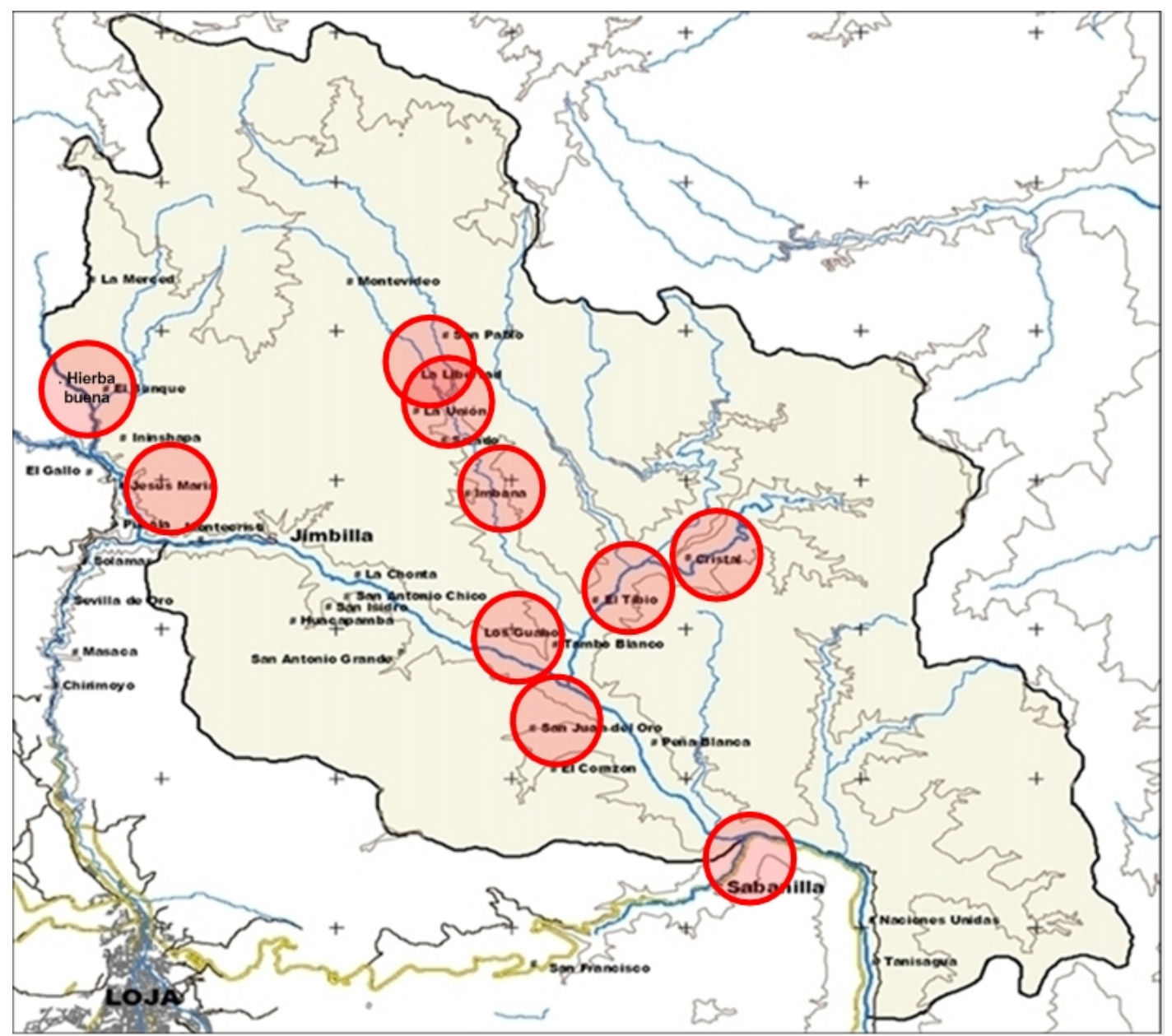

Figure 4.3: Bosque Protector Corazón de Oro

[Red circle: communities included in the second research phase].

In Table 4.2 the communities are classified according to accessibility. They were divided into three groups, those with no access, even with a $4 \times 4^{1}$ car those with limited access by car and those with good access by car (see also table note $b$ in Table 4.2). The telecommunications criterion describes whether the local population has no accesses to telecommunications, access to mobile telephones, or access to a phone at home, or both. These factors may influence the possibilities of accessing information on

\footnotetext{
${ }^{1}$ A four-wheel automotive vehicle (e.g., a pickup truck) equipped with four-wheel drive.
} 
agroforestry tree species, as face-to-face communication becomes more important. As observed in Table 4.2, access to telephones is restricted to some communities with good access. Ethnicity is explained in Section 4.3.2. Table 4.2 presents the interviewed communities:

Table 4.2: Researched Communities

\begin{tabular}{lllll}
\hline Communities & $\mathbf{N}^{\mathrm{a}}$ & Access $^{\mathrm{b}}$ & Ethnic Majority & Telecommunications $^{\mathrm{c}}$ \\
\hline El Cristal & 11 & Bad & Saraguro & No \\
El Tibio Alto & 24 & Regular & Saraguro & No \\
El Tbio Bajo & 16 & Regular & Saraguro & No \\
Hierbabuena & 20 & Good & Saraguro & Full \\
Imbana & 32 & Regular & Mestizo-colono & Middle \\
San Jual del Oro & 12 & Bad & Mestizo-colono & Middle \\
Los Guavos & 23 & Regular & Mestizo-colono & No \\
La Libertad & 10 & Regular & Mestizo-colono & No \\
La Union & 19 & Regular & Mestizo-colono & No \\
Sabanilla & 19 & Good & Mestizo-colono & Full \\
Jesus Maria & 22 & Regular & Mestizo-colono & No \\
\hline
\end{tabular}

${ }^{\text {a }}$ Number of household heads interviewed, contacts of respondents are not included.

${ }^{\mathrm{b}}$ Good if it was possible to access by car on a paved road, Regular if was possible to access by car in an unpaved road, and $\mathrm{Bad}$ if was impossible to access by car through any kind of road.

${ }^{c}$ Full refers to communities with access to mobile telephone signal and optionally a home telephone. Middle indicates access to one communal telephone for all the community. No means no access to mobile telephone or home telephone. In some cases a weak mobile telephone signal was identified but it was unstable and easily disrupted (tested in the field).

\subsubsection{Interview Instrument and the Data}

Following, we proceed to describe the kind of data collected during field research, which is the basis upon which we test the hypotheses in Section 4.4 empirically. Based on the $N=208$ respondents the network, $g_{T}$, was constructed, by asking each respondent where they obtained information about the tree species and fruit tree species that they planted (see Table 4.1) and from whom they obtained information about these species. The respondents answered by giving names of persons. These names are also called nominations. 
The result is a list of many names per respondent, these nominations are ordered by question, and for each tree species. The resulting network is classified as a directed network, because the nominations indicate a specific actor as the source of information. This network was comprised of 403 individuals (nodes, actors) who are interconnected by 687 ties. The respondents were also asked additional questions about income and characteristics of the tree species.

In order to obtain a list of agroforestry tree species, the list obtained by Gonzalez et al. (2010)[27] was used. In the questionnaire all the tree species that were planted were listed. The most important trees cited in the answers are listed in Table 4.1. Once the trees were listed, each respondent was asked whom he approached for information. We note here that the information shared not only comes from a search for advice but also from casual conversations, workshops and other possible sources. This way, a detailed map of the search for information network for each respondent regarding each agroforestry tree species was obtained. More specifically, the summary of each question is listed below:

- $(i)$ who recommended the tree species to the respondent,

- (ii) where did the respondent learn about the usefulness of the tree,

- (iii) who was sought if there was a problem,

- (iv) who was sought if there was any question about the cultivation, etc.,

- (v) who had recommended any course or workshop,

- (vi) who had recommended changes or improvement in the tree plantation and its use,

- (vii) whether the person had had any general conversations about the trees with other relatives, neighbors etc.

We interviewed all (census) household heads in all the communities included, see Table 4.2. We did not sample the network (Frank in Carrington et al. 2005)[15]. It is important to clarify that we only interviewed the household heads. Therefore, the network was based only on their answers, and it was assumed that they were the 
persons who made decisions regarding whether or not to adopt any of the tree species on Table 4.1.

To generate the names (nomination) of the actors (nodes) in the advice network we asked each interviewee openly to name those individuals he turned to for advice and to search for information about agroforestry tree species. We did not ask for a fixed number of nominations. Setting a fixed number of possible nominations in a directed network can carry some problems. For instance, interpretation of mutualized (ties that are reciprocal as explained in Section 4.2) data can be complicated (Goodreau, 2007)[28]. Another method to generate names (nominations) is the use of a list of actors, but this may be problematic if there is a large population or even a big community. We tried this last method in the pretest of the survey questionnaire, and after doing so we decided to leave the nominations open. This list was quite big and could have caused problems in the formal survey, consuming more time (more than an hour).

One important situation observed during the pretest was that in the nomination of information sources there were some nominated ties that live outside the research area. We considered that including these actors would be suitable to capture their role as source of information. Our target population was still the respondents of the communities in Table 4.2. For the case of the information network for agroforestry species, $g_{T}, 32 \%$ (129) of individuals' nominations were living outside the sample research area.

Data limitations: knowing that we include sources of information nominated outside, we would expect a higher number of asymmetric ties than would be the case without these actors. However, this may not affect the inference about the network. Only ten respondents refused to be interviewed, and some of them were mentioned as contacts. In spite of this, the network data were quite complete.

We only questioned the household heads and those who took the decision regarding adoption. There were some actors nominated who were not respondents and who lived in a household in the communities of the sample research area. These cases were few. One possibility for dealing with these actors would be to set each household as the actors of the network; and not each respondent and person nominated. Nonetheless, this would create difficulties when testing the hypotheses that refer to differences between Saraguro and Mestizo-colono ethnic groups. For example, there are households where the head of the house is Saraguro and his wife is Mestizo-colono. Such cases 
would have created some difficulties when trying to draw conclusions regarding ethnic differences.

\subsection{Empirical Methods: Network Analysis}

In order to test empirically the hypotheses described in Section 4.4 we use network descriptive statistics and an Exponential Random Graph Model (ERGM) as follows:

- $H_{1}$ : The Mestizo-colono ethnic group has the individuals with highest degree centrality in the network: tested with network descriptive statistics (degree and indegree centrality) and ERGM (model term: indegree $*$ ethnic - group, specifically with the parameter: $\eta_{i n E t}$ ).

- $\mathrm{H}_{2}$ : Actors with higher income tend to be questioned preferentially for advice and information: tested with the ERGM, specifically with the model term indegree $*$ income with the parameter $\eta_{\text {inI }}$. The correlation between indegree centrality and income also helps us to test this hypothesis.

- $H_{3}$ : There is a high tendency to form transitive triads within members of the same ethnic group: tested with descriptive statistics (transitivity local and global) and the ERGM, specifically with the model term transitivities that has the parameter $\eta_{t r}$.

- $H_{4}$ : The model with network endogenous variables, Model A, can better estimate the probability of tie formation than the model with only homophilous variables, Model B: tested with the ERGM by comparing the Akaike Information Criterion (AIC) and the Goodness of Fit (GOF) of Model A and Model B.

- $H_{5}$ : Saraguros have a higher probability offorming homophilous ties than Mestizocolonos do: tested with the ERGM, specifically with the model term homophily, applied for the ethnic group attribute class, homophily - Mestizo - $c$ (parameter: $\eta_{H_{\text {om }}: M-C}$ ) and homophily - Saraguro (parameter: $\eta_{H o m_{L: S g}}$ ).

The empirical procedure for testing each hypothesis is explained below. Generally, we wanted to identify structural patterns that could organize the search for information 
on agroforestry tree species, to describe how it takes place and to set the basis upon which to understand structural patterns that give form to the network structure. In the questionnaire described in Section 4.5.2, the nominations resulting from the questions are the units that make up $g_{T}$. For example, if Maria nominated Jose as a source of information, than Maria and Jose are two vertices in $g_{T}$ that share and edge (tie). The directionality of the tie is given by who sent the tie. In this case the tie of Maria is an outgoing (outdegree) tie and an incoming (indegree) tie for Jose.

\subsubsection{Network Specification}

Formally, our network $g_{T}$ has an order $n=403$, the $V\left(g_{T}\right)$ is the number of vertices in $g_{T}, V=\left\{v_{1} \ldots v_{403}\right\}$, where $v$ denotes a vertex in $g_{T}$. If $E\left(g_{T}\right)$ is the number of edges in $\left(g_{T}\right)$, the $u=687$ defines the size of $g_{T}$ as follows: $E=\left\{t_{1} \ldots t_{687}\right\}$, where $t$ denotes an edge in $g_{T}$.

If a vertex $i \in V\left(g_{T}\right), i$ can belong to two ethnic groups Saraguro or Mestizo colono, thus actor $i$ can have an attribute $L$, where:

$$
L= \begin{cases}1 & \text { if } i \text { Mestizo-colono } \\ 0 & \text { otherwise }\end{cases}
$$

The universe of $M$ can be located inside or outside the research sample communities listed in Table 4.2, thus, $m=\{i n$, out $\}$. The actor $i$ can live in 11 communities inside or in 44 outside, where $m$ is one community, the $m \in M, M=\left\{m_{1} \ldots m_{h}\right\}$, where $h$ is the total number of communities. The number of actors living within each community $m$ is defined by $c_{m}$. This number of actors $c_{m}$ can take a value $1 \leq c_{m} \leq n$.

Formally, the network of searching for information on agroforestry tree species, $g_{T}{ }^{1}$, can be decomposed into two subgraphs, $g_{T_{S}}$, for the Saraguro ethnic group whose network includes only intra-ethnic linkages. The second subgraph is $g_{T_{M}}$ for intraethnic linkages of the Mestizo-colono. Thus, we can compare some statistics for the search for information in the whole network and for each ethnic subgraph.

\footnotetext{
${ }^{1} g_{T}$ also includes interaction with institutions related to diffusion of information on agroforestry tree species.
} 


\subsubsection{Descriptive Statistics}

The network statistics to be used are briefly explained below. The purpose of using descriptive statistics is not only to test empirically some hypotheses, but also to identify some possible network patterns. These patterns are incorporated in the ERGM as the configurations used to model the network. Some of these statistics, such as indegree, outdegree centrality, in - out - degree correlation and transitivity were already explained in more detail in Section 4.2. In this section we explain them from a practical perspective. The term node is used within the social network descriptions, while vertex (plural: vertices) is used within the graph theoretical context. Actors and individuals are terms used in a more general context of description and analysis. They are always used with the same meaning.

- degree centrality: degree centrality is a network statistic that accounts for the number of ties that an actor has (Brandes and Erlebach, 2005)[11].

- indegree centrality: indegree centrality is the number of incoming ties that an actor has (Brandes and Erlebach, 2005)[11]. With respect to the items of the questionnaire (see Section 4.5.2), indegree centrality represents the number of other respondents that nominated a current respondent as an actor from whom they requested and obtained information or advise.

- outdegree centrality: this statistic is the number of outgoing ties that an actor has (Brandes and Erlebach, 2005)[11]. If a respondent nominates 4 other actors as actors who obtained information or requested advice, then outdegree centrality is reported as 4 (cf. Section 4.5.2).

- in-out-degree correlation: this statistic shows the correlation between indegree and outdegree centrality. On a sacle from 0 to 1 it shows whether the people $I$ question the same people that question me in their search for information on agroforestry tree species (Agneessens and Wittek, 2012)[4]. For example, if the correlation is 1 , it means that those I question are precisely those who question me.

- betweenness centrality: this statistics estimates the proportion of shortest paths between two actors, e.g., $i$ and $j$, that pass through a third actor $s$. Then actor $s$ 
has the position of being between the two other actors in the network, given the possible shortest paths in the network connecting $i, j$ (Freeman, 1977)[25]. For an explanation of shortest path see average path length below.

- transitivity (global and local): As described in Section 4.2 and as depicted in Figure 4.1, this statistic shows that the person who I(i) question is same person who my neighbor, $(j)$ (with whom I also have a tie $(i j)$ ) also questions for information. For this reason the information may tend to be the same for me $(i)$ and my neighbor $(j)$. Moreover, there will be a tendency toward a hierarchy (actor $s$ has more ties, 2 ) since one actor $(s)$ is questioned by two actors.

The transitivity can be global, these are transitive triads (three edges) given the number of connected triads. The local transitivity is the average of transitive triads given the number of connected triads based on each vertex (Brandes and Erlebach, 2005)[11]. For example, for global transitivity, if the value is 0.2 this means that $20 \%$ of the triads are transitive. These should be analyzed in the social context to see if it is a high or low value.

- reciprocity: this statistic implies that an actor, $i$, who sends a tie to actor, $j$, also receives a tie from actor $j$ (Agneessens and Skvoretz, 2012)[3]. This measure has a value between 0 and 1 . For example, if reciprocity $=0.6$, this means that $60 \%$ of the dyads have reciprocated ties.

- average path length: average number of the shortest paths (an edge between two nodes) than an actor has to cross in order to reach any other actor in the network (Brandes and Erlebach, 2005)[11]. If we assume that actor, $i$, wants to reach another actor, $j$, in the network following the shortest way (with the least persons in between), and if this actor ( $i$ ) wants to choose the shortest way to the other actor $(j)$, he $(i)$ would choose the shortest - path. Now, we assume that actor, $i$, can choose this path to reach every other actor in the network, and if we take the average of all these paths for actor $i$, we would obtain the average path length for actor $i$. If we estimate this average for each actor in the network and take the average of the results we obtain the average path length for the network. This statistic is important, because as smaller that average path length, better reachable would be every actor to all other actors. This may be a more efficient 
network to diffuse information.

- number of cliques: cliques are perfectly dense groups, where each individual has edges with each other member (all members). Formally, a clique can be seen as a perfectly dense cohesive structure that is compact and connected (Kosub in Brandes and Erlebach, 2005)[11]. If we estimate how many cliques are in the network, we can have a notion of how divided into completely connected substructures the network is. There is no purpose in comparing few vs. many cliques, as this will depend on each network. However, the more cliques the network has, the more clustered the network is.

\subsubsection{The Applied Model: The ERGM}

\subsubsection{Model Terms}

In order to test the five hypotheses, which are also described at the beginning of this section, we have constructed two Exponential Random Graph Models (ERGM).

- $H_{1}$ : The Mestizo-colono ethnic group has the individuals with higheest degree centrality in the network.

- $\mathrm{H}_{2}$ : Actors with higher income tend to be searched preferentially for advice and information.

- $H_{3}$ : There is a high tendency to form transitive triads within members of the same ethnic group.

- $H_{4}$ : The model with network endogenous variables, Model A, can better estimate the probability of tie formation than the model with only homophilous variables, Model B.

- $\mathrm{H}_{5}$ : Saraguros have a higher probability offorming homophilous ties than Mestizocolonos do.

As explained in detail in Section 4.2.4, ERGM identifies the network patterns that recreate the observed network by modeling it based on configurations. The configurations' importance in reproducing the observed network will be estimated as explained 
in Section 4.2.4 by the parameter and the significance of the model terms, and will be summarized for the practical case below. To construct the ERGM we include the main statistics that show ethnic differences and that could alert us to the presence of some network pattern presented in the data. The statistics are presented in Table 4.3 in Section 4.7.1. The selected network statistics to be incorporated in the ERGM are:

- in-out-degree correlation: this statistic will be represented in the model by the twopath configuration. For explanation of twopath see Section 4.2.

- betweenness centrality: this statistic is represented in the model by Mixed.2star configuration.

- transitivity: is represented by the configuration transitivities. This model term is used to test $H_{3}$.

- reciprocity: this statistics is not directly addressed. However, asymmetric ties (as the opposite of symmetric ties) is addressed, which refer to the fact that a tie has been reciprocated. The presence of asymmetric ties is expected because of the actors nominated in the questionnaire who are living outside the sample research area, as explained in Section 4.5.2. This configuration controls on this ties.

A detailed explanation of the descriptive statistics results is presented in Section 4.7, and a detailed explanation of the model terms is presented below. We have also verified that the network configurations have theoretical and methodological support. This is explained for each model term below and in Section 4.2. To construct the models we followed Robins et al. (2007a)[55] and Goodreau (2007)[28], and some trial-and-error model construction.

We constructed two models. These two models include the model term indegree * income, which is used to test $H_{2}$. This configuration captures whether there is any influence of income on having been nominated. To test the hypothesis $H_{4}$ we address one model that includes homophilous variables of ethnicity and gender, Model B. The main motivation for testing this model it is to see whether is possible to reconstruct the observed network mainly by addressing configurations that account for similarity (ethnicity and gender) between actors. 
Model A includes network statistics known as network endogenous variables (see Section 4.2). We want to test whether some structural configurations are significant for understanding tie formation. By these means we want to determine which network configurations can reproduce the observed network. For instance, if a parameter estimator is positive, the configuration is present in the observed network. If the parameter is large (high value) and positive, there are many of the configurations in the observed network.

The model terms used are available in the ergm package of STATNET (Handcock et al., 2003; Morris et al., 2008)[32][45], which runs in $R$ [51] statistical program, this is explained in detail in Section 4.6.3.2. In the following, we explain the model terms. Their topological illustration is presented in Figure 4.4:

- Arcs: This model term accounts for the number of ties (edges) in the network, i.e., outgoing or incoming ties (Robins et al., 2007b)[56]. This term is called arcs because it is based on the number of ties of the observed network, which is a directed network. Therefore a tie shows a direction of the relation in a dyad, sending a tie (outdegree) or receiving a tie (indegree). The Arcs term must be included in each model, and this can be calculated as follows $A(y)=\sum_{i<j} y_{i j}$. This can be seen as the intercept of the model and the baseline propensity of forming a tie. For example, if the parameter is negative, this means that the ties occurrence is relatively rarely if they are not within another configuration, e.g., transitivities (Robins et al., 2007a)[55]. For the model term, arcs, the probability of forming a tie simulating the observed network will be presented by the parameter, $\eta_{\text {arcs }}$. In other words, if we want to reconstruct the observed network by just including the probability of forming a tie by considering the number of edges, we build a model only with the arcs term. However, this model may not be so close to reality since the observed network may have other patterns ocurring, e.g., degree centrality, transitivity, etc.

- Homophily: We have applied the concept of homophily to capture the likelihood one actor $(i)$, would search another actor with the same attributes when $i$ searches information about agroforestry tree species, based on $i$ 's attributes of ethnicity (Saraguro, Mestizo-colono) and gender (male, female). This model term tests the hypothesis $\mathrm{H}_{5}$. 
As explained in Equation (4.1) in Section 4.2.4, $X$ of node attributes consists of the following statistics: $x_{e i}$ is the attribute value for actor $i$ for attribute $e$. In our case $e$ can refer to two attributes: for the ethnic-group $L$ and for the gender $B$. $X_{e a}$ is the set of all nodes with value $a$ for attribute $e$. For example, as explained at the beginning of this section, if the actor is a Mestizo-colono, then $L=1$, $x_{L_{1}}$, where $x$ will be the realization for actor $i$. This is the basis upon which to estimate the degree centrality of each actor. The degree statistic for attribute $e$ and value $a$ is: $S_{e, a}(y)=\sum_{i \in X_{e a}} d_{i}$. Where, $d_{i}=\sum_{j} y_{i j}$, equal to the degree of node $i$. This way we estimate the possible number of contacts for each actor in each ethnic group.

Once we have estimated the degree centrality for the ethnic groups, we proceed to estimate the degree within each ethnic group. This is called uniform homophily and includes only the within-group preferences for forming a tie with group members (Goodreau, 2007; Morris et al., 2008)[28][45]. This term is equivalent to the term that we have been using until now, homophily. In the expression $H_{e}(y)=\sum_{i<j} y_{i j}\left\{x_{e i}=x_{e j}\right\}$ if the equivalent affirmation in curved brackets is true then the value is 1 and 0 otherwise.

For example, there is an edge between actor $i$ and actor $j$ for the attribute ethnic group $e_{L}$. If there is an edge $y_{i j}=1$ in $g_{T}$, and if for $i$ it is true that $X_{e_{L} a}=x_{L_{1}}=1$, this mean that actor $i$ is Mestizo-colono. We also know that it is true for actor $j$ that $X_{e_{L} a}=x_{L_{0}}=0$ if actor $j$ is Saraguro, then it is $T R U E$ that $=y_{i j}\{0\}$. Thus, the tie $y_{i j}=1$ is not included as homophilous tie in $H_{e}(y)$.

- Indegree * Income: the term is calculated by means of the absolute difference between the income of actor $i$ and actor $j$, thus, $w_{i j}=$ income $_{i}-$ income $_{j}$. This is calculated for all indegree edges, $i \rightarrow j,\{i, j\}$ in the network, $y$, as follows $\sum_{i j} w_{i j} y_{i j}$ (Morris et al., 2008; Robins and Daraganova in chapter 8 in Lusher et al.,

2013)[45][42]. Where we can prove that the income, $w$, is related to search for information, therefore, it is related to tie formation $\{i j\}$ in $g_{T}$. The tie that we analyzed here is the tie formed when actor $i$ questions actor $j$ for information (indegree), see Figure 4.4 for illustration. The income was standardized by di- 
viding it by the standard deviation, before it was entered into the models.

If the parameter of Indegree * Income is large and positive, the interpretation is that people of high income are more likely to consult low income actors. In our case, we expect that actors search for information from those who have economic success and high economic status (Agneesseens et al., 2012)[4]. Therefore, we expect the parameter of the term to be negative, and this will confirm that there is a tendency for ties to be formed between individuals of low and high income.

We assume the actor tends to mimic the positive experiences others have had. These positive experiences and successes are reflected in a higher income of the discussion partner. This way, we consider the way of thinking of the actors, who chooses to maximize the farm's profit. Including this variable is similar to the logic applied by Stoneman (1981)[62], Besley and Case (1993)[9], Udry and Conley (2004)[63] and Conley and Udry (2001)[16], among others. For instance, combining the in-degree network variable and the income of actors involved in the tie, we want to capture how a individual learns to improve household income. This model term tests the research hypothesis $\mathrm{H}_{2}$, as explained at the beginning of this section.

- Indegree * Ethnic group: the in-degree centrality for $i$ receiving nominations from other individuals, $C_{i_{D}}{ }^{i n}=d^{-}(i)=\sum_{j} y_{i j} I$. For instance, $I=1$ if $i$ is Mestizo-colono and 0 otherwise (Koschützki et al. in Brandes and Erlebach, 2005; Goodreau, 2007)[11][28]. This term controls for the indegree of each ethnic group. The aim is to capture the skewed degree distribution observed in Figure 4.5b. We have decided to distinguish between ethnic groups because Mestizo-colonos seems to be more central (higher degree centrality and indegree centrality, see Section 4.7.1). This model term parameter will test the hypothesis $H_{1}$.

- Asymmetric ties: we have included the asymmetric ties to capture the actors living outside the sample research area and the low reciprocity shown in Table 4.3. This term counts the number of asymmetric ties in $g_{T}$, if $i \rightarrow j$ but not $j \rightarrow i, \sum_{j} y_{i j}\left|x_{i j}-x_{j i}\right|$. If the difference in brackets is zero (symmetric) there is no asymmetric tie counted. 
- Alt-outdegree $u$ and Alt-outdegree decay $\theta$ : These terms include the Geometrically weighted degree (GWD) statistic (Hunter, 2007; Hunter and Handcock, 2006)[36][35]. They are measured as follows (Hunter, 2007)[36], where $y$ is the empirical network based on the interactions in $g_{T}$ described in Section 4.6.1:

$$
u(y ; \theta)=e^{\theta} \sum_{i=1}^{n-1}\left\{1-\left(1-e^{-\theta}\right)^{i}\right\} D_{i}^{+}(y)
$$

Equation (4.3) presents a re-parametrization of the Alternating $k-$ star of Snijders et al. (2006)[60]. Hunter and Handcock (2006)[35] presented it for degree distribution; we apply here to the out-degree distribution. This term puts more weight on the number of nodes with lower outdegrees. This weight decreases geometrically as the outdegrees increase. The speed of this decay is defined by $\theta$. The higher $\theta$ is, the slower the decay (Hunter, 2007; Robins et al. 2007)[56]. $u$ captures that the number of ties that are outdegrees decreases as the individual have sent already many ties, $n$ is the number of actors, and $D_{i}^{+}(y)$ counts the number of ties (outdegree statistic) (Hunter, 2007)[36]. The adjacent neighbors contacted decrease as more ties are established, and the members of the network at greater distances can not be reached directly. As depicted in Figure 4.4 actor $i$ can have many contacts, that are direct adjacent, until $k$ (are limited). If the parameter of Alt-outdegree is negative, it means that the actors have similar levels of outdegree (Lusher et al. 2013)[42].

- Mixed.2star: This term emphasizes whether actor $i$ is in the middle of two other actors, $j$ and $s$, and if actor $i$ forms a bridge from $j$ to $s, j \rightarrow i \rightarrow s$, $\sum_{i} \sum_{j, s, j \neq s} x_{j i} x_{i s}$. This term is similar to twopath, the difference is that mixed.2star focuses on the probability of a new tie situating actor $i$ so as to connect or bridge two of his neighbors (see Figure 4.4 for illustration). The topological representation of mixed.2star and twopath is the same, the difference is in the interpretation (Morris et al., 2008)[45]. For instance, if there is already a tie from $j \rightarrow i$ and the tie formed goes from $i \rightarrow s$, the count of this tie induces a new mixed.2star in the network.

- Twopath: This term controls for the correlation between indegree and outdegree 
(Robins et al., 2009; Lusher et al. 2013)[42][57]. The term twopath is similar to mixed.2star, the difference is that twopath emphasizes the formation of a tie from the sides (Morris et al., 2008)[45] (see Figure 4.4 for illustration). For example, if there is already a tie from $i \rightarrow s$ and the tie formed goes from $j \rightarrow i$, the count of this tie induces a new twopath in the network.

- Transitivities: This term adds one statistic to the model, equal to the number of ties $i \rightarrow j$ if there is a twopath between $i$ and $j$ (Handcock et al., 2003)[32]. We have calculated this statistic for the attribute ethnic group, $L$. In this case all three nodes involved in the transitive triad have the same ethnic group. The reason for including this term in the model is to determine if the search for information is concentrated in members of the same ethnicity. Therefore, we can identify if there are dense regions in the network that are segmented by ethnic interactions. In Figure 4.4 we show graphically the network terms included in the models. This model term tests the hypothesis $H_{5}$.

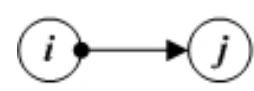

Homophily Ethnic

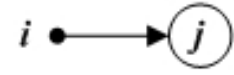

Indegree * Ethnic

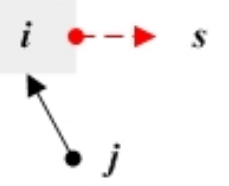

Mixed.2star

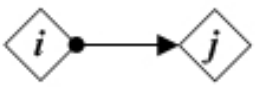

Homophily Gender

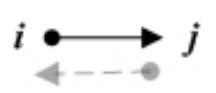

Asymmetric Tie

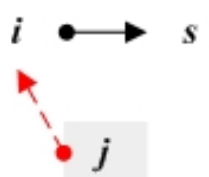

Twopath

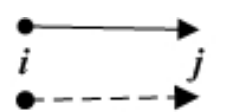

Income* indegree

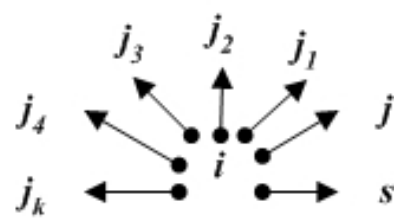

Alt-outdegree

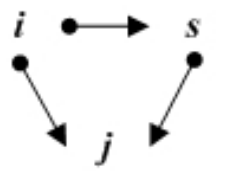

Transitivities

Figure 4.4: Topological illustration of model terms 


\subsubsection{Model Estimation and Goodness of Fit (GOF)}

- Model Estimation: As explained in Section 4.2.4, the models were fit using a random algorithm (Metropolis-Hastings) based on a Markov chain. The model simulation is based on a Montecarlo maximum likelihood estimation (Robins et al, 2007a)[55]. For more details, see Hunter and Handcock (2006)[35]; Snijders et al. (2010)[61] and Lusher et al. (2013)[42]. This produces a random sample from a probability distribution in the sample space of all networks (possible networks given the number of vertices). The sample is used to approximate ${ }^{1}$ the true likelihood function. The approximated likelihood function is maximized in order to obtain the parameters of the model statistics (Hunter, 2007)[36].

Degeneracy and near degeneracy are some problems that can happen during the modeling process that can affect the output of the model. For example, if one network configuration is used in the model as term, but this configuration is not found in the observed network. This will produce a degenerate graph with high probability of occurrence. It is degenerate in this context because indeed there is no Maximum Likelihood Estimation possible (Koskinen and Snijders in chapter 12 in Lusher et al., 2013)[42]. We avoid this problem by addressing the most important descriptive statistics results, as explained in Section 4.6.3.1. Near degeneracy appears if there are very few possible graphs in the distribution. These are usually an empty or a full (totally connected) graph. This problem is more likely to appear if only low order configurations ( 2 or 3 node configurations) are included as terms in the model (Robins et al., 2007b)[56]. We avoid this problem by including the term Alt-outdegree.

For each model tried we tested the model degeneracy (Goodreau et al., 2008; Hunter et al., 2008)[29][37]. To estimate the parameters' $(\eta)$ Maximum Likelihood Estimation (MLE), logistic regression was used, in the case of Model B. In the case of the dependence model ${ }^{2}$, Model A, MCMC (Markov Chain Monte Carlo) was used (Hunter, 2007; Hunter and Handcock, 2006)[36][35].

For each trial, the autocorrelation of the statistics was checked, to see after how

\footnotetext{
${ }^{1}$ In a similar way as when the sample mean is used to approximate a population mean.

${ }^{2}$ It includes Markov random model configurations such as mixed - $2-$ stars and high order configurations such as Alt-outdegree.
} 
many samples the correlation with the first sample decays to zero. We have confirmed that all were below a value of 0.4 , as recommended Koskinen and Snijders in Lusher et al. (2013).[42] The last lag should always be close to zero (Robins and Lusher in Lusher et al., 2013)[42]. This was true for Model A.

Given the interval of the sample, the percentages of acceptance moves were verified to be between $30 \%-70 \%$, to know if the chain had a good mixing. For the case of Model A the percentage was: $37.2 \%$, and for Model B it was: $73.2 \%$. For instance, less than $30 \%$ indicates that much of the space is not explored. Therefore, few points represent much of the simulation. For Model B it was verified that the numbers of steps accepted is also constant, and did not variate too much along the chain. This would suggest that the model did not degenerate (Goodreau et al., 2008)[29].

It was also determined whether the sample statistics were significantly different from observed network ones ( $p$-values and differences). All these results are obtained using the MCMC (Markov Chain Monte Carlo) diagnostics and the simulation results. For more information on Monte Carlo methods and the Metropolis-Hastings algorithm see Robert and Casella (2010)[53], and Goodreau et al. (2008)[29] and Lusher et al. (2013)[42] for application in network data. In the end Model B was chosen, as it was the model that better fulfilled the requirements described above, and it presented a good fit (see Goodness of Fit (GOF)) below.

The ergm package was used to fit the exponential-family graph (ERG) models to network data (Handcock et al., 2003)[32]. It was run in the R environment for statistical analysis[51]. In the ergm function we use a MCMC-sample size of 10000, a chain burn-in of 100000 and an interval between successive samples of 2000. Therefore, the chain has a length of $100000+10000 \times 2000=20.1$ million steps (Goodreau, 2007; Goodreau et al., 2008 )[28][29]. The descriptive statistics were estimated in the igraph package version 0.5x (Gabor, 2012)[26], and sna (Butts, 2012)[13] version 2.2-0 of STATNET (Handcock et al., 2003)[32] both in the $R$ environment[51].

- Goodness of Fit (GOF): To determine whether we have a good model once it has converged, we assess the goodness of fit (GOF). The main idea is to determine 
whether the model captures the network configuration that has not been included in the model (Koskinen and Snijders in Lusher et al., 2013)[42]. If the model explains the other configurations (those not included in the model) to a degree, we can be sure that the model can capture many of the network properties. It is important to observe that these variables are not extreme in the plots.

In testing the GOF we have used Geodesic distance and the Triad census, which are part of the five network features suggested by Robins et al. (2009)[57] to be used in GOF for directed networks. The other three: graph counts and associated statistics (e.g., Markov configurations such as mixed.2star and twopath), degree distributions, and closure (i.e., transitive triads) have been included in the model. The geodesic distance consists of the pairwise path distances between two actors (first share adjacent actors (1) are at the first distance and so on) in $g_{T}$. The triad census counts for the sixteen types of triads of Holland and Leinhardt (1970) (Holland and Leinhardt, 1970; Goodreau et al., 2009; Robins and Lusher in Lusher et al., 2013)[33][30][42]. To select which model better represented the data (observed network $y=g_{T}$ ) we compared the GOF and the Akaike Information Criterion (AIC) (Goodreau, 2007)[28]. These two methods used together are best to yield the choice of the model that best fits the data (Hunter et al., 2008)[38].

\subsection{Empirical Results}

In this section we present the results of the statistical analysis. These results are the basis upon which to test our hypotheses, described in Section 4.4. We have organized the section into two subsections. In the first part we aim to describe the main network statistics that $g_{T}$ shows. This step is crucial to determine which network statistic can capture the network patterns. In the second part, the statistical analysis of network patterns will be depicted in the ERGM results. The aim is to detect the local patterns of information searching. 


\subsubsection{Network Descriptive Statistics}

Table 4.3 depicts some of the main statistics used to understand the general network features in $g_{T}$. Moreover, from these results we can identify important statistics to include in the ERGM.

Table 4.3: Agroforestry sp. Network Statistics

\begin{tabular}{|c|c|c|c|}
\hline Network Statistics & $\begin{array}{l}\text { Network }^{\mathbf{a}} \\
\left(g_{T}\right)\end{array}$ & $\begin{array}{l}\text { subgraph-Sarag. } \\
\left(g_{T_{S}}\right)\end{array}$ & $\begin{array}{l}\text { subgraph-Mestizo-c. } \\
\left(g_{T_{M}}\right)\end{array}$ \\
\hline Vertices & 403 & 134 & 224 \\
\hline Edges & 687 & 132 & 273 \\
\hline Mean-degree & 3.71 & 2.27 & 2.77 \\
\hline Mean-indegree & 1.70 & 1.14 & 1.38 \\
\hline Mean-outdegree & 1.70 & 1.14 & 1.30 \\
\hline in-outdegree correlation ${ }^{\mathrm{b}}$ & $0.13[t=3.28]$ & $0.06[t=0.06]$ & $0.20[t=2.86]$ \\
\hline betweenness & 22 & 1.92 & 6.74 \\
\hline Transitivity - global $^{\mathfrak{c}}$ & 0.054 & 0.081 & 0.056 \\
\hline${\text { Transitivity }- \text { local }^{\mathrm{d}}}^{\mathrm{d}}$ & 0.268 & 0.24 & 0.34 \\
\hline Reciprocity & 0.048 & 0.04 & 0.061 \\
\hline Average - path-length & 2.75 & 2.28 & 2.22 \\
\hline Clique $^{\mathrm{e}}$ & 5 & 3 & 5 \\
\hline
\end{tabular}

\footnotetext{
${ }^{\mathrm{a}}$ Includes institutions

b The $p$-values are the following: $g_{T}: 0.0012, g_{T_{S}}: 0.459$ and for $g_{T_{M}}: 0.0046$.

${ }^{c}$ Ratio of transitive triads and connected triple (three nodes) of the graph.

${ }^{d}$ Ratio of transitive triads linked to the vertex and connected triple (three nodes) of each vertex

${ }^{\mathrm{e}}$ In clique estimation the directionality of the graph was ignored.
}

Following the network statistics in Table 4.3, the average path length in $g_{T_{S}}$ (2.28) is slightly higher than in $g_{T_{M}}$ (2.22). This information means that the average distance in the average between individuals of the same ethnic group is greater for Saraguros searching for information. The higher global - transitivity of Saraguros (0.081) may show a stronger tendency for group cohesiveness within that ethnic-group than within Mestizo-colonos (0.056). At the subgraph level, Saraguros tend to be more clustered than Mestizo-colonos.

Relatively higher local - Transitivity (0.34), and higher reciprocity (0.061) than Saraguros $(0.24,0.04)$ may indicate that Mestizo-colonos access information on agro- 
forestry species with relative ease. The actor with highest degree centrality is a Mestizocolono. Around him there are many actors that form cluster substructures (actor based transitivity), as observed in Figure 4.5. This is also suggested by the higher number of cliques in $g_{T_{M}}$ (5) than in $g_{T_{S}}(3)$. This idea is also reinforced by higher mean betweenness (6.74) centrality and the highest in - outdegree correlation (0.20: significant) for Mestizo-colonos as compared to Saraguros (1.92, 0.06: not significant). The average indegree and outdegree centrality is slightly higher for the Mestizo-colono subgraph $(1.38,1.30$ respectively) than for the Saraguro subgraph $(1.14,1.14$ respectively). The Mestizo-colono ethnic group has the actor with the highest degree centrality, as observed in Figure 4.5b. Figure 4.5a presents the network representation for $g_{T}$ and Figure $4.5 \mathrm{~b}$ presents the same network, but in this graph the size of the network actors (vertices) is based on their number of contacts (degree centrality).

\subsubsection{The Exponential Random Graph Model (ERGM)}

A very influential Mestizo-colono is the main source of information regarding agroforestry species, as we can observe in Figure 4.5b (more details in the discussion of results, Section 4.8). For instance, we want to test the hypotheses $H_{1}$ and $H_{2}$, i.e., whether indeed being a Mestizo-colono increases the likelihood of accessing information on agroforestry species, by applying an Exponential Random Graph Model. To see results of the model, refer toTable 4.4, which depicts the parameter estimators in brackets, the standard error and the level of significance (c.f. $p-v a l u e$ ). We show a probit model of only the homophily covariates and a mixed-term of income and indegree, Model B. In Model A, the aim is to see how we can understand more of the network by including statistics that capture the endogenous process of the network interaction. We want to test hypothesis $H_{4}$, with Model B, which supposes mainly that homophilous effects are able to explain the probability of forming a tie, by fitting the data.

\subsubsection{Comparing Models}

We start by considering the differences between the two proposed models. Model B was emphasized in estimating the effect of homophily in the network. The homophily effects have the same tendency in both models for the case of ethnicity. There is a 


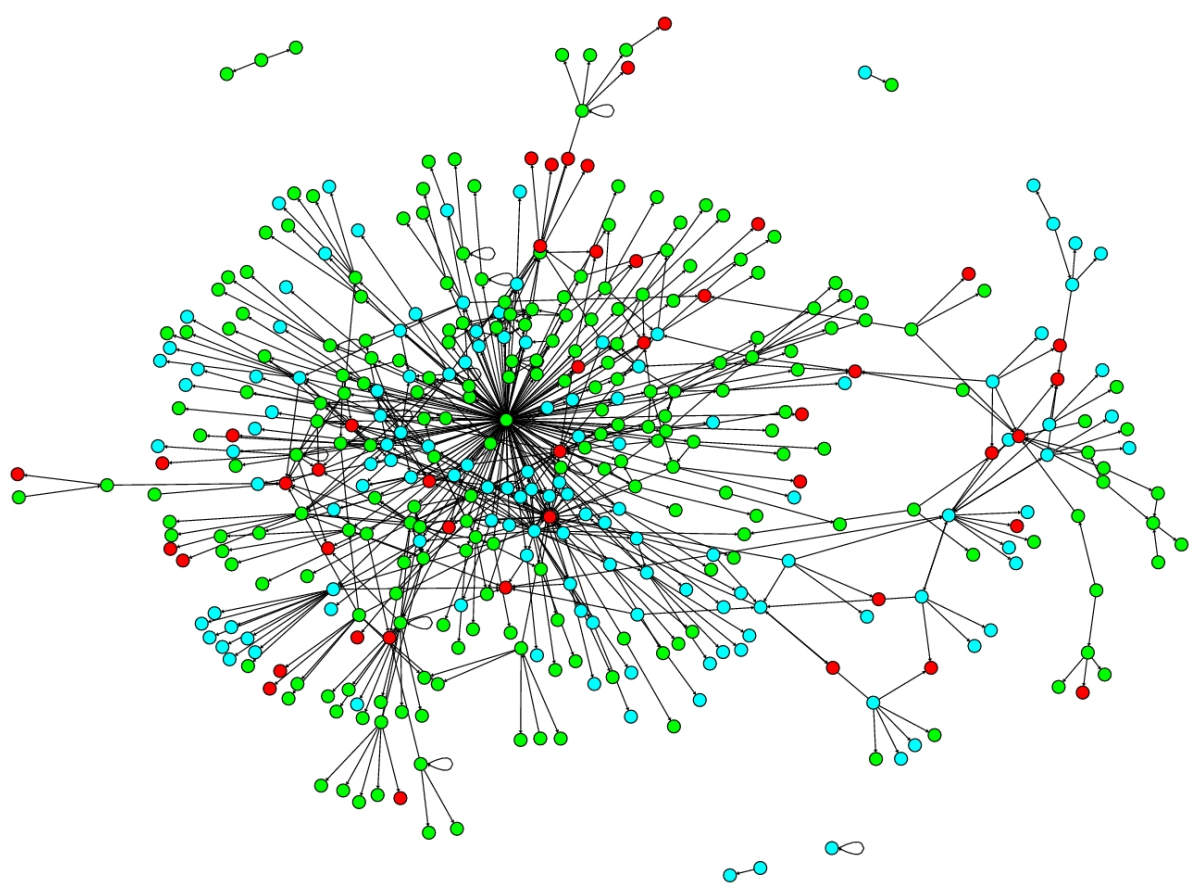

(a) $g_{T}$ agroforestry species information search network

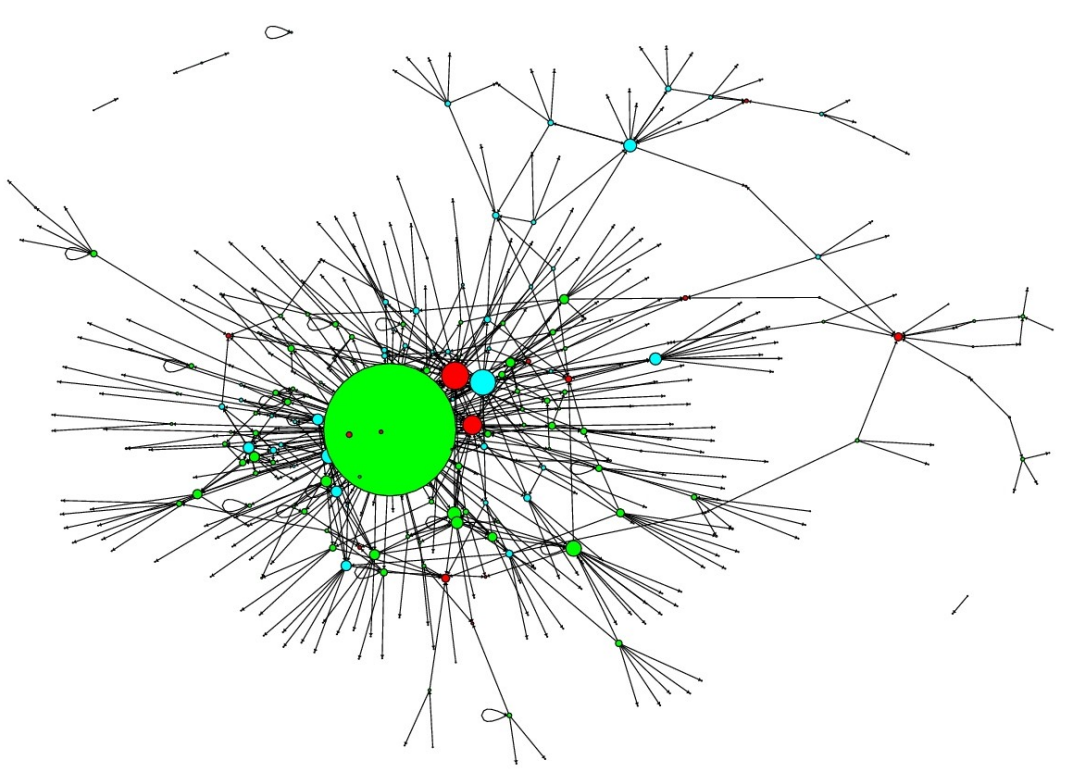

(b) $g_{T}$ vertex size based on degree centrality

Figure 4.5: $g_{T}$ Agroforestry tree species information search network and actors' degree centrality

[Vertex color $:$ Red=Institution, Green=Mestizo - colono, Cyan=Saraguro $]$ 
tendency of Saraguros seeking other Saraguros for information sharing. Nonetheless, only homophily for Mestizo-colonos is significant in both models.

For the case of gender, the models have opposite predictions. There are some effects of tie formation that network variables included in Model A account for, and that Model B may have underestimated. In Model A we have included network terms that may affect the probability of a tie. The AIC shows that Model A fits better, together with the results of GOF in Figure 4.6. For this reason we will concentrate on the results of Model A.

\subsubsection{Model Parameters}

We present here the results of Model A for each model term described in Section 4.6.3.1. Importantly, all the endogenous network terms are significant, as shown in Table 4.4.

- Arcs: The arcs term shows the baseline of the propensity to form a tie in information sharing about agroforestry species. Model A's arcs coefficient $\left(\eta_{\text {arcs }}\right)$ is -1.27 . This means that there is a $21.9 \%^{1}$ probability that one actor will search for information from another actor, without taking into account other network configurations.

- Homophily: The formation of a tie between similar actors was only significant for Mestizo-colonos. The parameter $\eta_{H o m_{L: M-C}}=-0.84$ can be understood as a low tendency of consulting an actor just because he/she is Mestizo-colono as well (i.e., same as $m e$, only true if $I$ am Mestizo-colono).

In the case of Saraguros' homophily, although the parameter is not significant, $\left(\eta_{\text {Hom } m_{\mathrm{L} g}}=0.026, p-\right.$ value $\left.=0.10\right)$, there is a tendency for Saraguros to form a tie within their own ethnic group, since $\eta_{H o m_{L: S g}}$ is positive. In the case of gender homophily, it would be less probable for females $\left(\eta_{H o m_{B: F}}\right)$ to form a tie (when they are searching for information) with other females than for a male $\left(\eta_{\text {Hom }_{\text {B:M }}}\right)$ to form a tie with other males. These parameters for gender homophily $\left(\eta_{\mathrm{Hom}_{B}}\right)$ are not significant in Model A.

\footnotetext{
${ }^{1}$ According to Goodreau et al. (2008)[29], $-1.040 \times \delta\left(g_{\operatorname{arcs}}(y, X)\right)_{i j}$. If there is formation of a tie (any) in the network $g_{T}$ changes $g_{A}(y, X)$ by 1 . The probability corresponds to the log-odds: $\exp (-1.27) /(1+\exp (-1.27))=0.219$.
} 
- Indegree * Income: This term is negative and low $\left(\eta_{\text {inI }}=-0.1067: p-\right.$ value $=$ 0.024), therefore, receiving a tie from actors with lower income has a tendency of tie formation. The result verifies that there is tendency for one actor with low income to search for information from one actor with high income, with a negative parameter $\eta_{\text {inI }}$.

- Indegree *Ethnic group: This variable made a difference in understanding tie formation. This statistic captures the high centrality of a Mestizo-colono almost completely. A tie in $g_{T}$ can be explained mostly as an incoming tie of a Mestizocolono, with a large and positive parameter $\left(\eta_{\text {inEtM }}=9.07: p-\right.$ value $\left.=0.000\right)$. Institutions also have a positive parameter $\left(\eta_{\text {inEtI }}=1.44: p-\right.$ value $\left.=0.000\right)$, which is higher than that for the Saraguro, who also have a positive but low parameter $\left(\eta_{\text {inEt } S}=0.55: p-\right.$ value $\left.=0.0036\right)$. Thus, a tie formed has a high tendency of being an incoming tie to Mestizo-colono.

- Asymmetric ties: The parameter of asymmetric ties is negative $\left(\eta_{A s y}=-1.95\right.$ : $p-$ value $=0.000$ ). To a certain extent, in a dyadic relation, the probability that the formed tie will be asymmetric is low. This means that the ties in $g_{T}$ tend not to be asymmetric ties. There is a low tendency toward finding ties that are not reciprocated (one directionality).

- Alt-outdegree and Alt-outdegree decay $\theta$ : The negative parameter Alt-outdegree $\left(\eta_{\text {Alt-out }}=-1.78: p-\right.$ value $\left.=0.000\right)$ shows that most of the actors in $g_{T}$ tend to have the same number of outdegrees. In addition, actors who already have many outgoing ties have a decaying probability of having another outgoing tie. As the positive $\theta$ parameter $(\theta=2.05: p-$ value $=0.000)$ shows, the speed at which the actor reduces the formation of ties is slow (positive and large $\left.\eta_{\theta}\right) . \theta$ value is moderate, there still are many neighbors who can be questioned for information and who are reachable by a direct outgoing tie. The actors that can be questioned are potential consulting partners.

- Mixed.2star: The negative parameter $\left(\eta_{M 2 s}=-3.9: p-\right.$ value $\left.=0.000\right)$, shows that the tendency of a tie to build a bridge between two of an actor's adjacent neighbors tends to be low, given all the other parameters. The negative parameter 
shows a low tendency in the observed network of many actors having relevant betweenness positions.

- Twopath: The twopaths parameter $\left(\eta_{2 P}=-0.27: p-\right.$ value $\left.=0.000\right)$ is negative and small. A negative parameter was expected. This shows that the correlation between indegree and outdegree in $g_{T}$ is low. Therefore, there is a tendency for the persons I ask for information not to consult me for information on agroforestry tree species.

- Transitivities: The transivities parameter is positive $\left(\eta_{t r}=2.23: p-\right.$ value $=$ 0.000 ); there is a high probability that the tie will be a transitive tie between three members of the same ethnic group. Thus, there is a search for information in $g_{T}$ that take place only among three actors of the same ethnic group. Among these three actors, one is consulted by two actors and one actor consults two actors. This is a sign of a hierarchical structure. In other words, there is a tendency for one actor to be consulted by many people, and there may be a reason, e.g., he knows more about agroforestry tree species. The search for information tends to be hierarchical. This will be explored in the discussion of results, see Section 4.8

\subsubsection{Goodness of Fit (GOF)}

As explained in Section 4.6.3.2 we estimate the GOF to see if the models fit the data. Figure 4.6 presents the GOF for Model A and Model B. The $Y$-axis is the log-odds (re-scaled). The solid line represents the observed network, the boxplots show the distribution of the statistic across 100 simulated networks (generated from the given model). For example, in Figure 4.6a the left side figure depicts the geodesic distance given the log-odds of Model A, and the line shows whether the log-odds approximate the value (x-axis) of this statistic (Goodreau, 2007; Goodreau et al., 2009)[28][30].

Model B did not capture the geodesic distance (underestimate) of $g_{T}$ and did somewhat better with the triad-census. Nonetheless, this model was unable to fit the data well. We present this model because we wanted to know whether only homophily terms could explain, to a point, many of the tie formation patterns of the search for information on agroforestry tree species. Model A did quite better in representing the two statistics that had not been explicitly added in the model. Model A captures the 
Table 4.4: ERGM Model Results

\begin{tabular}{|c|c|c|c|c|}
\hline Terms & $\begin{array}{l}\text { Model A } \\
\text { Estimate(Std.Error) }\end{array}$ & $p$-value & $\begin{array}{l}\text { Model B } \\
\text { Estimate(Std.Error) }\end{array}$ & $p-v_{a l u e} e^{\mathrm{a}}$ \\
\hline Arcs & $-1.27(0.23)$ & $0.000 * * *$ & $-5.55(0.063)$ & $0.000 * * *$ \\
\hline Homophily-Mestizo-c. & $-0.84(0.11)$ & $0.000 * * *$ & $-1.19(0.107)$ & $0.000 * * *$ \\
\hline Homophily - Saraguro & $0.026(0.10)$ & 0.800 & $0.35(0.093)$ & $0.000 * * *$ \\
\hline Homophily-Male & $-0.12(0.09)$ & 0.188 & $-0.13(0.087)$ & 0.138 \\
\hline Homophily-Female & $-0.01(0.11)$ & 0.848 & $0.03(0.102)$ & 0.742 \\
\hline Income $*$ indegree & $-0.107(0.047)$ & $0.025 *$ & $-0.48(0.086)$ & $0.000 * * *$ \\
\hline indegree - Mestizo $-c$. & $9.07(0.000)$ & $0.000 * * *$ & & \\
\hline indegree - Institution & $1.44(0.132)$ & $0.000 * * *$ & & \\
\hline indegree - Saraguro & $0.54(0.19)$ & $0.000 * *$ & & \\
\hline Asymmetric Ties & $-1.95(0.18)$ & $0.000 * * *$ & & \\
\hline Alt-outdegree & $-1.78(0.20)$ & $0.000 * * *$ & & \\
\hline Alt - outdegree decay $\theta$ & $2.05(0.018)$ & $0.000 * * *$ & & \\
\hline Mixed.2star & $-3.9(0.044)$ & $0.000 * * *$ & & \\
\hline Two-Paths ${ }^{\mathrm{b}}$ & $-0.27(0.044)$ & $0.000 * * *$ & & \\
\hline Transitivities(ethnic) & $2.23(0.000)$ & $0.000 * * *$ & & \\
\hline$A I C$ & 6291 & & 9297 & \\
\hline
\end{tabular}

\footnotetext{
a Significance codes: "***" $0.001, " * * * 0.01, " * " 0.05, ", " 0.1$. If the Term is significant it means that the observation is highly unlikely to be the result of random chance alone. Therefore, there is an influence of the variable on the formation of a tie.

$\mathrm{b}$ This parameter captures the correlation between indegree and outdegree.
} 
global property of distance in quite an acceptable way, near the mean. The triad census is also well captured. This model captures many of the important properties of $g_{T}$. As Robins et al. (2009)[57] point out, modeling a highly skewed degree distribution in directed networks is quite difficult, especially when there tends to be more than one mode, i.e., two or more actors with high degree centrality. It is almost impossible to simulate exactly the same observed network, but a good model approximates and represents the most relevant properties of the network.

\subsubsection{The Tested Research Hypotheses}

After having presented the empirical results it is convenient that we link them to the research hypotheses described in Section 4.4. Here we explain briefly how each hypothesis has been accepted or rejected. A detailed analysis is made in the discussion of results, in Section 4.8.

- $H_{1}$ : The Mestizo-colono ethnic group has the individuals with highest degree centrality in the network: tested with network descriptive statistics and ERGM.

The descriptive statistics have shown a higher indegree centrality average in the Mestizo-colono subgraph, $g_{T_{M}}$, than in the Saraguro subgraph, $g_{T_{S}}$. The network visualization of the degree centrality, depicted as vertex size in Figure 4.5 shows that the Mestizo-colono ethnic group has the individuals with higher degree centrality in the network. The large and positive parameter of indegree * ethnicgroup in the ERGM, $\eta_{\text {inEtM }}(9.6: p-$ value $=0.000)$, for Mestizo-colono has statistically confirmed the results. For this reason we accept $H_{1}$.

- $\mathrm{H}_{2}$ : Actors with higher income tend to be searched preferentially for advice and for information: tested with the ERGM.

The parameter of the model term indegree $*$ income, $\eta_{\text {inI }}(-0.106: p-$ value $=$ $0.047)$, was negative and small. This shows that actors with higher income are indeed questioned for information by actors with lower income. The correlation between indegree centrality and income shows $(0.45, t=9.98: p-$ value $=$ $0.000)$ a moderate correlation between high income and high indegree centrality. We partially accept, $H_{2}$. This is discussed in the next section. 

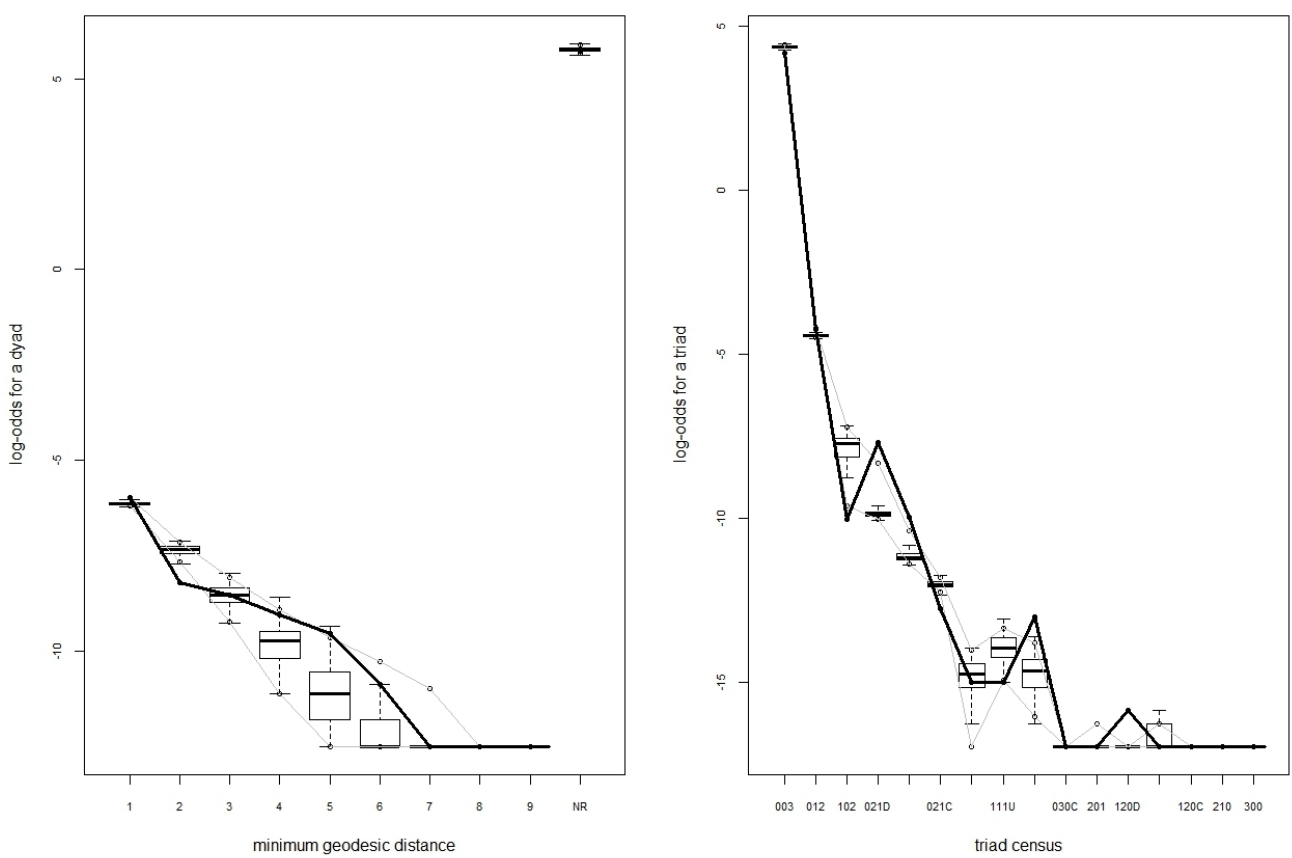

(a) Goodness of Fit Model A
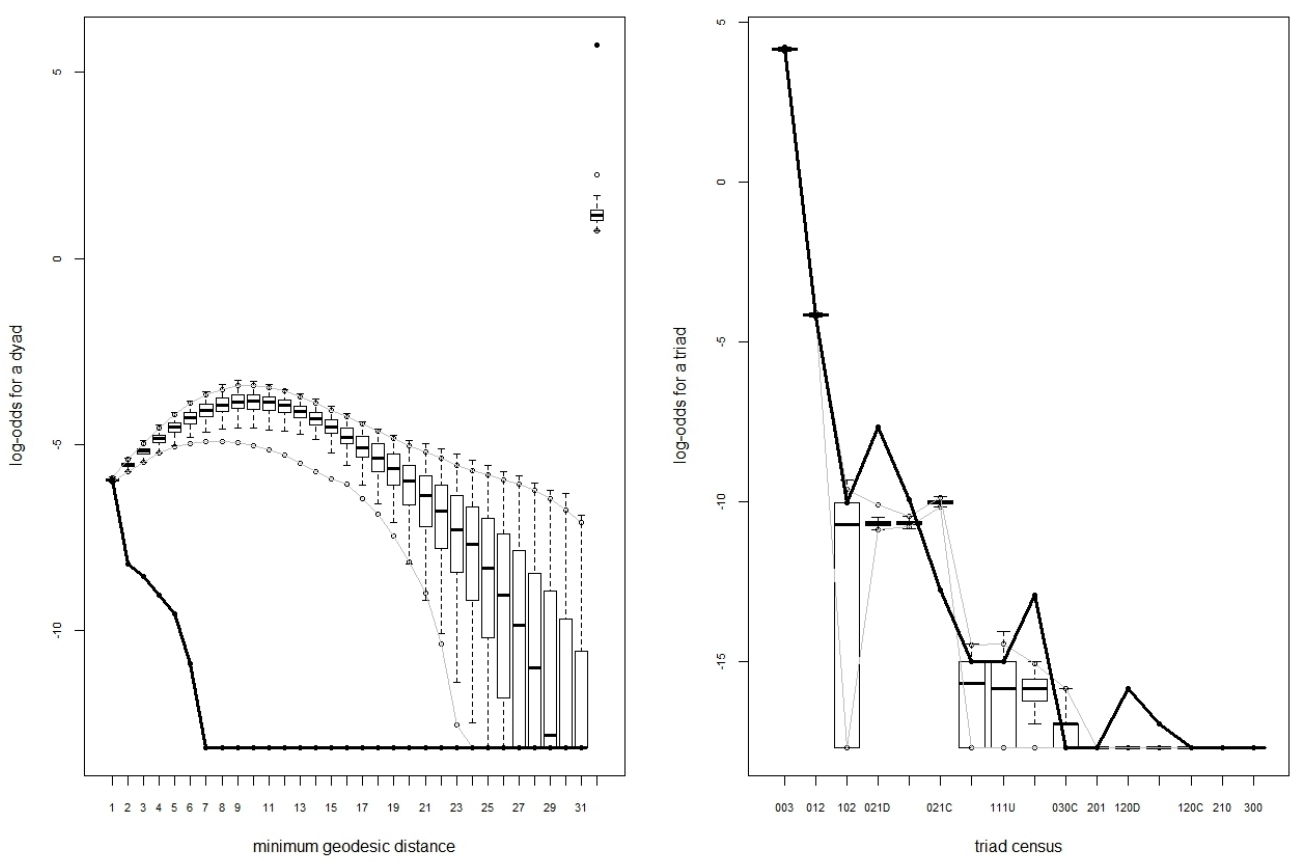

(b) Goodness of Fit Model B

Figure 4.6: Models Goodness of Fit 
- $\mathrm{H}_{3}$ : There is a high tendency to form transitive triads within members of the same ethnic group: tested with descriptive statistics and the ERGM.

The transitivity statistics shown that there are differences between Mestizocolono and Saraguro subgraphs, however, this information alone does not provide clarity, and we cannot draw conclusion about $H_{3}$. If we address the results of the ERGM, the parameter of the model term transivities, $\eta_{t r}(2.23: p-$ value $=$ 0.000 ), is positive, and confirms that there is a tendency of the actors to form transitive triad structures based on ethnicity. Therefore, we accept $H_{3}$. However, the tendency is moderate. We discuss this point in the next section.

- $H_{4}$ : The model with network endogenous variables, Model A, can better estimate the probability of tie formation than the model with only homophilous variables, Model B: tested with the ERGM.

The models' results described in the previous subsection and presented in Table 4.4 confirm that Model A definitively performs better the modeling of the observed network, as explained in Section 4.7.2.1. The AIC for Model A (6291) is quite lower than the AIC of Model B (9297). The GOF plots show that Model B has more extreme results. We accept $H_{4}$.

- $H_{5}$ : Saraguros have a higher probability of forming homophilous ties than Mestizocolonos do: tested with the ERGM.

Based on the ERGM results, we partially reject $H_{5}$; the parameter of the model term homophily for the case of the Mestizo-colono ethnic group, $\eta_{H_{\text {om }}: M-C}$ $(-0.84: p-$ value $=0.000)$, is significant and negative. The parameter of Saraguro homophily, $\eta_{H_{\text {om }}: S g},(0.026: p-$ value $=0.10)$, presented in Table 4.4, is not significant but positive, for this reason the homophilous influence, for Saraguro, on the search for information on agroforestry tree species may be higher than for Mestizo-colonos. This is discussed in the next section. 


\subsection{Discussion of Results}

\subsubsection{Model Advantages}

As we described in Section 4.2.2, in a model we can have exogenous network variables such as homophily and endogenous variables, such as twopath, that can be influenced by network interactions of other actors. We prove by comparing Model A and Model $\mathrm{B}$ that alone homophily effects cannot explain social relations in the network $g_{T}$. For this reason the hypothesis $H_{4}$ was accepted. There is an interrelation between actors in the network in order to search for information on agroforestry species, and this situates the actor in a specific position in the network. In this position the actor can access information about different tree species. As we saw in the previous section, Model A, by including network endogenous configurations, better explains better the observed network than Model B. This is because we incorporate the fact that the relations of one actor in the network influence the information that can be accessed by other actors (Lusher et al., 2013)[42].

\subsubsection{Central Actors and the Diffusion of Information}

As we demonstrated in the results explained in Section 4.7.3, we accepted the hypothesis $H_{1}$. The second hypothesis, $H_{2}$, was partially accepted, therefore, the complexity within the hypothesis statement must be discussed.

As we observe in Table 4.4, the indegree centrality of Mestizo-colonos can explain a great proportion of the probability of an actor forming a tie. From 687 edges in $g_{T}$, 405 (59\%) edges are edges within ethnic groups and $287(41 \%)$ are between ethnic groups. Most of the searching for information on agroforestry species takes places within ethnic groups. Importantly, 96 (34\%) edges are ties betweenn ethnic groups regarding one tree species, Pinus patula (pine). Figure $4.5 \mathrm{~b}$ shows that a central actor, a Mestizo-colono, is the one who participates the most in the search for infomation (based on his contacts: degree centrality). Information about this actor is explained below. There are also some institutions that promote information about agroforesty tree species. The information diffused by these institutions is diverse, as we observe in Figure 4.7, where the red node represents the institutions. We observe that they are closely related to all tree species and are not concentrated on one tree species 
exclusively.

The twopaths suggest that people ask few actors, and that some of those asked do not tend to consult those who ask them, as the negative and small parameter shows, $\eta_{2 P}=-0.27$. Furthermore, as the descriptive statistics suggest in Table 4.3, the reciprocity is lower in the subgraphs of Saraguros (0.04) than in those of Mestizocolonos (0.061). This suggests that Saraguros had lower tie reciprocity within their ethnic group than did Mestizo-colonos. This argument is confirmed by the correlation in-outdegree, actors who send ties to their neighbors do not tend to receive a tie back from the same actor they questioned. This verifies that some of the information is sought by few actors. For the case of the Saraguro ethnic group this correlation may be influenced by their ties with the central actor $\left(i_{c}\right)$.

The model term income $*$ indegree in Model A shows that there is tendency for actors with low ${ }^{1}$ income to search for information actors with high income. Similar results were obtained in Chapter 3 analyzing the advice network of agricultural activities, $g_{a}$. The Mestizo-colono central actor (highest degree centrality) has the highest income in $g_{T}$ ( $=g_{T_{i n c}}$, see footnote) as presented in Figure $4.8^{2}$. In $g_{T_{i n c}}$, the mean income (in the year 2010) for Mestizo-colonos is 3450 USD and the mean income for Saraguros is 2095 USD. The mean income for Mestizo-colonos is higher than for Saraguros as Maza et al. (2010)[43] also found. However, the income of Mestizocolonos is biased due to the income of the central actor, which is around 10000 USD. The mean income of Mestizo-colonos $\left(g_{T_{M}}\right)$ without the income of the central actor $\left(I_{i_{c}}\right)$ is 2080 USD. This means that both Saraguros and Mestizo-colonos that search for information on agroforestry tree species tend to have a low income. Generally, the actors that search for information about agroforestry tree species tend to send many ties, tend to have low income and tend to seek information about many trees and fruit trees.

This description can be explained by the experience with and knowledge of plant-

\footnotetext{
${ }^{1}$ According to the UN country statistics. Where the Gross National Income (GNI) for Ecuador per capita in the year 2009 was 4082.8 USD. Thus lower means here lower than the actor. http://data.un.org. Information not available for the year 2010.

${ }^{2}$ In Figure 4.8 are not included: 129 actors living outside the research region, 54 institutions, 11 actors that refuse giving information about their income (they believed information was too private), and 10 actors who were mentioned as a source of information and refused to be interviewed. This way we obtain a network with $V_{i n c}\left(g_{T}\right)=199$ vertices and $E_{\text {inc }}\left(g_{T}\right)=311$ edges for $g_{T_{i n c}}$, built only with actors that are related to an income.
} 
ing that the most central actor $\left(i_{c}\right)$ has. This actor has a pine plantation (Pinus patula). He works for the government, but in an institution related to health care in the region, and for that he earns a salary. He is also related to agricultural activities such as blackberry (considered an innovation in the region) and cattle ranching. Because of his work he visits many communities in the region and has many contacts throughout the sample research area. This actor has an university degree and can be classified as what Rogers (2003)[58] would call, an agent with higher socio-economic status, high social participation, and cosmopoliteness since he has lived in many places in Ecuador.

Importantly, around 48\% (100) of the respondents have planted (adopted) Pinus patula. We assume that the central actor $\left(i_{c}\right)$ may have influenced the plantation of pine trees by having contact with many actors in the region $\left(i_{c_{\text {degree }}}=143, g_{T_{\text {mean-degree }}}=\right.$ 3.71). From 687 ties in $g_{T}, 243(35.4 \%)$ are related to the search for information about pine, as shown by the black colored edge in Figure $4.7^{1}$. Other important species are avocado Persea americana, (49 edges, edge color:cyan), peach Prunus persica, (54 edges, color:red), guato Erythrina edulis, (38 edges, color:blue), cypress Cupressus macrocarpa, (36 edges, color:Dark-Pink), and eucalypt Eucalyptus globulus, (32 edges, color:yellow). Other less searched species that also appaer in Figure 4.7 are: apple Malus domestica, (30 edges, color:light blue), nogal Juglans neotropica, (27 edges, color:green), aliso rojo Alnus acuminata, (22 edges, color:grey). For more information on the tree and fruit tree species see Table 4.1.

\footnotetext{
${ }^{1}$ For this analysis, there could be the case where an actor mentions someone as a contact for more than one tree species. Here we present the cases for the most important tree species. The presence of a tie with regard to more than one species was allowed. This overlap was prioritized based on the frequency that each actor was mentioned for each question related to the search for information. We have asked which are the sources of information for each tree species. For detailed explanation of the questionnaire see Section 4.5.2.
} 


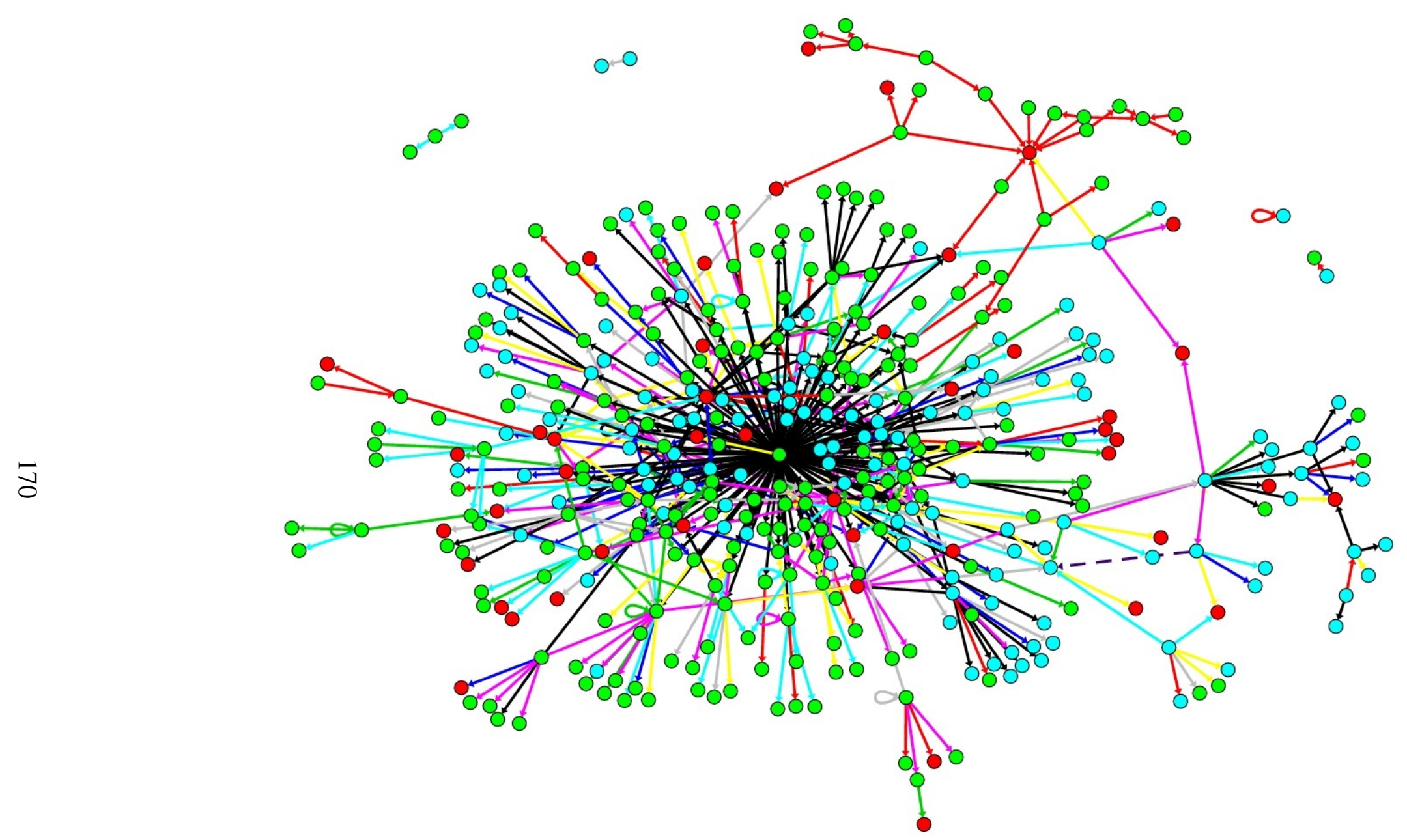
[Edge color: Black=Pine, Red=Peach, Cyan=Avocado, Blue=Guato, Dark-Pink=Cypres, Yellow=Eucalypt, Light-Blue=Apple, Green=Nogal, Grey=Aliso - rojo $]$ 
According to Model A, the probability that this information was passed on by the Mestizo-colono central actor is high, see Figure 4.5b. Importantly, from 243 ties formed to consult about pine, 202 ties $(83.13 \%)$ were directed at the central actor, $i_{c}$. In $g_{T_{i n c}}$ the correlation between having a high income and more ties (degree centrality) is large and positive, $0.45(t=9.98: p-$ value $=0.000)$. This confirms that having a high income and having many ties when sharing information on agroforestry species are closely related.

According to Agnneessens and Wittek (2012)[4], the probability that a tie is reciprocated and that the people I share information with will also share it with me (twopath: correlation in-outdegree centrality) decays as the economic status of the receiver (of the tie-nomination) increases. The probability that the central actor may return a tie or ask for information from an actor with less income may be very low. The special case of pine is related directly to timber wood, and therefore to income generation (Aguirre et al., 2006)[2]. This was verified by the negative twopath parameter, $\eta_{2 P}$. Accordingly, the high status actors would tend to consult other high status actors for information. This is status homophily, and may cause an innovation to diffuse horizontally (Rogers, 2003)[58]. In our case, the experience of the central actor $\left(i_{c}\right)$ with pine and his high income may serve as a force attracting others to seek him for information.

Therefore, the actors with low income search the actor with high income (heterophily in income). This is known as a "vertical" diffusion of information (Rogers, 2003)[58]. People may want to mimic or follow his success by learning how to plant pine (Conley and Udry, 2001; Stoneman, 1981; Udry and Conley, 2004)[16][62][63]. The ties around the central actor can be observed in Figure 4.7, edges in black, which represents the pine tree species. This is confirmed by the presence of a network hierarchical structure (few actors with high degree centrality, and many actors with low degree centrality). 

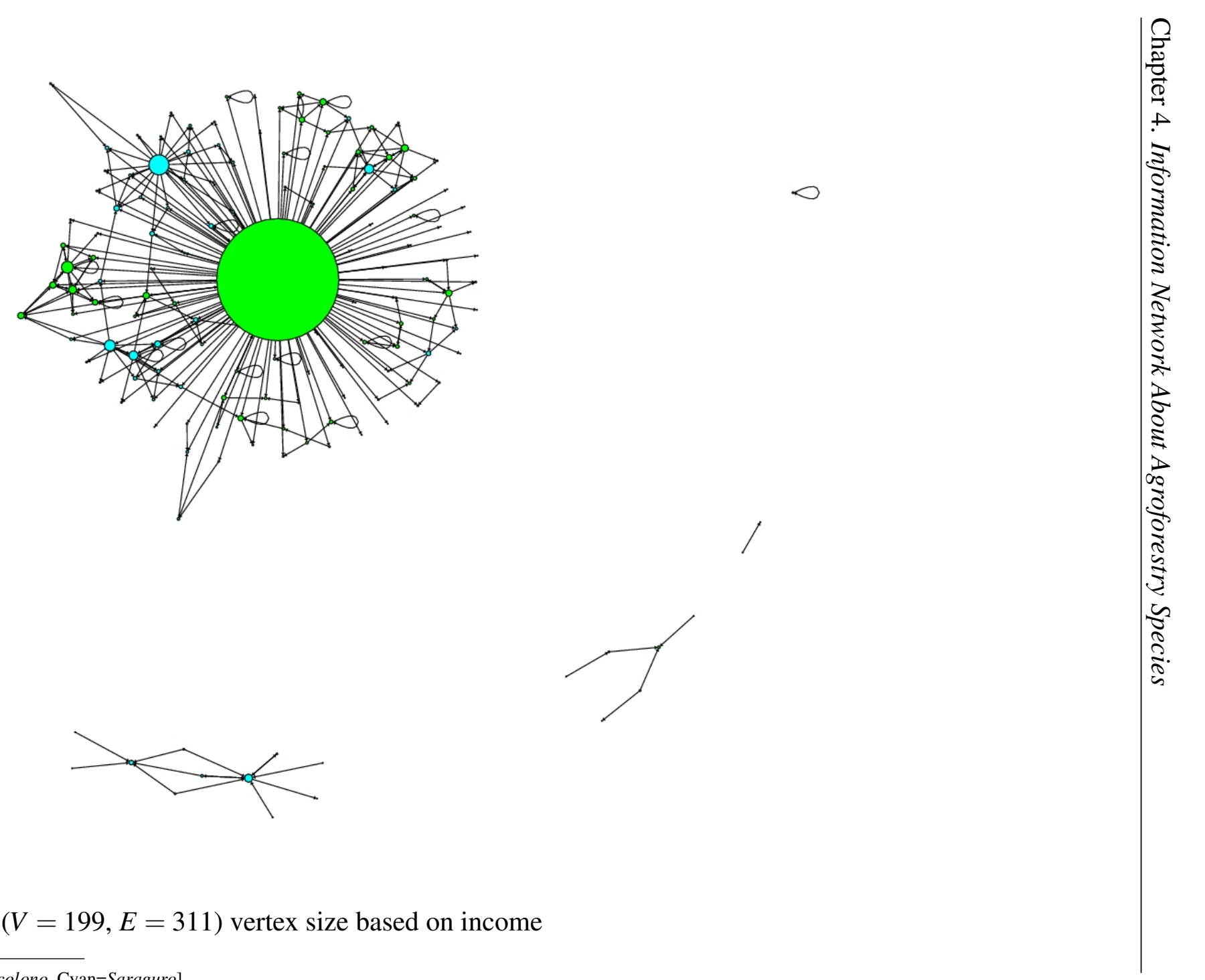

[Vertex color: Green=Mestizo - colono, Cyan=Saraguro $]$ 
The betweenness in Table 4.3 shows that the Saraguros' subgraph has a lower (1.92) betweenness than that of the Mestizo-colono's (6.74). There are fewer Saraguros positioned as bridge structures, and their information sharing depends much on the Mestizo-colono central actor. Therefore, the probability of a tie will form a Mixed.2star should be lower for Saraguros than for Mestizo-colonos. The Mixed.2star shows the probability that an actor may form a tie that will bridge two other actors. The likelihood that a tie is formed and that it serves as a bridge $\left(\eta_{M 2 s}=-3.9\right)$ between other two actors is low. This may be biased by the direct contact with the central actor when asking for information on pine trees. This accounts for an important proportion of the ties in $g_{T}$, as we mentioned.

\subsubsection{Network Structure and Homophilous Actors}

We have demonstrated that in the network there are transitivity effects related to homophily in ethnic groups. For this reason, we have accepted $H_{3}$. Nevertheless, it was not clear whether we would able to accept $H_{5}$. As we showed in Figure 4.7, there are dense regions around the central actor. In the periphery of the network, we observe that there is a search for information on several tree species. For example, a small group of Mestizo-colonos (vertex: green color) on the right of Figure 4.7, shared information about peach trees (edges: red color) with 5 different institutions and many Mestizocolonos. Generally, groups to the periphery of the graph tend to share more diverse information on different tree and fruit tree species. Basically, two main types uses of trees dominate the information sharing, those used for timber (pine, aliso rojo and eucalyptus) and those used for fruit production to sell or for household consumption (apple, peach and guato), see details in Table 4.1.

By analyzing subgraphs and tree and fruit tree species, we found some important differences (subgraphs applied to Figure 4.7). For Mestizo-colonos, the pine tree (edge color: black) is the most important issue for which there is a search for information, the second is peach (edge color: red) and the third, apple (edge color: light blue), as follows $g_{T_{M}}$ : (273 edges:100\%), pine (103 edges:38\% of total edges in $g_{T_{M}}$ ), peach (27 edges:10\%), apple (25 edges: 9.15\%). In the Saraguros' subgraph $, g_{T_{S}}:$ (132 edges:100\%), the most important tree species are: pine (44 edges:33\%), guato (28 edges:21\%), aliso rojo (16 edges:15.53\%). 
Peach and apple have well developed markets and are introduced species into the Andean region (Vozzo, 2010)[67]. The Mestizo-colono search for information is, nonetheless, mostly concerned with pine. In the case of Saraguros the search for information on tree species is better distributed over many species. In their communication, Saraguros tend to share more of the available information. Inn addition, it appears that Saraguros have more diverse information to share.

Mestizo-colonos are more concentrated on pine, which is tree with a developed market, though Saraguros also discuss this topic. Generally, this tree species is exotic (introduced into the region) and is more cash oriented than many local native species that do not have a developed local markt (Dawson et al., 2013)[19]. To increase their income, Saraguros seek information on more profitable agricultural practices, such as planting pine. Nevertheless, the positive parameter of the transitivities model term, $\eta_{t r}=2.23: p-$ value $=0.000$, shows that the information search within ethnic groups takes place mostly between culturally similar actors. The tendency in $g_{T}$ is to search actors within the same ethnic group, since shared cultural traits make communication easier (Rogers, 2003)[58].

Saraguros consult information on aliso rojo, Alnus acuminata, is a native tree species. This species has local acceptance for the quality of his wood, and for its high economic and ecological importance. However, there still is a lack of information on propagation techniques (Stimm et al., in chapter 33 in Beck et al., 2008)[8]. The Saraguros' second most important tree species to be informed about is Erythrina edulis, the guato. The guato is a native tree species from the Andean region (Barrera et al. in Vozzo, 2010)[67], and its fruit is consumed at the household level. This species was rarely considered by Mestizo-colonos, 9 edges: 3.3\%. This information suggests that Saraguros shar more knowledge of local tree species than do Mestizo-colonos, as Pohle and Gerique (2006)[49] indicate. Authors like Byg and Balsev (2006)[18] stress that indigenous peoples in southeastern Ecuador cultivate a palm for agroforestry because the knowledge on how to grow and use this species has been transmitted among generations traditionally. This may be the case for Saraguros, who, as Pohle and Gerique (2006)[49] indicate, share more knowledge on local flora than do Mestizo-colonos. Pohle and Gerique (in chapter 25 in Beck et al., 2008)[8] include the species Erythrina edulis, the guato, as grown within Saraguros' home gardens ${ }^{1}$.

\footnotetext{
${ }^{1}$ We discuss results with regard to an advice network. While its seems plausible that those species
} 
Therefore, Saraguros search for information throughout the network about native tree species more than Mestizo-colonos do. The fact that Saraguros have a strong and different group identity than Mestizo-colonos (Ogburn, 2007)[46], motivated us to test hypothesis $H_{5}$. We can say that as part of the attribute of Saraguros of being indigenous, they have a stronger group identity and more knowledge of local flora. The homophilous ties of Saraguros in Model A $\left(\eta_{\text {Hom } m_{L: S g}}=0.026: p-\right.$ value $\left.=0.800\right)$ were not significant. However, the search for information on pine may have influenced the significance of the parameter, $\eta_{H o m_{L: S g}}$.

The last statement can be proven if we see the descriptive statistics presented in Table 4.3 and Model A results presented in Table 4.4. The transitivities parameter based on ethnicity shows that around the most central actor, and other less central but also important actors, there are clusters of individuals in dense regions of the network. Transitive triads are formed within ethnic groups that share information on a diversity of tree and fruit tree species. The groups are based on ethnicity, since the parameter $\eta_{t r}=2.23: p-$ value $=0.000$ is positive and large (the second largest parameter in Model A). The information is still transmitted in groups based on ethnicity, although the main source of information is based on a central actor, $i_{c}$. This information concentrates mainly on one tree species, pine. Transitivity shows a tendency toward hierarchy in the network. In a transitive triad one actor receives two (incoming) ties and one actor sends two (outgoing) ties (Koskinen and Daraganova in Lusher et al., 2013)[42]. The local-transitivity indicates that Mestizo-colonos form more transitive relations than do Saraguros. This suggests that homophilous ties for Saraguros are less likely to be found in local transitive triangles than those of Mestizo-colonos. Nevertheless, local.transitivity (based on the vertex) may show that the more recent adoption of pine by the Saraguros makes them more dependent on the information provided by the most successful actor in planting pine.

Nonetheless, the higher global-transitivity of Saraguros shows that, at the network level, they are more connected by ties in homophilous subgroups. Saraguros in Model A show a tendency towards higher homophily tie formation than that of

which are planted are the ones that are the object of advice seeking and information providing, there can be substantial discrepancies between their occurence in the advice sharing network and actual usage/adoption. Fo eample, species for which there is interest but which are not yet adopted may feature more prominently in the network. On the other hand, very widely used, and familiar species that do not involve specific cultivation problems may rarely be the object of advice seeking. 
Mestizo-colonos $\left(\eta_{\text {Hom } \text { L:Sg }}=0.026: p-\right.$ value $=0.800$, two sided test $)$. For this reason, the average - path - length of the $g_{T_{S}}(2.28)$ subgraph for Saraguros is similar to the $g_{T_{M}}$ subgraph for Mestizo-colonos (2.22). The proliferation of a tree species that becomes popular because of its income importance can spread easily throughout the network. This might explain why the principal producer (a Mestizo-colono) of pine is the main source of information in $g_{T}$. Mestizo-colonos and Saraguros show differences in their knowledge of tree species. This help us to understand the network structure and why there are specific network patterns.

In order to understand why the search for information on pine influences the observed network structure of $g_{T}$ (see Figure 4.7) we should address the role of central actors in the diffusion of information. The most central Mestizo-colono $\left(i_{c}\right)$ presents many of the characteristics of an opinion leader (Rogers, 2003)[58] . Opinion leaders influence others positively and make more effective the diffusion of an innovation in the network (Burt, 1999; Rogers, 2003; Valente and Davis, 1999)[17][58][65]. The experience with planting pine gives him more knowledge over other, less experienced actors, and his high income gives him higher socioeconomic status. These attributes facilitate the diffusion of the information on pine. The Saraguros consult $i_{c}$ with the aim of improving their farm income, despite their cultural differences. Another factor that influences, the spread of information on pine is that actor $i_{c}$ visits many communities personally because of his job. This facilitates greater contact with other actors in the network and also a direct contact, represented by black colored ties in Figure 4.7. In other words, $i_{c}$ has higher exposure to many actors. There is a possibility of a higher contagion for the adoption of tree species. In this context, contagion, refers to the degree of influence on the actor receiving information, as reflected in his inclination toward adopting the new practice (planting the trees in question) (Burt, 1999; Gonzalez et al., 2010)[17][27].

At a more global level, the network structure of $g_{T}$ tends to have a core/periphery structure. This structure refers to a very cohesive and dense core, that is surrounded by connected through one tie (Everett and Borgatti, 1999)[22].This structure is not completely clear for the case of $g_{T}$. There are some dense regions around the possible core. There are many links to actors who have a low degree, and also many links to actors in the core. This is shown by the negative parameter of Alt-outdegree $\left(\eta_{\text {Alt-out }}=-1.78: p-\right.$ value $\left.=0.000\right)$. This parameter confirms that most actors in 
the network, $g_{T}$ have similar levels of information seeking (outdegrees).

The core may not have a limited size, and there could still be many ties that can be created (it is not yet very dense) (Robins et al., 2009)[57]. The large and positive parameter $\eta_{\theta}$ indicates that the tie formation by outdegree decays slowly, therefore, in the dense regions there still are many ties that could be formed. In the dense regions around the core there are some triangulations formed, and this may produce some improvement in the connectivity ${ }^{1}$ of the network. This can be caused by the diversity of shared information on trees, therefore, different interests represent heterogeneous information in the network, since Mestizo-colonos and Saraguros consult information on different species.

Nevertheless, the pine share of information is concentrated around one major actor. This worsens the connectivity of the network, the degree of network connectedness is $\kappa=0.81^{2}$, and $\kappa$ is closer to 1 as the network is less connected (this depends on few actors or actor pairs). This means that, if the central actor were to "disappear", the network would not fall apart entirely. Network actors would still be connected, since they search much information about other tree species, such as guato and peach. However, the information on pine depends mostly on the central actor $\left(i_{c}\right)$, and without this actor's pine's search for information will be reduced to a few ties. As we observe in Figure 4.7, the periphery and clusters surrounding the central actor share information mostly about species other than pine. This is also supported because the core in $g_{T}$ is generated by the "popularity" or high degree centrality of $i_{c}$ (Mestizo-colono central actor).

Some network modeling remarks can be made about the twopath configuration. It may have helped to capture the ties made from the network core, to the clusters in the dense regions of $g_{T}$, and then to the periphery. The inclusion of this term may have improved the fit of Model A. This was also reported by Robins et al. (2009)[57] for the modeling of a direct network with a skewed degree distribution.

\footnotetext{
${ }^{1}$ Connectivity shows the level to which a network depends on few actors to remain connected.

${ }^{2} \mathrm{~A}$ graph is connected if each vertex can reach every other vertex in the network. The degree of connectedness is defined as: $\kappa=1-\left[\frac{P}{N(N-1) / 2}\right]$, where $P$ is the number of vertices that are mutually reachable, and $N$ is the total number of vertices. The denominator is the total number of pairs (Krackhardt, 1994)[40].
} 


\subsection{Conclusions}

Returning to the hypotheses presented in Section 4.4, we accepted the hypothesis $H_{4}$. Model A with network structural statistics was able to explain patterns of tie formation. Model B, which included mostly homophily terms based on actors' attributes, can explain less of the information search. We have accepted $H_{1}$, and we can conclude that the netwok of information search on agroforestry tree species is centralized around a central actor $\left(i_{c}\right)$. This central actor is a Mestizo-colono, who is related mostly to pine, a tree species planted to sell wood.

By testing $H_{5}$, we conclude that there is no significant evidence that Saraguros have more homophilous ties than do Mestizo-colonos. Nevertheless, the tendency suggests that Saraguros do have homophilous preferences when sharing information. The concentration of indegree ties on the central actor has an influence on this result. Proving $\mathrm{H}_{3}$, we found that the transitivities model term significantly show that triad structures are based on ethnicity. Searching information on tree species other than pine takes place within ethnic groups. Moreover, both ethnic groups are centralized around the information search on one tree species, pine. The pine tree is the major inter-group (34\%) information topic.

The relation on income and the degree centrality shows that the ingoing ties are related to a higher income and to the plantation of pine. We partially accept $H_{2}$. The search for information on other tree species (less related to sellable products) is more homogeneous, with more ingoing and outgoing ties, and distributed among many actors. There is an effect on the "popularity" of a central actor that is produced by the economic attraction of the pine production. We conclude that the $g_{T}$ structure is also the result of the search for information about many different tree species. This reflects different types of knowledge about local flora.

To summarize up, the search for information on agroforestry tree species is based around a few species, of which pine is the most important. Pine is an introduced species and may be seen as an innovation in the region. For this reason, available information on this species may not be abundant. Therefore, directly contacting the central actor who has the information is the main access to it. To clarify this point, a dynamic analysis which takes into account the year on which the plsanting took place and the year of friendship formation will clarify whether social contact indeed 
influences the adoption of agroforestry species over time. This is important work for future research on this region.

The region may be able to improve the local economy by means of projects, in which communal leaders such as $i_{c}$ become involved in agroforestry. The socioeconomic status and positive experience with the activity are important factors for the diffusion of information on innovations in the research area. The profitability of the tree species planted can overcome the barrier of homophily as Rogers (2003) calls it. This barrier refers to the fact that dissimilar actors (heterophilous actors) tend to have lesser effective communication. Therefore, actors prefer to communicate with others who are similar. This implies less effort for social communication. Nevertheless, as we observe, the Saraguros search $i_{c}$ for information on pine, since that may represent an improvement in household income.

From a sustainable development perspective, the promotion of native species such as guato would benefit not only local agrobiodiversity but also help preserve the Saraguros' local knowledge on flora. However, such a project must be developed a long with market and tree propagation research on the selected tree species. The Saraguros' local knowledge about the use of local species would be important enough to be included in any project related to the adoption of innovations. Therefore, a project must incorporate many aspects of different areas. This would incorporate the Saraguros into the local economy, and would increase their access to economic benefits to a degree. Saraguros may have more advantages commercializing these species because they already share much information and their information network structure is not centralized around a single actor. Centralization around an actor gives vulnerability to the diffusion of information, since there is a high dependence on that actor. There are advantages to supporting the plantation of native trees species as long as they are related to a profit and real opportunities to improve household income. The introduction of a new exotic tree species has a disadvantage if, as compared to a native tree species, the process of diffusion of information must start from zero and the construction of an information network that supports the diffusion needs much effort and resources. Furthermore, information on native tree species' has already been transmitted through generations.

Conclusively, including the participation of Saraguros' communal leaders, who already have a certain socio-economic status, in agroforestry programs would make more 
effective the communication in the process of the diffusion of information. For example, it would produce more cohesiveness and a diffusion of the knowledge that would reach more actors. At the same time, this may contribute, to a reduction of centralization in the search for information. An information network that depends less on central actors and where many actors share the information may facilitate greater participation of new actors in the network. Tree species such as guato may have this advantage. Together with the increase in the number of trees on the farms, this would create more sustainable conditions in the communities. This is highly important because of the communities' close proximity to the Podocarpus National Park. 


\section{References}

[1] Abbott A. (2005). Counting Beans: Agrobiodiversity, indigeneity and agrarian reform. The Professional Geographer 57(2): pp:98-212. 2, 44, 45, 58, 59, 60, $129,130,131$

[2] Aguirre N., Günter S., Weber M., and Stimm B. (2006). Enrichment of Pinus patula patula plantations with native species in Southern Ecuador. lyonia 10(1): pp:33-45. 3, 171

[3] Agneessens F. and Skvoretz J. (2012). Group differences in reciprocity, multiplexity and exchange: Measures and application. Quality and Quantity 46: pp: 1523-1545. 49, 88, 93, 146

[4] Agneessens F. and Wittek R. (2012). Where do intra-organizational advice relations come from? The role of the informal status and social capital in social exchange. Social Networks 34: pp: 333-345. 47, 48, 74, 88, 89, 91, 128, 137, 145, 151,171

[5] Arnold J. (1983). Economic considerations in agroforestry projects. Agroforestry Systems 1: pp:299-311. 133

[6] Bhagwat S., Willis K.J., Birks J.B. and Whittaker R.J. (2008). Agroforestry: a refuge for tropical biodiversity?. Trends in Ecology and Evolution 23(5): pp:261267. $3,134,136$

[7] Barabási A.L. and Albert R. (1999). Emergence of scaling in random networks. Science 286(5439): pp:509-512. 118

[8] Beck E., Kottke I, Bendix F. Makeschin F. and Mosandl R. (2008). Gradients in a Tropical Mountain Ecosystem of Ecuador: Vol. 198. Ecological studies. Berlin 
Heidelberg. Germany: Springer-Verlag. 1, 2, 17, 22, 23, 58, 60, 61, 114, 129, 130, $131,132,133,134,136,174$

[9] Besley T. and Case A. (1993). Modeling technology adoption in developing countries. The American Economic Review 83 (2): pp:396-402. 18, 90, 151

[10] Bodin Ö. and Prell C. (2011). Social Networks and natural resource management. Cambridge University Press. Cambridge. UK. 46, 114

[11] Brandes U. and Erlebach T. (2005). Network Analysis: Fundamental Foundations. Springer-Verlag Berlin Heidelberg. Germany. 19, 20, 47, 49, 50, 145, 146, 147,151

[12] Burt R. (2005). Brockerage and Closure: An introduction to social capital. Oxford University Press. Oxford. UK. 53, 87, 88, 95

[13] Butts C. (2012). Package 'sna'. www.statnet.org. 72, 80, 155

[14] Byg A. and Salick J. (2007). Indigenous Peoples and Climate Change. Centre Publication Tyndall Centre for Climate Change Research, Oxford, United Kingdom. 43,113

[15] Carrington P., Scott J. and Wasserman S. (2005). Models and Methods in Social Network Analysis. Cambridge University Press. New York. USA. 19, 32, 33, 34, $52,53,62,120,141$

[16] Conley T. and Udry C. (2001). Social learning through networks: The adoption of new agricultural technologies in Ghana. American Journal of Agricultural Economics 83(3): pp:668-673. 18, 90, 151, 171

[17] Burt R. (1999). The social capital of opinion leaders. Annals of the American Academy of Political and Social Sciences 566: pp: 37-54. 176

[18] Byg A. and Balsev H. (2006). Palms in indigenous and settler communities in southeastern Ecuador: farmers' perception and cultivation practices. Agroforestry Systems 67: pp: 147-158. 5, 174 
[19] Dawson I., Guariguata M., Loo J., Weber J, Lengkeek A., bush D., cornelius J., Guarino L., Kindt R., Orwa C., Russell J. and Jamnadass R. (2013). What is the relevance of smallholders' agroforestry systems for conserving tropical tree species and genetic diversity in circa situm, in situ and ex situ settings? A review. Biodiversity Conservation 22: pp:301-324. 3, 113, 133, 134, 136, 174

[20] De la Torre L. Muriel P. and Balslev H. (2006). Etnobotánica en los Andes del Ecuador. In Edit. Moraes M, Øllgaard B, Kvist L, Borchsenius F and Balslev H. Universidad Mayor de San Andrés, Botánica Económica de los Andes Centrales: pp:246-267. La Paz, Bolivia. 60, 131

[21] Dove M. (2006). Indigenous People and Environmental Politics. Annual Review of Anthropology 35: pp. 191-208. 61, 132

[22] Everett M. and Borgatti S. (1999). Peripheries of cohesive subsets. Social Networks 21: pp. 397-407. 52, 72, 176

[23] FAO (2005). Realizing the economic benefits of agroforestry: experiences, lessons and challenges. In State of the World's Forests. FAO 2005. pp:88-97. 2, 3, $113,114,133,134$

[24] Frank Ove and Strauss D. (1986). Markov Graphs. Journal of the American Statistical Association 81(395): pp: 832-842. 119

[25] Freeman L. (1977). A set of measures of centrality based on betweenness. Sociometry 40(1): pp. 35-41. 20, 47, 146

[26] Csardi G. (2012). Package 'igraph'. http://igraph.sourceforge.net/. 54, 72, 155

[27] Gonzalez V., Barkmann J. and Marggraf R. (2010). Social network effects on the adoption of agroforestry species: Preliminary results of a study on differences on adoption patterns in Southern Ecuador. Procedia-Social and Behavioral Sciences 4: pp: 71-82. 43, 45, 56, 60, 61, 113, 132, 134, 136, 138, 141, 176

[28] Goodreau S. (2007). Advances in exponential random graph $\left(p^{*}\right)$ models applied to a large social network. Social Networks 29: pp: 231-248. 65, 125, 128, 142, $148,150,151,155,156,162$ 
[29] Goodreau S., Handcock M, Hunter D, Butts C and Morris M. (2008). A statnet Tutorial. Journal of Statistical Software 24(9). 126, 154, 155, 160

[30] Goodreau S., Kitts J. and Morris M. (2009). Birds of a feather, or friend of a friend? using Exponential random Graph Models to investigate adolescent social network. Demography 46(1): pp: 103-125. 118, 123, 156, 162

[31] Granovetter M. (1973). The Strength of Weak Ties. The American Journal of Sociology 78(6): pp: 1360-1380. 18, 49, 53, 88, 116

[32] Handcock M., Hunter D., Butts C., Goodreau S. and Morris M. (2003). statnet: Software tools for the Statistical Modeling of Network Data. www.statnet.org. 72, $149,153,155$

[33] Holland P. and Leinhardt S. (1970). A method for detecting structure in sociometric data. American Journal of Sociology 76: pp: 492-513. 156

[34] Homeier, J. (2008). The influence of topography on forest structure and regeneration dynamics in an Ecuadorian montane forest. In: S.R., Gradstein, J. Homeier, and D. Gansert (Eds.), Biodiversity and Ecology Series (2): The tropical mountain forest (97-107). Göttingen: Universitätsverlag Göttingen. 22, 23, 129

[35] Hunter D. and Handcock M. (2006). Inference in curved exponential family models for networks. Journal of Computational and Graphical Statistics 15(3): pp: 565-583. 120, 122, 152, 154

[36] Hunter D. (2007). Curved exponential family models for social networks. Social Networks 29: pp: 216-230. 123, 126, 152, 154

[37] Hunter D., Handcock M, Butts C, Goodreau S. and Morris M. (2008). ergm: A package ti fit, simulate and diagnose exponential-family models for networks. Journal of Statistical Software 24(3). 154

[38] Hunter D., Goodreau S. and Handcock M. (2008b). Goodness of fit of social network models. Journal of the American Statistical Association 103(481): pp:248258. 156 
[39] Knoke T., Weber M., Barkmann J., pohle P., Calvas B., Medina C., Aguirre N., Günter S., Stimm B., Mosandl R., von Walter F., Maza B. and Gerique A. (2009). Effectiveness and Distributional Impacts of Payments for Reduced Carbon Emissions from Deforestation. Erdkunde 63(4): pp: 365-384. 114, 133

[40] Krackhardt D. (1994). Graph Theoretical Dimensions of Informal Organizations. In Carley K. and Prietula M. Eds. Computational Organization Theory: pp: 89111. Lawrence Erlbaum and Associates. Hillsdale, N.J. 80, 177

[41] Lazega E., Mounier L., Snijders T. and Tubado P. (2012). Norms, status and the dynamics of advice networks: A case study. Social Networks 34: pp: 323-332. 48, $49,56,57,71,88,89,94,121,129$

[42] Lusher D, Koskinen J. and Robins G. (2013). Exponential Random Graph Models for Social Networks. In series Structural Analysis in the Social sciences 35. Edt. Granovetter M. Cambridge University Press. New York. 117, 118, 119, 122, 124, $125,126,127,128,150,152,153,154,155,156,167,175$

[43] Maza, B., Barkmann, J., von Walter, F., and Marggraf, R. (2010). Modelling smallholders production and agricultural income in the area of the Biosphere reserve "Podocarpus-El Condor", Ecuador. Georg-August-Universität Göttingen: Department of Agricultural Economics and Rural Development, Working Paper, 1004. 2, 21, 22, 23, 43, 45, 58, 59, 60, 89, 114, 129, 130, 131, 134, 168

[44] McPherson M., Smith-Lovin L. and Cook J. (2001). Birds of a Feather: Homophily in Social Networks. Annual Review of Sociology 27: pp: 415-444. 4, 45, $57,71,87,115$

[45] Morris M., Handcock M and Hunter D. (2008). Specification of exponentialfamily random graph models: Terms and computational aspects. Journal of Statistical Software 24(4). 149, 150, 152, 153

[46] Ogburn D.E. (2007). Incas Past and Present. Stanford Journal of Archaeology 5: pp: 134-163. 2, 44, 61, 87, 89, 93, 132, 175 
[47] Pattison P. and Wasserman S. (1999). Logit models and logistic regressions for social networks. II. Multivariate relations. British Journal of Mathematical and stadistical Psychology 52: pp: 169-194. 124

[48] Pattison P. and Robins G. (2002). Neighbourhood-based models for social networks. Sociological Methodology 22: pp: 301-337. 120

[49] Pohle, P. and Gerique, A. (2006). Traditional ecological knowledge and biodiversity management in the Andes of southern Ecuador. Geographica Helvetica, 61(4): , 275-285. 2, 16, 22, 43, 45, 58, 60, 89, 93, 113, 129, 131, 132, 174

[50] Price C. (1995). Economic evaluation of financial and non-financial costs and benefits in agroforestry development and the value of sustainability. Agroforestry Systems 30: pp:75-86. 16, 133

[51] R Development Core Team (2008). R: A language and environment for statistical computing. R Foundation for Statistical Computing, Vienna, Austria. ISBN 3-900051-07-0, URL http://www.R-project.org. 72, 149, 155

[52] Richardson D. (1998). Forestry Trees as Invasive Aliens. Conservation Biology 12(1): pp: 18-26. 136

[53] Robert C. and Casella G. (2010). Introducing Monte Carlo Methods with R. Springer Verlag. New York. 155

[54] Robins G., Pattison P. and Wasserman S. (1999). Logit models and logistics regression for social networks. III. Valued relations. Psychometrika 64: pp: 371-394. 124

[55] Robins G., Pattison P., Kalish Y. and Lusher D. (2007a). An Introduction to exponential random graph $\left(p^{*}\right)$ models for social networks. Social Networks 29: pp: 173-191. 124, 125, 148, 149, 154

[56] Robins G, Snijders T., Wang P., Handcock M. and Pattison P. (2007b). Recent developments in exponential random graph $\left(p^{*}\right)$ models for social networks. Social Networks 29: pp: 192-215. 125, 149, 152, 154 
[57] Robins G, Pattison P.and Wang P. (2009). Closure, connectivity and degree distributions: Exponential random graph $\left(p^{*}\right)$ models for directed social networks. Social Networks 31: pp: 105-117. 122, 128, 153, 156, 164, 177

[58] Rogers E. (2003). Diffusion of innovations. Free Press (5th ed.). New York. USA. $5,42,49,69,88,90,96,115,116,133,169,171,174,176$

[59] Sherr S. (1995). Economic factors in farmer adoption of agroforestry: Patterns observed in Western Kenya. World Development 23(5): pp:787-804. 3, 133, 134

[60] Snijders T., Pattison P., Robins G. and Handcock M. (2006). New specifications for exponential random graph models. Sociological methodology pp: 99-152. 122, 152

[61] Snijders T., Koskinen J. and Schweinberger M (2010). Maximum likelihood estimations for social network dynamics. The Annals of Applied statistics 4(2): pp: 567-588. 120, 154

[62] Stoneman P. (1981). Intra-firm diffusion, Bayesian learning and profitability. The Economic Journal 91(362): pp:375-388. 18, 90, 151, 171

[63] Udry C and Conley T. (2004). Learning About a New Technology: Pineapple in Ghana. Economic Growth Center. Yale University. Working Paper 888. 90, 151, 171

[64] Universidad Nacional de Loja (2006). Estado de Conservacion del area de Bosque y Vegetacion Protectora "Corazon de Oro". In Informe Tecnico: Estado de Conservacion de areas Protegidas y Bosques Protectores de Loja y Zamora Chinchipe y Perspectivas de Intervencion. Centro Integrado de Geometría Ambiental (CINFA), Herbario Reinaldo Espinosa Loja and Carrera de Ingenieria Forestal. Loja. Ecuador. 1, 8, 58, 62, 114, 129, 138

[65] Valente T. and Davis R. (1999). Accelerating the diffusion of innovations using opinion leaders. ANNALS, AAPSS, 56: pp: 55-67. 19, 26, 69, 176

[66] Van Cott D.L. (2007). Latin America's Indigenous Peoples. Journal of Democracy 18(4): pp:128-141. 44, 61, 131, 132, 133 
[67] Vozzo J.A. (2010). Manuel de Semillas de Arboles Tropicales. Department of Agriculture of the USA. Forestal Service. Accessed: http://www.rngr.net/publications/ttsm/species/PDF.2004-03-03.5315 134, 136,174

[68] Wasserman S. and Pattison P. (1996). Logit models and logistic regression for social networks. I. An introduction to Markov graphs and $p^{*}$. Psychometrica 61: pp: 401-425. 124 